\title{
The Synthesis and Structural Characterization of Novel Transition Metal Fluorides
}

\author{
William Jack Casteel, Jr.
}

Ph.D. Thesis

\author{
Lawrence Berkeley Laboratory \\ and \\ Department of Chemistry \\ University of California \\ Berkeley, California 94720 USA
}

September 1992

This work was supported by the Director, Office of Energy Research, Office of Basic Energy Sciences, Chemical Sciences Division of the U.S. Department of Energy under Contract No. DE - AC03 - 76SF00098

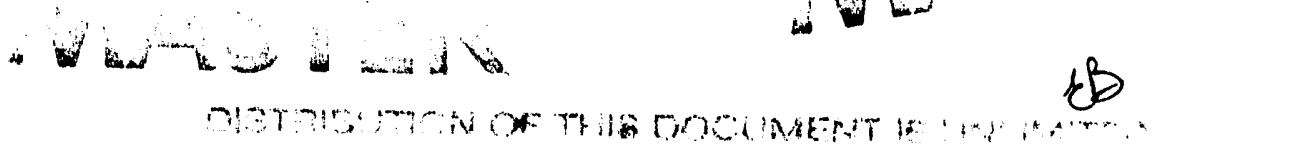


The Synthesis and Structural Characterization of Novel Transition Metal Fluorides

by

William Jack Casteel, Jr.

\begin{abstract}
High purity $\mathrm{KMF}_{6}$ and $\mathrm{K}_{2} \mathrm{MF}_{6}$ salts $(\mathrm{M}=\mathrm{Mo}, \mathrm{Re}, \mathrm{Ru}, \mathrm{Os}, \mathrm{Ir}, \mathrm{Pt})$ are obtained from reduction of the hexafluorides. A novel rhombohedral unit cell is observed for $\mathrm{KReF}_{6}, \mathrm{a}_{0}=5.021$ (3) $\AA, \alpha=97.16^{\circ}$ and a trigonal cell for $\mathrm{K}_{2} \mathrm{MoF}_{6}$, free of impurity phases for the first time, is observed with $a_{0}=5.860(2) \AA, c_{0}=4.634(3) \AA$.

Fluoride ion capture by Lewis acids from the hexafluorometallate (IV) salts affords high purity tetrafluorides for $\mathrm{M}=\mathrm{Mo}, \mathrm{Re}, \mathrm{Ru}, \mathrm{Os}$, and $\mathrm{Pd}$. The structure of $\mathrm{RuF}_{4}$ is determined from a combination of $\mathrm{X}$ - ray synchrotron and neutron powder data. The structure is related to the layered $\mathrm{SnF}_{4}$ type, however, a puckering of the sheets occurs in the monoclinic $\operatorname{RuF}_{4}$ unit cell, $\mathrm{a}_{\mathrm{o}}=5.6068(6) \AA, \mathrm{b}_{\mathrm{o}}=4.9456(5) \AA, \mathrm{c}_{\mathrm{o}}=5.413(2) \AA$, $\beta=121.27(2) \AA$. Unit cells based on the orthorhombic $\mathrm{PdF}_{4}$ type cell are derived from $X$ - ray powder data for $\operatorname{ReF}_{4} ; a_{0}=9.61(2) \AA, b_{o}=9.61(2) \AA, c=5.66(1) \AA$ and $\mathrm{OsF}_{4} ; a_{0}=9.89(1) \AA, b_{0}=9.36(1) \AA, c_{0}=5.70(1) \AA$.

Fluoride ion capture from $\mathrm{KAgF}_{4}$ provides the thermally unstable trifluoride as a bright, red, diamagnetic solid. The structure solution of $\mathrm{AgF}_{3}$ and the redetermination of the $\mathrm{AuF}_{3}$ structure from $\mathrm{X}$ - ray synchrotron and neutron powder data demonstrate that the two are isostructural: $\mathrm{AgF}_{3}, \mathrm{a}_{\mathrm{o}}=5.0782(2) \AA, \mathrm{c}=15.4524(8) \AA ; \mathrm{AuF}_{3}$, $a_{0}=5.1508(1) \AA, c_{0}=16.2637(7) \AA$. The thermal decomposition product of $\mathrm{AgF}_{3}$ is the mixed valence compound $\mathrm{AgII}_{\mathrm{Ag}_{2}}{ }^{\mathrm{III}} \mathrm{F}_{8}$.
\end{abstract}


Several new salts containing the $(\mathrm{Ag}-\mathrm{F})_{\mathrm{n}}{ }^{\mathrm{n}+}$ chain cation are prepared. The first linear $(\mathrm{Ag}-\mathrm{F})_{\mathrm{n}}^{\mathrm{n}+}$ chain is observed in $\mathrm{AgF}^{+} \mathrm{BF}_{4}^{-}$which crystallizes in a tetragonal unit cell with $\mathrm{a}_{0}=6.693(3) \AA, c_{0}=4.004(3) \AA . \mathrm{AgFAuF}_{4}$ has a triclinic unit cell with $a_{0}=5.906(6) \AA, b_{0}=4.769(5) \AA, c_{0}=3.933(5) \AA, \alpha=107.01(5)^{\circ}, \beta=99.46(4)^{\circ}$, $\gamma=90.75(4){ }^{\circ}$ and is isostructural with $\mathrm{CuFAuF}_{4} . \mathrm{AgFAuF}_{6}$ has an orthorhombic unit cell with $a_{0}=7.600(4) \AA, b_{0}=7.156(4) \AA, c_{0}=10.137(5) \AA$ and appears to be isostructural with $\mathrm{AgFAsF}_{6}$. A second mixed valence silver fluoride, $\mathrm{Ag}^{\mathrm{II}_{A g}} \mathrm{III}_{\mathrm{F}_{5}}$, is prepared, which magnetic measurements indicate is probably an $\mathrm{AgF}^{+}$salt. Magnetic data for all of the $\mathrm{AgF}^{+}$salts exhibit low magnitude, temperature independent paramagnetism characteristic of metallic systems.

Cationic $\mathrm{Ag}(\mathrm{II})$ in acidic $\mathrm{AHF}$ solutions is demonstrated to be an exceedingly powerful oxidizer, capable of oxidizing $\mathrm{Xe}$ to $\mathrm{Xe}(\mathrm{II})$ and $\mathrm{O}_{2}$ to $\mathrm{O}_{2}{ }^{+}$. Reactions with $\mathrm{C}_{6} \mathrm{~F}_{6}$ and $\mathrm{C}_{3} \mathrm{~F}_{6}$ suggest an electron capture mechanism for cationic $\mathrm{Ag}(\mathrm{II})$ oxidations. 
To Mom and Dad

I love you 
The Synthesis and Structural Characterization of Novel Transition Metal Fluorides

\section{Table of Contents}

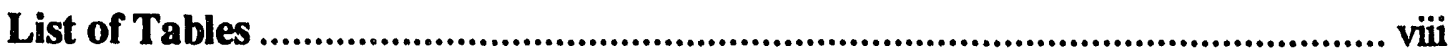

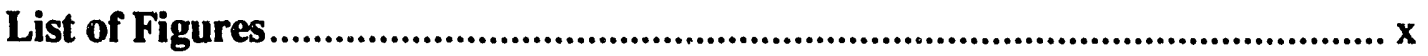

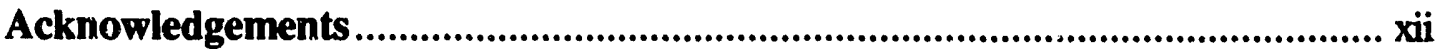

Chapter 1. General Introduction and experimental methods .................................... 1

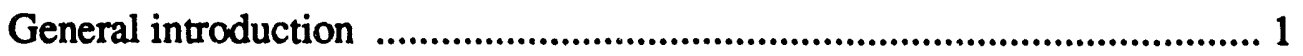

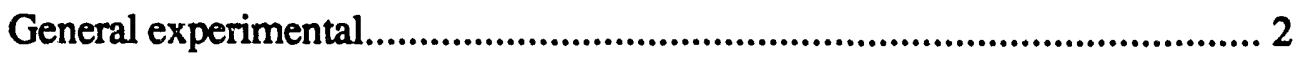

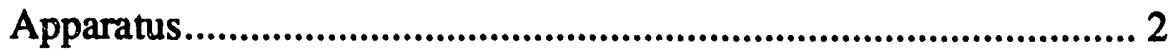

Vacuum lines and reactors ............................................... 2

Reagents ...................................................................... 4

Characterization ............................................................................... 4

$\mathrm{X}$ - Ray powder diffraction .................................................. 4

Vibrational spectroscopy........................................................ 5

Magnetic measurements ......................................................... 5

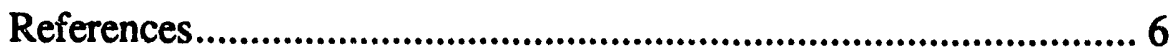

Chapter 2. The Preparation of Second and Third Transition Series $\mathrm{KMF}_{6}$ and $\mathrm{K}_{2} \mathrm{MF}_{6}$

Salts from the Hexafluorides................................................................ 8

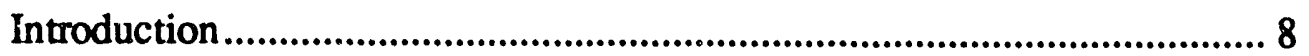

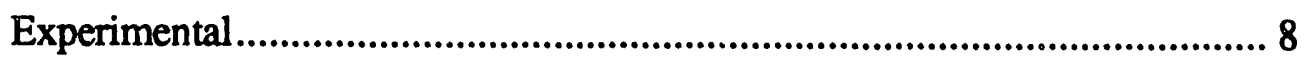

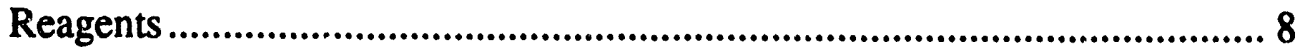

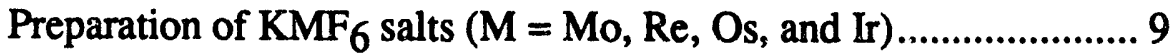


Preparation of $\mathrm{K}_{2} \mathrm{MF}_{6}$ salts $(\mathrm{M}=\mathrm{Mo}, \mathrm{Re}, \mathrm{Os}$, and $\mathrm{Ir}) \ldots \ldots \ldots \ldots \ldots \ldots . . . . .10$

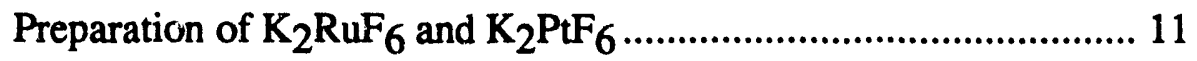

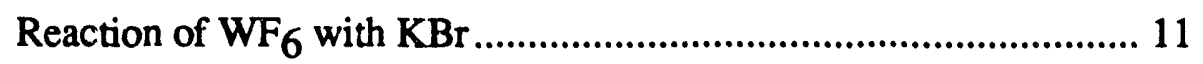

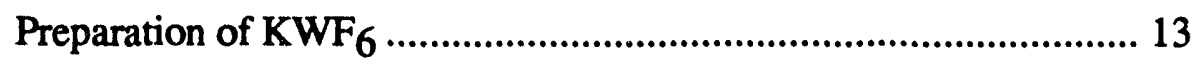

Results and discussion................................................................................... 13

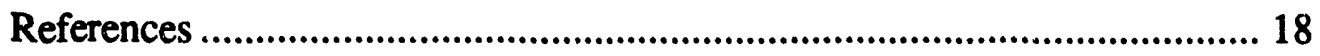

Chapter 3. Preparation and Structure of Ruthenium Tetrafluoride and a Structural

Comparison with Ruthenium Trifluoride and Ruthenium Pentafluoride. 19

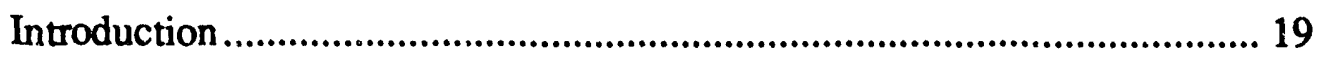

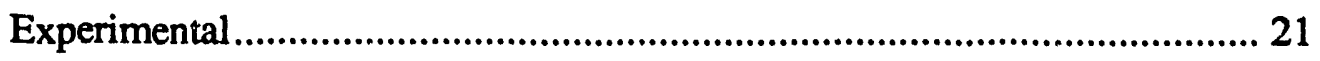

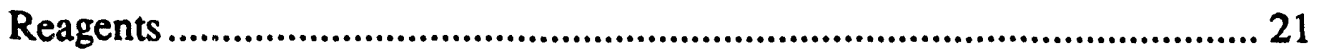

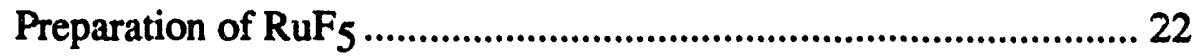

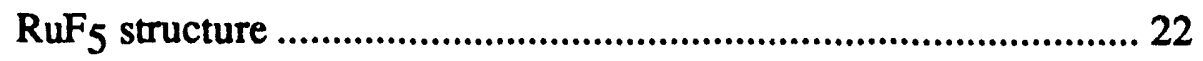

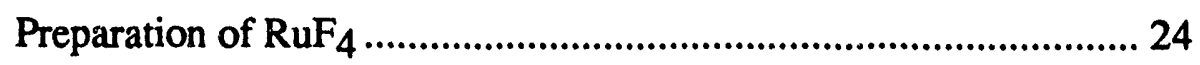

Structure of RuF 4 : Data collection ................................................... 25

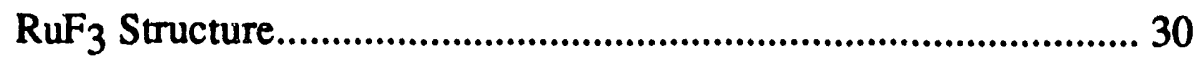

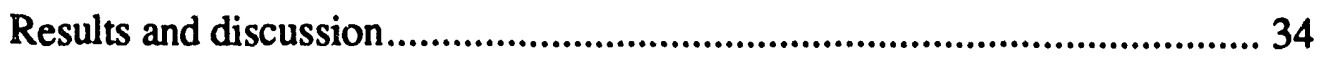

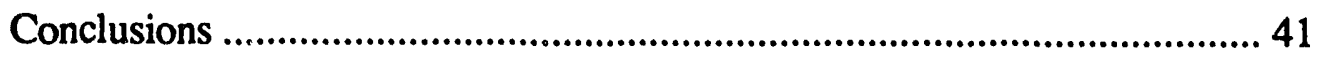

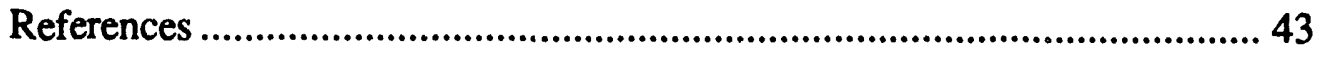

Chapter 4. Synthesis and structure types of the transition metal tetrafluorides........50

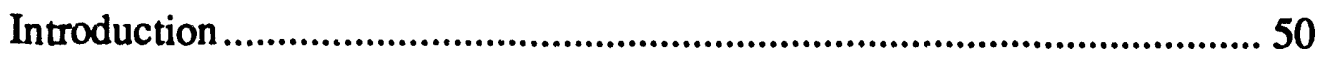

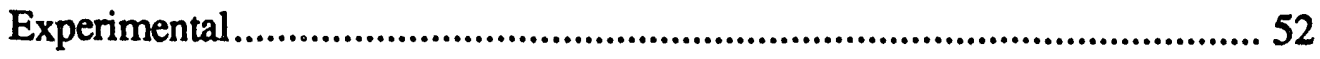

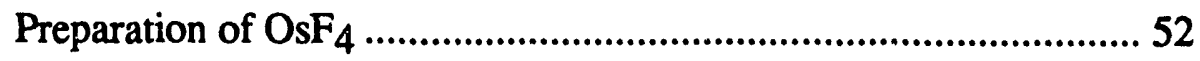

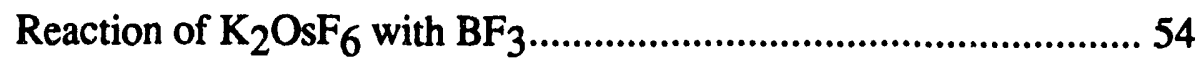




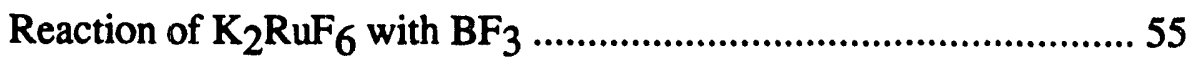

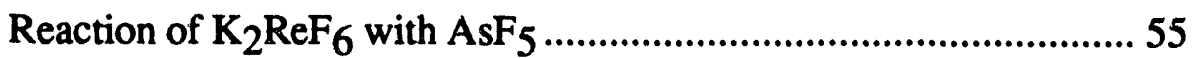

Preparation of $\mathrm{ReF}_{4}$

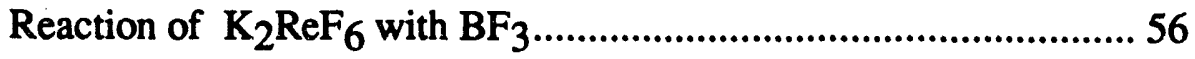

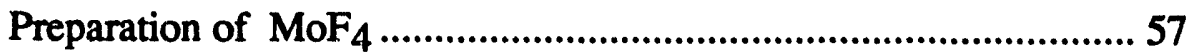

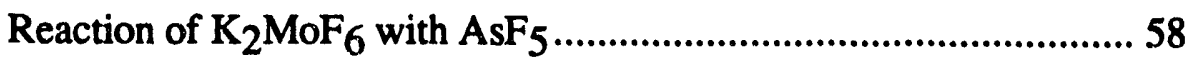

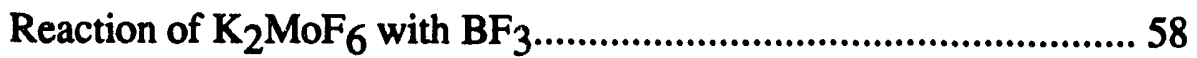

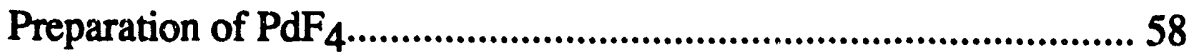

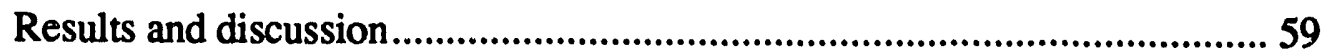

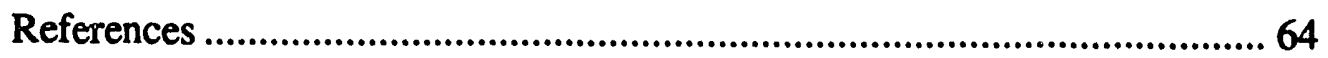

Chapter 5. Silver trifluoride: preparation, crystal structure, some properties, and

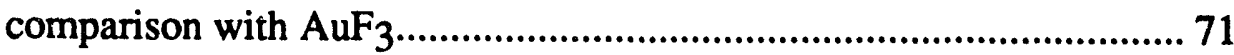

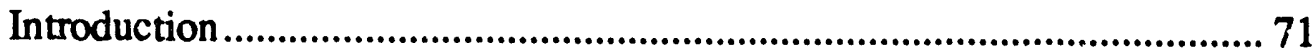

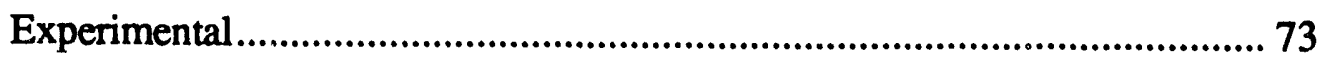

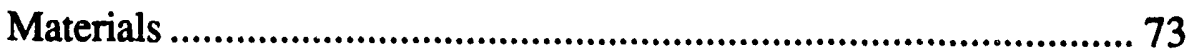

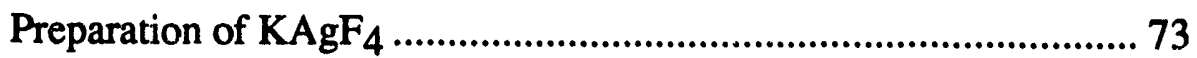

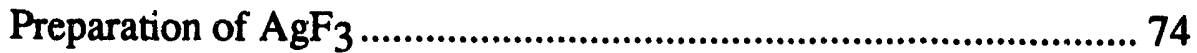

Synchrotron $\mathrm{X}$ - ray powder diffraction data collection and structure

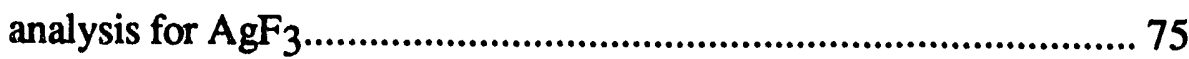

Neutron powder diffraction data collection and structure analyses for

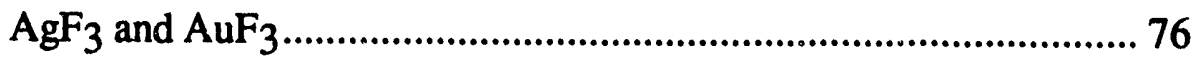

Interaction of $\mathrm{AgF}_{3}$ with $\mathrm{AsF}_{5}$ in $\mathrm{AHF}$......................................... 78

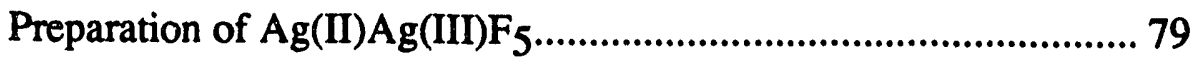

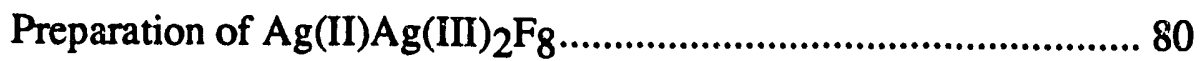

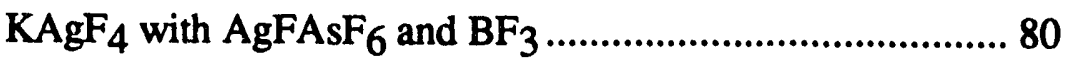

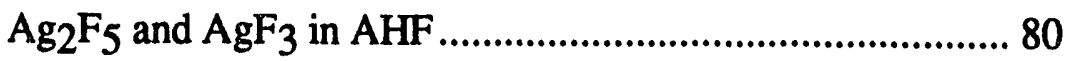




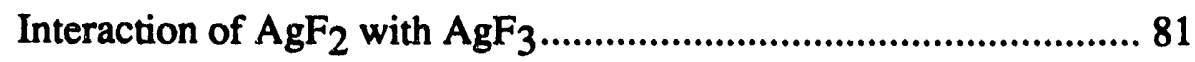

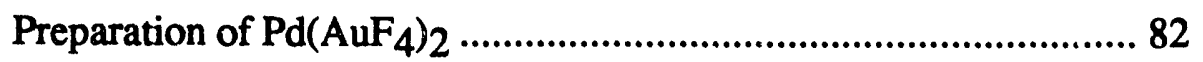

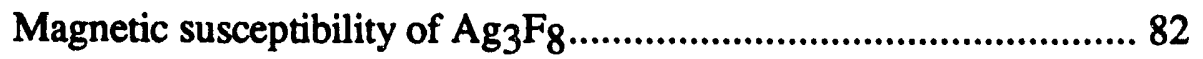

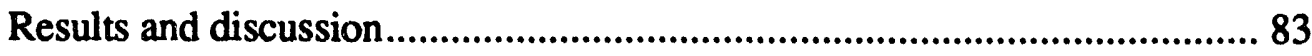

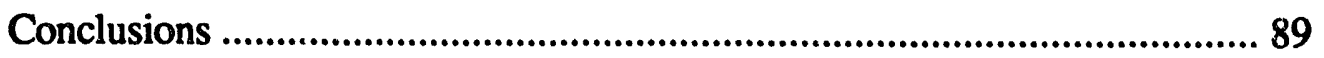

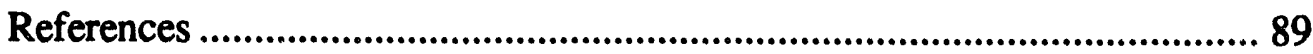

Chapter 6. The synthesis, structural characterization, and magnetic properties of $\mathrm{AgF}^{+}$

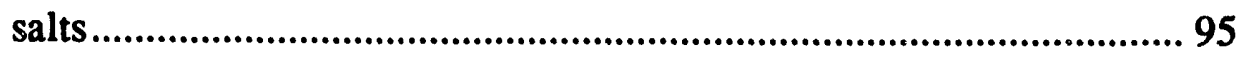

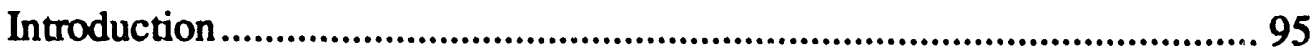

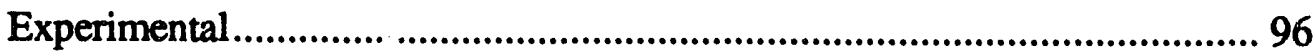

Materials ........................................................................................... 96

Preparation of $\mathrm{AgFBF}_{4}$..................................................................... 96

Preparation of $\mathrm{AgFBF}_{4}$ from $\mathrm{AgF}_{2}$ and $\mathrm{BF}_{3} \ldots \ldots \ldots \ldots . . . . . . . . . . . . . . . . . . . . . . .97$

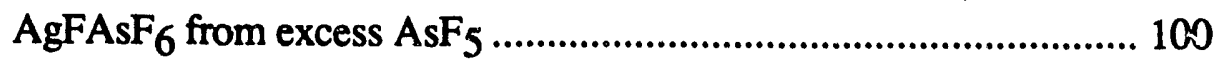

$\mathrm{AgFAsF}_{6}$ from excess $\mathrm{AsF}_{5}$ at low temperature ............................... 101

$\mathrm{AgFAsF}_{6}$ from stoichiometric $\mathrm{AsF}_{5}$ addition ....................................... 101

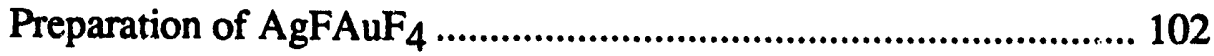

Preparation of AgFAuF 6 .............................................................. 104

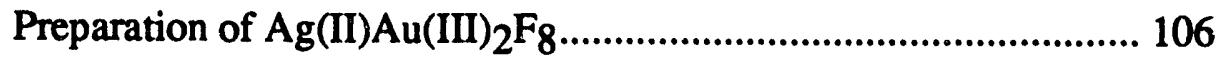

Interaction of $\mathrm{AgSbF}_{6}$ with fluorine in $\mathrm{AHF}$....................................... 108

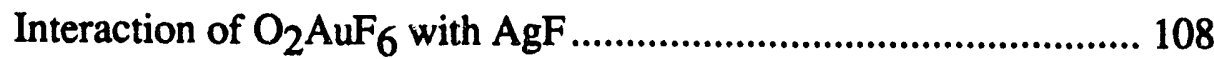

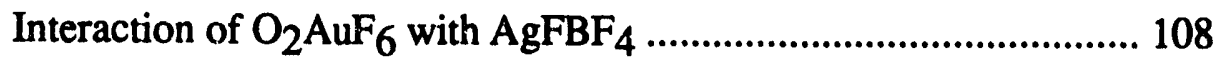

Interaction of $\mathrm{AgFAsF}_{6}$ with $\mathrm{AHF}$.................................................... 110

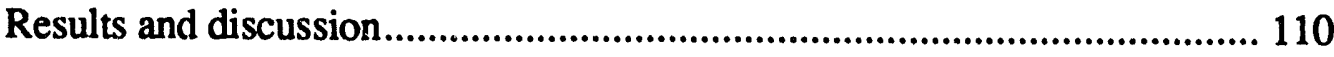

Magnetic measurements.................................................................... 116 
Conclusions

References

Chapter 7. The oxidizing properties of cationic silver (II) .................................... 126

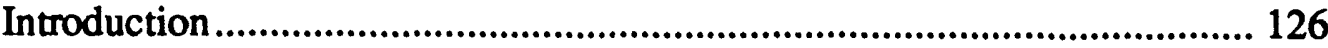

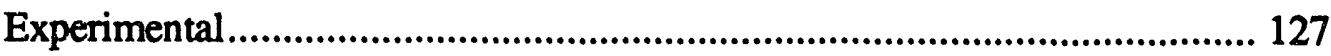

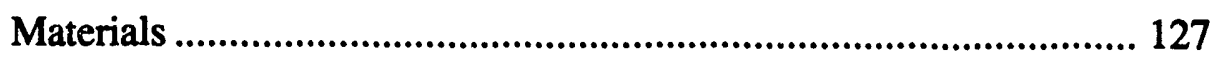

Cationic $\mathrm{Ag}(\mathrm{II})$ from $\mathrm{AgFBF}_{4}$ and $\mathrm{BF}_{3}$ with $\mathrm{Xe}$ in $\mathrm{AHF}$.................. 127

Cationic $\mathrm{Ag}(\mathrm{II})$ with $\mathrm{C}_{3} \mathrm{~F}_{6}$ in $\mathrm{AsF}_{5}$ rich $\mathrm{AHF}$.................................. 128

Cationic $\mathrm{Ag}(\mathrm{II})$ with $\mathrm{C}_{6} \mathrm{~F}_{6}$ in $\mathrm{AsF}_{5}$ rich $\mathrm{AHF}$................................. 129

Cationic $\mathrm{Ag}(\mathrm{II})$ with $\mathrm{O}_{2}$ in $\mathrm{AsF}_{5}$ rich $\mathrm{AHF}$...................................... 129

Interaction of $\mathrm{AgF}_{3}$ with $\mathrm{O}_{2}$ in $\mathrm{AsF}_{5}$ rich $\mathrm{AHF}$............................... 130

$\mathrm{AgF}_{3}$ with $\mathrm{NF}_{3}$ in $\mathrm{AsF}_{5}$ rich $\mathrm{AHF}^{2}$..................................................... 131

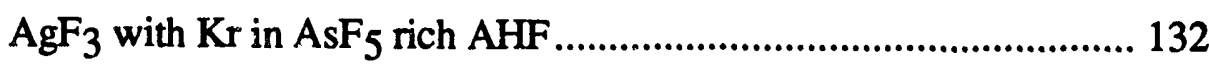

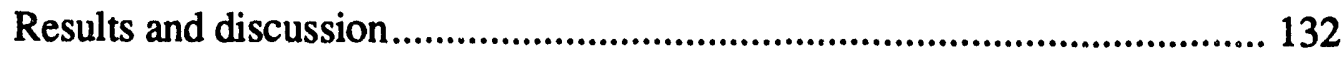

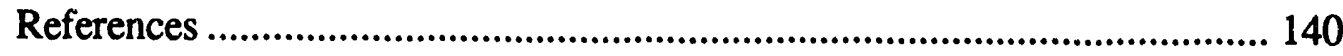




\section{List of Tables}

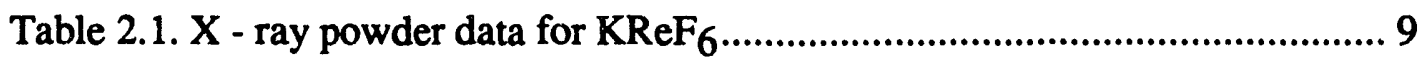

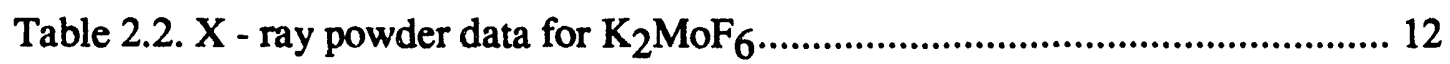

Table 2.3. A comparison of lattice parameters and unit cell volumes for some close packed hexafluorometallate salts............................................................................... 17

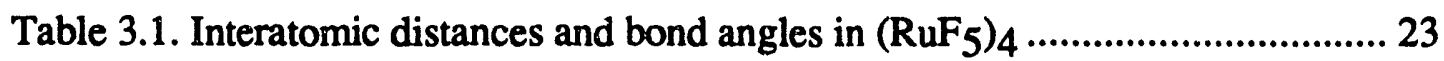

Table 3.2 $\mathrm{RuF}_{4} \mathrm{X}$ - ray synchrotron data collection ............................................... 26

Table 3.3. A comparison of the restrained $(r)$ and unrestrained $(u)$ refinements of the structural models for $\mathrm{RuF}_{4}$ in space group $\mathrm{P} 2_{1} / \mathrm{n}$.................................................... 28

Table 3.4. Interatomic distances ( $\AA$ units) and angles(deg.) in $\mathrm{RuF}_{4}$........................ 29

Table 3.5. $\mathrm{X}$ - ray powder data for the $\mathrm{RuF}_{4}$ monoclinic unit cell............................. 29

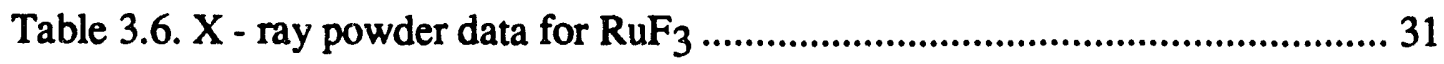

Table 4.1. Structures of the second and third transition series trifluorides.................50

Table 4.2. Structures of the second and third transition series pentafluorides.......... 51

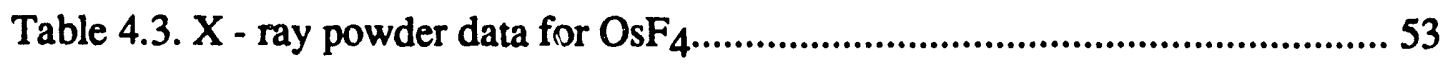

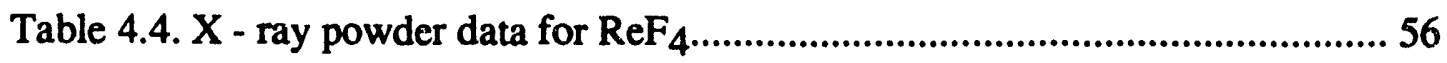

Table 4.5. $\mathrm{X}$ - ray powder data for $\mathrm{MoF}_{4}$ and a comparison with Payne and Asprey data

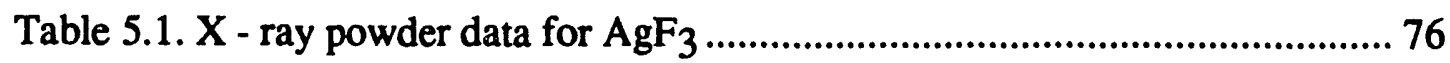

Table 5.2. Details of the neutron diffraction data collection for $\mathrm{AgF}_{3}$ and $\mathrm{AuF}_{3}$..... 77

Table 5.3. Final models from neutron diffraction structure refinements for $\mathrm{AgF}_{3}$

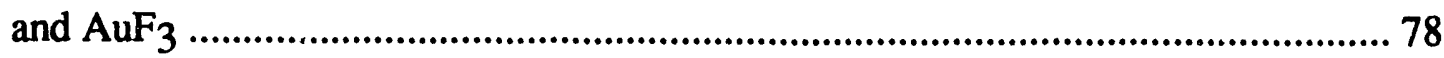

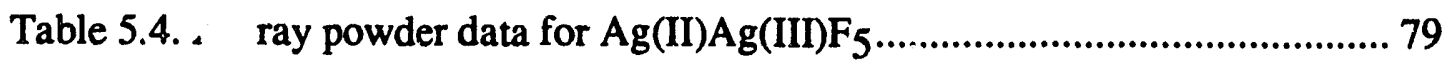

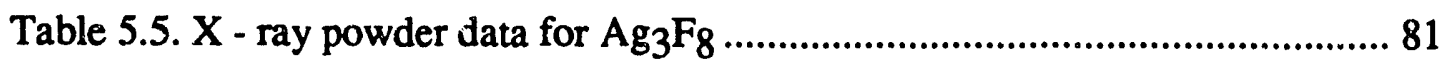

Table 5.6. Selected distances $(\AA)$ and angles (deg.) for $\mathrm{AgF}_{3}$ and $\mathrm{AuF}_{3} \ldots \ldots \ldots \ldots \ldots \ldots . . . .85$ 
Table 5.7. Comparison of formula unit volumes $\left(\AA^{3}\right)$ of $\mathrm{Ag}(\mathrm{III})$ and $\mathrm{Au}(\mathrm{III})$

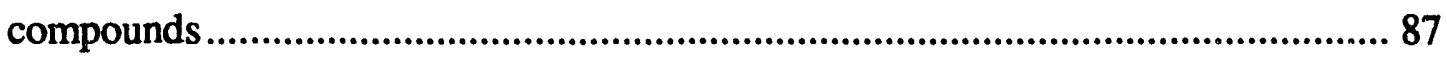

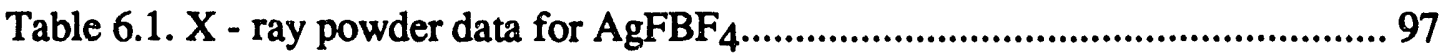

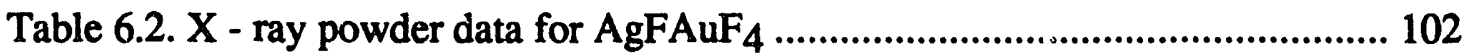

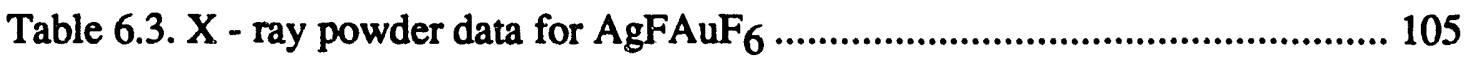

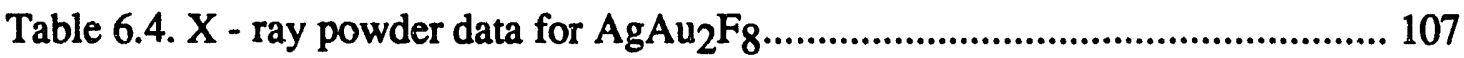

Table 6.5. $\mathrm{X}$ - ray powder data for $\mathrm{O}_{2} \mathrm{AuF}_{6} / \mathrm{AgFBF}_{4}$ phase.................................... 109

Table 7.1. The second ionization potentials of the coinage metals and xenon........... 135

Table 7.2. Observed $O$ - $O$ stretching frequencies ....................................................... 138 


\section{List of Figures}

Figure 1.1. Teflon valve schematic ............................................................ 7

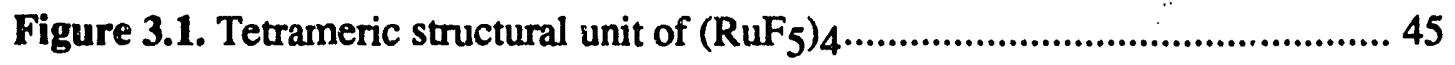

Figure 3.2. Observed neutron time - of - flight powder diffraction data for $\mathrm{RuF}_{4} \ldots 46$

Figure 3.3. View of the puckered - sheet structure of $\mathrm{RuF}_{4}$ 47

Figure 3.4. Relationship of the $\left(\mathrm{RuF}_{5}\right)_{4}$ geometry to an element of the $\mathrm{RuF}_{3}$ infinite hexagonal nearly - close - packed $\mathrm{F}$ atom array 48

Figure 3.5. $M$ - F interatomic distances, terminal and bridging $(\AA)$ for the binary fluorides of $\mathrm{Nb}$ through $\mathrm{Rh}$ 49

Figure 4.1. Observed structure types of the second and third transition series tetrafluorides 66

Figure 4.2. The $\mathrm{SnF}_{4}$ type structure 67

Figure 4.3. The $\mathrm{PdF}_{4}$ structure viewed along the $c$ axis 68

Figure 4.4. View along the 110 plane of the $\mathrm{PdF}_{4}$ type structure (a) and a comparison with the rutile structure (b)

Figure 4.5. The $\mathrm{PdF}_{4}$ structure (a) in which all unique $\mathrm{F}$ ligands are pointed up with respect to the 110 plane and a section of the hypothetical 2 - D sheet (b) which would result if the placement of the unique $F$ ligands was alternated up and down with respect to the 110 plane 70

Figure 5.1. Portions of the fitted neutron time - of - flight powder diffraction patterns for data taken on the $+153^{\circ} 2 \theta$ bank on HIPD for (a) $\mathrm{AgF}_{3}$ and (b) $\mathrm{AuF}_{3}$ 91

Figure 5.2. Curie - Weiss plot for $\mathrm{Ag}_{3} \mathrm{~F}_{8}$ 92

Figure 5.3. View down $a$ showing unit cell contents and the $F(2)$ interchain bridging in $\mathrm{AgF}_{3}$ and $\mathrm{AuF}_{3}$ 93 
Figure 5.4. Interatomic distances $(\AA)$ for the elongated octahedral $F$ ligand

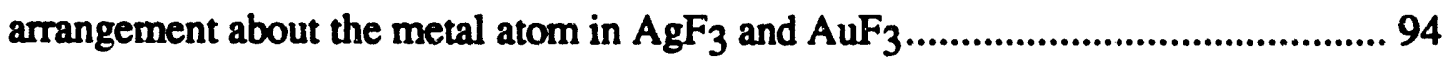

Figure 6.1. Magnetic susceptibility data for $\mathrm{AgFAsF}_{6}$ and $\mathrm{AgFAuF}_{6} \ldots \ldots \ldots \ldots \ldots . . . . . . . .121$

Figure 6.2. Magnetic susceptibility data for $\mathrm{Ag}_{2} \mathrm{~F}_{5}$ and $\mathrm{AgFAuF}_{4} \ldots \ldots \ldots \ldots \ldots \ldots \ldots . . . . . . . . . . . .122$

Figure 6.3. Curie - Weiss plots for $\mathrm{AgAu}_{2} \mathrm{~F}_{8}$ and $\mathrm{Ag}\left(\mathrm{SbF}_{6}\right)_{2} \ldots \ldots \ldots \ldots . . . . . . . . . . . . . . . . . . .123$

Figure 6.4. Magnetic susceptibility data for the black solvolysis product of

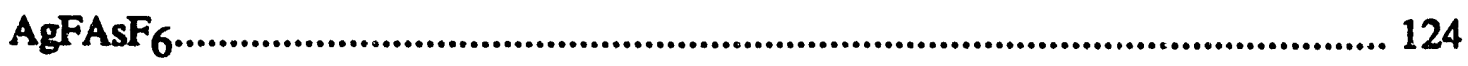

Figure 6.5. Magnetic susceptibility data for dilute $\mathrm{AgF}_{2}\left(15 \% \mathrm{AgF}_{2}, 85 \% \mathrm{CaF}_{2}\right) . .125$

Figure 7.1. Electron Oxidation by cationic $\mathrm{Ag}(\mathrm{II})$................................................... 137 


\section{Acknowledgements}

I would like to thank Professor Neil Bartlett for his warm and patient guidance throughout the course of this work. I certainly have appreciated his genuine enthusiasm for chemistry, the creative insight and clarity that he brings to the untangling of difficult problems, as well as the good humor and grace that he has shown to me.

This work could not have been completed without the friendship and help of many gifted scientists and good people. I am indebted to Professor Boris Zemva for his creative input and technical assistance on the synthetic portion of this thesis, Dr. Angus Wilkinson for the structure determination of $\mathrm{AgF}_{3}$ and $\mathrm{RuF}_{4}$, and Dr. Horst Bormann for the structure determination of $\mathrm{RuF}_{5}$ (Special thanks go to Angus and Horst for he'pit.s irss the time during a slow week at Los Alamos).

Because I have been here awhile, I must thank two "generations" of Bartlett students and post - docs. To Steve Mayorga, Mike Lerner, and Rika Hagiwara, who have since gone on: thank you for "showing me the ropes." To Byron Shen: thanks for your friendship and thoughtfulness throughout the entire time. To the youngsters, George Lucier and Lisa Chacon: Thanks for learning so quickly and being patient with a highly "entropic" senior grad student.

Additional thanks go to these people and to rest of the $5^{\text {th }}$ floor Latimer family who provided many of the fond memories I'll take from this place. Truly, we had some "BIG" times.

A very special thanks goes to my friends in the Graduate and International Fellowship, particularly my housemates, for praying for me, building me up, and bringing me to the One who can help.

This work was supported by the U.S. Dept. of Energy under contract No. DE-AC03-76-SF00098 and supplemented over the last year by an IBM Fellowship. 


\section{Chapter 1}

\section{General Introduction}

A broad range of simple binary and ternary transition metal fluorides have been synthesized in an effort to obtain structural data of sufficiently high quality to draw meaningful correlations between electronic configuration and molecular structure. Some of the materials of interest were of intermediate oxidation state and presented the synthetic problem of obtaining them free of other oxidation states. The synthetic schemes were also designed to ensure freedom from oxide since the similarity in size and $\mathrm{X}$ - Ray scattering power of $\mathrm{O}^{-2}$ and $\mathrm{F}^{-}$has often in the past led to confusion of oxyfluorides with fluorides. ${ }^{1}$ Chapter 2 describes a general anhydrous route to high purity hexafluorometallate salts. These salts, each containing the transition metal in a particular oxidation state and free of oxygen ligation were used as precursors in high purity binary fluoride synthesis. Higher precision unit cell data obtained from these salts provide also for the assessment of cation and anion effective volumes. Chapter 3 begins to compare structural data for the $+3,4,5$, and 6 oxidation state binary fluorides from groupV through VII, focusing, however, on the $\mathrm{Ru}$ - fluorides describing their high purity synthesis and details of their structure. Chapter 4 descibes structure types of the poorly characterized tetrafluorides and a general route to their synthesis exemplified by that of $\mathrm{RuF}_{4}$.

The remainder of this work focuses on the high oxidation state chemistry of $\mathrm{Ag}(\mathrm{III})$ and $\mathrm{Ag}(\mathrm{II})$. Chapter 5 describes the synthesis and structural characterization of neutral $\mathrm{AgF}_{3}$. The details of the structure are compared with $\mathrm{AuF}_{3}$ and the oxidizing properties of the two are discussed. In Chapter 6, the synthesis of a variety of cationic $\mathrm{Ag}$ (II) materials including two mixed valence $\mathrm{Ag}(\mathrm{II}) / \mathrm{Ag}$ (III) fluorides is described and their 
magnetic properties are discussed. Chapter 7 evaluates the oxidizing power of $\mathrm{Ag}(\mathrm{III})$ and cationic Ag(II).

\section{General Experimental.}

Apparatus: Vacuum Lines and Reactors. Reactions involving volatile materials were carried out in a stainless steel vacuum line constructed from 3/8 in. O.D. 316 stainless steel tubing, connected by Autoclave Engineers fittings and $30 \mathrm{VM}$ series valves with vee stems rated to 30,000 psi (Autoclave Engineers, Corp, Erie, PA). A small teflon vacuum manifold consisting of teflon valves and 1/4" O.D. FEP Tubing(AIN plastics, Concord,CA) was attached to the main vacuum line for the manipulation of strongly acidic materials. The teflon valves were made in the college of chemistry machine shop to a design described below. The pressure was monitored with an Acco - Helicoid guage(Con Val, Fremont, CA) which has a range of $0-1500$ Torr $\pm 0.25 \%$ and a Varian 801 Thermocouple guage (College of Chemistry Stores) for $0-2000 \mathrm{mTorr}$ readings. A cylinder of $\mathrm{F}_{2}$ (Air Products, Allentown, PA) was attached to the main vacuum line through Monel high pressure tubing and Monel Autocalve Engineers fittings and $30 \mathrm{VM}$ valves rated to hangle $30,000 \mathrm{psi}$. A high pressure Helicoid guage (600psi) was fixed to this $F_{2}$ handling portion of the line to monitor pressures therein. A mechanical forepump was connected to the vacuum line through a Pyrex cold trap cooled to $-196^{\circ} \mathrm{C}$. The manifold could be evacuated directly, or through a soda-lime scrubber to dispose of $F_{2}$ and other volatile oxidative fluorinators, as well as fluoroacids such as anhydrous hydrogen fluoride $(\mathrm{AHF})$ and $\mathrm{BF}_{3}$. After passivation of the vacuum line with 2 atm $\mathrm{F}_{2}$ for several hours, pressures of 10 - 50 mTorr were generally achieved upon evacuation.

The reaction vessels routinely used were of three types. Single armed reaction vessels consisting of a FEP tube sealed at one end and joined to a teflon valve and two 
armed reactors consisting of two such FEP tubes, joined to a teflon valve by means of a teflon tee piece (Oakland Valve and Fitting, Concord, CA), were used for reactions involving liq AHF in which pressures would not exceed 2atm. FEP tubes were sealed by heating one end over a flame, pinching it shut with pliers when it had softened as signaled by increased transluscence. Teflon valves, Fig 1.1, consisted of a teflon valve body, a Kel F stem containing an inserted teflon stem tip, and teflon packing washers, were designed so that the seat side of the valve which would be exposed to vapors from highly acidic oxidizing solutions could only come in contact with the teflon tip of the stem, while closed. The teflon packing nuts were pressed against the stem and valve body, to make a seal, by means of an additional aluminum packing washer and nut which could be screw tightened. Connections could be made to the inlet and outlet of the valve by means of $1 / 4$ " Swagelok fittings, or through $1 / 4$ " FEP tubing which could be sweated on to the knurled opening at the seat side of the valve.

For reactions at elevated temperatures, involving pressures of 5 to $20 \mathrm{~atm}$ Monel cans (100 and 250ml) equipped with SS 1KS4 Whitey valves (Oakland Valve and Fitting, Concord, CA) were employed. Copper gasketed Monel Parr bombs equipped with Autoclave Engineers VM30 valves were used when pressures greater than $20 \mathrm{~atm}$ were required.

Involatile, air - sensitive materials were handled in the dry Ar atmosphere of a Vacuum Atmospheres Corp. DRILAB. The atmosphere therein was kept rigorously dry by circulation through drying trains which were regenerated frequently. Freedom of the atmosphere from significant oxygen, or water contamination was judged by the burning of an incandescent filament for at least several days. 


\section{Reagents.}

Anhydrous Hydrogen Fluoride (AHF): Anhydrous HF 98\%, as obtained from Matheson, (Newark, CA) was reported to contain as much as $2 \%$ water. Rigorous drying of the HF was effected by condensing it on to dioxygenyl salts $\left(\mathrm{O}_{2}+\mathrm{SbF}_{6}^{-} \text {, or } \mathrm{O}_{2}{ }^{+} \mathrm{Sb}_{2} \mathrm{~F}_{11^{-}}\right)^{2}$ or $\mathrm{K}_{2} \mathrm{NiF}_{6}$ (Ozark - Mahoning - Pennwalt). These reagents oxidize water to ozone which was removed from the AHF by successive freeze - pump - thaw cycles.

The commonly used reagent gases $\mathrm{BF}_{3}$ (Matheson, Newark, $\mathrm{CA}$ ), $\mathrm{PF}_{5}$, and $\mathrm{AsF}_{5}$ (Ozark - Mahoning - Pennwalt, Tulsa, OK) were each checked before use by I.R. spectroscopy 3 and when found to be free of major volatile impurities were used without further purification. The much less volatile liquids $\mathrm{BrF}_{3}$ (Matheson) and $\mathrm{SbF}_{5}$ (Ozark Mahoning) were generally distilled out of their cylinders directly into reaction vessels. Bromine usually accompanied $\mathrm{BrF}_{3}$ distillation, however, since this served as a useful diluent and was a byproduct of $\mathrm{BrF}_{3}$ oxidations, further purification was unnecessary. When small amounts of volatile $\mathrm{O}_{2} \mathrm{SbF}_{6}$ impurity in the $\mathrm{SbF}_{5}$ could not be tolerated, it was removed by exposing the distilled $\mathrm{SbF}_{5}$ to $\mathrm{C}_{6} \mathrm{~F}_{6}$ (PCR, Gainesville, $\mathrm{FL}$ ) which was oxidized to $\mathrm{C}_{6} \mathrm{~F}_{6}{ }^{+}$by any $\mathrm{O}_{2}{ }^{+}$present. ${ }^{4}$ At one point it was necessary to prepare our own $\mathrm{AsF}_{5}$. This was accomplished by burning As metal in liq. $\mathrm{F}_{2}$ at $-196^{\circ} \mathrm{C}$ in a high pressure Monel bomb.

\section{Characterization:}

Powder Diffraction: Debye - Scherrer photographs were taken on General Electric Precision Powder cameras (45cm circumference) using Ni filtered, $\mathrm{CuK}<\alpha>$ radiation. Powder samples for X - Ray photographs were loaded into 0.3 or $0.5 \mathrm{~mm}$ diameter quartz capillaries (Charles Supper Co., Natick, MA) inside the DRILAB and temporarily sealed 
with KEL - F grease (Halocarbon Product Corp., N. Augusta, SC). The capillaries were finally sealed outside the DRILAB by drawing down using a micro-torch.

Refinement of Debye - Scherrer data was accomplished using the program, CELLREF 5

Vibrational Spectroscopy: Infrared Spectra were measured on a Nicolet 5DX Fourier Transform Spectrophotometer. Volatile materials were expanded into a $10 \mathrm{~cm}$ length Monel cell fitted with $\mathrm{AgCl}$ windows and a Whitey valve. Usually pressures of $10-25$ Torr were employed.

Magnetic Measurements: Variable temperature magnetic susceptibility data were collected on SQUID magnetometers manufactured by S.H.E. Corp. and Quantum Dynamics. Samples were held in cylindrical containers made in the College of Chemistry machine shop. These containers consisted of two Kel - F halves, one fitting inside the other. Usually the seperate halves were passivated with 2 atm of a $F_{2} / A_{s F}$, or $F_{2} / \mathrm{BF}_{3}$ mixture overnight before use. Inside the DRILAB a known quantitiy of material was packed into the smaller half of the container using a Kel - F packing tool which had been through the same passivation as the container. The two halves of the container were pressed together, being sealed with a small amount of Kel - F grease. Typically measurements were taken at 5 and $40 \mathrm{kG}$ between $6 \mathrm{~K}$ and $280 \mathrm{~K}$. 


\section{References}

1. Chamberland, B.L. "Crystal Chemistry of Oxyfluorides," Inorganic Solid

Fluorides, p. 208, P.Hagenmuller, ed., Academic Press, Orlando, FL, 1985.

2. McKee, D.E.; Bartlett, N. Inorg. Chem. 1973, 12, 2738.

3. Nakamoto, K. "Infrared Spectra of Inorganic and Coordination Compounds," Wiley, New York, 1963.

4. Richardson, T.J.; Tanzella, F.L.; Bartlett, N. J. Am. Chem. Soc. 1986, $108,4937$.

5. CELLREF - "A least squares program to refine unit cell parameters from hkl, 20." 


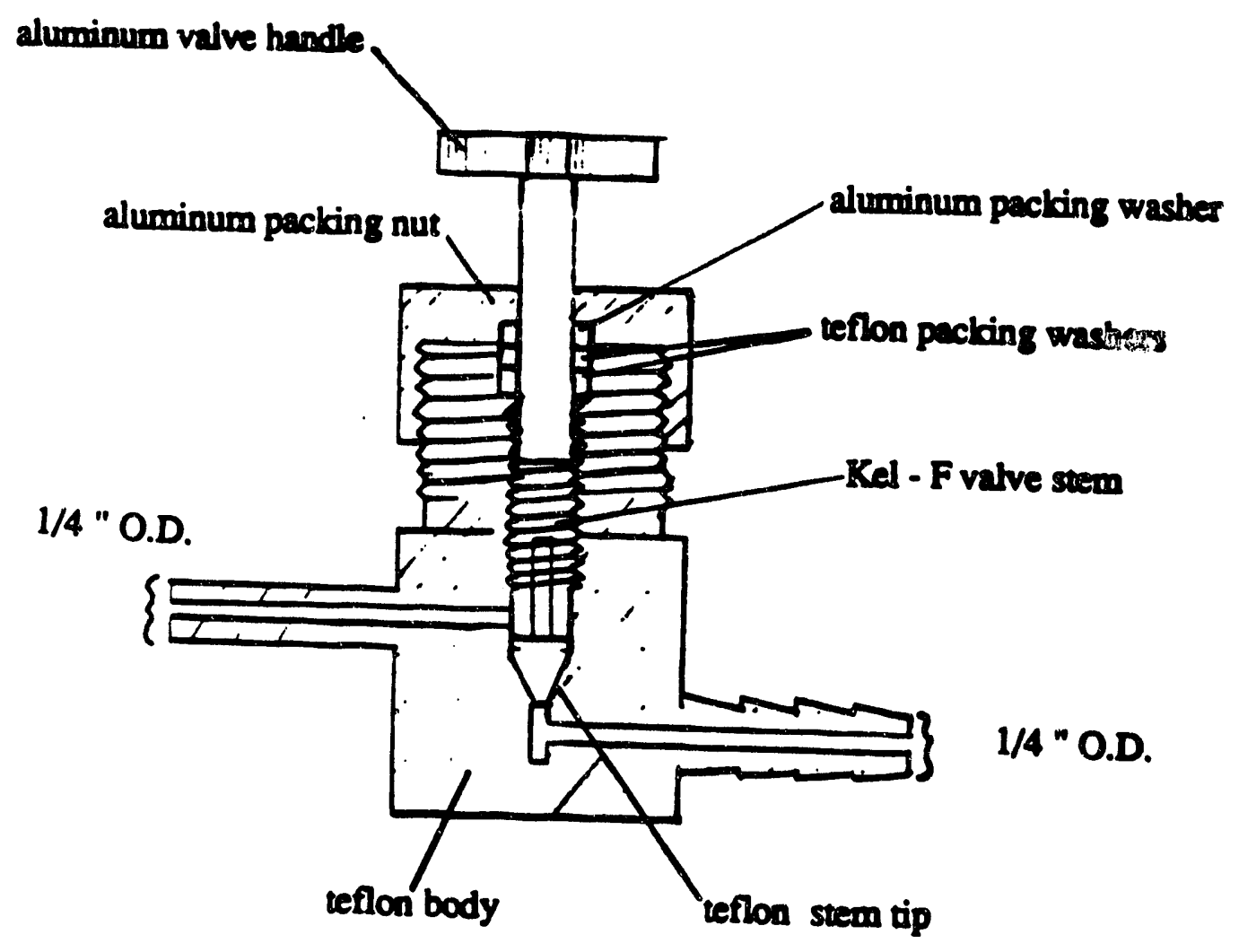

Figure 1.1 Teflon valve schematic 


\section{Chapter 2}

\section{The Preparation of Second and Third Transition Series $\mathrm{KMF}_{6}$ and $\mathrm{K}_{2} \mathrm{MF}_{6}$ Salts from the Hexafluorides}

\section{Introduction.}

A new, general method for synthesizing binary fluorides from fluorometallate precursors was discovered recently in these laboratories. ${ }^{1}$ Some consequences of this discovery will be discussed in chapters 3,4 , and 5 . The successful synthesis of high purity binary fluorides by this method requires high purity fluorometallate salts which are free of oxide contamination as well as contamination by other oxidation states. This is particularly true for the synthesis of a binary fluoride in an intermediate oxidation state and this is commonly the case for tetrafluorides of second and third transition series elements from group V through VIII. In addition previous syntheses have not rigorously avoided oxygen. Instances of this are the preparation of $\mathrm{K}_{2} \mathrm{RuF}_{6}{ }^{2}, \mathrm{~K}_{2} \mathrm{OsF}_{6},{ }^{3}$ and $\mathrm{K}_{2} \mathrm{IFF}_{6}{ }^{3}$ by the reduction of the $\mathrm{KMF}_{6}$ salt with water, or hydroxide. In all cases, some hydrolysis was observed. Furthermore,the precursor $\mathrm{KMF}_{6}$ salts, as well as $\mathrm{K}_{2} \mathrm{PtF}_{6},{ }^{4}$ have often been made using $\mathrm{BrF}_{3}$ in glass vessels. This has been shown to lead to oxide contamination. 5

A non aqueous route ${ }^{6}$ to $\mathrm{K}_{2} \mathrm{MoF}_{6}$ involved reduction of the hexafluoride with excess $\mathrm{KI}$ in $\mathrm{SO}_{2}$, but the products were acknowledged to contain a mixture of oxidation states. Therefore, a new approach to the synthesis of $\mathrm{K}_{2} \mathrm{MoF}_{6}$ was also required. This and several other $\mathrm{MF}_{6}{ }^{-}$and $\mathrm{MF}_{6}^{-2}$ salts have been prepared in high purity.

\section{Experimental.}

Reagents: Prior to use $\mathrm{KBr}$ and $\mathrm{KI}$ (Fisher, Fair Lawn, NJ) were dried by heating to $200^{\circ} \mathrm{C}$ under a vacuum of $10^{-8}$ Torr. Hexafluorides were prepared by direct interaction of the 
metal(previously reduced with hydrogen at $450^{\circ} \mathrm{C}$ ) with an excess of fluorine at $250^{\circ}$ in a monel can.

Preparation of $\mathrm{KMF}_{6}$ Salts $(\mathrm{M}=\mathrm{Mo}, \mathrm{Re}, \mathrm{Os}$, and Ir).In the DRILAB, $\mathrm{KBr}$ (usually $1.5 \mathrm{~g}, 13 \mathrm{mmol}$ ) was loaded into : 1/2" O.D. FEP tube equipped with a KS4 Whitey valve. The reactor w'as degassed under dynamic vacuum(better than 0.05 Torr) and a slight excess of the hexafluoride, MF6, was condensed on to the $\mathrm{KBr}$, followed by $7 \mathrm{ml} \mathrm{AHF}$. As the $\mathrm{HF}$ began to melt $\mathrm{Br}_{2}$ evolution and vigorous gas evolution were observed. Agitation of the reaction mixture was begun to help insure contact between the hexafluoride in solution and any $\mathrm{HBr}$ gas which may have formed on interaction of the $\mathrm{HF}$ with $\mathrm{KBr}$, and was continued for $30 \mathrm{~min}$ until all gas evolution had ceased and the mixture, which had become slightly warm, had cooled to room temperature. Bromine and HF were removed from the voluminous precipitate under dynamic vacuum leaving, the $\mathrm{KMF}_{6}$ salt in quantitative yield. $X$ - Ray powder data of each salt were indexed.That for $\mathrm{KReF}_{6}$ revealed a novel rhombohedral unit cell and is given in Table 2.1. The unit cells for the other salts were roughly in accord with earlier reports. 7,8

Table 2.1. $\mathrm{X}$ - Ray powder data $\left(\mathrm{CuK}<\alpha>\right.$ radiation, $\mathrm{Ni}$ filter) for $\mathrm{KReF}_{6}$ with a

\begin{tabular}{llcc} 
rhombohedral cell: & $a_{0}=5.021(3) \AA ; \alpha=97.16(4)^{\circ} ;$ & $V=122.7(3) \AA^{3}$. \\
& \multicolumn{1}{c}{$1 / d^{2} \times 10^{4} \AA^{-2}$} & \\
//I ${ }^{a}$ & obsd & calc & hkl \\
9 & 414 & 413 & 010 \\
9 & 718 & 708 & $0 \overline{10}$ \\
8 & 937 & 943 & 110 \\
7 & 1130 & 1121 & $1 \overline{1} 1$ \\
7 & 1657 & 1651 & $0 \overline{2} 0$ \\
4 & 1843 & 1829 & $1 \overline{2} 0$ \\
6 & 2146 & 2124 & $1 \overline{2} 1$ \\
6 & 2289 & 2298 & 210 \\
10 & 2370 & 2359 & $2 \overline{1} 1$
\end{tabular}


Table 2.1. cont.

\begin{tabular}{|c|c|c|c|c|}
\hline & & & & \\
\hline I/I & obsd & calc & & hkl \\
\hline 6 & 2860 & 2832 & & $2 \overline{2} 0$ \\
\hline 6 & 3045 & 3063 & & 211 \\
\hline 6.5 & 3266 & 3245 & & $2 \overline{2} 1$ \\
\hline 7 & 3724 & 3714 & & $0 \overline{3} 0$ \\
\hline 7 & 3793 & 3771 & - & 220 \\
\hline & & 3775 & & $1 \overline{3} 0$ \\
\hline-- & $\ldots$ & 4422 & & $3 \overline{1} 1$ \\
\hline 9 & 4470 & 4479 & & 310 \\
\hline & & 4483 & & $2 \overline{2} 2$ \\
\hline 3 & 4690 & 4653 & & 221 \\
\hline & & 4661 & & $2 \overline{3} 0$ \\
\hline 5 & 5000 & 4956 & & $2 \overline{3} 1$ \\
\hline 4 & 5207 & 5191 & & $3 \overline{2} 1$ \\
\hline 2 & 5329 & 5361 & & 311 \\
\hline 4 & 5890 & 5895 & & $3 \overline{1} 2$ \\
\hline 3 & 6423 & 6360 & & 222 \\
\hline & & 6372 & & $3 \overline{3} 0$ \\
\hline 4 & 6565 & 6546 & & $1 \overline{4} 0$ \\
\hline 4 & 6640 & 6603 & & $0 \overline{4} 0$ \\
\hline & & 6607 & & $1 \overline{4} 1$ \\
\hline 3 & 6818 & 6785 & & $3 \overline{3} 1$ \\
\hline 4 & 7014 & 7068 & & 321 \\
\hline
\end{tabular}

Preparation of $\mathbf{K}_{2} \mathbf{M F}_{6}$ Saits $(\mathbf{M}=\mathbf{M o}$, Re, Os, and $\mathbf{r})$. In the DRILAB 1:1 mixtures (usually $5 \mathrm{mmol}$ ) of $\mathrm{KMF}_{6}$ and $\mathrm{KI}$ were loaded into one arm of a two armed teflon-FEP reactor. A red discoloration due to the formation of a small amount of $I_{2}$ was observed upon contact of the solid reagents. The reactor was degassed in a dynamic vacuum, the arm containing the reactants being cooled to avoid transferring $I_{2}$ into the stainless steel vacuum line. AHF $(10 \mathrm{ml})$ was condensed on to the reactants. On melting of the HF copious $\mathrm{I}_{2}$ formation was observed, along with some gas evolution. Agitation of the reactor was maintained until the mixture had warmed to room temperature and was continued intermittantly over the next hour. At this time a solid precipitate of $I_{2}$ was 
observed in a colored solution, the color being dependent upon the $\mathrm{MF}_{6}{ }^{2-}$ anion in solution. The readily soluble $\mathrm{K}_{2} \mathrm{MF}_{6}$ salt was easily separated from the insoluble $\mathrm{I}_{2}$ by decantation of the HF solution into the free arm of the reactor. Back distillation of the HF into the original reaction arm followed by decantation was repeated (usually 5 times) until a colorless solution remained above the $I_{2}$. After the last back distillation, the HF over the I2 was frozen at $-196^{\circ} \mathrm{C}$. The reactor was filled with dry $\mathrm{N}_{2}$ (1atm), and the arm containing the $\mathrm{K}_{2} \mathrm{MF}_{6}$ was sealed with a screw clamp. This arm was removed from the reactor, fitted to a Whitey valve, and attatched to the stainless steel vacuum line for final drying under dynamic varsuum. Quantitative yields of $\mathrm{K}_{2} \mathrm{MF}_{6}$ salts were obtained. The XRay powder data for each salt was indexed completely on the basis of a trigonal $\mathrm{K}_{2} \mathrm{GeF}_{6}$ type cell, ${ }^{9}$ that for the $\mathrm{K}_{2} \mathrm{MoF}_{6}$ salt being observed for the first time, Table 2.2

Preparation of $\mathrm{K}_{2} \mathrm{RuF}_{6}$ and $\mathrm{K}_{2} \mathrm{PtF}_{6}$. In the DRILAB $1: 1$ mixtures of $\mathrm{KMF}_{6}$ (made from the pentafluoride and $\mathrm{KF}$ in $\mathrm{AHF}$ ) and $\mathrm{KBr}$ were loaded into a one armed FEP reactor fitted with a Whitey valve. The reactor was degassed under dynamic vacuum, and $5 \mathrm{ml}$ AHF was condensed on to the solid reagents. Immediately upon melting, $\mathrm{Br}_{2}$ evolution and vigorous gas evolution were observed. The reactor was agitated intermittantly as the reaction warmed to room temperature and for $30 \mathrm{~min}$ thereafter. A dark brown solution and red $\mathrm{Br}_{2}$ vapor resulted. Removing the $\mathrm{HF}$ and $\mathrm{Br}_{2}$ under dynamic vacuum gave quantitative yields of $\mathrm{K}_{2} \mathrm{RuF}_{6}$ and $\mathrm{K}_{2} \mathrm{PtF}_{6} . \mathrm{X}$ - Ray powder data for each material was indexed completely on the basis of a trigonal $\mathrm{K}_{2} \mathrm{GeF}_{6}$ type cell.

Reaction of $\mathrm{WF}_{6}$ with $\mathrm{KBr}$. The reaction was performed identically to the general $\mathrm{KMF}_{6}$ salt preparation, however only $0.5576 \mathrm{~g}(4.69 \mathrm{mmol}) \mathrm{KBr}$ was used with an excess of $\mathrm{WF}_{6}$. After degassing under dynamic vacuum $5 \mathrm{ml}$ AHF was condensed on to the reactants. On melting, vigorous gas evolution and $\mathrm{Br}_{2}$ evolution were observed as with 
other $\mathrm{KMF}_{6}$ preparations. However, on cessation of gas evolution, the increase in the volume of solid product was considerably less than expected for $\mathrm{KWF}_{6}$ formation. After removing the $\mathrm{HF}$ and $\mathrm{Br}_{2}$ only $0.7487 \mathrm{~g}$ products were obtained. $\mathrm{X}$ - Ray powder photographs revealed the presence of $\mathrm{KHF}_{2}$ in addition to $\mathrm{KWF}_{6}$.

Table 2.2. X - Ray powder data ( $\mathrm{CuK}<\alpha>$, Ni filtered radiation) for $\mathrm{K}_{2} \mathrm{MoF}_{6}$ with a trigonal cell; $\mathrm{a}_{\mathrm{o}}=5.860(2) \AA, \mathrm{c}_{\mathrm{o}}=4.634(3) \AA$.

\begin{tabular}{cccc}
$\mathbf{I} / \mathbf{I}_{\mathbf{n}}$ & obsd & $1 / \mathbf{d}^{2} \times 10^{4}$ & hkl \\
6 & 388 & calc & 100 \\
4 & 464 & 388 & 001 \\
9 & 852 & 466 & 101 \\
7 & 1159 & 854 & 110 \\
- & - & 1165 & 200 \\
2 & 1627 & 1553 & 111 \\
- & - & 1631 & 002 \\
10 & 2015 & 1863 & 201 \\
6 & 2253 & 2019 & 102 \\
- & - & 2251 & 210 \\
- & - & 2718 & 112 \\
6 & 3169 & 3028 & 211 \\
7 & 3402 & 3184 & 202 \\
3 & 3482 & 3416 & 300 \\
- & - & 3495 & 003 \\
4 & 4580 & 4191 & 103,212 \\
4 & 4654 & 4580 & 220 \\
- & - & 4659 & 310 \\
- & - & 5048 & 221 \\
4 & 5366 & 5125 & 113,302 \\
4 & 5525 & 5357 & 311 \\
2 & 5730 & 5513 & 203 \\
- & - & 5744 & 400 \\
- & - & 6212 & 222 \\
2 & 6673 & 6522 & 401 \\
3 & 6920 & 6678 & 213,312 \\
- & - & 6910 & 320 \\
2 & 7687 & 7377 & 303 \\
3 & 7851 & 7686 & 321 \\
& & 7843 & \\
\hline & & &
\end{tabular}


Preparation of KWF 6 . In the DRILAB usually $800 \mathrm{mg}(5 \mathrm{mmol}) \mathrm{KI}$ was loaded into one arm of a two armed teflon reactor. After evacuation on the vacuum line,an excess of WF6, usually $10 \mathrm{mmol}$, was condensed onto the $\mathrm{KI}$. On w aming to room temperature the liquid $\mathrm{WF}_{6}$ took on a blood red color. AHF ( $5 \mathrm{ml}$ ) was condensed on to this reaction mixture. As the reactor was warmed to room temperature, vigorous gas evolution ensued. During this time and for thirty minutes after all gas evolution had ceased, the reactor was intermittantly agitated. On standing, dark red insoluble $I_{2}$ remained in a colorless solution. A soluble colorless product was washed into the other arm of the reactor by decantation. The process of back distillating the AHF into the original reaction arm at $-196^{\circ} \mathrm{C}$, followed by decantation into the second arm was repeated 10 times to effect complete separation of the product from $I_{2}$. Finally all AHF was condensed into the reaction arm containing the $\mathrm{I}_{2}$. The arm containing the colorless product was sealed with a screw clamp and fitted to a Whitey valve on the vacuum line for thorough removal of AHF under dynamic vacuum. The colorless $\mathrm{KWF}_{6}$, obtained quantitatively, gave $\mathrm{X}$ - Ray powder data which was indexed completely on the basis of a tetragonal unit cell appropriate for $\mathrm{KWF}_{6} \cdot 10$

\section{Results and Discussion.}

Synthesis of $\mathrm{K}_{2} \mathrm{MF}_{6}$ salts from hexafluorides, $\mathrm{MF}_{6}$, has been achieved by the two step reduction process in AHF:

$$
\begin{gathered}
\mathrm{MF}_{6}+\mathrm{KBr} \stackrel{\mathrm{AHF}}{\longrightarrow} \mathrm{KMF}_{6}+1 / 2 \mathrm{Br}_{2} \\
\mathrm{KMF}_{6}+\mathrm{KI} \stackrel{\mathrm{AHF}}{\longrightarrow} \mathrm{K}_{2} \mathrm{MF}_{6}+1 / 2 \mathrm{I}_{2}
\end{gathered}
$$


The use of iodide alone as the reducing agent for the preparation $\mathrm{MF}_{6}{ }^{-2}$ had been shown to produce mixtures of oxidation states by Edwards in the synthesis of $\mathrm{K}_{2} \mathrm{MoF}_{6}$ even when a 1:2 stoichiometry of hexafluoride to iodide was rigorously maintained. The source of the problem probably lies in the ability of the hexafluorides, all aggressive oxidizing agents, to oxidize $\mathrm{I}^{-}$beyond $\mathrm{I}_{2}$ to iodine fluorides, thus complicating the reaction and making the determination of stoichiometry difficult. The $\mathrm{MF}_{6}{ }^{-}$salts do not appear to oxidize $\mathrm{I}^{-}$beyond $\mathrm{I}_{2}$ thereby avoiding the difficulties of a complex reaction.

A hexafluoride, in slight excess, was reduced by $\mathrm{KBr}$ in $\mathrm{AHF}$ to give a high purity, microcrystalline $\mathrm{KMF}_{6}$ salt. The isolated sait was then reduced in a separate step by one equivalent of $\mathrm{KI}$, also in $\mathrm{HF} . \mathrm{KMF}_{6}(\mathrm{M}=\mathrm{Mo}$, Re, Os, and Ir) have been prepared by reaction 1. The rhombohedral form $\mathrm{KReF}_{6}$ (Table 2.1), observed here for the first time, indicates a close structural relationship to the later elements of the third transition series. A tetragonal cell was previously reported. ${ }^{11} \mathrm{~A}$ rhombohedral cell is adopted by all later third row transition series $\mathrm{KMF}_{6}$ salts. However, a transition to a tetragonal cell, in which the fluorine and potassium atoms are no longer close packed, is observed in $\mathrm{KWF}_{6}$ and $\mathrm{KMoF}_{6}$; therefore it is possible that $\mathrm{KReF}_{6}$ is dimorphic.

Because of the difficulty in obtaining the thermally unstable hexafluorides, $\mathrm{RuF}_{6}$ and $\mathrm{PtF}_{6}$, their $\mathrm{KMF}_{6}$ salts were obtained by interaction of the pentafluorides with $\mathrm{KF}$. The preparation of $\mathrm{K}_{2} \mathrm{MF}_{6}(\mathrm{M}=\mathrm{Mo}, \mathrm{Re}, \mathrm{Os}$, and $\mathrm{Ir})$ has been achieved by reaction 2. $\mathrm{X}$ ray powder data for $\mathrm{K}_{2} \mathrm{MoF}_{6}$, which has been obtained in crystallographically pure form for the first time, are given in Table 2.2 .

The oxidizing power of the hexafluorides, the $\mathrm{MF}_{6}-$ salts, and the $\mathrm{MF}_{6}-2$ salts is expected to increase across each transition series as the effective nuclear charge increases. This is clearly seen in the synthetic work. In general bromide ion reduces $M(V I)$ fluorides to $M(V)$, eq.1, with the more powerfully reducing iodide ion being required to reduce $M(V)$ completely to $M(I V)$. However, there are exceptions. Bromide will not completely 
reduce $\mathrm{W}(\mathrm{VI})$ to $\mathrm{W}(\mathrm{V})$ as judged by the formation of $\mathrm{KHF}_{2}$ in the $\mathrm{WF}_{6} / \mathrm{KBr}$ reaction and the resulting poor yield of $\mathrm{KWF}_{6}$. Iodide was required to bring about the complete reduction. Among the later transition metals, $\mathrm{Ru}(\mathrm{V})$ and $\mathrm{Pt}(\mathrm{V})$ reduction to $\mathrm{M}(\mathrm{IV})$ fluorides is easily affected by $\mathrm{Br}^{-}$ion. This increase in oxidizing power across a transition series is the result of the increasing electronegativity of the metal center arising from the ineffective shielding of increasing nuclear charge by antibonding $\pi$ electrons. A similar increase in shielding of the nucleus down a group, on moving to higher $d$ sheils, results in the decreasing oxidizing power and increased difficulty in reduction observed.

Interaction of AHF with alkali-metal halides produces the alkali-metal fluoride and the corresponding hydrogen halide according to the solvolysis reaction 12

$$
\mathrm{AX}+\mathrm{HF} \longrightarrow \mathrm{HX}+\mathrm{AF}
$$

A sharp increase in pressure above the vapor pressure of HF was observed when reactions 1 and 2 were run without agitation, indicating that some solvolysis to volatile, HF insoluble $\mathrm{HBr}$ and $\mathrm{HI}$ was occuring. Furthermore, if the pressure was reduced to the HF vapor pressure by evacuation, reactions 1 and 2 failed to go to completion, instead producing large quantities of $\mathrm{KHF}_{2}$ along with the intended product. Thus the sparingly soluble $\mathrm{HBr}$ and $\mathrm{HI}$ are important reducing species in these reactions along with $\mathrm{Br}^{-}$and $\mathrm{I}^{-}$ . A two step process, involving a one electron reduction followed by the attack of the fluorobase KF, must therefore complement reactions 1 and 2

$$
\begin{gathered}
\mathrm{MF}_{6}+\mathrm{HBr} \stackrel{\mathrm{AHF}}{\longrightarrow} \mathrm{MF}_{5}+1 / 2 \mathrm{Br}_{2}+\mathrm{HF} \\
\mathrm{MF}_{6}^{-}+\mathrm{HI} \stackrel{\mathrm{AHF}}{\longrightarrow} \mathrm{MF}_{5}^{-}+1 / 2 \mathrm{I}_{2}+\mathrm{HF}
\end{gathered}
$$




$$
\begin{gathered}
\mathrm{K}_{\mathrm{n}} \mathrm{MF}_{5} \mathrm{n-}+\mathrm{KF} \stackrel{\mathrm{AHF}}{\longrightarrow} \mathrm{K}_{\mathrm{n}+1} \mathrm{MF}_{6}(\mathrm{n+1})- \\
\text { where } \mathrm{n}=0 \text { or } 1
\end{gathered}
$$

The low solubility of $\mathrm{Br}_{2}$ and $\mathrm{I}_{2}$ in $\mathrm{AHF}$ lowers their activity and contributes to the effectiveness of the reduction. The reducing capability of $\mathrm{HBr}$ and $\mathrm{HI}$ in $\mathrm{AHF}$ as expressed in equations 5 and 6 suggests that they may be useful in the synthesis of lower oxidation state binary fluorides.

The ready synthesis of high purity, microcrystalline $\mathrm{KMF}_{6}$ and $\mathrm{K}_{2} \mathrm{MF}_{6}$ salts has afforded the opportunity of evaluating the lattice constants and formula unit volumes of these salts to higher precision (Table 2.3). As expected, a decrease in formula unit volumes from early to late transition metals is observed. Again this can be accounted for on the basis of the increasing electronegativity of the metal center. This effect must counter that of filling the $2 \mathrm{~g}^{*}$, antibonding $\pi$ orbitals, which increase electron density on the $\mathrm{F}$ ligand away from the nucleus. It is apparent, however, that this decrease in volume is not monotonic, but is itself, decreasing. Evidently, as the effective volume of the metal center decreases, F ligand - F ligand repulsion becomes more important.

Because the rhombohedral $\mathrm{KMF}_{6}$ salts and the trigonal $\mathrm{K}_{2} \mathrm{MF}_{6}$ salts both consist of close packed layers of fluorine and potassium atoms with the metal occupying octahedral holes, it is anticipated that the difference in formula unit volumes will roughly measure the volume of the potassium cation. However such an estimate assumes no volume difference between the $\mathrm{MF}_{6}^{-}$and the $\mathrm{MF}_{6}{ }^{2-}$ anions. Due to the increased electron density on the fluorine atoms of the $\mathrm{MF}_{6}{ }^{2-}$ anion, this anion must be larger than $M_{6}{ }^{-}$. The difference in volume, $\Delta V$, of the $M(V)$ and $M(I V)$ salts of $\approx 14.7 \AA^{3}$ (shown in Table 2.3) is contant within experimental error across the third transition series, and is signicantly larger than the volume of $13.3 \AA^{3}$ calculated from Pauling's radii. 13 This difference, perhaps signifies the difference in anion sizes and indicates that the dianion is probably no more than $1.5 \AA^{3}$ larger than the monoanion. 
Table 2.3. A Comparison of Lattice Parameters and Unit Cell Volumes for Some Closepacked Hexafluorometallate Salts

$\begin{array}{cccccc} & \mathrm{Re} & \mathrm{Os} & \mathrm{Ir} & \mathrm{Pt} 14,15 & \mathrm{Ru} \\ \mathrm{KMF}_{6} \mathrm{a}_{0}(\AA) & 5.012(4) & 4.987(1) & 4.9744(7) & 4.96 & 4.968(1) \\ \mathrm{KMF}_{6} \alpha\left(^{\circ}\right) & 97.15(4) & 97.18(1) & 97.399(9) & 97.4 & 97.40(1) \\ \mathrm{KMF}_{6} \mathrm{~V}\left(\AA^{3}\right) & 122.7(3) & 120.8(1) & 119.72(5) & 118.7 & 119.3(1) \\ \mathrm{K}_{2} \mathrm{MF}_{6} \mathrm{a}_{0}(\AA) 5.852(2) & 5.824(2) & 5.798(2) & 5.76 & 5.755(2) \\ \mathrm{K}_{2} \mathrm{MF}_{6} \mathrm{c}_{\mathrm{o}}(\AA) 4.594(3) & 4.617(2) & 4.617(2) & 4.64 & 4.657(4) \\ \mathrm{K}_{2} \mathrm{MF}_{6} \mathrm{~V}\left(\AA^{3}\right) 137.4(2) & 135.6(2) & 134.4(2) & 133.3 & 133.6(2) \\ \Delta \mathrm{V}^{3}\left(\AA^{3}\right) & 14.7 & 14.8 & 14.7 & 14.7 & 14.3\end{array}$


1. Žemva, B; Lutar, K.; Jesih, A.; Casteel, W.J.; Bartlett, N. J. Chem. Soc., Chem. Commun. 1989, 346.

2. Hepworth, M.A.; Peacock, R.D.; Robinson, P.L. J. Chem. Soc. 1954, 4835.

3. Hepworth, M.A.; Robinson, P.L.; Westland, G.J. J. Chem. Soc. 1958, 611.

4. Sharpe, A.G.; J. Chem. Soc. 1950, 3444.

5. Holloway, J.H.; Peacock, R.D. J. Chem. Soc. 1963, 527.

6. Edwards, A.J.; Steventon, B.R. J. Chem. Soc., Dalton Trans. 1977, 1860.

7. Hargreaves, R.; Peacock, R.D. J. Chem. Soc. 1957, 4212.

8. Hepworth, M.A.; Jack, K.H.; Westland, G.J. J. Inorg. Nucl. Chem. 1956, 2, 79.

9. Hoard, J.L.; Vincent, W.B. J. Am. Chem. Soc. 1939, 61, 2849.

10. Kemmitt, R.D.; Russell, D.R.; Sharp, D.W.A. J. Chem. Soc., 1956,

11. Peacock, R.D.; J. Chem. Soc. 1957, 407.

12. Glemser, O. J. Fluorine Chem. 1986, 33, 50.

13. Pauling, L. "The Nature of the Chemical Bond," p.514, Cornell University Press, Ithaca, NY, 1960.

14. Bartlett, N.; Lohmann, D.H. J. Chem. Soc. 1964, 619.

15. Mellor, D.P.; Stephenson, N.C. Australian J. Sci. Res. 1951, 4A, 406 


\section{Chapter 3}

\section{Preparation and Structure of Ruthenium Tetrafluoride and a Structural Comparison with Ruthenium Trifluoride and Ruthenium Pentafluoride}

\section{Introduction.}

A large body of structural information exists for the transition metal binary fluorides and a number of generalizations can be made. 1,2 With the exception of seven coordinate $\mathrm{ReF}_{7}$ and the group III and IV transition metals which prefer eight coordination, the binary fluorides maintain at least roughly octahedral coordination of six fluorine ligands. This octahedron can be distorted quite severely if $\mathrm{e}^{*} \mathrm{~g} \sigma$ antibonding orbitals are populated, and $\mathrm{d}^{8}$ systems such as $\mathrm{AuF}_{3}$ are more often thought of as square planer complexes. ${ }^{3}$ However, when these orbitals are left vacant as they are in the second and third transition series from group V through VIII distortions from octahedral symmetry are relatively minor. Those distortions that do occur, result because all systems in these series with oxidation state lower than the +6 of the monomeric hexafluorides must involve $\mathrm{F}$ ligands in $\mathrm{M}$ - F - $\mathrm{M}$ bridging to maintain 6 coordination. The pentafluorides involve 2 fluorine ligands in bridging and form either tetramers, or chain polymers. Tetrafluorides must involve $4 \mathrm{~F}$ ligands in bridging to remain 6 - coordinate and are known to form 2 - D and 3 - D polymers. Regular octahedral geometry is again observed for the trifluorides which involve all $6 \mathrm{~F}$ ligands in bridging. Only symmetric M - F - M bridges have been observed, indicating that the shared $\mathrm{F}$ ligands in bridging systems are equivalently held by the two involved metal centers. 
A remarkable feature of the structural data is the apparent uniformity of metal fluorine interatomic distances from group V through VIII in the second and third transition series. The interatomic distance in the $M-F_{\text {unique }}$ bond is always $\approx 1.80 \AA$, while $\mathrm{M}$ - F bridging interatomic distances are $\approx 2.00 \AA$ regardless of the metal center and oxidation state. Subtle differences show up when more precise structures can be compared, but even these differences e surprising. In the rhodium fluorides precise $\mathbf{M}$ Fbridging interatomic bond distances are known for the pentafluoride 4 and trifluoride 5 , averaging $2.000(3) \AA$ and $1.961(2) \AA$ respectively. The lower oxidation state which contains more $\mathrm{t}_{2 \mathrm{~g}}{ }^{*}$ antibonding electrons appears to make shorter $\mathrm{M}$ - F bonds! Data for $\mathrm{NbF}_{5}$ and $\mathrm{NbF}_{3}$, while of lower precision, 6,7 indicate nearly identical $\mathrm{M}$ - F $\mathrm{F}_{\text {bridging }}$ interatomic distances, as well. Unfortunately a complete set of high precision data for all the oxidation states of a given metal has not been available to allow firm conclusions to be drawn. An effort was made, therefore, to acquire such a data base.

The binary fluorides of ruthenium suggested themselves as a good set for further evaluation. As a second row transition metal, the possibility of obtaining high precision bond lengths from $\mathrm{X}$-ray data was much greater than for one of the heavier third row metals. A high precision strucure of $\mathrm{RuF}_{3}$ had already been obtained. 8 It appeared that the pentafluoride structure, ${ }^{9}$ although of low quality, could readily be redetermined to high precision and would offer valuable comparisons with the well defined $\mathrm{RhF}_{5}$ structure. Existing structural information on impure samples of the tetrafluoride suggested that it exhibited a new structure type for the tetrafluorides. In addition, the hexafluoride of $\mathrm{Ru}$ is also known and although it is of limited thermal stability, it is known to be octahedral. 10 Gas electron diffraction studies could give a highly precise $\mathbf{M}-\mathrm{F}_{\text {unique }}$ interatomic distance. 


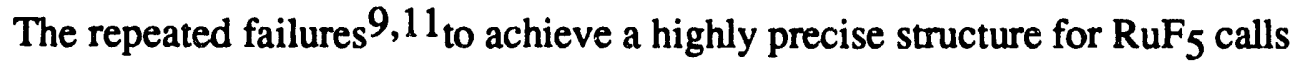
attention to a significant problem in undertaking such a structural study, that being the possibility of oxide contamination. The oxide ligand is practically indistinguishable from $\mathrm{F}^{-}$ by $\mathrm{X}$-rays, or neutrons, but its presence can result in dramatically altered "M - F" bond distances. Even the third structure determination of $\mathrm{RuF}_{5}$ is unacceptably imprecise. It is nearly certain that the first crystal to be examined contained some dissolved $\mathrm{RuOF}_{4}$, this being subsequently shown as a co-product with $\mathrm{RuF}_{5}$ in the $\mathrm{BrF}_{3}$ oxidation of $\mathrm{Ru}$ in glass containers. 12 Jack and his coworkers 8 reported variable lattice parameters, for different samples of $\mathrm{RuF}_{3}$ and this, being prepared from reduction of $\mathrm{RuF}_{5}$ made in the above manner, is likewise probably a consequence of oxide contamination. Therefore a reinvestigation of the $\mathrm{RuF}_{3}$ structure was also warranted.

An even greater challenge was involved in the synthesis of pure $\mathrm{RuF}_{4}$. Previous attempts at its synthesis by the reduction of higher fluorides have resulted in inseparable mixtures of the tetrafluoride, trifluoride, and Ru metal. ${ }^{13}$ This is a common problem in the synthesis of polymeric binary fluorides of intermediate oxidation state. It was expected that a structure determination of $\mathrm{RuF}_{4}$ would require powder diffraction methods, the likelihood of obtaining single crystals being small. Therefore, a high purity synthesis of $\mathrm{RuF}_{4}$ was essential.

\section{Experimental.}

Reagents.Powdered ruthenium, supplied by Alfa Products, Thiokol, Danvers, MA 01923, was reduced in hydrogen at $450^{\circ} \mathrm{C}$ for $6 \mathrm{~h}$ and stored in the DRILAB prior to use. 
RuF5 Preparation. In the DRILAB 300mg of Ru powder was loaded into a small nickel vessel and placed into a $250 \mathrm{ml}$ Monel can reactor which had been passivated with 4atm of $\mathrm{F}_{2}$ at $250^{\circ} \mathrm{C}$ for $24 \mathrm{~h}$. The can was fitted with a valved lid, which could be cooled during the experiment, and evacuated to better than $10^{-2}$ Torr on a stainless steel vacuum line. After pressurizing the can to $4 \mathrm{~atm}$ with $\mathrm{F}_{2}$, the can was heated to $250^{\circ} \mathrm{C}$ and held at this temperature for $24 \mathrm{~h}$, the lid being cooled with cold water. On cooling the can to room temperature, the remaining $F_{2}$ was evacuated through a glass $U$-trap, cooled to $-196^{\circ} \mathrm{C}$, into a soda-lime scrubber. A small amount of red-brown $\mathrm{RuF}_{6}$ was collected in the U-trap. The can was opened in the DRILAB. revealing waxy, lime-green $\mathrm{RuF}_{5}$ on the lid and cooler portions of the can. For crystal growth, the $\mathrm{RuF}_{5}$ was loaded into a flame-dried, 0.25 in o.d. Pyrex tube, which was cooled in liquid $N_{2}$ and then sealed off under a vacuum of $10^{-8}$ Torr. The tube containing the $\mathrm{RuF}_{5}$ was set up vertically and the bottom heated to $65^{\circ} \mathrm{C}$. Crystals suitable for X-ray studies were grown by Dr. Horst Bormann by sublimation over several days. Selected crystals were inserted into nominally $0.3 \mathrm{~mm}$ capillaries which had been drawn down further to provide for the tight fit of such small crystals. The structure refinement was performed by Dr. Horst Bormann and details of the refinement are given in ref. 14 .

RuF $_{5}$ Structure. The structure is no different, qualitatively, from that derived originally by Holloway and his coworkers. ${ }^{9}$ It consists of tetrameric units closely-packed such that the $\mathrm{F}$ ligand arrangement is almost that of a hexagonal-close-packed array. The greater precision now attained clearly differentiates the bridge $\mathrm{Ru}-\mathrm{F}$ interatomic distances from the non-bridging and accurately defines the coordination sphere about each Ru atom. The distances and angles of chemical interest are given in Table 3.1. Fig. 3.1 illustrates the 
tetramer geometry, with $\mathrm{Ru}-\mathrm{F}$ interatomic distances and Ru-F-Ru bridging angles specified.

Table 3.1. Interatomic Distances and Bond Angles in $\left(\mathrm{RuF}_{5}\right)_{4}$

\begin{tabular}{llclll} 
Atom & Atom 2 & Interatomic Distances (in Angstrom Units) & \\
1 & & Distance & Atom 1 & Atom 2 & Distance \\
\hline Ru1 & F1 & $1.798(1)$ & & & \\
Ru1 & F2 & $1.793(1)$ & Ru2 & F5 & $2.007(1)$ \\
Ru1 & F3 & $1.821(1)$ & Ru2 & F6 & $2.003(1)$ \\
Ru1 & F4 & $1.817(1)$ & Ru2 & F7 & $1.795(1)$ \\
Ru1 & F5 & $1.995(1)$ & Ru2 & F8 & $1.823(1)$ \\
Ru1 & F6 & $1.999(1)$ & Ru2 & F9 & $1.796(1)$ \\
& & & Ru2 & F10 & $1.824(1)$
\end{tabular}

\begin{tabular}{|c|c|c|c|}
\hline $\mathrm{F} 1-\mathrm{Ru} 1-\mathrm{F} 2$ & $93.99(6)$ & F5 - Ru2 - F6 & $86.20(4)$ \\
\hline F1 - Ru1 - F3 & $92.36(6)$ & F5 - Ru2 - F7 & $175.67(5)$ \\
\hline F1 - Ru1 - F4 & $92.04(6)$ & $\mathrm{F} 5-\mathrm{Ru} 2-\mathrm{F} 8$ & $87.83(5)$ \\
\hline F1 - Ru1 - F5 & $175.50(6)$ & F5 - Ru2 - F9 & $90.21(5)$ \\
\hline $\mathrm{F} 1-\mathrm{Ru} 1-\mathrm{F} 6^{\prime}$ & $89.08(5)$ & F5 - Ru2 - F10 & $87.30(6)$ \\
\hline F2 - Ru1 - F3 & $92.12(6)$ & F6 - Ru2 - F7 & $89.51(5)$ \\
\hline $\mathrm{F} 2-\mathrm{Ru} 1-\mathrm{F} 4$ & $92.47(6)$ & F6 - Ru2 - F8 & $88.00(5)$ \\
\hline $\mathrm{F} 2-\mathrm{Ru} 1-\mathrm{F} 5$ & $90.51(5)$ & F6 - Ru2 - F9 & $176.41(5)$ \\
\hline F2 - Ru1 - F6' & $176.93(5)$ & F6 - Ru2 - F10 & $87.54(5)$ \\
\hline F3 - Ru1 - F4 & $173.40(6)$ & F7 - Ru2 - F8 & $92.62(6)$ \\
\hline F3 - Ru1 - F5 & $87.54(5)$ & F7 - Ru2 - F9 & $94.08(6)$ \\
\hline F3 - Ru1 - F6' & $87.61(5)$ & F7 - Ru2 - F10 & $91.93(6)$ \\
\hline F4 - Ru1 - F5 & $87.68(5)$ & F8 - Ru2 - F9 & $92.00(6)$ \\
\hline F4 - Rul - F6' & $87.55(5)$ & F8 - Ru2 - F10 & $173.60(5)$ \\
\hline F5 - Rul - F6' & $86.42(4)$ & F9 - Ru2 - F10 & $92.16(6)$ \\
\hline Ru1 - F5 - Ru2 & $140.83(6)$ & Ru2 - F6 - Ru1' & $136.80(6)$ \\
\hline
\end{tabular}

It is seen that the six $\mathrm{F}$ ligands about each $\mathrm{Ru}$ atom are in approximately octahedral array a cis pair of $\mathrm{F}$ atoms being each shared with another $\mathrm{Ru}$ atom, such linkages forming the tetrameric ring. The bridging Ru-F distances range from 1.995(1) to 2.007(1) $\AA$, these 
being barely significantly different from $2.000 \AA$. The Ru - F - Ru bridges are bent, as in the other ideally hcp pentafluorides, creating the puckered ring shown. The symmetry of the cell allows for two the different bridging angles of $136.80(6)^{\circ}$ for the bridges which point into the tetrameric unit and $140.83(6)^{\circ}$ for those pointing away from this unit.

The non-bridging Ru-F distances are geometrically classified into two significantly different sets. Those non-bridging Ru-F trans to the bridges are shorter than those perpendicular to the plane containing each $\mathrm{Ru}$ atom and its bridging $\mathrm{F}$ ligands. The distances for the former range from 1.793(1) to $1.798(1) \AA$, whereas the latter values span $1.817(1)$ to $1.824(1) \AA$. There are slight but significant departures from an octahedral framework, the non-bridging Ru-F trans to the bridges subtending an angle at the Ru atom significantly greater than $90^{\circ}$, the pair of bridging $\mathrm{F}$ atoms subtending an angle correspondingly less than $90^{\circ}$. In addition the non-bridging $\mathrm{F}$ atoms normal to the plane, defined by the $\mathrm{Ru}$ atom and its bridging $\mathrm{F}$ ligands, are displaced slightly along the bisector of the angle subtended by the Ru-F bridging atoms. These angle deformations and displacements are consistent with ligand-ligand repulsive interactions, those associated with the shortest Ru-F being strongest and those with the longest $\mathrm{Ru}-\mathrm{F}$ (the bridging distances) being weakest.

Preparation of $\mathrm{RuF}_{4}$. In the DRILAB $600 \mathrm{mg}(2 \mathrm{mmol})$ was loaded into one arm of a teflon tee apparatus. The reactor was evacuated through a teflon manifold connected to the main stainless steel vacuum line and $5 \mathrm{ml} A H F$ was condensed on to the solid $\mathrm{K}_{2} \mathrm{RuF}_{6}$. The solid completely dissolved at room temperature giving a golden solution. To the solution, $\mathrm{AsF}_{5}$ was slowly admitted (slow addition giving a more crystalline product) resulting in the immediate formation of a deep-pink precipitate, and was continued until the precipitate in a colorless solution remained. To facilitate removal of the $\mathrm{KAsF}_{6}$ 
formed as a side product in the reaction, the $\mathrm{AsF}_{5}$ rich $\mathrm{AHF}$ was removed under vacuum and $5 \mathrm{ml}$ of pure were condensed back on to the solid mixture. The insoluble $\mathrm{RuF}_{4}$ was washed free of $\mathrm{KAsF}_{6}$ by decantation into the free arm of the reactor, followed by back distillation, under static vacuum, into the arm of the reactor containing the $\mathrm{RuF}_{4}$. This process was repeated 10 times, a cloudiness of the $\mathrm{AHF}$ above the $\mathrm{RuF}_{4}$ usually signalling that the material was free of $\mathrm{KAsF}_{6}$.

Although $\mathrm{PF}_{5}$ proved to be ineffective in forming $\mathrm{RuF}_{4}$, it giving rise to a dark brown solution (probably of $\mathrm{RuF}_{5}{ }^{-}$) and $\mathrm{KPF}_{6}$, it was useful in combination with $\mathrm{AsF}_{5}$, the product being somewhat more crystalline than with $\mathrm{AsF}_{5}$ alone. For this procedure, the solution of $\mathrm{K}_{2} \mathrm{RuF}_{6}$ was first treated with $\mathrm{PF}_{5}$ until no further uptake was observed, $\mathrm{AsF}_{5}$ then being introduced with agitation for several hours. The solid was washed as above leaving on evacuation, homogeneous deep-pink $\mathrm{RuF}_{4}$. To analyze the pink solid, it was decomposed in aqueous sodium hydroxide, $\mathrm{F}^{-}$in the filtrate being determined as $\mathrm{PbClF}$. Decomposition of of a sample in steam at $300^{\circ} \mathrm{C}$ followed by reduction in hydrogen at $450^{\circ} \mathrm{C}$ gave the metal. Anal. Found: F, 42.1; Ru, 57.7. Calcd for $\operatorname{RuF}_{4}: \mathrm{F}$, $42.9 ; \mathrm{Ru}, 57.1$. $\mathrm{X}$ - Ray powder patterns of the $\mathrm{RuF}_{4}$ prepared in this way proved to be the same as those of the $\mathrm{RuF}_{4}$ phase present in the product of the reduction of $\left(\mathrm{RuF}_{5}\right)_{4}$ with Ru metal or $\mathrm{RuF}_{3}$.

Structure of RuF 4. Data Collection. Synchrotron powder X-Ray diffraction data were collected by Drs. David Cox and Angus Wilkinson on a sample of $\mathrm{RuF}_{4}$ contained in a $0.5 \mathrm{~mm}$ diameter quartz capillary using beam line X7A at Brookhaven National Laboratory (details in Table 3.2). Additionally, time-of-flight powder neutron diffraction data were collected on approximately $50 \mathrm{mg}$ of material contained in a 2-mm diameter quartz capillary using the high-intensity powder diffractometer (HIPD) at Los Alamos National 
Laboratory. 15 The availability of instruments such as HIPD, with very high neutron flux and medium resolution, allows the study of small samples, such as those required for work in special environments or where there are sample handling and synthesis difficulties. The neutron data were collected for 20 hours with the source operating at a proton current of $90 \mathrm{~mA}$. Normally a period of 1-2 hours would be used for the collection of data from a much larger sample (typically 5-10g of material), consequently the present data is of considerably lower statistical quality than that usually obtained.

Table 3.2. $\mathrm{RuF}_{4} \mathrm{X}$-Ray Synchrotron Data Collection

Instrument Employed
Sample
Wavelength
Diffraction Geometry
Data Range

Brookhaven National Laboratory National Synchrotron Light Source Beam Line X7A $\mathrm{RuF}_{4}$ contained in a $0.5 \mathrm{~mm}$ Diameter Quartz Capillary $\lambda=1.24805 \AA$ from a $S i(111)$ channel cut monochromator Debye-Scherrer, with a $0.55 \mathrm{~mm}$ receiving slit $70 \mathrm{~cm}$ from the sample $13.0^{\circ}$ to $58.4^{\circ}$ in $0.04^{\circ}$ steps with 64 contributing reflections

The Bragg peaks resulting from the main phase in the powder X-Ray pattern had a FWHM of at least $0.24^{\circ}$. The peaks due to the presence of a small amount of $\mathrm{KAsF}_{6}$ were considerably sharper and were comparable with the instrumental resolution (approximately $0.09^{\circ}$ ). The first 16 peak positions in the X-Ray data excluding those from $\mathrm{KAsF}_{6}$ were located precisely using a least squares fitting procedure and were used as input for the auto indexing program TREOR. 16 The best solution was a monoclinic cell with $a_{0}=5.614(1) \AA, b_{0}=4.9508(7) \AA, c_{0}=5.414(1) \AA, B=121.41(2)^{\circ}, M_{16}=49$ (Ref 17) giving $Z=2$. The observed systematic absences were consistent with the space 
group $P 2_{1} / n$, but a space group could not be unambiguously assigned due to the small range of well resolved data. The program GSAS 18 was used for further analysis. The Ru atoms were assigned to a special position in the space group $\mathrm{P} 21 / \mathrm{n}$ and the fluorine atoms located in a rourier difference map. The resulting model was then refined using the Rietveld method ${ }^{19}$ to give a chemically plausible structure, but a poor fit to the diffraction ᄀattern. A more crystalline $\mathrm{RuF}_{4}$ sample containing less $\mathrm{KAsF}_{6}$ impurity was prepared for the neutron diffraction work using $\mathrm{PF}_{5}$ in combination with $\mathrm{AsF}_{5}$ (q.v. preparation). Neutron diffraction data were collected using this sample.

The X-Ray structural model was used as a starting point for the time-of flight powder neutron diffraction data. This analysis employed the data collected on the $+153^{\circ}$, $-153^{\circ}$ and $-90^{\circ}$ banks of the instrument HIPD, the resolution of the lower angle banks being too low to warrant inclusion in the refinement. The count rate in the $+90^{\circ}$ bank appeared to be anomalously low hence these data were excluded from the refinement. A refinement using a cosine Fourier series background was performed but did not produce a satisfactory background fit. Subsequently the background was modeled assuming that it contained a contribution due to scattering from an amorphous component, the resulting fit was improved but the refined background parameters had no physical significance. An unrestrained refinement including all positional parameters and isotropic temperature factors was initially performed. A second refinement which included restraints on the Ru F distances (bridging Ru-F distance $2.00 \AA$ and terminal Ru-F distance $1.82 \AA$ ) was then carried out. The results of both refinements are given in Table 3.3 and the interatomic distances and angles are given in Table 3.4 for comparison. The fitted neutron time of flight powder diffraction data are shown in Fig. 3.2. There is no significant difference in the quality of the fit for either of these models as judged by the profile $\mathbf{R}$ factors, but the $R_{F}$ 's (the normal crystallographic $R$ factors) appear to be significantly lower for the 
restrained model. The slightly better compatibility of the diffraction data, with the restrained model, is also evident from the lower esd's on the co-ordinates and bond lengths from that refinement.

Table 3.3. A Comparison of the Restrained ( $r$ ) and Unrestrained ( $u$ ) Refinements of the Structural Models for $\mathrm{RuF}_{4}$ in Space Group $\mathrm{P}_{1} / \mathrm{n}$

$R$ factors
$-90^{\circ}$ bank
(including 233
reflections)$$
a_{0}=5.6068(6) \AA, b_{o}=4.9456(5) \AA, c_{o}=5.413(2) \AA, B=121.27(2)^{\circ}
$$

\begin{tabular}{|c|c|c|c|}
\hline & $4.54 \%$ & $2.81 \%$ & $4.90 \%$ \\
\hline \multirow{2}{*}{$\begin{array}{l}+153^{\circ} \text { bank } \\
\text { (including } 630 \\
\text { reflections) }\end{array}$} & $3.12 \%$ & $2.14 \%$ & $17.20 \%$ \\
\hline & $3.13 \%$ & $2.14 \%$ & $15.25 \%$ \\
\hline \multirow{2}{*}{$\begin{array}{l}-153^{\circ} \text { bank } \\
\text { (including } 629 \\
\text { reflections) }\end{array}$} & $3.42 \%$ & $2.33 \%$ & $14.26 \%$ \\
\hline & $3.43 \%$ & $2.34 \%$ & $13.31 \%$ \\
\hline
\end{tabular}

overall $\mathrm{X}^{2}=1.388$ for the free refinement and 1.397 for the restrained refinement.

$\begin{array}{llllll} & x & y & z & 100 \times U_{\text {iso }} & \\ \operatorname{Ru}(1) & 0.0 & 0.0 & 0.0 & 1.98(9) & \text { u } \\ & & & & 2.02(9) & \mathrm{r} \\ \mathrm{F}(1) & 0.8662(24) & 0.1523(11) & 0.2231(10) & 2.0(1) & \mathrm{u} \\ & 0.8762(10) & 0.1498(9) & 0.2212(8) & 1.6(1) & \mathrm{r} \\ \mathrm{F}(2) & 0.3636(24) & 0.1674(9) & 0.2485(10) & 1.7(1) & \mathrm{u} \\ & 0.3736(6) & 0.1696(6) & 0.2509(8) & 1.8(1) & \mathrm{r}\end{array}$


Table 3.4. Interatomic Distances ( $\AA$ units) and Angles (deg.) in $R_{4} F_{4}$

$\begin{array}{llc} & & \text { Model } \\ 2 \times R u(1)-F(1) & \text { unrestrained } & \text { restrained } \\ 2 \times R u(1)-F(2) & 1.88(2) & 1.82(1) \\ 2 \times R u(1)-F(2) & 1.95(3) & 2.00(3) \\ & 2.02(1) & 2.00(1) \\ F(1)-R u(1)-F(2) & & \\ F(1)-R u(1)-F(2) & 89.4(6) & 89.7(6) \\ F(2)-R u(1)-F(2) & 88.2(4) & 89.3(2) \\ F(1)-R u(1)-F(2) & 89.2(12) & 90.3(12) \\ F(1)-R u(1)-F(2) & 90.6(6) & 90.3(6) \\ F(2)-R u(1)-F(2) & 91.8(4) & 90.7(2) \\ R u(1)-F(2)-R u(1) & 90.8(12) & 89.7(12) \\ & 134.9(8) & 133.0(6)\end{array}$

The observed Debye Scherrer data together with relative intensities calculated for the restrained model are given in Table 3.5 and the structure is illustrated in Fig. 3.3.

Table 3.5 X-Ray powder data ( $\mathrm{CuK}<\alpha>$ radiation, Ni filter) for the $\mathrm{RuF}_{4}$ monoclinic unit cell indexed based on the unit cell parameters from the neutron diffraction data with $a_{0}=5.6068(6), b_{0}=4.9456(5), c_{0}=5.413(2) \AA, B=121.27(2)^{\circ}$, $V=128.3 \AA^{3}, Z=2$, space group $P 21 / n$.

\begin{tabular}{|c|c|c|c|c|}
\hline \multirow[b]{2}{*}{$\mathbf{I}_{\mathbf{I}}$} & \multicolumn{4}{|c|}{$1 / d^{2} \times 10^{4}$} \\
\hline & Icalc & obs & calc & h $\mathbf{k} \mathbf{l}$ \\
\hline vs & 100 & 430 & 434 & $10 \overline{1}$ \\
\hline vS & 0 & 840 & 843 & $11 \overline{1}$ \\
\hline & 83 & & 844 & 110 \\
\hline vs & 81 & 877 & 876 & 011 \\
\hline $\mathbf{m}$ & 22 & 1374 & 1371 & 101 \\
\hline
\end{tabular}


Table 3.5. cont.

\begin{tabular}{|c|c|c|c|c|}
\hline $\mathbf{I}_{\Pi}$ & Icalc & obs & calc & h k l \\
\hline $\mathbf{w}$ & 7 & 1640 & 1635 & 020 \\
\hline $\mathbf{w}$ & 11 & 1675 & 1681 & $21 \overline{1}$ \\
\hline \multirow[t]{2}{*}{$\mathbf{s}$} & 11 & 1739 & 1738 & $20 \overline{2}$ \\
\hline & 14 & & 1741 & 200 \\
\hline \multirow[t]{2}{*}{$\mathrm{ms}$} & 24 & 1774 & 1776 & $11 \overline{2}$ \\
\hline & 0 & & 1779 & 111 \\
\hline vvw & 1 & 1869 & 1868 & 002 \\
\hline \multirow[t]{2}{*}{$\mathbf{m}$} & 19 & 2053 & 2070 & $12 \overline{1}$ \\
\hline & 0 & & 2071 & 120 \\
\hline $\mathrm{m}$ & 9 & 2095 & 2102 & 021 \\
\hline \multirow[t]{2}{*}{$\mathrm{m}$} & 8 & 2146 & 2146 & $21 \overline{2}$ \\
\hline & 8 & & 2150 & 210 \\
\hline-- & 0 & -.. & 2277 & 012 \\
\hline--- & 0 & --. & 2907 & $22 \overline{1}$ \\
\hline \multirow[t]{4}{*}{$\mathrm{ms}$} & 0 & 2999 & 2978 & $30 \overline{2}$ \\
\hline & 6 & & 2981 & $30 \overline{1}$ \\
\hline & 0 & & 3003 & $12 \overline{2}$ \\
\hline & 13 & & 3006 & 121 \\
\hline vww & 4 & 3240 & 3235 & $10 \overline{3}$ \\
\hline \multirow[t]{4}{*}{$s(b r)$} & 11 & 3391 & 3372 & $22 \overline{2}$ \\
\hline & 10 & & 3377 & 220 \\
\hline & 9 & & 3387 & $31 \overline{2}$ \\
\hline & 0 & & 3390 & 311 \\
\hline $\mathbf{m}$ & 15 & 3503 & 3504 & 022 \\
\hline \multirow[t]{2}{*}{$s(b r)$} & 17 & 3656 & 3546 & $21 \overline{3}$ \\
\hline & 17 & & 3554 & 211 \\
\hline \multirow[t]{2}{*}{$w$} & 0 & 3656 & 3644 & $11 \overline{3}$ \\
\hline & 9 & & 3649 & 112 \\
\hline
\end{tabular}

$\mathbf{R u F}_{3}$ Structure: High purity, oxide free $\mathrm{RuF}_{3}$ was prepared at Princeton University in 1969 by Mr.Robert Serfass from the reductive thermal decomposition of $\mathrm{SF}_{3}{ }^{+} \mathrm{RuF}_{6}{ }^{-}$.

Details are given in Ref. 14. X-Ray powder diffraction photographs of this material using 
$\mathrm{LiF}$ monochromatized $\mathrm{CuK}<\alpha>$ radiation were sharp and of low background. The patterns were indexed completely on the basis of a rhombohedral cell (see Table 3.6) and refinement yielded unit cell parameters with $a_{0}=5.4098(4) \AA, \alpha=54.67(1)^{\circ}$. Jack and his coworkers $\delta$ had observed a range of lattice parameters in various preparations of $\mathrm{RuF}_{3}$. Ultimately they settled on the largest cell parameters, $a_{0}=5.408 \pm 0.001 \AA, \alpha=$ $54.67 \pm 0.01^{\circ}$ as indicative of pure $\mathrm{RuF}_{3}$. These are not significantly smaller than those obtained from the pyrolysis of $\mathrm{SF}_{3}+\mathrm{RuF}_{6}-$. The relative line intensities obtained here from the X - Ray photographs of the material prepared by Serfass, were not significantly different from those given by Jack and his coworkers. Applying the positional parameter found by Jack and his coworkers $(x=-0.100$, for which $3 \sigma$ is \pm 0.005$)$ to their cell, the $\mathrm{Ru}-\mathrm{F}$ interatomic distance is $1.981(6) \AA$. With the cell parameters found in this work $\mathrm{Ru}-\mathrm{F}$ $=1.982(6) \AA$. The Ru-F-Ru bridging angle found here is $136(1)^{\circ}$.

Table 3.6. $\quad \mathrm{X}$-Ray powder data (CuK $<\alpha>$ radiation, $\mathrm{LiF}$ monochromator) for $\mathrm{RuF}_{3}$ with a rhombohedral unit cell with $a=5.4098(4) \AA, \alpha=54.68(1)^{\circ}$, $V=98.08 \AA^{3}, Z=2$, space group $R \overline{3} c$.

$\begin{array}{lrrr}\mathrm{I}_{0} & \text { obs } & \text { calc } & \mathrm{hk} \mathrm{k} \\ 10 & 757 & 751 & 110 \\ 6.5 & 1400 & 1385 & 21 \\ 4 & 1635 & 1620 & 10 \overline{1} \\ 1 & 1920 & 1902 & 22 \\ 4 & 2114 & 2095 & 201^{*} \dagger \\ 5 & 2389 & 2371 & 200 \\ 5 & 3030 & 3005 & 220 \\ 10 & 3545 & 3522 & 321 \\ -- & --- & 3833 & 20 \overline{1}^{*} \\ 4 & 3945 & 3921 & 332 \\ 6 & 4015 & 3991 & 21 \frac{1}{1} \\ 6 & 4650 & 4625 & 310\end{array}$


Table 3.6. cont.

\begin{tabular}{|c|c|c|c|}
\hline $\mathrm{I}_{0}$ & obs & calc & h $\mathbf{k} \mathbf{l}$ \\
\hline 6 & 4877 & 4860 & $2 \overline{1} \overline{1}$ \\
\hline$-\cdots$ & --- & 5100 & $320^{*}$ \\
\hline 4 & 5554 & 5541 & 422 \\
\hline 4 & 5842 & 5822 & 433 \\
\hline 1 & 5937 & 5898 & $432^{*} \dagger$ \\
\hline--- & --- & 6368 & $421^{*}$ \\
\hline 3 & 6492 & 6480 & $20 \overline{2}$ \\
\hline 3 & 6778 & 6761 & 330,411 \\
\hline 1 & 6974 & 6955 & $31 \overline{1} * \dagger$ \\
\hline$\cdots$ & --- & 7073 & $2 \overline{2} 1 *$ \\
\hline 6 & 7183 & 7160 & 431 \\
\hline 6 & 7240 & 7231 & $30 \overline{1}$ \\
\hline 4 & 7447 & 7442 & 442 \\
\hline 3 & 7610 & 7606 & 444 \\
\hline 5 & 7864 & 7865 & $32 \overline{1}$ \\
\hline--- & ---- & 8340 & $410^{*}$ \\
\hline 6 & 8384 & 8381 & 420 \\
\hline 3 & 8829 & 8851 & $22 \overline{2}$ \\
\hline 4 & 9057 & 9062 & 532 \\
\hline 4 & 9226 & 9226 & 543 \\
\hline 3 & 9491 & 9485 & 400 \\
\hline --- & -- & 9608 & $430^{*}$ \\
\hline --- & -- & 10171 & $542^{*}$ \\
\hline--- & --- & 10313 & $30 \overline{2}^{*}$ \\
\hline 5 & 10400 & 10400 & 521 \\
\hline 4 & 10479 & 10471 & $31 \overline{2}$ \\
\hline--- & --- & 10758 & $531^{* \dagger}$ \\
\hline 3 & 10900 & 10893 & 554 \\
\hline 4 & 11106 & 11105 & $41 \overline{1}$ \\
\hline 4 & 11346 & 11340 & $3 \overline{2} \overline{1}$ \\
\hline --- & --- & 11580 & $42 \overline{1}$ \\
\hline 1 & 11817 & 11815 & $32 \overline{2}, 40 \overline{1} *+$ \\
\hline 3 & 12030 & 12020 & 440 \\
\hline 5 & 12292 & 12302 & 541 \\
\hline 7 & 12475 & 12466 & 633,552 \\
\hline$\cdots$ & --- & 12513 & 644 \\
\hline--- & $\cdots$ & 12707 & $643^{*}$ \\
\hline
\end{tabular}


Table 3.6. cont.

\begin{tabular}{|c|c|c|c|}
\hline $\mathrm{I}_{\mathbf{l}}$ & obs & calc & h $\mathbf{k} \mathbf{l}$ \\
\hline$\cdots$ & --. & 12848 & $520^{*}$ \\
\hline 10 & 13243 & 13241 & $43 \overline{1}, 510$ \\
\hline-- & $\cdots$ & 13411 & $632 *$ \\
\hline-- & -- & 13505 & $654^{*}+$ \\
\hline 7 & 13647 & 13640 & 530 \\
\hline-- & --- & 13711 & $\overline{4} 11$ \\
\hline 5 & 13933 & 13922 & 622 \\
\hline 6 & 14125 & 14133 & 653 \\
\hline 4 & 14348 & 14345 & $33 \overline{2}$ \\
\hline 5 & 14579 & 14580 & $30 \overline{3}$ \\
\hline-- & $\cdots$ & 15055 & $4 \overline{2} 1 * \dagger$ \\
\hline 6 & 15328 & 15331 & $40 \overline{2}$ \\
\hline 6 & 15543 & 15542 & 631 \\
\hline-- & --- & 15618 & $540 * \dagger$ \\
\hline 5 & 15697 & 15679 & 664 \\
\hline-- & --- & 15947 & $652 *$ \\
\hline 6 & 15964 & 15965 & $4 \overline{2} 2$ \\
\hline-- & --- & 16440 & $5 \overline{1} 1 *$ \\
\hline 5 & 16477 & 16481 & $52 \overline{1}$ \\
\hline
\end{tabular}

* These are fluorine-only reflections $(\mathrm{h}+\mathrm{k}+\mathrm{l}$, odd)

$\dagger$ Fluorine only reflections for which $h+k+1=3(2 n+1)$ 


\section{Results and Discussion:}

The synthesis of high purity $\mathrm{RuF}_{4}$ has been achieved by fluoride ion capture from a liexafluorometallate (IV) salt using a strong acid:

$$
\mathrm{K}_{2} \mathrm{RuF}_{6}+2 \mathrm{AsF}_{5} \stackrel{\mathrm{AHF}}{\longrightarrow} \mathrm{RuF}_{4} \downarrow+2 \mathrm{KAsF}_{6}
$$

The reaction, while certainly facilitated by the low solubility of $\mathrm{RuF}_{4}$, must primarily be driven by the greater acidity of $\mathrm{AsF}_{5}$ than $\mathrm{RuF}_{4}$ in AHF. This is implied by rapid completion of the reaction(seconds with agitation)when using $\mathrm{AsF}_{5}$ compared with the inability of the weaker acid, $\mathrm{PF}_{5}$, to carry out the displacement of $\mathrm{RuF}_{4}$. The production of $\mathrm{KPF}_{6}$ from the interaction of $\mathrm{PF}_{5}$ with $\mathrm{K}_{2} \mathrm{RuF}_{6}$, however, indicates that $\mathrm{PF}_{5}$ is sufficiently strong to abstract $\mathrm{F}^{-}$from $\mathrm{RuF}_{6}{ }^{-2}$. Use of $\mathrm{PF}_{5}$ in conjunction with $\mathrm{AsF}_{5}$ :

$$
\begin{aligned}
& 2 \mathrm{~K}_{(\text {solv })}{ }^{+}+\mathrm{RuF}_{6}{ }^{-2}+\mathrm{PF}_{5} \stackrel{\mathrm{AHF}}{\longrightarrow} \mathrm{RuF}_{5}^{-"} \text { sol'n }+\mathrm{KPF}_{6}+\mathrm{K}^{+} \text {(solv) } \\
& + \\
& \mathrm{RuF}_{4}+\mathrm{PF}_{5}+2 \mathrm{KAsF}_{6} \stackrel{\mathrm{AHF}}{\longleftarrow} 2 \mathrm{AsF}_{5}
\end{aligned}
$$

resulted in a slower reaction and more crystalline samples of $\mathrm{RuF}_{4}$. It may be that the less soluble $\mathrm{PF}_{5}$ displaced from $\mathrm{KPF}_{6}$ in step 2 simply acts as a barrier gas, slowing $\mathrm{AsF}_{5}$ uptake.

$\mathrm{X}$ - ray synchrotron data from samples obtained by this two step process allowed for unambiguous determination of the unit cell. However, the final structure Hetermination was based on a knowledge of the $\mathrm{RuF}_{5}$ and $\mathrm{RuF}_{3}$ structures. It is therefore useful to examine the results of these structures first. 
The determination of bond lengths and angles in $\mathrm{RuF}_{5}$ to high precision, combined with the confirmation of the $\mathrm{RuF}_{3}$ structure enabled a meaningful comparison of the two. Both the tetrameric $\mathrm{RuF}_{5}$ and the $3-\mathrm{D}$ polymeric $\mathrm{RuF}_{3}$. arrange their fluorine ligands in a nearly hexagonal closed packed array, as do their rhodium counterparts. The similarities of the structures are clearly seen in Fig. 3.4. For an atom occupying an octahedral hole in an hep network, the ideal bridging angle is $132^{\circ}$. The $\mathrm{RhF}_{5} \mathrm{M}-\mathrm{F}-\mathrm{M}$ bridging angles = $134.4(1)^{\circ}$ and $135.7(1)^{\circ}$ and those of $\mathrm{RhF}_{3}=132^{\circ}$. These are significantly closer to the ideal bridging angle of $132^{\circ}$ for hcp than the analogous ruthenium compounds in which $M-F-M \angle=136.80(6)^{\circ}$, and $140.83(6)^{\circ}$ for the pentafluoride and $136(1)^{\circ}$ for the trifluoride.

The angle of the $\mathrm{M}$ - F - M bridges can be correlated with the increased population of $\mathrm{t}_{2 \mathrm{~g}}{ }^{*}$ antibonding $\pi$ orbitals. Increase in $\mathrm{t}_{2 \mathrm{~g}}{ }^{*}$ population can account for the decrease in bridging angle from $\mathrm{Ru}$ to $\mathrm{Rh}$. In $\mathrm{d}^{3} \mathrm{RuF}_{5}$ a single electron is in each of the $\mathrm{t}_{2 \mathrm{~g}}{ }^{*}$ orbitals (these orbitals are actually split by the slight distortion from octahedral symmetry caused by having two types of $\mathrm{F}$ ligands), hence a single electron fills the orbital in the

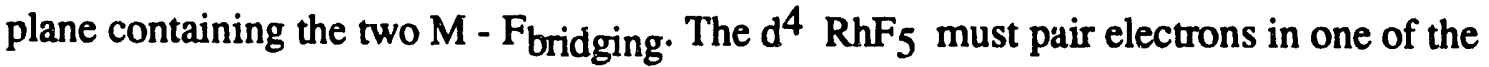
" $\mathrm{t}^{\mathrm{g}}$ " orbitals and they must do so in the orbital in the plane containing the bridging $\mathrm{F}$ ligands, this orbital being lowest in energy. Complete filling of this orbital effectively shuts down any $\pi$ bonding interaction allowing the minimum angle for hcp to be approached. A similar situation exists for the trifluorides. The low spin $\mathrm{d}^{6}$ configuration pertaining in $\mathrm{RhF}_{3}$ fills each of the $\pi$ antibonding orbitals, effectively quenching any $\pi$ interaction and accounting for the almost ideal hexagonal close packing observed in that fluoride. One fewer electron is placed in the orbitals involved in the six bridges of $\mathrm{RuF}_{3}$, allowing for a slightly increased bridging angle. 
The greatly improved precision of the interatomic distances in $\mathrm{RuF}_{5}$ also allows

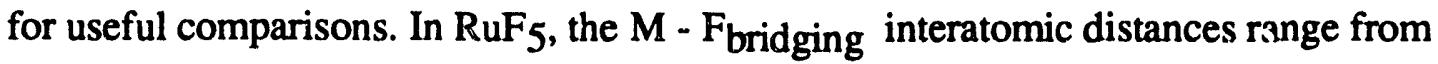
$1.995(1) \AA$ to $2.007(1) \AA$. This is longer, although perhaps not significantly so, than the $R u$ - Fbridging interatomic distance of $1.982(6) \AA$ observed in $\mathrm{RuF}_{3}$. Considering the increase in the antibonding $\pi$ electron population from $\mathrm{Ru}(\mathrm{V})$ to $\mathrm{Ru}(\mathrm{III})$, this is quite remarkable. Yet this is not an isolated case. Morrell et. al. ${ }^{6}$ found $\mathrm{Rh}-\mathrm{F}_{\text {bridging interatomic distances }}$ to range from $1.993(4) \AA$ to $2.005(3) \AA$ in their structure of $\mathrm{RhF}_{5}$. This is significantly longer than the 1.961(2) $\AA \mathrm{Rh}$ - Fbridging distance observed by Grosse and Hoppe in their single crystal structure of $\mathrm{RhF}_{3}$. There appears to be no tendency for interatomic distances of $\mathrm{M}$ - $\mathrm{F}_{\mathrm{bridging}}$ bonds to increase as the $\mathrm{t}_{2 \mathrm{~g}}{ }^{*}$ antibonding orbital population is increased on lowering the oxidation state. Apparently $\mathrm{F}$ ligand repulsions play an important role in determining interatomic distances in these systems and outweigh the effects of $\pi^{*}$ orbital occupancy. The repulsive impact of short-bonded unique fluorine ligands are expected to be greater than that of the long-bonded bridging $F$ ligands. The bridging $\mathrm{M}-\mathrm{F}$ bonds in the higher oxidation state $\mathrm{RuF}_{5}$ and $\mathrm{RhF}_{5}$ find all their bonds somewhat stretched by the steric interaction of 4 unique $F$ atoms. The lower oxidation state trifluorides, which contain no short bonded sterically active unique $F$ ligands, are able to form the shortest bridging bonds.

While their impact of the $\mathrm{t}_{2 \mathrm{~g}}{ }^{*}$ electron population on $\mathrm{M}-\mathrm{F}$ bond lengths is not clear in the above comparison, it appears that the orbital population is not without effect. A comparison of the highly precise $R u(V)$ and $R h(V)$ fluoride structures serves to

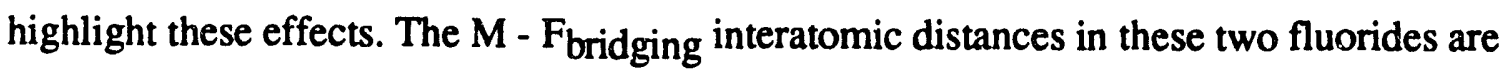
not significantly different from each other, all being aimost exactly $2.000 \AA$. However, small but signicant differences are observed in the $\mathrm{M}$ - $\mathrm{F}_{\text {unique }}$ interatomic distances of the two pentafluorides. In RuF 5 (Fig. 3.1) the $\mathrm{M}-\mathrm{F}_{\text {unique interatomic distances for }}$ 
those $F$ ligands trans to the bridging $F$ ligands are $1.798(1) \AA$ and $1.793(1) \AA$. These distances are significantly shorter than those observed for the $\mathrm{F}$ ligands disposed cis to the bridging F ligands, these being $1.821(1) \AA$ and $1.817(1) \AA$ respectively. The $\mathrm{RhF}_{5}$ cis and trans counterparts might be expected, in the absence of antibonding $\pi$ effects, to exhibit slightly shorter $M$ - $F_{\text {unique }}$ interatomic distances, because the effective nuclear charge increases as the atomic number increases in the presence of the poorly shielding antibonding $\pi$ electron. This is in fact the case for the cis unique $F$ ligands in which the $M$ - F unique interatomic distance are $1.802(4) \AA$ and $1.803(4) \AA$ respectively, these being significantly shorter than the analogous $\mathrm{Ru}-\mathrm{F}$ bonds. However, the unique $\mathrm{F}$ ligands trans to the bridging $F$ ligands in $R F_{5}$ give rise to $M-F_{\text {unique }}$ distances of $1.817(4) \AA$ and $1.820(4) \AA$. These are decidedly longer than the comparable bonds in $\mathrm{RuF}_{5}$. This is again, likely a consequence of going from the $d^{3} R u(V)$ configuration to the $d^{4} R h(V)$ configuration. As observed above, the $\mathrm{Rh}(\mathrm{V})$ system must place 2 electrons, as opposed to 1 in the $\mathrm{Ru}(\mathrm{V})$ case, in the antibonding $\pi$ orbital in the plane containing the bridging $\mathrm{F}$ ligands and the unique $\mathrm{F}$ ligands trans to them. This increased antibonding character in the bridging plane has the effect of lengthening these $\mathrm{M}-\mathrm{F}_{\text {unique }}$ bonds a small, but significant amount, with respect to their $\mathrm{Ru}$ counterparts and may explain why no decrease is seen in $\mathrm{M}$ - F bridging interatomic distances of $\mathrm{RhF}_{5}$ with respect to $\mathrm{RuF}_{5}$.

A much more perplexing difficulty, is the definite shortening of the $M-F_{\text {unique }}$ bonds in $\mathrm{RuF}_{5}$ of the unique $\mathrm{F}$ ligands trans to the bridging $\mathrm{F}$ ligands with respect to those which are cis. This may simply be a consequence of the unique $\mathrm{F}$ ligands in trans positions being in the same plane as the slightly lower energy antibonding orbital created by the longer bridge bonds. Hence, the antibonding effect is smaller than for the cis unique $F$ ligands which feel the impact of the two singly occupied higher energy antibonding $\pi$ orbitals. It is perhaps more likely that a trans electrostatic effect is shortening the trans 
unique $\mathrm{F}$ ligands. That is, the longer bonded, more electron rich bridging $\mathrm{F}$ ligands may be viewed as on the ionization pathway to $\mathrm{F}^{-}$. This pulling away of electron density from one side of the metal $d_{x y}$ orbital results in contraction of the electron density on the opposite side, with the resultant shortening of $\mathbf{M}$ - $F_{u n i q u e}$ interatomic distances.

$\mathrm{X}$-Ray powder data had indicated that $\mathrm{RuF}_{4}$ was not isostructural with the two known tetrafluoride structure types, $\mathrm{PdF}_{4}$ and $\mathrm{SnF}_{4} \cdot{ }^{20-23}$ This data had, however, suggested $\mathrm{M}$ - $\mathrm{M}$ distances similar to those of the $\mathrm{PdF}_{4}$ related structures, indicating the $\mathrm{M}$ - F - M bridges in $\mathrm{RuF}_{4}$ were probably similarly bent to an angle of $\approx 135^{\circ}$. The structure solution from X-Ray synchrotron and neutron powder data has confirmed these conclusions.

The unit cell parameters obtained from the synchrotron data are highly precise. Combined with the neutron data they provide for an unambiguous assignment of the space group $P 21 / n$, which places the two Ru atoms in each cell at $0,0,0$ and $1 / 2,1 / 2,1 / 2$. Hence a nearest $R u$ - $R u$ distance of $3.664(2) \AA$ is obtained for the material. This distance is remarkably close to those observed in $\mathrm{RuF}_{3}$, where $R u-R u=3.672(4) \AA$ and $R F_{5}$, where $\mathrm{Ru}-\mathrm{Ru}=3.7207(2)$ and 3.7705(2) $\AA$. Hence the bridge bonding and bridging angle of the three oxidation state Ru fluorides must be very similar.

A Fourier distance map was unable to precisely place the $\mathrm{F}$ atoms in this structure, but does indicate a roughly octahedral arrangement of $6 \mathrm{~F}$ atoms about each Ru. More importantly it clearly shows that the $4 \mathrm{~F}$ ligands involved in bridging adjacent $\mathrm{Ru}$ atoms are in the same plane, the 2 unique $F$ ligands being trans. This arrangement results in a sheet structure with unique $F$ ligands from one layer nestling into holes made by unique $\mathrm{F}$ ligands of adjacent layers and is not too different from $\mathrm{SnF}_{4}$, or $\mathrm{NbF}_{4}$. This difference amounts to a puckering of the sheets in $\mathrm{RuF}_{4}$ 노 the flat sheets of $\mathrm{NbF}_{4}$ and simply results from the nonlinearity of the M - F- M bridge. 
A constrained refinement was chosen after the unrestrained refinement resulted in a structure with assymmetric $M-F-M$ bridging. This type of bridging has not been observed in any binary fluoride system, including the isomorphous relative of $\mathrm{RuF}_{4}, \mathrm{VF}_{4}$, whose structure was reported during the course of this work. ${ }^{24}$ The constrained refinement, which eventually gave a slightly better fit to the data than the unrestrained

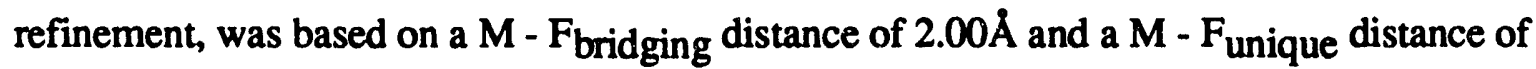
$1.82 \AA$. These distances were dictated by the corresponding $\mathrm{RuF}_{3}$ and $\mathrm{RuF}_{5}$ bond lengths and the the closeness of the $\mathrm{Ru}-\mathrm{Ru}$ distances in each of the fluorides.

The $\mathrm{Ru}-\mathrm{F}$ - Ru bridge angle arrived at in the chosen geometry is $133^{\circ}$. This is nearly the ideal for an hcp system and as such is smaller than bridge angles in $\mathrm{RuF}_{3}$ and $\mathrm{RuF}_{5}$. By shortening the $\mathrm{Ru}-\mathrm{F}$ bridging interatomic distances in $\mathrm{RuF}_{4}$, the bridge angle can be made larger, $1.99 \AA$ resulting in a $134^{\circ}$ angle, while the $1.98 \AA$ distance observed in $\mathrm{RuF}_{3}$ gives to a $135^{\circ}$ angle. However, this is perhaps unnecessary. The $\mathrm{d}^{4}$ configuration of $\mathrm{RuF}_{4}$ must place 2 electrons in the lowest energy orbital of the ideally $t_{2 \mathrm{~g}}{ }^{*}$ set. This orbital must be the one in the plane containing the 4 bridging $F$ ligands. Hence any $\pi$ bonding interaction which would favor more linear bridges is effectively quenched in this plane, resulting in the close approach to hcp.

The geometry of $\mathrm{RuF}_{4}$, Fig. 3.3, obtained from this refinement is particularly satisfying when compared with that of $\mathrm{RuF}_{5}$. Indeed, the $\mathrm{The} \mathrm{RuF}_{4}$ structure can be built up from the $\mathrm{RuF}_{5}$ tetramers. By taking the unique $\mathrm{F}$ ligands trans to the bridging $\mathrm{F}$ ligands of the pentafluorides and involving them in bridging in such a way that each new M - F $\mathrm{M}$ bridge is kinked in a manner opposite to that of its trans partner, an ideal $\mathrm{RuF}_{4}$ structure can be formed which is identical to that of $\mathrm{RuF}_{4}$.

Since precise bond lengths were not obtained for $\mathrm{RuF}_{4}$, an effort was made to obtain gas phase electron diffraction data for thermally unstable $\mathrm{RuF}_{6}$ in the hope that 
these data would allow for meaningful comparisons of $M$ - $F_{\text {unique interatomic differences }}$ with those of RuF5. While the structure has not been obtained to date, the possibie range for the $\mathrm{Ru}-\mathrm{F}$ interatomic distance can de derived from the available $\mathrm{MF}_{6}$ structural data. Unit cell parameters are available for all of the second and third series transition metal hexafluorides in both their orthorhombic and cubic forms. ${ }^{25}$ As was found in the hexafluorometallate salts (chapter 2), a significant contraction is observed in formula unit volumes from early to late transition metals, as the effective nuclear charge increases. In the second transition series, only the structure of $\mathrm{MoF}_{6}$ has been determined to high precision, having been found to contain an Mo - F distance of $1.820(3) \AA .26$ Using this distance as a starting point and assuming that all of the formula unit volume contraction observed in the unit cell data is due to shortening of the $\mathrm{M} \mathrm{-} \mathrm{F} \mathrm{bonds,} \mathrm{leads} \mathrm{to} \mathrm{an} \mathrm{estimated}$ $\mathrm{Ru}$ - F distance of $1.77 \AA$. In chapter 2 , however, it was suggested that part of the observed volume contraction was probably due to a greater polarization of the nonbonding electrons on the $\mathrm{F}$ ligands towards the metal centers of the more electronegative late transition metals. This notion is supported by electron diffraction data on the third transition series hexafluorides. 27 Here a remarkable near constancy of bond length; W - F $=1.833(4) \AA$, Os $-F=1.831(4) \AA$, and $I r-F=1.830(4) \AA$, is seen in spite of the significant contraction in formula unit volumes across the series. Presumably, while the increasing effective nuclear charge is acting to contract the system, the increasing population of the $\mathrm{t}_{2 \mathrm{~g}}{ }^{*} \pi$ antibonding orbitals is favoring, weaker, longer bonds, thus maintaining a nearly constant bond length. A dramatic decrease in hexafluoride vibrational force constants across the series, further supports this effect of filling the antibonding $\pi$ orbitals. Therefore, the Ru - F interatomic distance will almost certainly be larger than the $1.77 \AA$ value based on bond- shortening accounting for the formula unit volume decrease; and it may not be significantly smaller than the Mo - F distance of $1.820(3) \AA$. If this is the case, 
then the $\mathrm{Ru}$ - F distance in the hexafluoride would not be significantly different from that observed in the pentafluoride for the unique $F$ ligands which are cis to the bridging $F$ ligands.

\section{Conclusions:}

The available data on bridging and unique $M-F$ interatomic distances in the group $V$ to VIII binary fluorides of the second transition series are summarized in Fig. 3.5. Clearly $M$ - F distances, for both bridging and unique $F$ ligands, do not vary significantly from $2.00 \AA$ and $1.80 \AA$, respectively. This suggests, as do the third transition series hexafluoride data, that while the effect of the $t_{2} g^{*}$ antibonding orbital population on $\mathrm{M}$ - F interatomic distances must be small, it is sufficient to nearly counter the expected decrease in interatomic distances with increased nuclear charge across the transition series.

Moreover, the trend in $\mathrm{M}$ - F bridging interatomic distances of decreasing with decreasing oxidation state observed for the $\mathrm{Rh}$ fluorides and nearly so for the $\mathrm{Ru}$ fluorides appears to hold across the entire series. Although data for $\mathrm{NbF}_{5}$ and $\mathrm{MoF}_{5}$ are much too imprecise to make the above conclusion a firm one, change in oxidation state certainly does not have a large effect on the bond distances in these systems. Altering the $t_{2} g^{*}$ orbital population by changing oxidation state must not dramatically change the effective nuclear charge observed by the bridging $F$ ligands, these antibonding $\pi$ electrons being poorly shielding of the effective nuclear charge. Any changes observed, are apparently compensated and as suggested by the $\mathrm{Rh}$ - fluorides over-compensated for by steric interaction of short - bonded unique F ligands. Increasing the oxidation state, increases the number of short - bonded unique $F$, which must result in a stretching of the bridging bonds. 
Firm conclusions about changes in $\mathrm{M}$ - $\mathrm{F}_{\text {unique }}$ interatomic distances await either more precise data on $\mathrm{MoF}_{5}$, or a precise structure determination of $\mathrm{RuF}_{6}$. Interestingly, the imprecise $\mathrm{M}$ - $\mathrm{F}_{\text {unique }}$ distances observed for $\mathrm{NbF}_{5}$ and $\mathrm{MoF}_{5}$, suggest that they, like the same distances in $\mathrm{RuF}_{5}$ and $\mathrm{RhF}_{5}$, are in two distinct sets; those cis to the bridging $\mathrm{F}$ ligands(referred to here as axial) and those trans to the bridging $F$ ligands(referred to here as equatorial). If this is truly the case $\mathrm{MoF}_{5}$, being the $\mathrm{d}^{1}$ counterpart to $\mathrm{d}^{4} \mathrm{Rh}$ would be expected to display longer equatorial than axial unique F M - F distances. Similarly if a trans influence is the cause of the equatorial unique $\mathrm{F}$ bonds being shorter than the axial in $\mathrm{RuF}_{5}$, a like result is expected for its $\mathrm{d}^{0}$ analog, $\mathrm{NbF}_{5}$. These results are suggested by the data in Fig. 3.5, but much higher quality data is needed to confirm these tentative conclusions. 


\section{References}

1. Edwards, A.J.; Advances in Inorganic and Radiochemistry 1983, $27,83$.

2. Babel, D.; Tressaud, A., in "Inorganic Solid Fluorides," Hagenmüller, P., ed., Academic Press, Inc., New York, 1985, pp 78-204.

3. Einstein, F.W.B.; Rao, P.R.; Trotter, J.; Bartlett, N. J.Chem. Soc. A 1967, 478.

4. Morrell, B.K.; Zalkin, A.; Tressaud, A.; Bardlett, N., Inorg. Chem. 1973, 12, 2640.

5. Grosse, L; Hoppe, R., Z. Anorg. Allg. Chem, 1987, 552, 123.

6. Edwards, A.J., J. Chem. Soc., 1964, 3714.

7. Pouchard, M., Torki, M.R., Demazeau, G., Hagenmüller, P., C.R. Hebd. Sceances Acad. Sci. Ser. 1971, C273, 1093.

8. Hepworth, M.A.; Jack, K.H.; Peacock, R.D.; Westland, G.J., Acta Crystallogr. 1957, 10,63 .

9. Holloway, J.H.; Peacock, R.D.; and Small, R.W.H., LChem. Soc, 1964, 644.

10. Claasen, H.H.; Selig,H.; Malm, J.G.; Chernick, C.L.; Weinstock, B. JACS 1961, 83, 2390. Weinstock, B.; Claassen, H.H.; Chernick, C.L. J. Chem. Phys. 1963, 38, 1470.

11. Mitchell, S.J.; and Holloway, J.H., J. Chem. Soc. 1971, 2789.

12. Holloway, J.H; Peacock, R.D., J. Chem. Soc. 1963, 527.

13. A. Tressaud, unpublished results.

14. Casteel, W.J.; Wilkinson, A.P.; Bormann, H.; Serfass, R.E.; Bartlett, N. Inorg. Chem. $1992,31,3124$.

15. Myer, D.K., ed., Condensed Matter Research of LANSCE', Los Alamos Laboratory Report LALP 90-7, January 1990, pp 10-11. 
16. Werner, P.-E.; Eriksson, L.; Westdahl, M.J.; J. Appl. Crystallogr. 1985, 18, 367.

17. De Wolff, P.M., J. Appl. Crystallogr. 1968, 1, 108.

18. Larson, A.C.; Von Dreele, R.B., Los Alamos Laboratory Report, 1990, No LAUR86748.

19. Rietveld, H.M., J. Appl. Crystallogr. 1968, 2, 65.

20. Wright, A.F.; Fender, B.E.F.; Bartlett, N.; Leary, K., Inorg. Chem 1 1978, 17, 748.

21.Gortsema, F.P.; Didchenko, R. Inorg. Chem. 1965, 4, 182.

22. Schäfer, H.; Schnering, H.G.; Niehuess, K.J.; Nieder-Varenholz, H.G., J. Less Common Metals 1965, 9, 95.

23.Hoppe, R.; Dahne, W., Naturwiss., 1962, 49, 254.

24. Becker, S., and Müller, B.G., Angew. Chem. Int. Ed. 1990, 29, 406.

25. Siegel, S.; Northrop, D.A. Inorg. Chem. 1960, 5, 2187.

26. Seip, H.M., Seip, R., Acta Chem. Scand. 1966, $20,2699$.

27. Kimura, M.; Schomaker, V.; Smith, D.W.; Weinstock, B., J. Chem. Phys. 1968, 48 4001 .

28. LaValle, D.E., Steele, R.M., Wilkinson, M.K., Yakel, H.R. Jr., J. Am. Chem. Soc., 1960, 82, 2433.

29. Edwards, A.J., Peacock, R.D., Small, R.W.H., J. Chem. Soc., 1962, 4486.

30. Levy, J.H.; Sanger, P.L.; Taylor, J.C.; Wilson, P.W. Acta Crystallogr. 1974, B31, 1065. 


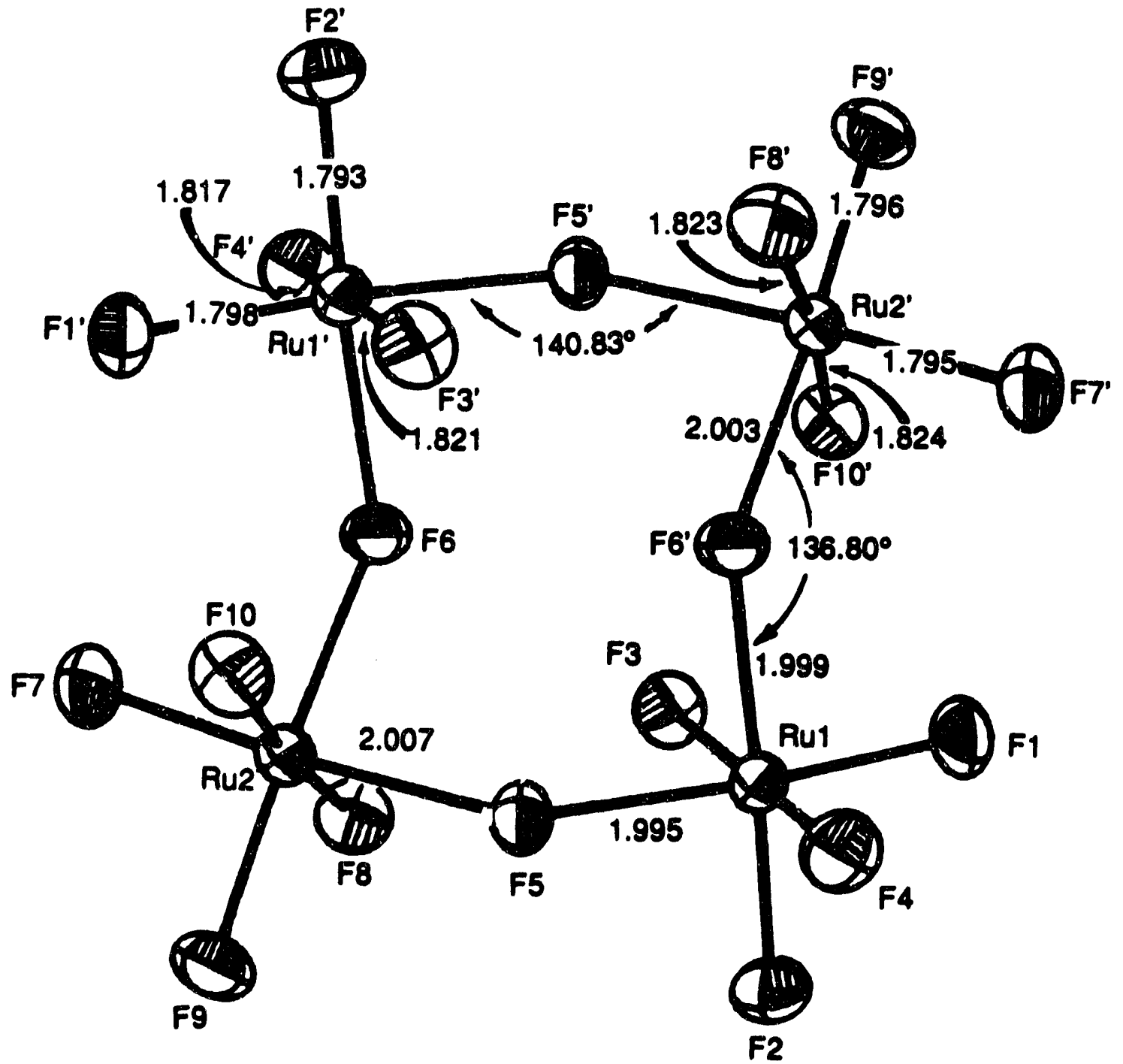

Figure 3.1. Tetrameric structural unit of $\left(\mathrm{RuF}_{5}\right)_{4}(70 \%$ probability ellipsoids ) with interatomic distances $(\AA)$ and bridge - bonding angles (deg). 


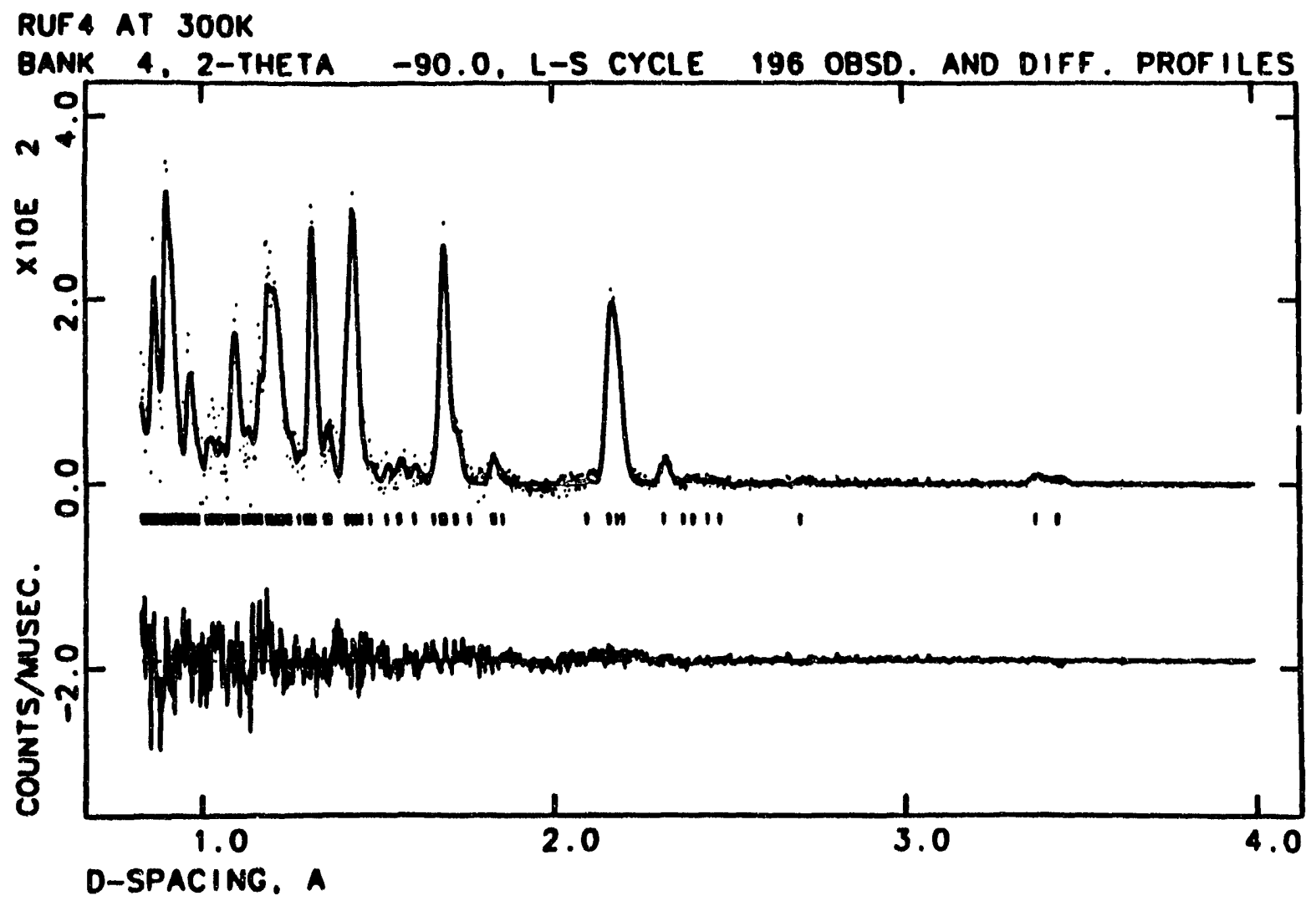

Figure 3.2. Observed neutron time - of - flight powder diffraction data minus the calculated background shown as dots. The calculated values from the constrained model with bridging $\mathrm{M}-\mathrm{F}=2.00 \AA$ and nonbridging $\mathrm{M}-\mathrm{F}=1.82 \AA$ are shown as a curve. $\mathrm{A}$ difference $\left(I_{o b s}-I_{c a l c}\right)$ curve and the reflection positions are also shown. 


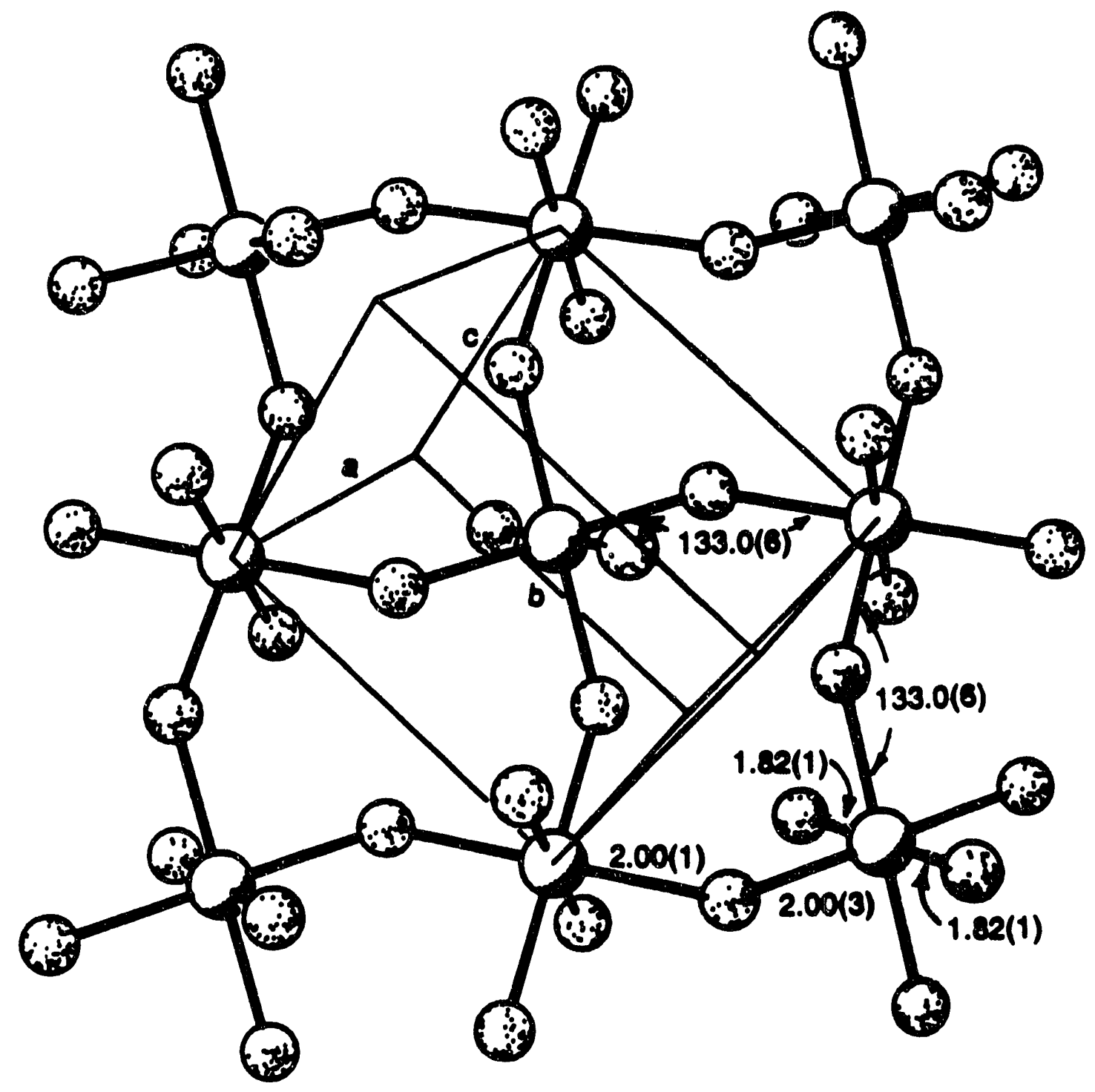

Figure 3.3. View of the puckered - sheet structure of $\mathrm{RuF}_{4}$ with interatomic distances $(\AA)$ and bridge - bonding angles (deg.) 


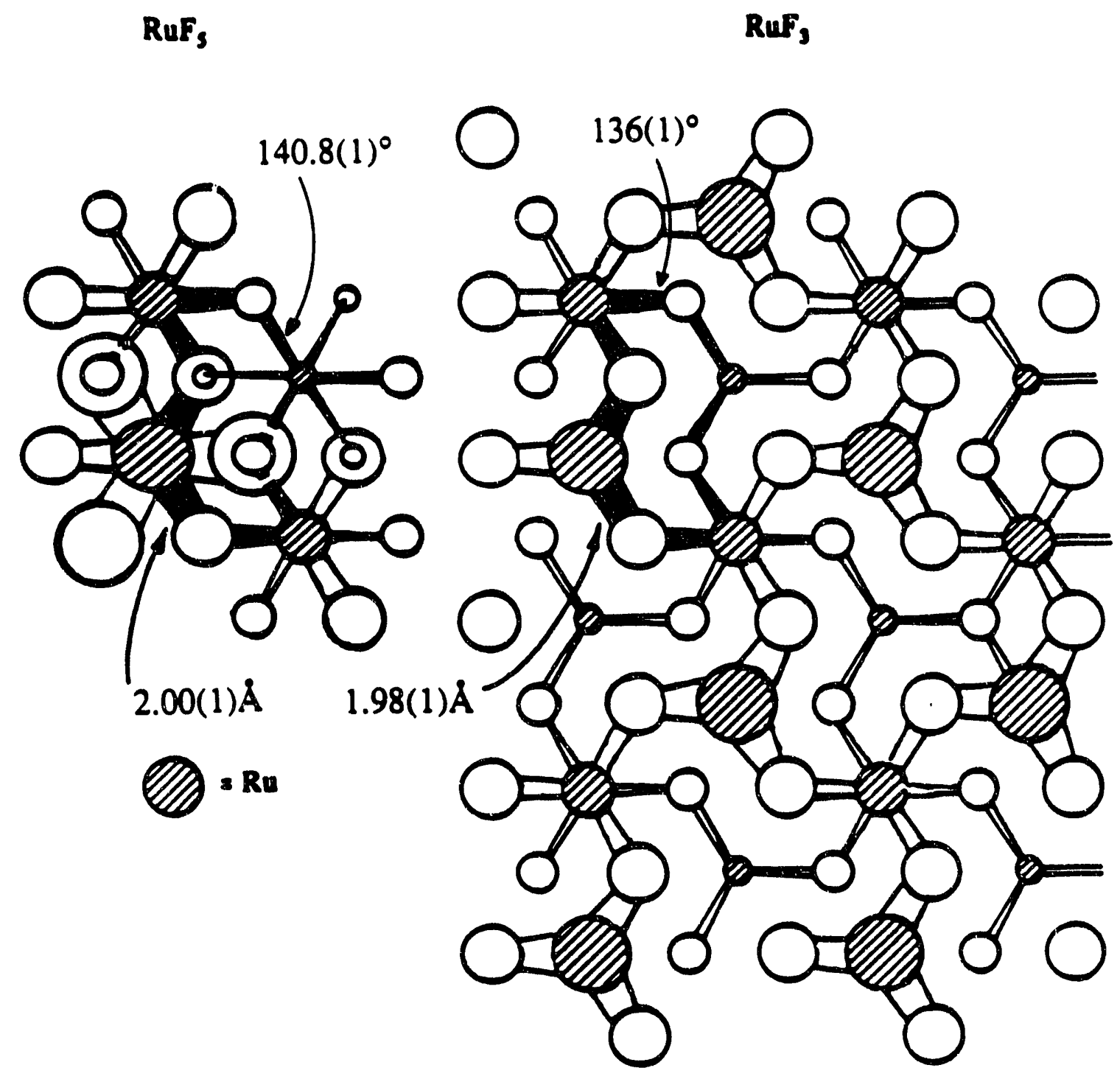

Figure 3.4. Relationship of the $\left(\mathrm{RuF}_{5}\right)_{4}$ geometry to an element of the $\mathrm{RuF}_{3}$ infinite hexagonal nearly - close - packed $\mathrm{F}$ atom array. 

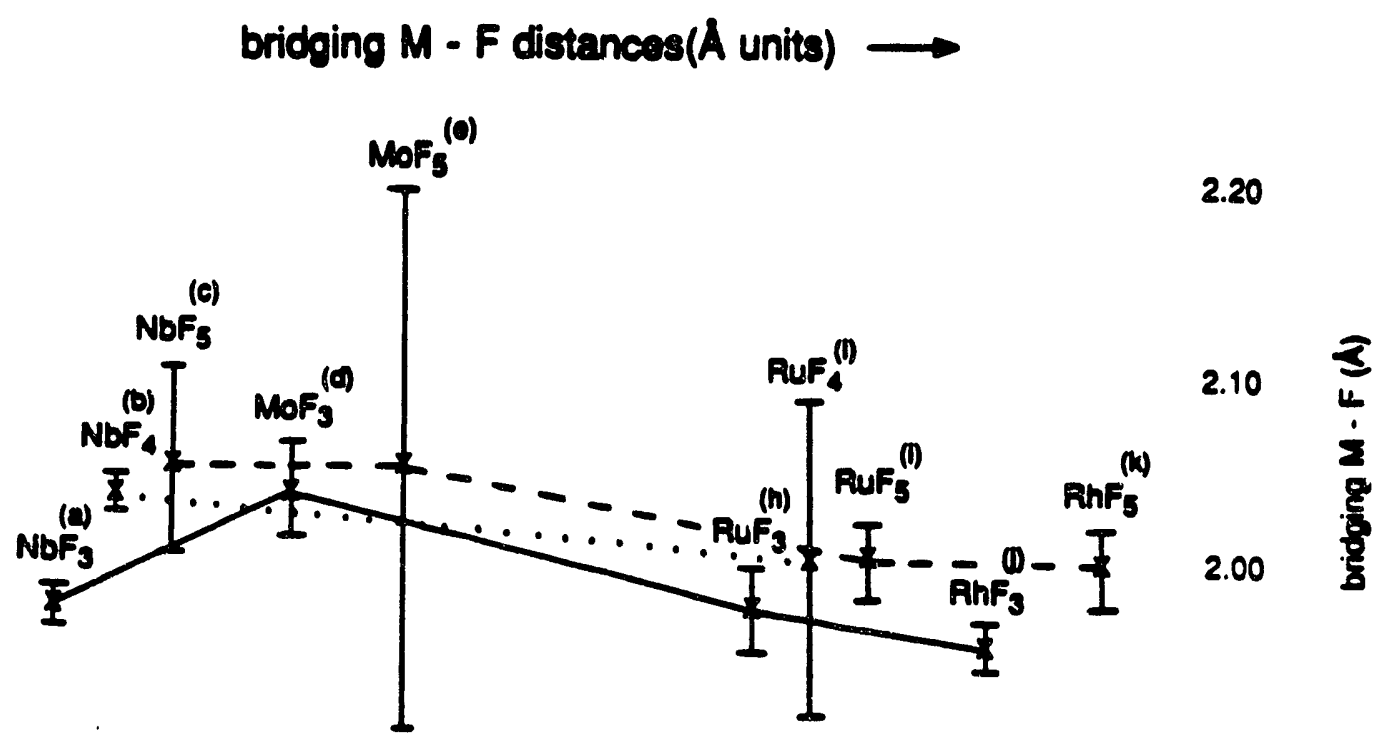

1.90

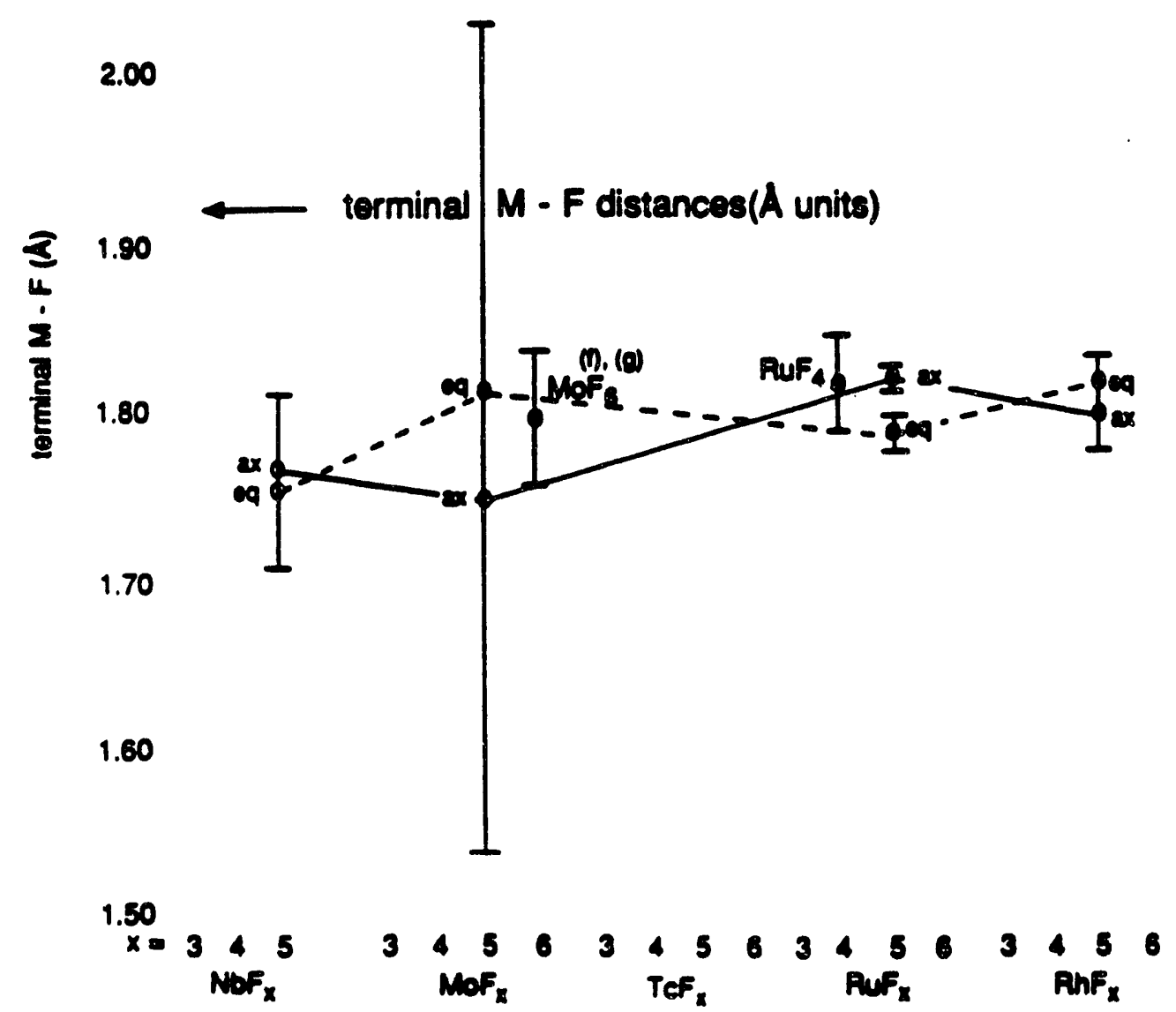

Figure 3.5. $M$ - F interatomic distances, terminal and bridging $(\AA)$ for the binary fluorides of $\mathrm{Nb}$ through $\mathrm{Rh}$ (errors bars represent $\pm 3 \sigma$ ). Reference key for footnotes: $a, 7 ; b, 21$ and 22; c, 6; d, 28; e, 29; f, 30; g, 26; h, 8; i, present work; j, 5; k, 4. 


\section{Chapter 4}

\section{Synthesis and Structure Types of the Transition Metal Tetrafluorides}

\section{Introduction}

In Chapter 3, a structural investigation of the Ru binary fluorides demonstrated remarkable constancy of $\mathrm{M}$ - $\mathrm{F}$ interatomic distances for bridging $\mathrm{F}$ - ligands with change in oxidation state. Comparisons were made with other metals in the second and third transition series from groups V through VIII and this constancy appeared to be general. Indeed, there appeared to be little change in $\mathbf{M}$ - Fbridging bond length for different metals in this series.

Those observations are particularly remarkable given the variety of structure types observed as the bridge bonding changes rather dramatically from linear $\mathrm{M}-\mathrm{F}$ - M bridging in the group V systems to $\approx 132^{\circ}$ bridging at the end of group VIII.

The trifluorides show three types of structures (Table 4.1), depending upon this bridging angle. $\mathrm{A} c \mathrm{cp}-\mathrm{ReO}_{3}$ type structure results when the bridges are linear and an hcp based distortion of this structure is observed when the bridge angle is $132^{\circ}$, this being the ideal M - F - M angle for hcp arrangements of fluorine atoms with regular 1/3 occupancy of the octahedral holes. ${ }^{1}$ Intermediate bridging angles give rise to structures which may be viewed as distortions from the hcp and ccp structures.

Table 4.1. Structures of Second and Third Transition Series Trifluorides

$\begin{array}{lccccc} & \mathrm{Nb}^{2} & \mathrm{Mo}^{3} & \mathrm{Ru}^{1} & \mathrm{Rh}^{4} & \mathrm{PdPdF}_{6}{ }^{5} \\ \mathrm{MFM} \angle\left(^{\circ}\right) & 180 & 141 & 136 & 132 & 132 \\ & & & & \mathrm{Ir}^{1} & \mathrm{PtPtF}_{6}{ }^{6} \\ \mathrm{MFM} \angle\left(^{\circ}\right) & & & & 132 & 132\end{array}$

The pentafluorides also exhibit three structure types (Table 4.2), each placing the bridging F ligands cis to each other. Two of these, those with linear M - F - M bridges 
and those with an $\mathrm{M}-\mathrm{F}$ - $\mathrm{M}$ angle $\approx 135^{\circ}$ are based on tetramers. Interestingly these tetrameric pentafluorides again may be viewed as ccp and hcp arrangements of $F$ atoms, for linear and $132^{\circ} \mathrm{M}-\mathrm{F}$ - M bridges, respectively, with $\mathrm{M}$ regularly occupying $1 / 5$ of the octahedral holes. ${ }^{7}$ The third structural conformation is the chain polymer $\mathrm{VF}_{5}$ structure and occurs in those pentafluorides, $\mathrm{TcF}_{5}$ and $\mathrm{ReF}_{5}$, for which the $\mathrm{M}-\mathrm{F}-\mathrm{M}$ bridging angle $\approx 150^{\circ}$. The fluorines in this structure are not close packed.

Table 4.2. Structures of Second and Third Transition Series Pentafluorides

\begin{tabular}{ll|l|lll}
$\mathrm{V}$ & $\mathrm{VI}$ & $\mathrm{VII}$ & $\mathrm{VIII}$ & \\
$\mathrm{Nb}^{8}$ & $\mathrm{Mo}^{9}$ & $\mathrm{Tc}^{11}$ & $\mathrm{Ru}^{12}$ & $\mathrm{Rh}^{13}$ & \\
$\mathrm{Ta}^{8}$ & $\mathrm{~W}^{10}$ & $\mathrm{Re}^{11}$ & $\mathrm{Os}^{14}$ & $\mathrm{Ir}^{15}$ & $\mathrm{Pt}^{16}$ \\
$\mathrm{ccp}$ & & $\begin{array}{l}\text { not close } \\
\text { packed }\end{array}$ & & &
\end{tabular}

It is among the tetrafluorides, however, that the greatest structural diversity might be expected. The available data indicate that these materials undergo similar bending of their $\mathrm{M}$ - F - M bridges, across the transition series as do the trifluorides and pentafluorides on going from $\mathrm{NbF}_{4}$ which contains linear bridges 17 to $\mathrm{PdF}_{4}$ with an $\mathrm{M}$ $\mathrm{F}$ - $\mathrm{M}$ angle of $135^{\circ} .18$ Moreover the two unique $\mathrm{F}$ ligands, in the octahedral framework about each metal atom, are observed in trans relationship in the $\mathrm{NbF}_{4}$ sheet structure and cis in the 3-D PdF 4 structure. The finding that the $\mathrm{VF}_{4}, \mathrm{~d}^{1}$ structure, ${ }^{19}$ is like that of $\mathrm{RuF}_{4}, \mathrm{~d}^{4}$ (Chapter 3), and places the unique fluorines trans to each other, in spite of significant bending in the bridge bonding further indicates that there is not a simple correlation with the "non - bonding" valence - electron configuration. In addition, the $\mathrm{M}$ - F - M bridging angles in the $\mathrm{RuF}_{4}$ sheet structure are not significantly different from those determined in the $\mathrm{PdF}_{4}, \mathrm{IrF}_{4}$, and $\mathrm{PtF}_{4}$ structures. Prior to this study, however, the only second and third transition series tetrafluorides known (and most of these are not 
well described) were those of $\mathrm{Zr}^{20}, \mathrm{Nb}, \mathrm{Rh}^{21}, \mathrm{Pd}, \mathrm{Ir}^{21}$, and $\mathrm{Pt}^{21}$. Indeed, many have never been synthesized in high purity.

The highest oxidation state fluorides can often be synthesized by direct fluorination, their volatility allowing them to be separated from lower fluorides by vacuum sublimation. ${ }^{22}$ The lower oxidation state systems, in this series the trifluorides, can often be made in high purity by reduction of higher fluorides using an excess of reducing agent, or by interaction of the metal with AHF at elevated temperatures. 23 The intermediate oxidation state tetrafluorides, being polymeric and difficult to separate from admixtures with trifluoride, awaited a general, high purity synthesis. The latter was of particular interest for reliable magnetic data, but the lower symmetry of tetrafluorides (in contrast to the high symmetry of trifluorides) also makes high purity a precondition for successful indexing of $\mathbf{X}$ - Ray powder diffraction data for such materials.

The successful synthesis of $\mathrm{RuF}_{4}$ by fluoride-ion capture from the hexafluorometallate salt, suggested a new access to high purity tetrafluorides, via:

$$
\mathrm{K}_{2} \mathrm{MF}_{6}+2 \mathrm{~A} \stackrel{\mathrm{AHF}}{\longrightarrow} \mathrm{MF}_{4} \downarrow+2 \mathrm{KAF}
$$

$A$ in eq. 1 is the fluoroacid $\mathrm{BF}_{3}, \mathrm{AsF}_{5}$, or $\mathrm{SbF}_{5}$ and $\mathrm{M}$ is any metal from which the hexafluorometallate(IV) salt can be synthesized in high purity(Chapter2). This was observed in this study for Os, Re, Mo, and Pd.

\section{Experimental}

Preparation of $\mathrm{OsF}_{4}$. In the DRILAB usually $600 \mathrm{mg}(1.5 \mathrm{mmol}) \mathrm{K}_{2} \mathrm{OsF}_{6}$ (chapter 2) was loaded into one arm of a two armed Teflon $\mathrm{T}$ apparatus. The reactor was attached to a Teflon/FEP manifold of the vacuum line and evacuated. AHF $(6 \mathrm{ml})$ was condensed on to the $\mathrm{K}_{2} \mathrm{OsF}_{6}$ which completely dissolved on warming to room temperature. The addition of $\mathrm{AsF}_{5}$ to the yellow solution brought about the immediate precipitation of a heavy 
yellow - brown solid. On attaining a colorless supernatent solution, $\mathrm{AsF}_{5}$ addition was ceased. It was found that the $\mathrm{KAsF}_{6}$ side product in this reaction was not very soluble in the presence of dissolved $\mathrm{AsF}_{5}$. For this reason the $\mathrm{AsF}_{5}$ containing $\mathrm{AHF}$ was removed, by evacuation through a small trap containing $\mathrm{KF}$, from the mixture of products. A second $6 \mathrm{ml}$ aliquot of AHF was condensed on to the yellow brown solid in the reactor and the $\mathrm{KAsF}_{6}$ was then removed by decantation of the supernatent solution into the free arm of the reactor. Cooling the original reaction arm distilled the AHF back on to the product for further washing. This decantation/ distillation procedure was repeated 10 times to completeiy remove $\mathrm{KAsF}_{6}$ from the product. Finally the AHF was evacuated through a soda - lime scrubber, the solid being dried under dynamic vacuum. Nearly quantitative yields of $\mathrm{OsF}_{4}$ were obtained, there being some loss in the decantation process. $\mathrm{X}$ - Ray powder data, Table 4.3, could be indexed completely on the basis of the orthorhombic $\mathrm{PdF}_{4}$ type cell the extinctions of which are in harmony with space group Fdd2, with is the group established for $\mathrm{PdF}_{4}$.

Table 4.3. X-Ray powder data ( $\mathrm{Cu} \mathrm{K}<\alpha>$ radiation, $\mathrm{Ni}$ filter) for $\mathrm{OsF}_{4}$, orthorhombic cell with $a=9.89(1) \AA, b=9.36(1) \AA, c=5.70(1) \AA, z=8, V=528 \AA^{3}$, possible space group, Fdd2.

\begin{tabular}{llcl} 
& \multicolumn{3}{c}{$1 / \mathrm{d}^{2} \times 10^{4}$} \\
I/lo & Obs & Calc & hkl \\
w & 431 & 409 & 200 \\
& & 456 & 020 \\
vs & 523 & 524 & 111 \\
w & 1351 & 1341 & 311 \\
w & 1454 & 1437 & 131 \\
s & 1636 & 1635 & 400
\end{tabular}


Table 4.3 cont.

\begin{tabular}{|c|c|c|c|}
\hline \multirow[t]{2}{*}{ I/Io } & Obs & Calc & hks \\
\hline & & 1639 & 20 \\
\hline $\mathrm{m}$ & 1827 & 1826 & 04 \\
\hline \multirow[t]{2}{*}{$\mathrm{m}$} & 2099 & 2092 & 42 \\
\hline & & 2095 & 22 \\
\hline $\mathbf{w}$ & 2969 & 2983 & $11 ?$ \\
\hline vw & 3269 & 3262 & 15 \\
\hline \multirow[t]{2}{*}{ vs } & 3473 & 3461 & 440 \\
\hline & & 3464 & 24 \\
\hline vw & 3796 & 3801 & $31 ?$ \\
\hline vw & 3877 & 3896 & $13 ?$ \\
\hline \multirow[t]{2}{*}{ w } & 4699 & 4690 & 442 \\
\hline & & 4714 & $33 ?$ \\
\hline \multirow[t]{3}{*}{$\mathrm{ms}$} & 4940 & 4919 & 00 \\
\hline & & 5722 & 15 \\
\hline & & 5743 & 460 \\
\hline \multirow[t]{2}{*}{ vw } & 5758 & 5746 & 26 \\
\hline & & 5785 & 22 \\
\hline \multirow[t]{2}{*}{$\mathrm{m}$} & 6579 & 6539 & 35 \\
\hline & & 6555 & 40 \\
\hline $\mathrm{m}$ & 6748 & 6745 & 04 \\
\hline $\mathbf{w}$ & 7330 & 7304 & 080 \\
\hline $\mathrm{m}$ & 8436 & 8390 & 44 \\
\hline $\mathrm{m}$ & 8977 & 9027 & 064 \\
\hline$w$ & 11544 & 11525 & 026 \\
\hline $\mathrm{m}$ & 12268 & 12223 & 08 \\
\hline $\mathrm{m}$ & 13362 & 13379 & 175 \\
\hline vw & 13900 & 13855 & 484 \\
\hline
\end{tabular}

Reaction of $\mathrm{K}_{2} \mathrm{OsF}_{6}$ with $\mathrm{BF}_{3}$. In a reaction similar to that above, $\mathrm{BF}_{3}$ was added to a solution of $492 \mathrm{mg}(1.3 \mathrm{mmol}) \mathrm{K}_{2} \mathrm{OsF}_{6}$ in $5 \mathrm{ml} \mathrm{AHF}$. After washing, an orange insoluble solid (207 mg) was isolated which was completely amorphous to X - rays. Addition of 
$\mathrm{AsF}_{5}$ to this solid in AHF resulted in an immediated color change to yellow - brown. Washing as above left $\mathrm{OsF}_{4}$ as indicated by the $\mathrm{X}$ - Ray powder data.

Reaction of $\mathrm{K}_{2} \mathrm{RuF}_{6}$ with $\mathrm{BF}_{3}$. Interaction of $600 \mathrm{mg}(2.0 \mathrm{mmol}) \mathrm{K}_{2} \mathrm{RuF}_{6}$ with $\mathrm{BF}_{3}$ under conditions identical to those above produced an insoluble orange solid which gave no X-ray powder pattern. Interaction of this solid with $\mathrm{AsF}_{5}$ in $\mathrm{AHF}$ produced an immediate color change to the deep pink characteristic of $\mathrm{RuF}_{4}$. The $\mathrm{X}$ - Ray powder data contained only lines due to $\mathrm{RuF}_{4}$.

Reaction of $\mathrm{K}_{2} \mathrm{ReF}_{6}$ with $\mathrm{AsF}_{5} \cdot \mathrm{K}_{2} \mathrm{ReF}_{6}$ (chapter 2) dissolved in AHF to give a pale pink solution. Addition of $\mathrm{AsF}_{5}$ as above immediately produced a light pink solid. However on standing for $5 \mathrm{~min}$ in $\mathrm{AsF}_{5}$ rich $\mathrm{AHF}$ the pink solid dissolved giving a green solution, suggesting that oxidation of $\mathrm{ReF}_{4}$ to green $\mathrm{ReF}_{5}$ by $\mathrm{AsF}_{5}$ had occured. 24

Preparation of $\mathrm{ReF}_{4}$ : In the DRILAB $295 \mathrm{mg}(0.78 \mathrm{mmol}) \mathrm{K}_{2} \mathrm{ReF}_{6}$ was loaded into one arm of a two armed Teflon reactor. A large molar excess of $\mathrm{SbF}_{5}(1 \mathrm{ml}, 14 \mathrm{mmol})$ was introduced, in the DRILAB, into the other arm of the reactor. After adding AHF to both arms of the reaction vessel, the solution of $\mathrm{SbF}_{5}$ in AHF was poured into the AHF solution of $\mathrm{K}_{2} \mathrm{ReF}_{6}$ a pink precipitate was rapidly produced. On standing for $30 \mathrm{~min}$ in the $\mathrm{SbF}_{5}$ rich solution the pink solid showed signs of dissolution and gave a pale blue solution. This was washed in the usual way to leave $110 \mathrm{mg}(0.32 \mathrm{mmol}, 42 \%$ yield based on $\mathrm{ReF}_{4}$ formation) of pink solid. The $\mathrm{X}$-Ray powder pattern of the pink material was indexable on the basis of a tetragonal cell, akin to the orthorhombic cell of $\mathrm{PdF}_{4}$. The data are given in Table 4.4 . 
Table 4.4. X-Ray powder data ( $\mathrm{Cu} \mathrm{K}<\alpha>$ radiation, Ni filter) for $\mathrm{ReF}_{4}$, orthorhombic (pseudo tetragonal) with a=b=9.61(2) $\AA, c=5.66(1) \AA, z=8, V=522 \AA^{3}$, possible space group Fdd2

\begin{tabular}{llcl} 
& \multicolumn{3}{c}{$1 / d^{2} \times 10^{4}$} \\
I/lo & Obs & Calc & hkl \\
s & 537 & 529 & 111 \\
w(br) & 867 & 866 & 220 \\
m(br) & 1401 & 1395 & 311,131 \\
s & 1696 & 1683 & 202,022 \\
--- & --- & 1732 & 400,040 \\
vw & 2138 & 2116 & 222 \\
$-\cdots-$ & --- & 2165 & 420,240 \\
vw & 2240 & 2261 & 331 \\
w(br) & 3048 & 3029 & 113 \\
--- & --- & 3127 & 511,151 \\
vs(br) & 3450 & 3414 & 422,242 \\
& & 3465 & 440 \\
w(br) & 3920 & 3892 & 313,133 \\
--- & --- & 3994 & 531,351 \\
--- & --- & 4331 & 620,260 \\
vvw & 4723 & 4758 & 333 \\
w(br) & 4999 & 4994 & 004
\end{tabular}

Reaction of $\mathrm{K}_{2} \mathrm{ReF}_{6}$ with $\mathrm{BF}_{3}$. When $\mathrm{BF}_{3}$ was admitted to a solution of $\mathrm{K}_{2} \mathrm{ReF}_{6}$, an agglomerated black solid resulted. Increasing the $\mathrm{BF}_{3}$ concentration by cooling the solution to $-20^{\circ} \mathrm{C}$ resulted in a small amount of pink solid forming on the black product, but this disappeared on warming to room temperature. In order to add $\mathrm{SbF}_{5}$ by distillation under static vacuum, the black solid was evacuated to dryness and $1 \mathrm{ml}$ of $\mathrm{SbF}_{5}$ was condensed into the free arm of the two armed reactor. AHF ( $3 \mathrm{ml})$ was condensed into both arms of the reactor. On warming to room temperature, the $\mathrm{SbF}_{5}$ solution was poured on to the black solid in AHF, completely converting it to a pink solid, which is presumed 
to be $\mathrm{ReF}_{4}$. Unfortunately this material was of insufficient crystallinity to produce an $\mathrm{X}$ ray powder pattern.

Preparation of $\mathrm{MoF}_{4}$ : In a reaction similar to that for the preparation of $\mathrm{ReF}_{4}, 410 \mathrm{mg}$ (1.4 mmol) $\mathrm{K}_{2} \mathrm{MoF}_{6}$ was loaded into one arm of a two armed teflon/FEP tee reactor. The $\mathrm{K}_{2} \mathrm{MoF}_{6}$ dissolved in AHF to give a green solution. A solution of $\mathrm{SbF}_{5}$ in AHF in the other arm of the reactor was poured onto the green solution immediately producing a pale green insoluble precipitate. Addition of the $\mathrm{SbF}_{5} / \mathrm{AHF}$ was stopped when the solution above the green solid became colorless. Further addition of the $\mathrm{SbF}_{5} / \mathrm{AHF}$ solution caused some dissolution of the green solid producing a pale green supernatent solution. This product was washed in the usual way, the $\mathrm{AHF}_{\mathrm{S}} \mathrm{SbF}_{5}$ solution finally being removed through a soda - lime scrubber under dynamic vacuum. The green solid $(110 \mathrm{mg}, 0.58$ mmol, $41 \%$ yield based on $\mathrm{MoF}_{4}$ ) precipitated by addition of excess $\mathrm{SbF}_{5}$ in $\mathrm{AHF}$ proved to be very poorly crystalline, but the $\mathrm{X}$ - Ray powder data match the strongest lines in the pattern obtained by Payne and Asprey 25 for their MoF 4 . Data are given in Table 4.5. This pattern showed no similarity to those of $\mathrm{SnF}_{4}\left(\mathrm{NbF}_{4}\right.$ type), $\mathrm{RuF}_{4}$, or $\mathrm{PdF}_{4}$ and has not been indexed.

Table 4.5. $\mathrm{X}$ - ray powder data for $\mathrm{MoF}_{4}$ and Comparison with Payne and Asprey data

$\mathrm{I} / \mathrm{I}_{\mathbf{n}}$

10

3
$1 / \mathrm{d}^{2} \times 10^{4}$

$\mathrm{I} / \mathrm{I}_{\mathbf{o}}$

vw

vw

vw

$\mathrm{mb}$

m

m

$s$

sbr

w

$\mathbf{w}$
Payne, Asprey data

$1 / d^{2} \times 10^{4}$

152

210

331

452

516

625

692

793

995

1020 
Table 4.5 cont.

$\begin{array}{llll}\mathrm{II}_{\mathrm{n}} & 1 / \mathrm{d}^{2} \times 10^{4} & \mathrm{I} / \mathrm{I}_{\mathrm{n}} & 1 / \mathrm{d}^{2} \times 10^{4} \\ 7 & & \mathrm{w} & 1445 \\ & 2478 & \mathrm{~m} & 2500 \\ & & \mathrm{vw} & 2712 \\ 3 & & \mathrm{vw} & 2890 \\ 3 & 3093 & & \\ 1 & 3143 & \mathrm{vw} & 3156 \\ 1 & 4506 & \mathrm{vw} & 4565 \\ & 5676 & & \end{array}$

Reaction of $\mathrm{K}_{2} \mathrm{MoF}_{6}$ with $\mathrm{AsF}_{5}$ : Addition of $\mathrm{AsF}_{5}$ to a solution of $\mathrm{K}_{2} \mathrm{MoF}_{6}$ in $\mathrm{AHF}$ immediately produced a green solid which on standing in $\mathrm{AsF}_{5} / \mathrm{AHF}$ solution quickly became a pale, $\tan$ color, indicative of $\mathrm{MoF}_{5}, 9$

Reaction of $\mathrm{K}_{2} \mathrm{MoF}_{6}$ with $\mathrm{BF}_{3}$ : Addition of $\mathrm{BF}_{3}$ to a solution of $405 \mathrm{mg}(1.41 \mathrm{mmol})$ $\mathrm{K}_{2} \mathrm{MoF}_{6}$ in AHF produced a heterogeneous mixture of insoluble products containing a pale green friable solid and a rubbery yellow brown solid in AHF. The finely divided green solid tended to remain suspended in the AHF solution, which complicated the washing procedure.Significant losses of the green solid during washing are probably responsible for the low final product weight (based on the production of $\mathrm{MoF}_{4}$, or $\mathrm{KMoF}_{5}$ ) of $138 \mathrm{mg}$ $\mathrm{X}$ - Ray powder photographs show the strong lines seen in the $\mathrm{SbF}_{5}$ preparation above as well as some additional lines not attributable to the Payne and Asprey material. Addition of $\mathrm{SbF}_{5}$ to this mixture of products in AHF immediately produced a homogeneous pale green solid.

Preparation of $\mathrm{PdF}_{4}: \mathrm{K}_{2} \mathrm{PdF}_{6}$ prepared by the method of Sharpe ${ }^{26}$ was dissolved at $20^{\circ} \mathrm{C}$ in $\mathrm{AHF}$ to yield a yellow-orange solution. Addition of excess $\mathrm{AsF}_{5}$ with rapid stirring of the solution quickly produced a brown solid. With the reactor continously agitated and a high $\mathrm{AsF}_{5}$ concentration maintained in the AHF, the brown solid gradually 
took on the pink to red color associated with $\mathrm{PdF}_{4} \cdot{ }^{21}$ No further $\mathrm{AsF}_{5}$ uptake was observed after 12 hours. X-ray powder photographs of the red solid were identical to those of $\mathrm{PdF}_{4}$ prepared by high pressure fluorination.

\section{Results and Discussion}

The synthesis of several tetrafluorides, $\mathrm{MF}_{4}(\mathrm{M}=\mathrm{Mo}, \mathrm{Re}, \mathrm{Os}, \mathrm{Ru}$, and $\mathrm{Pd})$, in high purity has now been accomplished by fluoride ion capture from the hexafluorometallate(IV) salts via reaction (1). As with any class of complexes of a given oxidation state, the oxidizing power, and hence the stability to strong oxidizing agents, of these tetrafluorides is expected to increase, with the nuclear charge from early to late transition metals. This proved to be an important factor in the synthesis of different tetrafluorides. The tetrafluorides of Mo and Re are unstable with respect to the powerfully oxidizing acid $\mathrm{AsF}_{5}$, being oxidized to $\mathrm{Mo}(\mathrm{V})$ and $\operatorname{Re}(\mathrm{V})$ by that reagent. However, $\mathrm{RuF}_{4}, \mathrm{OsF}_{4}$, and $\mathrm{PdF}_{4}$ are stable with respect to oxidation by $\mathrm{AsF}_{5}$, and no further reaction with this reagent occurred over several hours of contact. Indeed, $\mathrm{PdF}_{4}$ is known to be a very powerful oxidizer and has been difficult to prepare, owing to its low thermal stability at temperatures usually required for the direct fluorination of lower oxidation state polymeric fluorides. 21 The low temperatures that can be used in reaction (1) are particularly favorable for thermodynamically unstable fluorides. This is best exemplified by the synthesis of $\mathrm{AgF}_{3}$ (Chapter 5).

An increase in Lewis acidity was also observed which appears to follow the trend in oxidizing power across the series. There is some evidence that $\mathrm{MoF}_{4}$ and $\mathrm{ReF}_{4}$ are produced by $\mathrm{BF}_{3}$, but that an equilibrium is set up in reaction (1) which only favors tetrafluoride production at the low temperatures where high concentrations of $\mathrm{BF}_{3}$ can be brought into the solution. To complete the reaction, a stronger acid, which was not a powerful oxidizer was required. $\mathrm{SbF}_{5}$ proved to be satisfactory. There was no indication 
that $\mathrm{BF}_{3}$ was able to produce any $\mathrm{RuF}_{4}$, or $\mathrm{OsF}_{4}$, so $\mathrm{AsF} 5$ was used to bring about these reactions. The strongest fluoroacid in this tetrafluoride series ought to be $\mathrm{PdF}_{4}$, and it may be that the formation of a low solubility $\mathrm{PdF}_{5}^{-}$salt was responsible for the very slow reaction to produce $\mathrm{PdF}_{4}$ as a homogeneous product. Increasing electronegativity of the metal center and increased Lewis acidity are expected to go hand in hand as long as the increased ligand - ligand repulsion, consequent upon shortening $\mathbf{M}$ - F distances, does not become too unfavorable. For the second and third series $\mathrm{MF}_{6}{ }^{-2}$ salts, however, there is not a large decrease in $\mathrm{M}$ - F distance through to $\mathrm{Pd}(\mathrm{IV})$ and $\mathrm{Pt}(\mathrm{IV})$, therefore a smooth increase in fluoroacidity might be expected across each series.

Reaction(1), while producing the tetrafluorides in high purity, does not result in very crystalline materials, therefore much of the structural data obtained is of low quality. Nevertheless, a number of meaningful conclusions can be drawn. With the exception of $\mathrm{MoF}_{4}$, which may prove to exhibit a new tetrafluoride structure, the tetrafluorides fall into three tetrafluoride structure types Fig. 4.1. The $\mathrm{SnF}_{4}$ structure, Fig. 4.2, so far only adopted by $\mathrm{NbF}_{4}$ among the transition metals, places the two unique $\mathrm{F}$ ligands of the octahedrally coordinated tetrafluoride in trans positions. The bridging $\mathrm{F}$ ligands are in a square plane, thus a sheet structure results. Because the $M-F-M$ bridges are linear, the sheets are flat and may be thought of as two dimensional sections of the $\mathrm{ReO}_{3}$ perovskite structure. $\mathrm{RuF}_{4}$ exhibits a similar sheet type structure, (see Fig. 3.3 ) however, now the $\mathrm{M}$ - F - $\mathrm{M}$ bridges subtend an angle of $133^{\circ}$ causing the sheets to be puckered. $\mathrm{VF}_{4}$ is also known to adapt this structure with a larger $M-F-M$ angle of $151^{\circ}$. The third structure places the two unique $F$ ligands cis to each other with bridging $M$ - F - M angles slightly greater than the hep limit of $132^{\circ}$, Fig. 4.3. This structure is related to rutile 27 and can be derived from such difluoride structures by ordered removal of every other metal atom from a rutile, $\mathrm{MF}_{2}$ - type structure (see Fig 4.4). This structure is apparently adopted by $\mathrm{RhF}_{4}, \mathrm{PdF}_{4}, \mathrm{ReF}_{4}, \mathrm{OsF}_{4}, \mathrm{IrF}_{4}$, and $\mathrm{PtF}_{4} 16$ all of which have the roughly isodimensional 
Fdd 2 orthorhombic unit cells. The $\mathrm{X}$ - ray powder diffraction patterns of all these tetrafluorides, except those of $\mathrm{RhF}_{4}$, and $\mathrm{OsF}_{4}$, resemble one another closely and support the expectation of the $\mathrm{PdF}_{4}$ structure being common to all. $\mathrm{RhF}_{4}$ and $\mathrm{OsF}_{4}$ may not be exactly of this structure type even though the observed extinctions are appropriate for space group Fdd2.

As may be seen from Fig 4.3 which shows a view of this cell along the $c$ axis, the metal atoms lie in the 220 planes, as is required for placing them in special positions of the Fdd 2 cell. Although there are $\mathrm{F}$ atoms in between these planes, they are much poorer scatterers of $\mathrm{X}$ - rays than the second and and third row transition metals, hence significant intensities are expected for the 220 reflection in these tetrafluorides. This is, in fact observed for $\mathrm{Re}, \mathrm{Ir}, \mathrm{Pd}$, and $\mathrm{Pt}$ tetrafluorides, however, in $\mathrm{RhF}_{4}$ this reflection is very weak ${ }^{21}$ and in $\mathrm{OsF}_{4}$ it is not present at all. This is not yet fully understood, but does indicate that an ordered $\mathrm{PdF}_{4}$ - type structure is not appropriate. The two fluorides have very similar powder patterns, the lines of which are broad, background heavy, and line intensity decreasing markedly with $2 \theta$ increase. All of this hints at substantial disorder in both the $\mathrm{RhF}_{4}$ and $\mathrm{OsF}_{4}$ structures. The view of the $\mathrm{PdF}_{4}$ structure down the 110 plane seen in Fig. 4.4 shows the connectivity of that structure along the $c$ axis arising because all the unique $\mathrm{F}$ ligands are on the same side of all octahedra (this is a polar space group). This connectivity can be broken by alternating the unique $F$ ligands up and down (Fig. 4.5) thus creating a two dimensional slab. A somewhat disordered arrangement of such 2 dimensional slabs could account for the absence of the 220 reflection. The first requirement to settle this structural problem is more crystalline $\mathrm{RhF}_{4}$, or $\mathrm{OsF}_{4}$. This is not a simple task, since even the high temperature synthesis 28 of $\mathrm{RhF}_{4}$ described by Rao, resulted in poorly crystalline material which was not significantly better than that produced by the low temperature route. In any event, the apparent isomorphicity of the unit cells strongly suggests similar distances of $\mathbf{M}$ - $\mathbf{M}$ closest approach and hence similar $\mathbf{M}-\mathbf{F}-\mathbf{M}$ bridge bonding. 
The change observed in the $\mathrm{M}$ - F - $\mathrm{M}$ bridge angle in the trifluorides and pentafluorides can be correlated with the $\mathrm{t}_{2} \mathrm{~g}^{*}$ antibonding orbital population across the transition series. For the most part, linear bridged fluorides exist for $\mathrm{d}^{0}$ and $\mathrm{d}^{1}$ configurations, $\mathrm{d}^{2}$ systems involve bridges with $\approx 150^{\circ}$ angles, and complexes with an electron configuration of $\mathrm{d}^{3}$ or higher generate bridging angles closer to $135^{\circ}$, nearly that of ideal hcp systems. A similar trend is now partially observed for the tetrafluorides (although $\mathrm{d}^{1} \mathrm{VF}_{4}$ contains $\mathrm{M}-\mathrm{F}$ - $\mathrm{M}$ bridges of $151^{\circ}$ ). $\mathrm{NbF}_{4}$ with a $\mathrm{d}^{1}$ configuration contains linear bridges, while tetrafluorides with 3 or more $\mathrm{t}_{2 \mathrm{~g}}{ }^{*}$ electrons all adopt structures where $\mathrm{M}$ - F - M bridging angles close to $135^{\circ}$ must pertain. If in fact it is antibonding $\pi$ orbital filling which is causing this dramatic change in bridging angle, then only a very small energy difference between the linear bridged ccp based structures and the bent bridged hcp based structures is indicated, since antibonding $\pi$ effects are expected to be small in transition metal fluorides where orbital overlap is poor.

A perplexing problem encountered during this study was the appearance of different structure types for the low spin $\mathrm{d}^{4}$ tetrafluorides $\mathrm{RuF}_{4}$ and $\mathrm{OsF}_{4}$ with trans and cis dispositions of the unique $\mathrm{F}$ ligands, respectively. $\mathrm{RuF}_{4}$ has a distorted $\mathrm{SnF}_{4}$ type sheet structure with the two unique $F$ ligands located trans to each other and an $M-F-M$ bridge angle of $133^{\circ}$, resulting in the puckering of the sheet. The X-ray powder data for $\mathrm{OsF}_{4}$, however, can be indexed on the basis of an orthorhombic $\mathrm{PdF}_{4}$ type cell, suggesting a cis disposition of the two unique $F$ ligands as well as a $M-F-M$ bridge angle which must be close to $135^{\circ}$. Ligand - Ligand repulsions are expected to provide the primary influence in determining which conformation is preferred, cis interactions playing the most important role. The cis interactions can be ranked in descending order of their unfavorable repulsions as follows: short - bond/short - bond > short - bond/long - bond > long bond/long - bond. This order of steric effects is indicated in the structures of the $\mathrm{RuF}_{5}$ and $\mathrm{RhF}_{5}$ tetramers(chapter 4 ). In the tetrafluorides the conformation placing the two unique 
F ligands in trans positions allows for no cis short - bond/short - bond F interactions and 8 cis short - bond/long - bond interactions. The cis conformation contains 1 cis short bond/short - bond interaction, but only 6 cis short/long - bonded interactions. Since $\mathrm{RuF}_{4}$ and $\mathrm{OsF}_{4}$ involve similar $\mathrm{d}^{4}$ electron configurations and have similar formula unit volumes (indicative of similar atom sizes) it can only be supposed that changes in the polarity of the $\mathrm{M}$ - $\mathrm{F}$ bonds ( $\mathrm{RuF}_{4}$ is likely to have lower bond polarity) favors one arrangement over the other. The energy difference must be subtle, yet decisive, since there has never been any hint of $\mathrm{RuF}_{4}$ adopting the $\mathrm{PdF}_{4}$ - type structure.

Among the third row transition metals only the cis conformation has been observed thus far (although the $\mathrm{OsF}_{4}$ structure is not known in detail), the $\mathrm{PdF}_{4}$ structure maintained for $\mathrm{d}^{3} \mathrm{ReF}_{4}$ through $\mathrm{d}^{6} \mathrm{PtF}_{4}$. Only a slight increase is expected in all $\mathrm{M}-\mathrm{F}$ interatomic distances over those of the second transition series based on larger M(IV) cores for the third series transition metals, but this may serve to weaken the single cis short - bond/short - bond repulsive interaction enough that the cis conformation, which is already probably slightly lower in energy in the second transition series, is favored exclusively in the third series, perhaps even for $\mathrm{d}^{4} \mathrm{OsF}_{4}$. Unfortunately, no data are available for $\mathrm{TaF}_{4}$ and $\mathrm{WF}_{4}$. 


\section{References}

1. Hepworth, M.A.; Jack, K.H.; Peacock, R.D.; Westland, G.J. Acta Crystallogr. $1957,10,63$.

2.Pouchard, M., Torki, M.R., Demazeau, G., Hagenmüller, P., C.R. Hebd. Sceances Acad. Sci. Ser. 1971, C273, 1093.

3. LaValle, D.E., Steele, R.M., Wilkinson, M.K., Yakel, H.R. Jr., J. Am. Chem. Soc., 1960, 82, 2433.

4. Grosse, L; Hoppe, R., Z. Anorg. Allg. Chem , 1987, 552, 123.

5. Bartlett, N.; Rao, P.R. Proc. Chem. Soc. 1964, 393.

6. Tressaud, A.; Pintchovski, F.; Lozano, L.; Wold, A.; Hagenmuller, P. Mater. Res. Bull. 1976, $11,689$.

7. Edwards, A.J. Adv. in Inorg. Chem. and Radiochem. 1983, 27, 83.

8. Edwards, A.J., J. Chem. Soc. 1964, 3714.

9. Edwards, A.J.; Peacock, R.D., Small, R.W.H., J. Chem. Soc., 1962, 4486.

10. Edwards, A.J.; J. Chem. Soc. A 1969, 909.

11. Edwards, A.J.; Jones, G.R.; J. Chem. Soc. A 1969, 1651.

12. Chapter 3 of this work.

13. Morrell, B.K.; Zalkin, A.; Tressaud, A.; Bartlett, N., Inorg. Chem. 1973, 12, 2640.

14. Mitchell, S.J.; Holloway, J.H. J. Chem. Soc. A 1971, 2789.

15. P. R. Rao, Ph.D. Thesis, University of British Columbia, 1964.

16. Müller, B.G.; Serafin, M. Eur. J. Solid State Inorg. Chem. 1992, 29, 625.

17. Gortsema, F.P.; Didchenko, R. Inorg. Chem. 1965, 4, 182.

18. Wright, A.F.; Fender, B.E.F.; Bartlett, N.; Leary, K. Inorg. Chem. 1978, 17, 749.

19. Becker, S., and Müller, B.G., Angew. Chem. Int. Ed. 1990, 29, 406. 
20. Burbank, R.D.; Bensey, F.N. U.S. At. Energy Comm. Rep. 1956, K - 1280.

21. Rao, P.R.; Tressaud, A.; Bartlett, N. Inorg. Nucl. Chem. Lett. 1976, 23.

22. Colton, R.; Canterford, J.R. "Halides of the Second and Third Transition Metals," p. 3, Wiley, London, 1968.

23. Muetterties, E.L.; Castle, J.E. J. Inorg. Nucl. Chem. 1961, 18, 148.

24. Hargreaves, G.B.; Peacock, R.D. J. Chem. Soc. 1960, 1099.

25. Payne, R.T; Asprey, L.B. Inorg. Chem. 1974, 13, 1529.

26. Sharpe, A.G. J. Chem. Soc. 1953, 197.

27. Bartlett, N.; Tressaud, A. C.R. Hebd. Seances Acad. Sci., Ser. C, 1974, 278, 1501.

28. Rao, P.R. Ph.D. Thesis, University of British Columbia, 1964. 


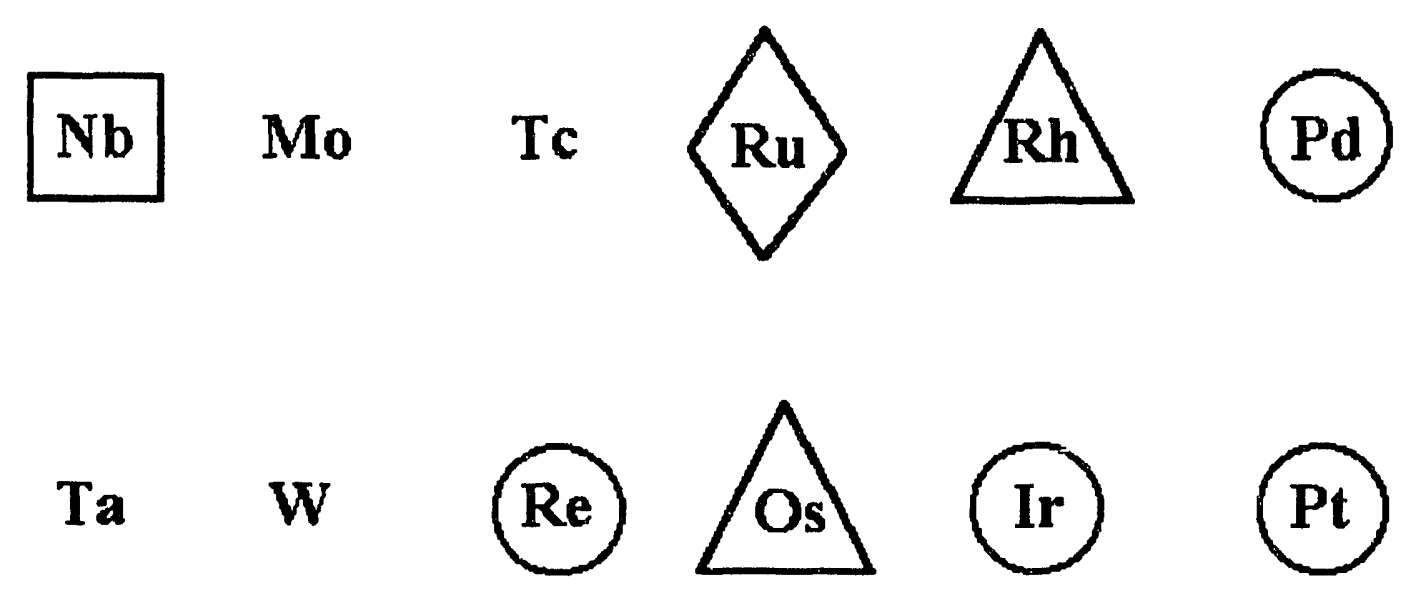

Figure 4.1. Observed structure types of the second and third transition series tetrafluorides. $\mathrm{SnF}_{4}$ type, $(\square)$, ref. $15 ; \mathrm{RuF}_{4}$ type, $(0)$, this work; $\mathrm{PdF}_{4}$ type, $(O)$, ref. 16,22, and this work; possible $\mathrm{PdF}_{4}$ type, $\Delta$, ref. 22 and this work. 


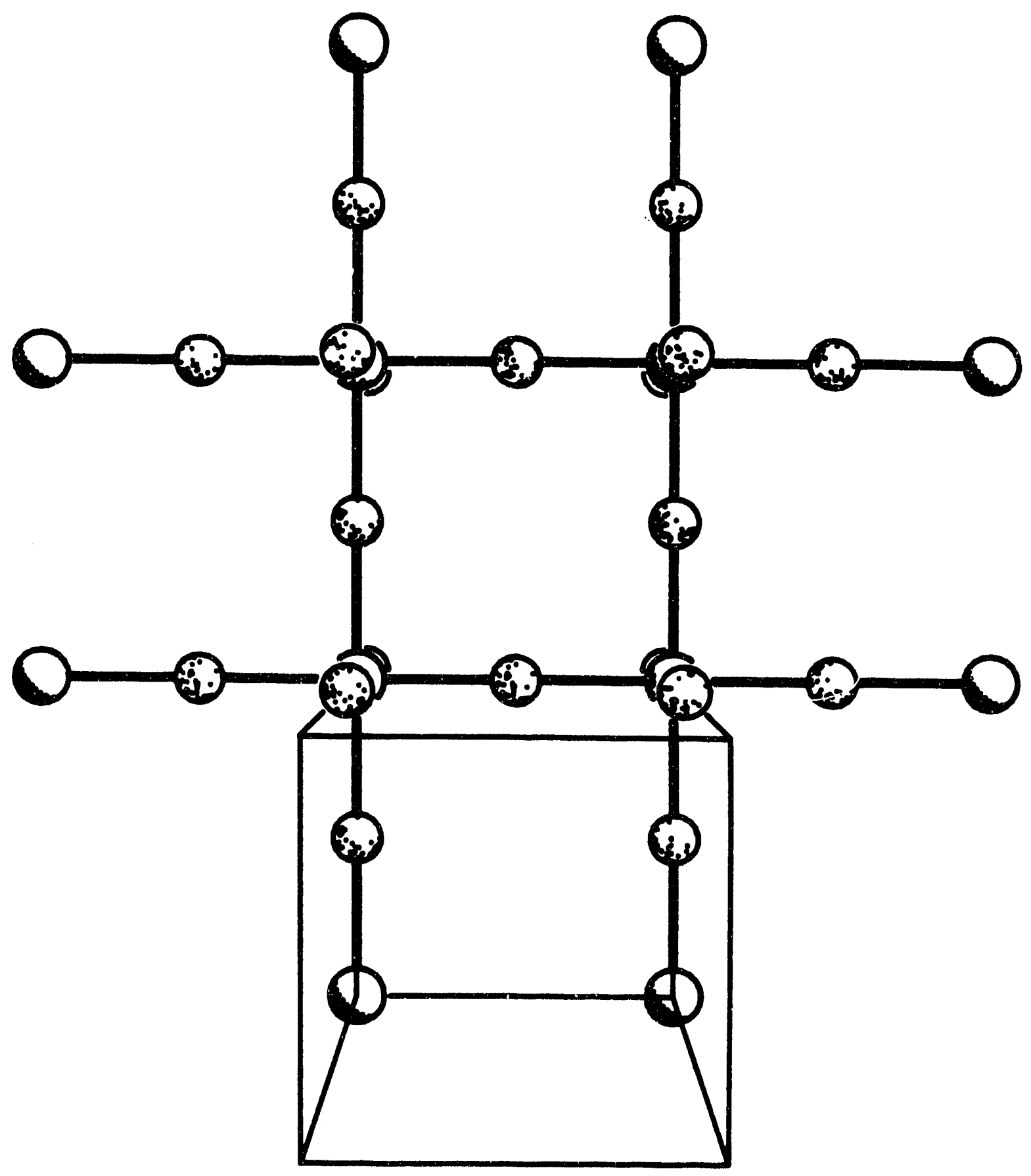

Figure 4.2. The $\mathrm{SnF}_{4}$ type structure. 


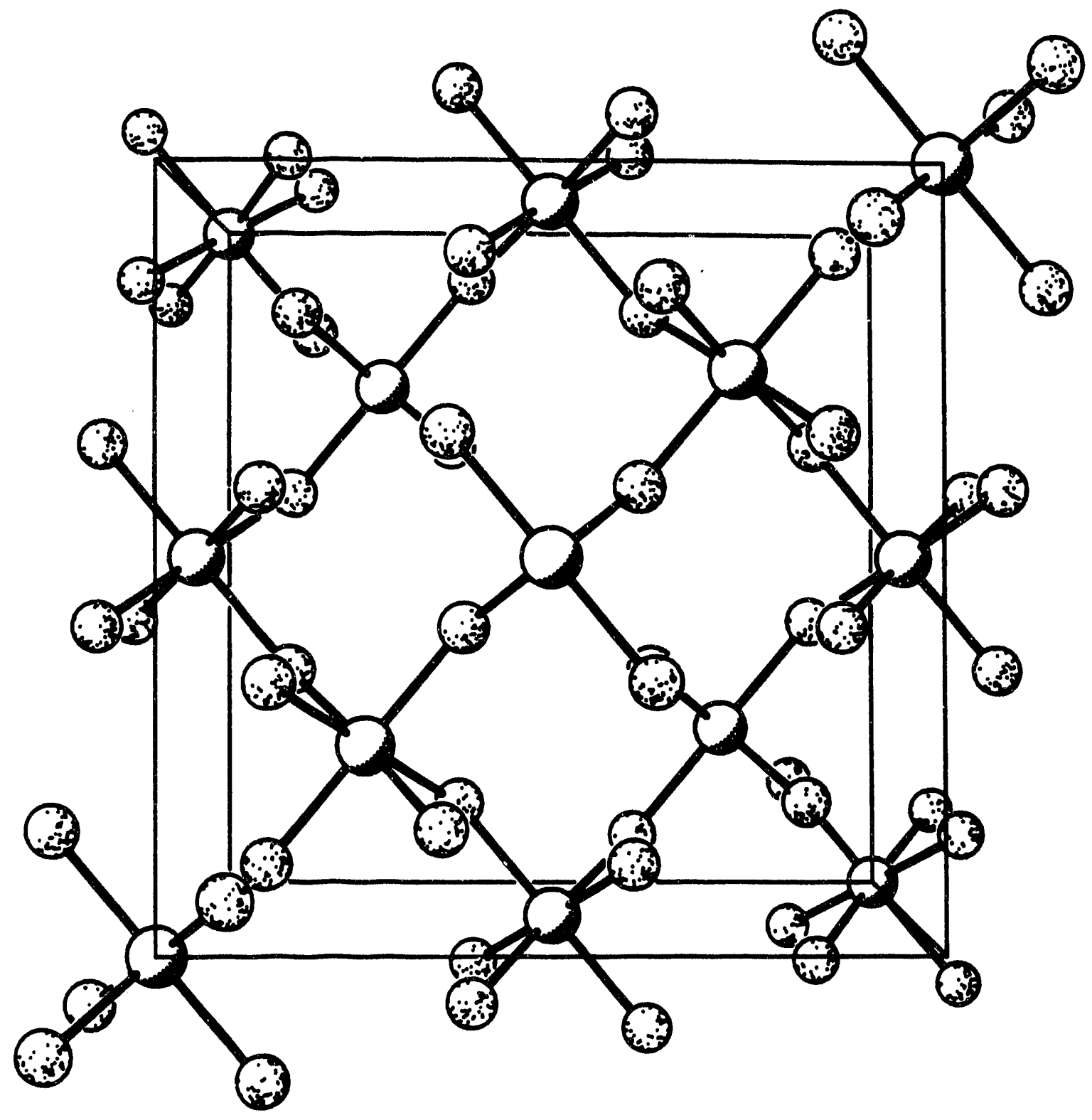

Figure 4.3. The $\mathrm{PdF}_{4}$ structure viewed along the $c$ axis. 

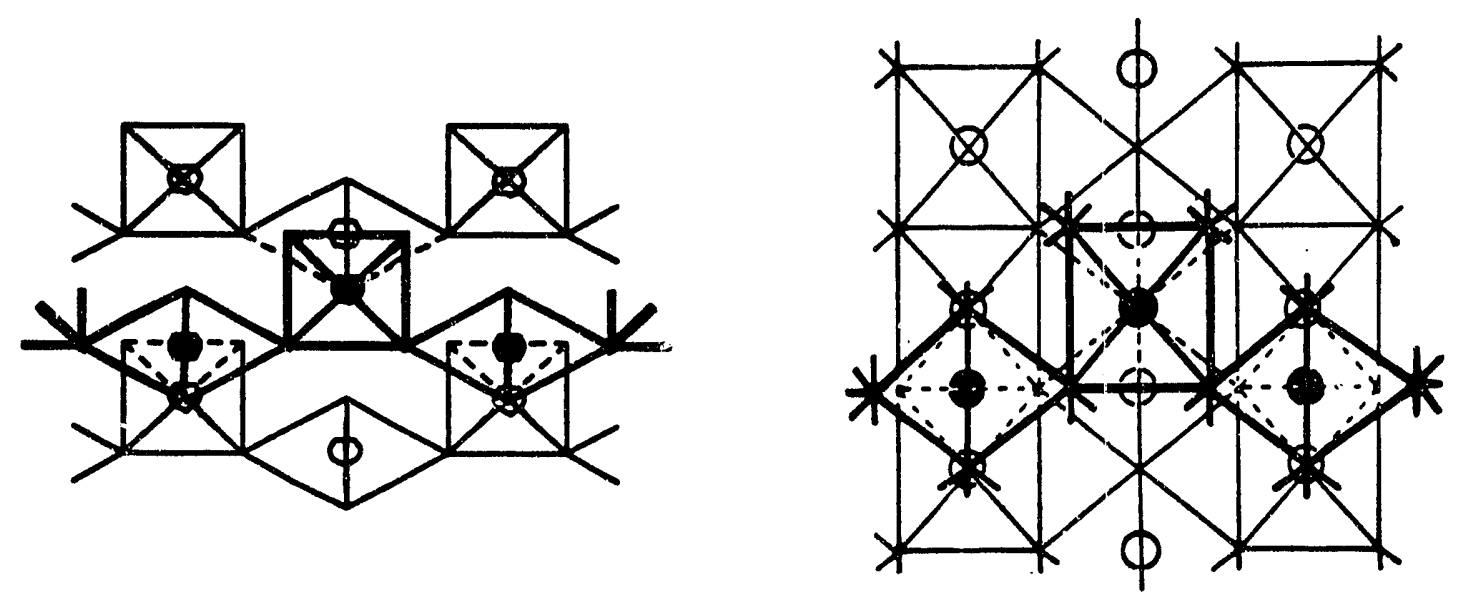

a

b

Figure 4.4. View along the 110 plane of the $\mathrm{PdF}_{4}$ type structure (a) and a comparison with he rutile structure (b). 


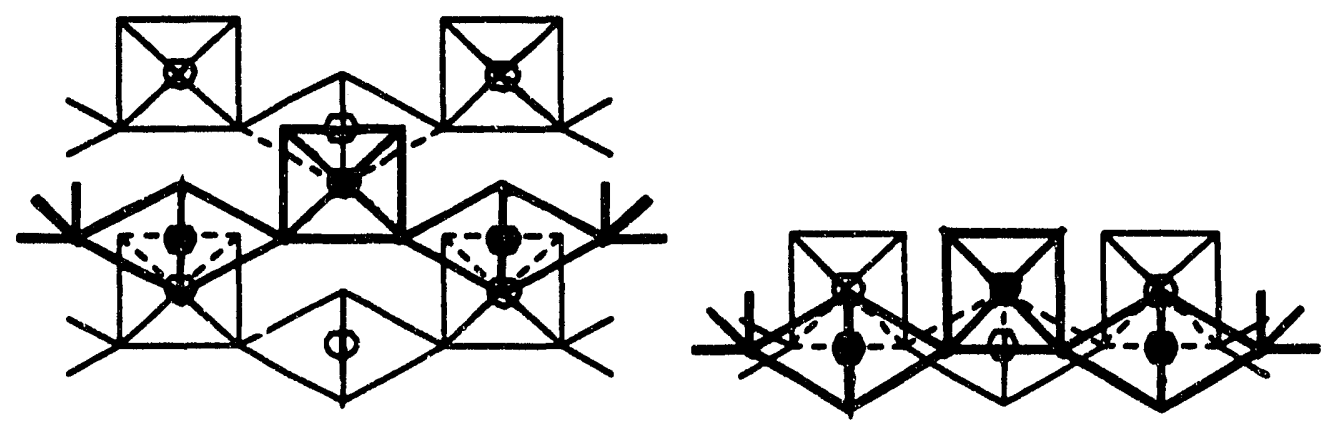

a

b

Figure 4.5. The $\mathrm{PdF}_{4}$ structure (a) in which all unique $\mathrm{F}$ ligands are pointed up with respect to the 110 plane and a section of $2-D$ sheet (b) which would result if the placement of the unique $F$ ligands was alternated up and down with respect to the 110 plane. 


\section{Chapter 5}

\section{Silver Trifluoride: Preparation, Crystal Structure, Some Properties, and Comparison with $\mathrm{AuF}_{3}$}

\section{Introduction}

Some interesting differences are observed in the high oxidation state chemistry of the coinage metals, silver and gold. Gold is easily oxidized to $\mathrm{Au}$ (III) and several complex ternary fluorides as well as neutral $\mathrm{AuF}_{3}$ are known. ${ }^{1}$ Under more rigorously oxidizing conditions, $A u(V)$ can be obtained as the hexafluoroaurate(V), $\mathrm{AuF}_{6}{ }^{-}$anion. ${ }^{2}$ Thermal decomposition of the dioxygenyl salt containing this anion, $\mathrm{O}_{2}+\mathrm{AuF}_{6}$, has even afforded small quantities of neutral $\mathrm{AuF}_{5}{ }^{3}$ Obtaining similar levels of oxidation in silver has proven much more difficult. Conditions similar to those which produce $\mathrm{Au}(\mathrm{V})$ salts were employed by Hoppe to produce the first $\mathrm{Ag}$ (III) salts. ${ }^{4}$ The majority of such salts contained $\mathrm{Ag}(\mathrm{III})$ as the square tetrafluoroargentate ion, $\mathrm{AgF}_{4}{ }^{-}$and were found to be isomorphous with the analogous $\mathrm{AuF}_{4}^{-}$salts and similarly diamagnetic, but Hoppe and Homann ${ }^{5}$ have described $\mathrm{Cs}_{2} \mathrm{KAgF}_{6}$ which has the elpasolite structure with octahedrally coordinated $\mathrm{Ag}(\mathrm{III})$ and a ground state triplet $\mathrm{d}^{8}$ electron configuration.

$X$ - ray powder data had indicated significantly smaller formula unit volumes in the $\mathrm{Ag}(\mathrm{III})$ compunds with respect to the $\mathrm{Au}$ (III) compounds. Subsequent structure determinations by Hoppe and Homann indicated that at least a portion of this volume decrease could be attributed to $\mathrm{M}-\mathrm{F}$ bond shortening in the square planer $\mathrm{MF}_{4}^{-}$units of the silver compounds; $\mathrm{Ag}-\mathrm{F}=1.90 \AA ; \mathrm{Au}-\mathrm{F}=2.00 \AA .6$ Such bond shortening can only account for roughly $1 / 3$ of the volume decrease, however. It is likely that the greater electronegativity of the $\mathrm{Ag}(\mathrm{III})$ metal center which results in shorter more covalent $\mathrm{M}-\mathrm{F}$ bonds is also reducing the spacial extension of the remaining $\mathrm{Ag}(\mathrm{III})$ valence electrons, 
principally that of greatest steric effect, $d_{z}{ }^{2}$.

Compounds containing $\mathrm{Ag}(\mathrm{V})$ have been claimed by Hagenmuller et al., ${ }^{7}$ however Zemva et al. have shown that even the most powerful oxidizing agents known, the krypton fluoride oxidizers, give no further oxidation of $\mathrm{Ag}(\mathrm{III})$ even though $\mathrm{Au}(\mathrm{V})$ is readily produced by these reagents. 8

As $\mathrm{F}$ ligands (non - bridging) are added to a central atom, the electronegativity of that atom must increase. Probably as a consequence of strong F - F repulsions, the coordination rarely exceeds six and octahedral coordination is commonly encountered, particularly with the less electropositive transition elements. Very high oxidation states are much more stable as anions, the additional electron density effectively reducing the electronegativity of the coordination center. Neutral systems of the same high oxidation state are consequently more difficult to obtain and can be thermodynamically unstable, yot preparable.

In 1983 Bougon reported that $\mathrm{AgF}_{3}$ could be obtained from the room temperature fluorination of silver or lower silver fluorides using $\mathrm{KrF}_{2}$ in $\mathrm{AHF} .{ }^{9}$ The material obtained, however, was not isomorphous with $\mathrm{AuF}_{3}$. Furthermore, it was paramagnetic, 10 indicating that it could not be a low spin $\mathrm{d}^{8}$ system as is $\mathrm{AuF}_{3}$. Hoppe and Homann had demonstrated the existence of high spin $\mathrm{Ag}$ (III) in $\mathrm{Cs}_{2} \mathrm{KAgF}_{6}$, indicating that the high spin octahedral conformation of $\mathrm{Ag}(\mathrm{III})$ is close energetically to that of low spin, square planer $\mathrm{Ag}(\mathrm{III})$. Kiselev et al. subsequently reported a similar preparation of $\mathrm{AgF}_{3}$ from the fluorination of $\mathrm{AgF}_{2}$ with $\mathrm{O}_{2} \mathrm{~F}_{2}$, which is comparable to $\mathrm{KrF}_{2}$ as a $\mathrm{F}$ atom source. $\mathrm{A}$ hexagonal unit cell, not isomorphous with $\mathrm{AuF}_{3}$ was reported for this material, but no magnetic data were given. ${ }^{11}$ The Kiselev et al diffraction data indeed bore a close resemblance to those given by Bougon and his coworkers.

In an effort to test the validity of a radically different structure for $\mathrm{AgF}_{3}$ fron that already established 12 for $\mathrm{AuF}_{3}$ an independent synthesis was sought. The ability of strong 
fluoroacids to displace binary fluorides from their parent fluoroanions, Chapter 4, suggested that similar removal of $\mathrm{F}^{-}$from $\mathrm{AgF}_{4}^{-}$salts, which are readily characterized and obtainable in high purity, would afford high purity $\mathrm{AgF}_{3}$. This has proved to be so.

\section{Experimental}

Materials. $\mathrm{KNO}_{3}, \mathrm{AgNO}_{3}$ (Fisher Scientific, Fair Lawn, NJ) and Au powder (LBL stores)were used as supplied. $\mathrm{PdBr}_{2}{ }^{13}$ and $\mathrm{AgF}_{2}{ }^{14}$ were prepared by literature methods. The preparation of $\mathrm{AgFAsF}_{6}$ will be described in Chapter 6.

Preparation of $\mathrm{KAgF}_{4}:$ Roughly $1: 1$ mixtures of $\mathrm{KNO}_{3}(1.81 \mathrm{~g}, 17.9 \mathrm{mmol})$ and $\mathrm{AgNO}_{3}$ $(2.86 \mathrm{~g}, 16.8 \mathrm{mmol})$ were ground together with a mortar and pestle before being loaded into the nickel insert of a high pressure Monel Parr bomb equipped with an Autoclave Engineering valve. The nitrate salts were heated above their eutectic melting point to $\approx 150$ ${ }^{\circ} \mathrm{C}$ for thirty minutes. On cooling, the Ni insert was placed inside the Parr bomb which was then sealed with a copper gasket and shown to be leak free with a He leak detector prior to the fluorination step. It was evacuated on a stainless steel vacuum line and cooled in liquid $\mathrm{N}_{2}$ to condense in $33 \mathrm{mmol}$ of $\mathrm{F}_{2}$ which resulted in a pressure of $30 \mathrm{~atm}$ at room temperature. The bomb was heated in a sand bath to between 350 and $400{ }^{\circ} \mathrm{C}$ for $24 \mathrm{~h}$. At this time the reactor was cooled to to room temperature and volatile materials were evacuated through the soda - lime scrubber. A second aliquot of $F_{2}$ was added followed by a second heating cycle. After similar cooling and removal of the volatiles the bomb was opened in the DRILAB to reveal a bright orange solid admixed with a small amount of brown solid. The crude product was loaded into one arm of a two armed teflon tee reactor and removed to a vacuum line where $7 \mathrm{ml}$ AHF was condensed in at $-196^{\circ} \mathrm{C}$. On warming a deep orange solution formed over the brown solid. Successive washings by decantation 
of the orange solution freed bright orange $\mathrm{KAgF}_{4}(2.1 \mathrm{~g}, 9.4 \mathrm{mmol} ; 56 \%$ yield)from the brown insoluble solid which proved, by $\mathrm{X}$ - ray powder diffraction, to be largely $\mathrm{AgF}_{2}$. Usually X-Ray powder photographs of the washed material cculd be indexed completely on the basis of the tetragonal $\mathrm{KAgF}_{4}$ pattern. ${ }^{6}$ However small amounts of $\mathrm{KHF}_{2}$ were present as a consequence of $\mathrm{AgF}_{2}$ formation. Some of the $\mathrm{KHF}_{2}$, being much more soluble than $\mathrm{KAgF}_{4}$, could be removed by washing the contaminated $\mathrm{KAgF}_{4}$ with successive small amounts of $\mathrm{AHF}$ at $\approx 0{ }^{\circ} \mathrm{C}$. However, when the $\mathrm{F}^{-}$concentration became too low in the AHF, partial solvolysis of the $\mathrm{KAgF}_{4}$ to $\mathrm{AgF}_{3}$ and $\mathrm{KF}$ was observed to occur, so $\mathrm{KHF}_{2}$ could not be completely removed in this manner.

Preparation of $\mathrm{AgF}_{3}$ : In the DRILAB KAgF 4 , usually $600 \mathrm{mg}$ ( $27 \mathrm{mmol}$ ) was loaded into one arm of a two armed teflon tee reactor which had been passivated with 2 atm $F_{2}$ for several hours. The reactor was attached to an all Teflon - FEP manifold of the vacuum line and evacuated. AHF, $6 \mathrm{ml}$, was condensed on to the $\mathrm{KAgF}_{4}$ by cooling to $-196{ }^{\circ} \mathrm{C}$. On warming to room temperature, a small amount of red brown precipitate (presumed to be $\mathrm{AgF}_{3}$ formed by solvolysis) formed in an orange solution. When this material had settled, the orange solution was decanted into the free arm of the reactor. $\mathrm{BF}_{3}$ was slowly admitted and immediately a bright red precipitate began to form. Addition of $\mathrm{BF}_{3}$ was continued until the supernatant solution was colorless. Even in the presence of excess $\mathrm{BF}_{3}$, no further reaction with the $\mathrm{AgF}_{3}$ was observed. The $\mathrm{AgF}_{3}$ was washed free of $\mathrm{KBF}_{4}$ by decantation of the supernatant $\mathrm{AHF}$ solution into the other arm of the reactor. This AHF was distilled back on to the $\mathrm{AgF}_{3}$ by cooling it to $-196^{\circ}$. This decantation and back distillation procedure was done 8 times, quickly to minimize decomposition of the $\mathrm{AgF}_{3}$ in $\mathrm{AHF}$ at room temperature. AHF was removed through the soda - lime scrubber under dynamic vacuum, the $\mathrm{AgF}_{3}$ product being finally dried by evacuation through the main trap. Usually $400 \mathrm{mg}$ ( $2.4 \mathrm{mmol}) \mathrm{AgF}_{3}$ was obtained, some being lost in the 
decantation process. $X$ - Ray powder patterns showed no $\mathrm{KBF}_{4}$ and indicated that $\mathrm{AgF}_{3}$ was isomorphous with $\mathrm{AuF}_{3}$. The analysis of $\mathrm{AgF}_{3}$ was performed in the laboratories of Žemva et al. ${ }^{15}$ They measured, by tensimetry, the quantity of $\mathrm{F}_{2}$ liberated by $\mathrm{AgF}_{3}$ as it decomposed in AHF over $19 \mathrm{~h}$ and found it to correspond to: $3 \mathrm{AgF}_{3} \rightarrow \mathrm{Ag}_{3} \mathrm{~F}_{8}+$ $1 / 2 \mathrm{~F}_{2}$. The composition of $\mathrm{Ag}_{3} \mathrm{~F}_{8}$ for the thermal decomposition product was determined directly by their analysis and from its synthesis by other routes in this work(q.v.). The diamagnetism of the material freshly precipitated (with $\mathrm{BF}_{3}$ ) was measured in these laboratories and its close structural relationship with $\mathrm{AuF}_{3}$ (q.v.) combined with these other observations settled the composition as $\mathrm{AgF}_{3}$.

\section{Synchrotron X-ray Powder Diffraction Data Collection and Structure Analysis for}

AgF 3. X - Ray synchrotron powder diffraction data were collected at Brookhaven National Laboratory by Dr. David Cox and Dr. Angus Wilkinson who also analyzed the data. A wavelength of $1.24805 \AA$ was employed as a compromise between the conflicting requirements of minimizing the sample absorption, maintaining reasonable pattern resolution and operating at an energy where the $\mathrm{X}$-ray source had a high output. The data collected showed Bragg peaks with FWHM's greater than $0.18^{\circ}$ which is considerably in excess of instrumental resolution. All the peaks in the pattern, with the exception of a single weak line, were indexed on a hexagonal unit cell, $a=5.0753(3) \AA$, $c=15.448(1) \AA$, (see Table 5.1) similar to that of $A_{u F} \cdot 12$ The unindexed diffraction maximum at $d \sim 3.7 \AA$ is attributable to the strongest Bragg reflection of a small amount of $\mathrm{Ag}_{3} \mathrm{~F}_{8}$ impurity, this particular $\mathrm{AgF}_{3}$ sample having been prepared (q.v.) using $\mathrm{AsF}_{5}$. 
Table 5.1. X-Ray Powder Data for $\mathrm{AgF}_{3}{ }^{\mathrm{a}}$ (Synchrotron Radiation, $\lambda=1.24805 \AA$ )

$\begin{array}{crcc}\mathrm{h}, \mathrm{k}, \mathrm{l} & \mathrm{L} / \mathrm{I}_{\mathrm{o}} & \begin{array}{c}1 / \mathrm{d}^{2} \times 10^{4} \\ \text { obsd }\end{array} & \begin{array}{c}1 / \mathrm{d}^{2} \times 10^{4} \\ \text { calcd }\end{array} \\ 100 & 31 & 518 & 518 \\ 101 & 21 & 560 & 560 \\ 102 & 19 & 685 & 685 \\ 103 & 100 & 895 & 895 \\ 104 & 6 & 1187 & 1188 \\ 006 & 5 & 1508 & 1509 \\ 110 & 10 & 1550 & 1553 \\ 105 & 10 & 1565 & 1565 \\ 111 & 5 & 1596 & 1595 \\ 112 & 12 & 1720 & 1720 \\ 113 & 2 & 1928 & 1930 \\ 106 & 10 & 2026 & 2026 \\ 200 & 5 & 2070 & 2070 \\ 114 & 1 & 2213 & 2223 \\ 202 & 19 & 2239 & 2238 \\ 203 & 3 & 2447 & 2448 \\ 107 & 4 & 2575 & 2571 \\ 115 & 25 & 2602 & 2600 \\ 204 & 16 & 2742 & 2741 \\ 116 & 12 & 3061 & 3062 \\ 108 & 3 & 3200 & 3200\end{array}$

a Hexagonal unit cell with $\left(20^{\circ} \mathrm{C}\right) \mathrm{a}_{\mathrm{o}}=5.0753(3) \AA, c_{\mathrm{o}} 15.448(1) \AA, \mathrm{V}=344.62(7) \AA^{3}$; $\mathrm{z}=6$; space group $\mathrm{P}_{1} 22-\mathrm{D}_{6}{ }^{2}$ or $\mathrm{P} 6522-\mathrm{D}_{6}{ }^{2}$.

Neutron Powder Diffraction Data Collection and Structure Analyses for $\mathrm{AgF}_{3}$ and AuF 3. Drs. Horst Bormann, Angus Wilkinson, and Robert Von Dreele were involved in the data collection and analysis with this worker. Details of the data collection are given in Table 5.2. The High Intensity Powder Diffractometer (HIPD) was chosen because the extremely high incident neutron intensity afforded the possibility of using small samples of these very reactive fluorides. The success of this approach can be seen in the quality of the diffraction patterns (Fig. 5.1). The data collected in this way showed peaks down to $\sim 0.6 \AA \mathrm{d}$-spacing all of which are fitted quite closely by the Rietveld refinement procedure and afforded a precise structure determination of both $\mathrm{AgF}_{3}$ and $\mathrm{AuF}_{3}$. 
Both structures were refined with the package GSAS ${ }^{16}$ using neutron diffraction data collected at both $\pm 153^{\circ} 2 \theta$ for d-spacings $>0.6 \AA$. The results are given in Table 5.3. In both cases Fourier Series were used for the background and absorption coefficients were refined for each data set. For $\mathrm{AgF}_{3}$ an extinction coefficient was also refined; the value, $38(8) \mu \mathrm{m}^{2}$, indicates that the average grain size was $\sim 6 \mu \mathrm{m}$. No extinction effects were observed for $\mathrm{AuF}_{3}$. The peak profiles were considerably broadened and thus some of the coefficients of the peak shape function were also refined. Their values indicate that both materials exhibit a substantial degree of microstrain particularly perpendicular to the hexagonal axis.

Table 5.2. Details of the Neutron Diffraction Data Collection for $\mathrm{AgF}_{3}$ and $\mathrm{AuF}_{3}$

Instrument employed

Sample

Diffraction geometry

Data collection
Los Alamos National Laboratory

Manuel Lujan, Jr. Neutron Scattering Center

High Intensity Powder Diffractometer (HIPD)

$100 \mathrm{mg} \mathrm{AgF} 3$ contained in two $2.0 \mathrm{~mm}$ diameter quartz capillaries, sample length $\sim 35 \mathrm{~mm}$. $100 \mathrm{mg}$ $\mathrm{AuF}_{3}$ contained in a $2.0 \mathrm{~mm}$ diameter quartz capillary, sample length $\sim 35 \mathrm{~mm}$.

$9.0 \mathrm{~m}$ initial flight path, $1.25 \mathrm{~m}$ secondary flight paths to 4 each $1 / 2 \times 12^{1} 10 \mathrm{~atm}{ }^{3} \mathrm{He}$ detectors at $\pm 153^{\circ}$ $2 \theta$.

$0.6 \AA \leq \mathrm{d} \leq 4.8 \AA$ in $\sim 3800$ constant_t $t / t$ steps for $10.85 \mathrm{hrs}$. at $71.2 \mu \mathrm{A}$ beam current for $\mathrm{AgF}_{3}$ and for $4.19 \mathrm{hrs}$. at $70.19 \mu \mathrm{A}$ for $\mathrm{AuF}_{3}$. Range included 275 reflections for $\mathrm{AgF}_{3}$ and 298 reflections for $\mathrm{AuF}_{3}$. 
Table 5.3. Final models from Neutron Diffraction Structure Refinements for $\mathrm{AgF}_{3}$ and $\mathrm{AuF}_{3}$.

\begin{tabular}{|c|c|c|}
\hline & $\mathrm{AgF}_{3}{ }^{\mathrm{a}}$ & $\mathrm{AuF}_{3}$ \\
\hline Space Group & $\mathrm{P}_{6}{ }_{1} 22$ & $\mathrm{P}_{6}{ }_{12} 2$ \\
\hline a/A & $5.0782(2)$ & $5.1508(1)$ \\
\hline$c / \AA$ & $15.4523(8)$ & $16.2637(7)$ \\
\hline abs, $+153^{\circ}$ & $-0.023(5)$ & $0.291(14)$ \\
\hline abs, $-153^{\circ}$ & $-0.028(5)$ & $0.265(13)$ \\
\hline $\mathrm{ext} / \mathrm{um}^{2}$ & $38(8)$ & 0 \\
\hline profile coefficients & & \\
\hline$\left.\sigma_{1}{ }^{2} / \mu \mathrm{s} / \AA\right)^{2},+153^{\circ}$ & $77(4)$ & $50(3)$ \\
\hline$\left.\sigma_{1}^{2} / \mu \mathrm{s} / \AA\right)^{2},-153^{\circ}$ & $119(5)$ & $91(4)$ \\
\hline$\left.\sigma_{1 a^{2} / \mu \mathrm{s} / \AA}\right)^{2},+153^{\circ}$ & $-17(9)$ & $-26(5)$ \\
\hline$\left.\sigma_{1 \mathrm{a}} 2 / \mu \mathrm{s} / \AA\right)^{2},-153^{\circ}$ & $-18(12)$ & $-45(8)$ \\
\hline$A$ in $6(b): x, 2 x, 1 / 4 ; x$ & $0.2694(4)$ & $0.2399(3)$ \\
\hline $\mathrm{U}_{\mathrm{is} \alpha} / \AA^{2}$ & $0.0112(9)$ & $0.0111(8)$ \\
\hline$F(1)$ in $6(a): x, 0,0 ; x$ & $0.2176(8)$ & $0.1639(8)$ \\
\hline $\mathrm{U}_{\mathrm{is}} / \AA^{2}$ & $0.0233(12)$ & $0.0215(12)$ \\
\hline$F(2)$ in $12(c): x, y, z ; x$ & $0.8401(7)$ & $0.7761(6)$ \\
\hline $\mathbf{y}$ & $0.3186(10)$ & $0.3099(7)$ \\
\hline $\mathbf{z}$ & $0.0054(2)$ & $0.0053(2)$ \\
\hline $\mathrm{U}_{\mathrm{i} \Omega} / \AA^{2}$ & $0.0350(11)$ & $0.0328(10)$ \\
\hline $\mathbf{R}_{\text {Wn }}$ & $6.21 \%$ & $11.21 \%$ \\
\hline $\mathbf{R}_{\mathrm{n}}$ & $3.83 \%$ & $7.58 \%$ \\
\hline$\chi^{2}$ & 1.327 & 1.175 \\
\hline
\end{tabular}

a The lattice constants for $\mathrm{AgF}_{3}$ are slightly larger from the neutron experiment than from the synchrotron experiment. This difference is probably due to the slightly higher temperature in the neutron case and to the difficulty in estimating the exact scattering center in a time-of-flight experiment. As we are mainly interested in comparing $\mathrm{AgF}_{3}$ and $\mathrm{AuF}_{3}$, we have used the neutron data for calculating distances and angles.

Interaction of $\mathrm{AgF}_{3}$ with $\mathrm{AsF}_{5}$ in $\mathrm{AHF} \mathrm{AgF}_{3}(708.9 \mathrm{mg}, 4.30 \mathrm{mmole})$ in $\mathrm{AHF}(\sim 3 \mathrm{ml}$ was exposed to $\mathrm{AsF}_{5}\left(>>4.30 \mathrm{mmole}\right.$ ) at $\sim 20^{\circ} \mathrm{C}$, rapid dissolution of the $\mathrm{AgF}_{3}$ occurred, to produce a deep blue solution, this being accompanied by the evolution of gas which was not condensable at $-196^{\circ} \mathrm{C}$. This gas was shown to be $F_{2}$ by its quantitative interaction with clean $\mathrm{Hg}$. Removal of AHF under vacuum yielded a deep blue solid. The 
$\mathrm{X}$ - ray powder data of this material was indexed completely on the of basis the cell obtained by Gantar et al. (see Chapter 6) for AgFAsF $6 .^{17}$

\section{Preparation of $\mathrm{Ag}(\mathrm{II}) \mathrm{Ag}(\mathrm{III}) \mathrm{F}_{5}: \mathrm{KAgF}_{4}$ and $\mathrm{AgFAsF}_{6}$ in $\mathrm{AHF} \mathrm{KAgF}_{4}(238$}

$\mathrm{mg}, 1.07 \mathrm{mmole})$ dissolved in AHF( $5 \mathrm{~mL})$ contained in one leg of the FEP I apparatus, was poured, at $20^{\circ} \mathrm{C}$, slowly into a solution of $\mathrm{AgFAsF}_{6}(346 \mathrm{mg}, 1.10 \mathrm{mmole})$ in $\mathrm{AHF}(\sim$ $5 \mathrm{~mL}$ ) in the leg at right angles to it. A maroon solid precipitated immediately. Some of the $\mathrm{AHF}$ was back distilled into the $\mathrm{KAgF}_{4}$ leg to wash any remaining $\mathrm{KAgF}_{4}$ into the mixture. When the transfer of that salt was complete the supernatant AHF solution was colorless. This colorless supernatant AHF was then decanted into the empty leg of the $\mathrm{I}$ and the AHF back vacuum distilled on to the maroon residue to wash that solid free of $\mathrm{KAsF}_{6}$. The washing cycle was repeated 10 times and the AHF was then removed under vacuum at $20^{\circ} \mathrm{C}$. An X-Ray powder photograph of the maroon solid showed a sharp strong-line pattern of a new phase. Lines of $\mathrm{KAsF}_{6}, \mathrm{AgF}_{3}$ and $\mathrm{AgF}_{2}$ were absent. Data are given in Table 5.4. The weight of the solid $(326 \mathrm{mg}$ ) was appropriate for an almost quantitative yield of $\mathrm{Ag}_{2} \mathrm{~F}_{5}$ (1.05 mmole).

Table 5.4. X-Ray Powder Data for $\mathrm{Ag}^{\mathrm{II}} \mathrm{Ag}^{\mathrm{III}_{\mathrm{F}}} \mathrm{F}_{5}(\mathrm{CuK}<\alpha>\mathrm{Ni}$ Filter) at $293 \mathrm{~K}$

$\begin{array}{lclc}\mathrm{I} / \mathrm{I}_{\mathrm{O}} & \left(1 / \mathrm{d}^{2}\right) \times 10^{4} \text { (obsd) } & \mathrm{I} / \mathrm{I}_{\mathrm{O}} & \left.1 / \mathrm{d}^{2}\right) \times 10^{4} \text { (obsd) } \\ \text { vw } & 512 & & \\ \text { s } & 670 & \mathrm{~ms} & 2882 \\ \text { vs } & 755 & \mathrm{~m} & 3049 \\ \text { s } & 896 & \mathrm{vvw} & 3129 \\ \mathrm{~m} & 979 & \mathrm{vw} & 3204 \\ \text { vvw } & 1068 & \mathrm{vw} & 3294 \\ \text { s } & 1128 & \text { vvw } & 3366 \\ \text { ms } & 1245 & & \end{array}$


Table 5.4. cont.

$\begin{array}{lclc}\mathbf{I}_{\mathrm{O}} & 1 / \mathrm{d}^{2} \times 10^{4}(\mathrm{obsd}) & \mathrm{I} / \mathrm{I}_{\mathrm{o}} & 1 / \mathrm{d}^{2} \times 10^{4}(\mathrm{obsd}) \\ \mathrm{ms} & 1295 & \mathrm{~ms}(\mathrm{br}) & 3573 \\ \mathrm{~m} & 1445 & \mathrm{~ms} & 3729 \\ \mathrm{~m} & 1575 & \mathrm{vvw} & 3912 \\ \mathrm{~ms} & 1737 & \mathrm{vvw} & 4101 \\ \mathrm{vvw} & 1915 & \mathrm{vvw} & 4217 \\ \mathrm{vw} & 1956 & \mathrm{vvw} & 4319 \\ \mathrm{w} & 2109 & \mathrm{vvw} & 4498 \\ \mathrm{~s} & 2199 & \mathrm{vw} & 4790 \\ \mathrm{vww} & 2340 & \mathrm{vvw} & 4982 \\ \mathrm{vw} & 2470 & \mathrm{vvw} & 5234 \\ \mathrm{vvw} & 2646 & \mathrm{vvw} & 5424 \\ \mathrm{vw} & 2732 & & \end{array}$

Preparation of $\mathrm{Ag}(\mathrm{II}) \mathrm{Ag}(\mathrm{III})_{2} \mathrm{~F}_{8}$ : (a) $\mathrm{KAgF}_{4}$ with $\mathrm{AgFAsF}_{6}$ and $\mathrm{BF}_{3} . \mathrm{KAgF}_{4}(412$ $\mathrm{mg}, 1.85 \mathrm{mmole}$ ) dissolved in AHF ( $3 \mathrm{~mL})$ in one leg of an FEP T apparatus, was added slowly to a blue solution of $\mathrm{AgFAsF}_{6}$ ( $313 \mathrm{mg}, 0.99 \mathrm{mmole}$ ) dissolved in $\mathrm{AHF}(\sim 5 \mathrm{~mL})$. Immediate precipitation of a marcon solid (probably $\mathrm{Ag}_{2} \mathrm{~F}_{5}$ ) occurred, the supernatant AHF solution retaining the orange coloration of dissolved $\mathrm{AgF}_{4}^{-}$. To this mixture was then slowly added $\mathrm{BF}_{3}$ with brisk stirring. The suspended solid rapidly became deep redbrown in color, as the $\mathrm{AgF}_{4}^{-}$in the $\mathrm{AHF}$ was replaced by $\mathrm{BF}_{4}^{-}$, and at the end-point the supernatant $\mathrm{AHF}$ was colorless. This $\mathrm{AHF}$ solution (containing $\mathrm{KAsF}_{6}$ and $\mathrm{KBF}_{4}$ ) was decanted into the other leg of the FEP $T$, and the washing of the precipitate was carried out, as in the preparation of $\mathrm{Ag}_{2} \mathrm{~F}_{5}$. X-Ray powder photography showed that the wellwashed solid was free of $\mathrm{KAsF}_{6}$ and $\mathrm{KBF}_{4}$. There were no traces of $\mathrm{Ag}_{2} \mathrm{~F}_{5}, \mathrm{AgF}_{3}$ or $\mathrm{AgF}_{2}$ and the pattern matched that of the product of the decomposition of $\mathrm{AgF}_{3}$ in $\mathrm{AHF}$ and is given in Table 5.5. The yield of washed $\mathrm{Ag}_{3} \mathrm{~F}_{8}$ was $400 \mathrm{mg}(0.84 \mathrm{mmol}) 91 \%$. (b) $\mathrm{Ag}_{2} \mathrm{~F}_{5}$ and $\mathrm{AgF}_{3}$ in $\mathrm{AHF}$. A sample of $\mathrm{Ag}_{2} \mathrm{~F}_{5}(180 \mathrm{mg}, 0.57 \mathrm{mmole}$ ) was mixed with an equimolar quantity of $\mathrm{AgF}_{3}$ (93 mg, $0.57 \mathrm{mmole}$ ) in an $\mathrm{FEP}$ tube and $\mathrm{AHF}(6 \mathrm{~mL})$ was vacuum distilled on to the mixture, which was then briskly stirred at $\sim 20^{\circ} \mathrm{C}$. The color quickly changed to deep red-brown characteristic of $\mathrm{Ag}_{3} \mathrm{~F}_{8}$ and the $\mathrm{AHF}$ was removed 
under dynamic vacuum after $1 \mathrm{hr}$. X-Ray powder photography (see Table 5.5) established that this material was identical with that formed in preparation (a) and in the decomposition of $\mathrm{AgF}_{3}$ in $\mathrm{AHF}$. No other silver fluorides were present. The stoichiometry of this preparation and that of preparation (a) confirmed that the composition must be $\mathrm{Ag}_{3} \mathrm{~F}_{8}$.

Table 5.5. X-Ray Powder Data for $\mathrm{Ag}_{3} \mathrm{~F}_{8}(\mathrm{CuK}<\alpha>$, Ni Filter) at 293K

$\begin{array}{lclc}\mathrm{I}_{\mathbf{O}} & \left(1 / \mathrm{d}^{2}\right) \times 10^{4} \text { (obsd) } & \mathbf{I} / \mathrm{I}_{\mathbf{O}} & \left(1 / \mathrm{d}^{2}\right) \times 10^{4} \text { (obsd) } \\ \mathbf{w} & 321 & \mathrm{vw} & 2410 \\ \mathrm{~ms} & 482 & \mathrm{vw} & 2477 \\ \mathrm{mw} & 673 & \mathrm{~ms} & 2706 \\ \mathrm{~m} & 694 & \mathrm{~s}(\mathrm{br}) & 2944 \\ \mathrm{vvs} & 740 & \mathrm{~m} & 3269 \\ \mathrm{~m} & 839 & \mathrm{~m} & 3457 \\ \mathrm{~ms} & 920 & \mathrm{~m} & 3524 \\ \mathrm{mw} & 985 & \mathrm{~ms} & 3682 \\ \mathrm{vs} & 1087 & \mathrm{~m} & 3785 \\ \mathrm{mw} & 1142 & \mathrm{~s}(\mathrm{br}) & 3830 \\ \mathrm{w} & 1322 & \mathrm{~m} & 3924 \\ \mathrm{~m} & 1382 & \mathrm{~ms} & 4180 \\ \mathrm{w} & 1477 & \mathrm{~ms} & 4340 \\ \mathrm{~ms}(\mathrm{br}) & 1603 & \mathrm{~m} & 4555 \\ \mathrm{~m}(\mathrm{br}) & 1706 & \mathrm{~m} & 4686 \\ \mathrm{~ms} & 1840 & \mathrm{~m}(\mathrm{br}) & 4891 \\ \mathrm{~s}(\mathrm{br}) & 1940 & \mathrm{vw} & 5296 \\ \mathrm{vw} & 2038 & \mathrm{vw} & 5504 \\ \mathrm{~m} & 2215 & & \\ \mathrm{mw} & 2301 & & \end{array}$

Interaction of $\mathbf{A g F}_{2}$ with $\mathbf{A g F}_{3}$ In a reaction designed to remove $\mathrm{AgF}_{3}$ from a sample of $\mathrm{Ag}_{3} \mathrm{~F}_{8}, 245 \mathrm{mg}$ of the $\mathrm{Ag}_{3} \mathrm{~F}_{8} / \mathrm{AgF}_{3}$ mixture was loaded into a one armed teflon/FEP reactor along with $45 \mathrm{mg}(\mathrm{mmol}) \mathrm{AgF}_{2}$. The reactor was attatched to the teflon manifold of the vacuum line, evacuated, and charged with $5 \mathrm{ml} \mathrm{AHF}$ at $-196^{\circ} \mathrm{C}$. On warming to room temperature, the reactor was agitated for 1 hour, the sample becoming noticeably 
more brown during this time. The solvent was evacuated through the soda - lime scrubber and the sample dried for several hours under dynamic vacuum. No weight change was observed in the products. $X$ - Ray powder photographs showed largely $\mathrm{Ag}_{3} \mathrm{~F}_{8}$ and a small amount of $\mathrm{AgF}_{2}$. No lines attributable to $\mathrm{Ag}_{2} \mathrm{~F}_{5}$ were observed.

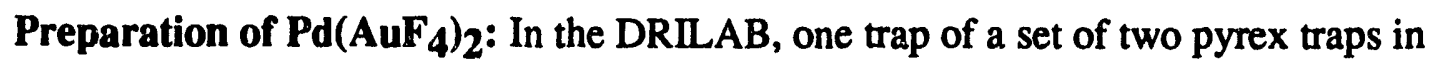
series was loaded with a 1:2 $(0.8 \mathrm{mmol})$ mixture of $\mathrm{PdBr}_{2}$ and $\mathrm{Au}$ metal. The traps were fitted with Whitey valves and removed to a stainless steel vacuum line where an excess of $\mathrm{BrF}_{3}$ was condensed on to the reactants under static vacuum by cooling the trap to $-196^{\circ} \mathrm{C}$. On warming to room temperature, a vigorous reaction ensued with $\mathrm{Br}_{2}$ evolution. The reaction was heated with a heat gun, the $\mathrm{Br}_{2}$ formed being condensed into the second trap by intermittant cooling with liquid $\mathrm{N}_{2}$. After $10 \mathrm{~min}$, the second trap was held at $-196{ }^{\circ} \mathrm{C}$ while the heating of the first trap was continued in order to remove excess $\mathrm{BrF}_{3}$. Final traces of $\mathrm{BrF}_{3}$ were removed from the heated lime - green product under a dynamic vacuum. The trap containing the product was sealed off under vacuum using a gas/oxygen flame. $\mathrm{X}$ - Ray powder photographs were indexed on the basis of the orthorhombic cell given by Muiller for ${ }^{18} \mathrm{Pd}\left(\mathrm{AuF}_{4}\right)_{2}$. Although the $\mathrm{X}$ - ray powder pattern for this material exhibited some similarities to that for $\mathrm{Ag}_{3} \mathrm{~F}_{8}$ the structures are evidently not closely related.

Magnetic Susceptibility of $\mathrm{Agg}_{3}$. A sample of $\mathrm{Ag}_{3} \mathrm{~F}_{8}$ (181 $\mathrm{mg} 0.380 \mathrm{mmole}$ ), prepared by route (a), was encapsulated in a Kel-F capsule previously passivated with $\mathrm{F}_{2}$ and $\mathrm{AsF}_{5}$. Magnetic susceptibility measurements made, at both 5 and 40 kGauss, over the temperature range 6 to $280^{\circ} \mathrm{K}$, obeyed the Curie-Weiss law, with a Weiss Constant $\theta=-4.2(5)^{\circ}$, the susceptibility being field independent. The data are shown in Fig. 5.2. The effective magnetic moment $\mu_{\mathrm{eff}}=1.924(3)$ B.M. 


\section{Results and Discussion}

Bright red, diamagnetic $\mathrm{AgF}_{3}$ has now been obtained via fluoride ion capture from tetrafluoroargentate salts according to the equation

$$
\mathrm{AgF}_{4}^{-}+\mathrm{A} \stackrel{\mathrm{AHF}}{\longrightarrow} \mathrm{AgF}_{3}+\mathrm{AF}^{-}
$$

where $\mathrm{A}=\mathrm{AsF}_{5}, \mathrm{BF}_{3}$

The material is thermodymically unstable at room temperature and loses fluorine according to the equation

$$
3 \mathrm{AgF}_{3} \stackrel{\mathrm{AHF}}{\longrightarrow} \mathrm{Ag}_{3} \mathrm{~F}_{8}+1 / 2 \mathrm{~F}_{2}
$$

This decomposition in AHF, occurs quantitatively in less than $24 \mathrm{~h}$, but dry samples of $\mathrm{AgF}_{3}$ exhibit considerable kinetic stability, no noticeable decomposit on occuring over several months in the DRIL.AB, nor over several hours of intense synchrotron $X$ - Ray radiation. The decomposition product, $\mathrm{Ag}_{3} \mathrm{~F}_{8}$, is a red - brown solid which gives an $\mathrm{X}$ Ray powder pattern identical to that obtained for the material described by Bougon as $\mathrm{AgF}_{3}$.

The ability of $\mathrm{BF}_{3}$ to carry out reaction (1) suggests that $\mathrm{AgF}_{3}$, like other transition metal trifluorides, is a relatively weak Lewis acid, particularly when compared with the pentafluorides and tetrafluorides. Žemva et al. ${ }^{8}$, however, have observed an equilibrium in reaction (1) when $\mathrm{PF}_{5}$ is used in conjunction with $\mathrm{XeF}_{5}{ }^{+} \mathrm{AgF}_{4}{ }^{-}$

$$
\mathrm{XeF}_{5}+\mathrm{AgF}_{4}^{-}+\mathrm{PF}_{5} \stackrel{\mathrm{AHF}}{\longrightarrow} \mathrm{AgF}_{3}+\mathrm{XeF}_{5}+\mathrm{PF}_{6}^{-}
$$


which only favors $\mathrm{AgF}_{3}$ production in the presence of an overpressure of $\mathrm{PF}_{5}$. Thus $\mathrm{AgF}_{3}$ must be comparable with $\mathrm{PF}_{5}$ in acidity and must be a significantly stronger acid than $\mathrm{AuF}_{3}$ which can be produced merely by the solvolysis of $\mathrm{XeF}_{5}+\mathrm{AuF}_{4}^{-}$in the weaker acid AHF:

$$
\mathrm{XeF}_{5}+\mathrm{AuF}_{4}^{-}+\mathrm{yHF} \longrightarrow \mathrm{XeF}_{5}+\mathrm{F}(\mathrm{HF})_{\mathrm{y}^{-}}+\mathrm{AuF}_{3} \downarrow
$$

Curiously, $\mathrm{AgF}_{3}$ also appears to behave as a stronger base than $\mathrm{AuF}_{3}$. This is suggested by the remarkable reduction of $\mathrm{AgF}_{3}$ by strong Lewis acids, including $\mathrm{AsF}_{5}$, which is itself a powerful oxidizer

$$
\mathrm{AgF}_{3}+\mathrm{AsF}_{5} \stackrel{\mathrm{AHF}}{\longrightarrow} \mathrm{AgF}^{+} \mathrm{AsF}_{6}^{-}+1 / 2 \mathrm{~F}_{2}
$$

A plausable mechanism for reaction (5) involves $\mathrm{F}^{-}$capture from $\mathrm{AgF}_{3}$ by $\mathrm{AsF}_{5}$ to form $\mathrm{AgF}_{2}{ }^{+} \mathrm{AsF}_{6}$. Such a reaction would place the $\mathrm{Ag}(\mathrm{III})$ in a cation. The electronegativity of $\mathrm{Ag}(\mathrm{III})$ in such a cation must be extremely high; so high, that it undergoes reductive elimination of fluorine to form the cationic $\mathrm{Ag}(\mathrm{II})$ salt, $\mathrm{AgF}^{+} \mathrm{AsF}_{6}{ }^{-}$, which is itself, a powerful oxidizer (Chapter 7). There is some indication that $\mathrm{AuF}_{3}$ reacts with very strong Lewis acids, however such reactions are very slow and have proven difficult to characterize. It is possible that the difference in reactivity of these trifluorides with strong acids is not a function of the basicity of the materials, but is due to the rapid decomposition, in acid solution, of any $\mathrm{Ag}$ (III) cation formed to very soluble cationic $\mathrm{Ag}$ (II) in AHF, from which $\mathrm{Ag}$ (III) cannot be regenerated. An Au(III) cation is certain to be much more stable with respect to fluorine elimination than the $\mathrm{Ag}$ (III) cation. No such decomposition has been observed for $\mathrm{AuF}_{3} .19$

$\mathrm{X}$ - Ray powder photographs of $\mathrm{AgF}_{3}$ obtained from reaction (1) indicated that 
authentic $\mathrm{AgF}_{3}$ was indeed isomorphous with $\mathrm{AuF}_{3}$, the data being completely indexable on the basis of a hexagonal $\mathrm{AuF}_{3}$ type cell . The subsequent structure determination of $\mathrm{AgF}_{3}$ and redetermination of $\mathrm{AuF}_{3}$ from neutron powder data confirmed that the two trifluorides have essentially the same structure Fig. 5.3. The structure consists of roughly square planer units which are joined by cis related $F$ ligands to make helical chains of $6_{1}$ symmetry, the unit cell containing $6 \mathrm{MF}_{3}$ formula units. The comparable interatomic distances (Table 5.6) within the $\mathrm{MF}_{4}$ unit are not significantly different in the trifluorides. Similarly, the $M$ - F - M bridges are significantly bent to $\approx 120^{\circ}$, the angle in $\mathrm{AgF}_{3}$ being slightly larger than that in $\mathrm{AuF}_{3}$. The absence of any $\pi$ bonding interaction (the antibonding $\pi$ orbitals are completely filled) coupled with the near removal of the axial $F$ ligands which allows for close approach of the canted $\mathrm{MF}_{4}$ units, accounts for the very small bridging angle.

Table 5.6. Selected distances $(\AA)$ and angles (Deg.) for $\mathrm{AgF}_{3}$ and $\mathrm{AuF}_{3}$

$\begin{array}{lcclcc} & \mathrm{Ag} & \mathrm{Au} & & \mathrm{Ag} & \mathrm{Au} \\ \mathrm{A}(1)-\mathrm{F}(1) \times 2 & 2.000(6) & 2.04(3) & \mathrm{F}(1)-\mathrm{A}(1)-\mathrm{F}(1) & 88.5(5) & 88(2) \\ \mathrm{A}(1)-\mathrm{F}(2) \times 2 & 1.883(8) & 1.91(4) & \mathrm{F}(1)-\mathrm{A}(1)-\mathrm{F}(2) \times 2 & 90.8(3) & 90(2) \\ \mathrm{A}(1)-\mathrm{F}(2) \times 2 & 2.526(8) & 2.69(4) & \mathrm{F}(1)-\mathrm{A}(1)-\mathrm{F}(2) \times 2 & 179.21(1) & 178(2) \\ & & & \mathrm{F}(2)-\mathrm{A}(1)-\mathrm{F}(2) & 89.9(5) & 92(2) \\ \mathrm{A}(1)-\mathrm{F}(1)-\mathrm{A}(1) & 121.8(6) & 116(3) & \mathrm{A}(1)-\mathrm{F}(2)-\mathrm{A}(1) & 139.7(5) & 148(3)\end{array}$

The most remarkable difference in the two structures involves the weak linkages of adjacent helical chains. Unique $\mathrm{F}$ ligands of a chain are nearly normal to $\mathrm{MF}_{4}$ planes of adjacent chains and serve to complete the grossly distorted octahedral arrangement of $F$ ligands about each metal, Fig. 5.4. In $\mathrm{AgF}_{3}$ this interatomic distance, termed $\mathrm{M}-\mathrm{F}_{\mathrm{axia}}$, is $2.540(4) \AA$. This is significantly shorter than for the comparable weak bonding in $\mathrm{AuF}_{3}$ 
where $A u-F_{a x i a l}=2.761(3) \AA$. The closer approach of chains might be expected to hinder the approach of $\mathrm{MF}_{4}$ units, and thus increase the $\mathrm{M}-\mathrm{F}-\mathrm{M}$ bridge angle in $\mathrm{AgF}_{3}$.

The shorter $\mathrm{M}-\mathrm{F}_{\text {axial }}$ bonds in $\mathrm{AgF}_{3}$ and the reduction of its formula unit volume with respect to $\mathrm{AuF}_{3}$ indicate much tighter binding of the remaining valence electrons in the $\mathrm{Ag}(\mathrm{III})$ compound. A comparison of formula unit volumes of $\mathrm{Ag}$ (III) and $\mathrm{Au}(\mathrm{III})$ compounds in Table 5.7 indicates smaller volumes for $\mathrm{Ag}$ (III) compounds in general. The difference is a constant $5 \AA^{3}$ in the fluorides. These differences are in contrast to the effective volumes of $\mathrm{Ag}$ and $\mathrm{Au}$ atoms in the metallic elements, which are $17.05 \AA^{3}$ and $16.97 \AA^{3}$ respectively, 20 and nicely illustrate the impact of relativistic effects on gold. These effects result in significant stabilization and contraction of all s orbitals in Au with respect to the s orbitals in $\mathrm{Ag}$, thus metallic $\mathrm{Au}$ is observed to be smaller than metallic $\mathrm{Ag}$ since the binding in the metal is primarily of s orbital character. The relativistic contraction of the s orbitals and to a lesser extent, the p orbitals, provides greater shielding for the $d$ and $\mathrm{f}$ orbitals, thereby having the secondary effect of enhancing the size increase of the $\mathrm{Au}$ $5 \mathrm{~d}$ orbitals over the $4 \mathrm{~d}$ orbitals of $\mathrm{Ag} .{ }^{21}$ In the $\mathrm{Ag}(\mathrm{III}) / \mathrm{Au}$ (III) compounds the valence shell s electrons have been removed, so that it is this latter effect which is observed. The $4_{\mathrm{z}} \mathrm{z}^{2}$ electron pair in $\mathrm{Ag}(\mathrm{III})$ is much more contracted and hence much more tightly bound than in $\mathrm{Au}(\mathrm{III})$. These electrons are expected to be much more difficult to involve in bonding than the $5 \mathrm{~d}_{\mathrm{z}}{ }^{2}$ electrons of $\mathrm{Au}(\mathrm{III})$ and in fact the most potent oxidative fluorinators known do not react with $\mathrm{Ag}(\mathrm{III})$, while they readily generate $\mathrm{Au}(\mathrm{V})$ complexes. The greater acidity observed above for $\mathrm{AgF}_{3}$ can be accounted for along these lines as well. The vacant LUMO available for donation by a Lewis base, $\mathrm{F}^{-}$, in these trifluorides is the $d_{x} 2-y 2$ orbital. The $4 d_{x}{ }^{2}-y^{2}$ orbital in $A g F_{3}$ is significantly contracted and hence of relatively lower energy, than the $5 d_{x^{2}}-y^{2}$ orbital of $A_{u F}$. 
Table 5.7. Comparison of Formula Unit Volumes $\left(\AA^{3}\right)$ of $\mathrm{Ag}(\mathrm{III})$ and $\mathrm{Au}(\mathrm{III})$ Compounds

$\begin{array}{ccccc}\mathrm{A} & \mathrm{XeF}_{5} \mathrm{AF}_{4} & \mathrm{KAF}_{4} & \mathrm{AF}_{3} & \mathrm{AO}_{3 / 2} \\ \mathrm{Ag} & 159.4^{\mathrm{a}} & 97.0^{\mathrm{b}} & 57.4^{\mathrm{c}} & 61.9^{\mathrm{e}} \\ \mathrm{Au} & 164.5^{\mathrm{a}} & 102.1^{\mathrm{b}} & 62.2^{\mathrm{d}} & 64.7^{\mathrm{f}}\end{array}$

ref. $a=7 ; b=5 ; c=$ this work, $d=14 ; e=22 ; f=23$

The final structural determination of $\mathrm{AgF}_{3}$ was carried out using samples prepared with $\mathrm{BF}_{3}$ because it was found that samples prepared with $\mathrm{AsF}_{5}$ always contained small amounts of an insoluble paramagnetic impurity. It was believed that this material was associated with the reduction of $\mathrm{AgF}_{3}$ to $\mathrm{Ag}(\mathrm{II})$ by $\mathrm{AsF}_{5}$, since small amounts of blue material indicative of cationic $\mathrm{Ag}(\mathrm{II})$ were observed, which subsequently disappeared when excess $\mathrm{AgF}_{4}^{-}$was present. In a separate experiment, shown in reaction (6), which was designed to mimic these conditions

$$
2 \mathrm{KAgF}_{4}+\mathrm{AgFAsF}_{6}+\mathrm{BF}_{3} \stackrel{\mathrm{AHF}}{\longrightarrow} \mathrm{Ag}(\mathrm{II}) \mathrm{Ag}^{(\mathrm{III})}{ }_{2} \mathrm{~F}_{8}+\mathrm{KAsF}_{6}+\mathrm{KBF}_{4} \text { (6) }
$$

two equivalents of $\mathrm{KAgF}_{4}$ were reacted with one equivalent of cationic $\mathrm{Ag}(\mathrm{II})$ in the form

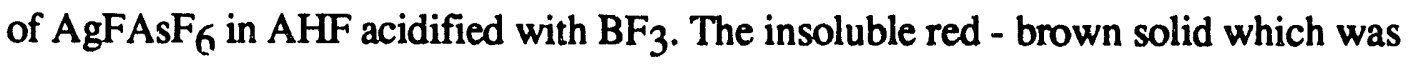
produced gave an X-Ray powder pattern which was identical to those obtained for the material described by Bougon as $\mathrm{AgF}_{3}$. It was also identical with the $\mathrm{Ag}_{3} \mathrm{~F}_{8}$ decomposition product obtained by reductive elimination of fluorine from authencic $\mathrm{AgF}_{3}$ in AHF. This material could also be obtained from a 1:2 mixture of $\mathrm{AgF}_{2} / \mathrm{AgF}_{3}$ in $\mathrm{AHF}$ according to the overall reaction: 


$$
\mathrm{AgF}_{2}+2 \mathrm{AgF}_{3} \stackrel{\mathrm{AHF}}{\longrightarrow} \mathrm{Ag}_{3} \mathrm{~F}_{8}
$$

Interestingly a 1:1 mixture of $\mathrm{AgF}_{2}: \mathrm{AgF}_{3}$ failed to give the $1: 1 \mathrm{acid} / \mathrm{base}$ adduct $\mathrm{AgF}^{+} \mathrm{AgF}_{4}^{-}$analogous to $\mathrm{AgF}^{+} \mathrm{AsF}_{6}^{-}$:

$$
2 \mathrm{AgF}_{2}+2 \mathrm{AgF}_{3} \stackrel{\mathrm{AHF}}{\longrightarrow} \mathrm{AgF}_{2}+\mathrm{Ag}_{3} \mathrm{~F}_{8}
$$

The 1:1 adduct, $\mathrm{Ag}^{\mathrm{II}} \mathrm{Ag}^{\mathrm{III}_{\mathrm{F}}}$ was obtained from $\mathrm{AgFAsF}_{6}$ and $\mathrm{KAgF}_{4}$ in $\mathrm{AHF}$ via

$$
\mathrm{AgF}^{+} \mathrm{AsF}_{6}^{-}+\mathrm{KAgF}_{4} \stackrel{\mathrm{AHF}}{\longrightarrow} \mathrm{AgII}^{\mathrm{Ag} \mathrm{III}_{\mathrm{F}}}+\mathrm{KAsF}_{6}
$$

It appears that this salt, $\mathrm{AgF}^{+} \mathrm{AgF}_{4}^{-}$, is thermodynamically unstable with respect to $\mathrm{AgF}_{2}$ and $\mathrm{Ag}_{3} \mathrm{~F}_{8}$.

The ability of $\mathrm{AgF}_{2}$ to act as a pseudo alkaline earth fluorobase, combined with the relatively good Lewis acidity of $\mathrm{AgF}_{3}$ suggest a composition of $\mathrm{AgII}_{(\mathrm{Ag}} \mathrm{III}_{\left.\mathrm{F}_{4}\right)_{2}}$ for $\mathrm{Ag}_{3} \mathrm{~F}_{8}$. The similarity in $\mathrm{X}$ - Ray powder data of this phase and $\mathrm{Pd}^{\mathrm{II}}\left(\mathrm{Au}^{\mathrm{III}_{2}}\right)_{2}$, for which the structure is known also supports such a composition. More convincing, however, is the magnetic data. As expected $\mathrm{Ag}_{3} \mathrm{~F}_{8}$ is paramagnetic. Moreover the variable temperature magnetic susceptibility data shown in Fig. 3 indicate that the material is a simple paramagnet, obeying the Curie law. The small Weiss constant, $\theta=-4.2(5)^{\circ}$, indicates that the material is magnetically dilute and supports a composition of a single paramagnetic $\mathrm{d}^{9} \mathrm{Ag}$ (II) cation well separated from other $\mathrm{Ag}$ (II) cations by two diamagnetic $\mathrm{AgF}_{4}{ }^{-}$anions as in $\mathrm{Ag}\left(\mathrm{AgF}_{4}\right)_{2}$. The observed magnetic moment of $1.95(8) \mu$ $\beta$ is identical to that reported by Bougon when " $\mathrm{AgF}_{3}$ " is adjusted to the $\mathrm{Ag}_{3} \mathrm{~F}_{8}$ formula. The identical X-Ray and magnetic data prove that $\mathrm{AgF}_{3}$ as described by Bougon et al. is in fact the lower fluoride $\mathrm{Ag}_{3} \mathrm{~F}_{8}$. 


\section{Conclusions}

The synthesis of high purity $\mathrm{AgF}_{3}$ by fluoride ion capture from the anion demonstrates the primary utility of the Lewis acid displacement of binary fluorides, namely the synthesis of thermally unstable, high oxidation state systems. Because $\mathrm{AgF}_{3}$ is thermally unstable at mom temperature or any temperature sufficiently high to activate the known oxidative fluorinators, it cannot be synthesized by oxidation of a lower fluoride. However, by obtaining the high oxidation state first as the more stable fluoroanion, in this case $\mathrm{AgF}_{4}^{-}$, heretofore inaccessible oxidation states in neutral systems can be obtained.

As expected authentic $\mathrm{AgF}_{3}$ is isostructural with $\mathrm{AuF}_{3}$. A comparison of structural data on these as well as other $\mathrm{Ag}(\mathrm{III}) / \mathrm{Au}(\mathrm{III})$ suggest the impact of relativistic effects on gold, which in turn help to explain the abundance of $\mathrm{Au}(\mathrm{V})$ chemistry in the absence of any such chemistry for silver.

The existence of two mixed valence silver fluorides has been demonstrated, with 1:1 and 1:2 $\mathrm{Ag}(\mathrm{II}): \mathrm{Ag}(\mathrm{III})$ ratios. The 1:2 compound, $\mathrm{Ag}_{3} \mathrm{~F}_{8}$, is identical to that described previously by Bougon et al as $\mathrm{AgF}_{3}$.

\section{References}

1. Müller, B.G. Angew. Chem. Int. Ed. Eng. 1987, 26, 1081.

2. Bartlett, N.; Leary, K. Rev. Chim. Minér.1976, 13, 82.

3. Edwards, A.J.; Falconer, W.E.; Griffith, J.E.; Sunder, W.A.; Vasile, M.J. J.Chem. Soc. Dalton Trans. 1974, 1129.

4. Hoppe, R., Z. Anorg. Chem. 1957, $292,28$.

5.Hoppe, R.; Homann, R., Naturwissenschaften 1966, 53, 501.

6. Hoppe, R.; Homann, R., Z. Anorg. Chem. 1970, 379, 193. 
7. Sorbe, P.; Grannec, J.; Portier, J.; Hagenmuller, P. C.R. Hebd. Séances Acad. Sci. Ser. C282 1976, 663.

8. Lutar, K.; Jesih, A.; Leban, I.; Žemva, B., and Bartlett, N., Inorg. Chem. 1989, 28 , 3467.

9. Bougon, R.; Lance, M., Comptes Rendus, Acad. Sci., Ser. 2 1983, 297, 117.

10. Bougon, R.; Bai Huy, T.; Lance, M.; Abazli, H., Inorg. Chem. 1984, 23, 3667.

11.Kiselev, Yu M.; Popov, A. I.; Timakov, A.A.; Bukharin, K.V.; Sukhoverkhov, V.F., Zhurnal Neorganicheskoi Khimii, 1988, 33, 1252.

12. Einstein, F.W.B.; Rao, P.R.; Trotter, J.; and Bartlett, N., L.Chem.Soc. (A), 1967, 478.

13. R.P. Rao, Ph.D. Thesis, University of British Columbia, 1965.

14. Gruner, E.; Klemm, W. Naturwissenschaften 1937, 25, 59.

15. Žemva, B.; Lutar, K.; Jesih, A.; Casteel, Jr., W.J.; Wilkinson, A.P.; Cox, D.E.; Von Dreele, R.B.; Bormann, H.; Bartlett, N. J. Am. Chem. Soc. 1991, 113, 4192.

16. Larson, A.C.; Von Dreele, R.B. Los Alamos Laboratory Report No. LA - UR - 86 - 748, 1987.

17. Gantar, D.; Frlec, B.; Russell, D.R.; Holloway, J.H. Acta Crystallogr. 1987, C43, 618 .

18. Müller, B.G. Z. Anorg. Allg. Chem. 1987, 555, 57.

19. K. Leary, Ph.D. Thesis, University of California, Berkeley, .

20. R.W.G. Wyckoff, "Crystal Structures", Interscience Publishers, London/Sydney, 1963, Vol. 1.

21. Pitzer, K., Accounts of Chemical Research 1982, 12, 271.

Pyykko, P.; and Desclaux, J.P.; Accounts of Chemical Research 1982, 12, 276.

22. Standke, B.; Jansen, M. Z. anorg. allg. Chem. 1986, 535, 39.

23. Jones, P. G.; Rumpel, H.; Schwarzmann, E.; Sheldrick, G. M. Acta. Crystallogr. 1979, B35, 1435. 

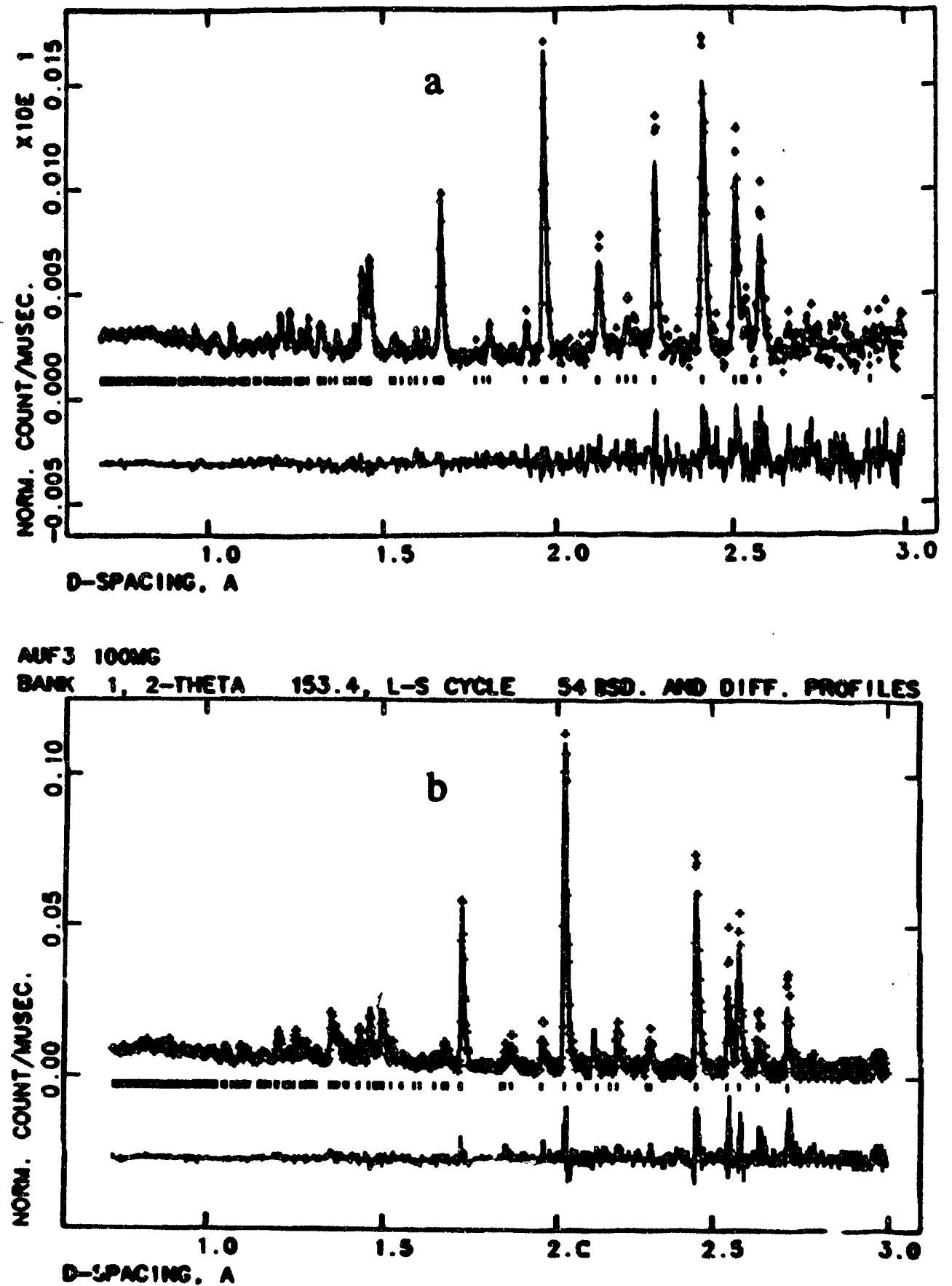

Figure 5.1. Portions of the fitted neutron time - of - flight powder diffraction patterns for data taken on the $+153^{\circ} 2 \theta$ bank on HIPD for (a) $\mathrm{AgF}_{3}$ and (b) $\mathrm{AuF}_{3}$. The observed values are shown as $(+)$ and the calculated values from the best fit are shown as a curve. A difference $\left(\mathrm{I}_{\mathrm{obs}}-\mathrm{I}_{\mathrm{Calc}}\right)$ curve and the reflection positions are also shown. All intensity values are normalized by a previously measured incident spectrum. 


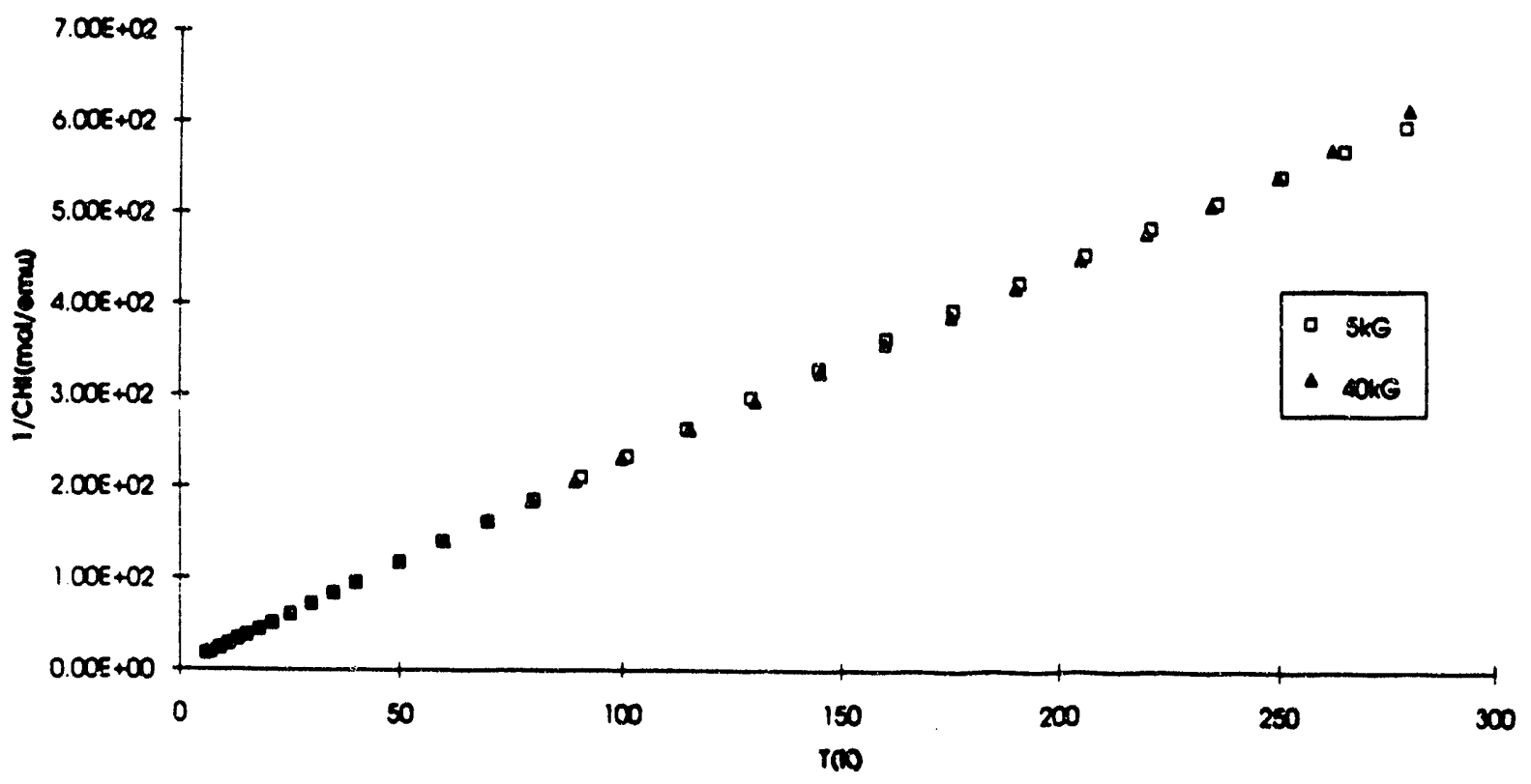

Figure 5.2. Curie - Weiss plot for $\mathrm{Ag}_{3} \mathrm{~F}_{8}$ : 


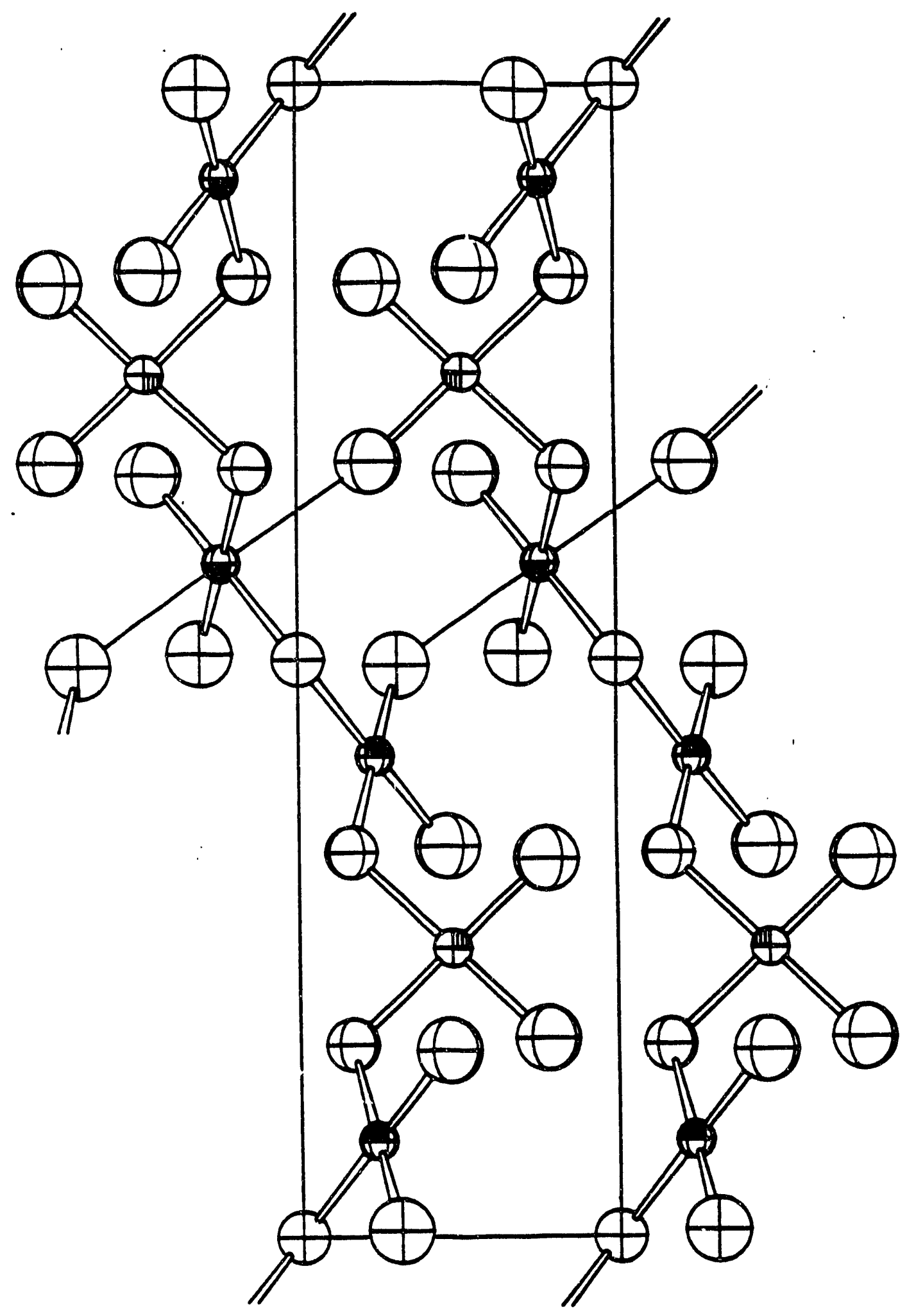

Figure 5.3. View down $a$ showing unit cell contents and the $F(2)$ interchain bridging in $\mathrm{AgF}_{3}$ and $\mathrm{AuF}_{3}$. 


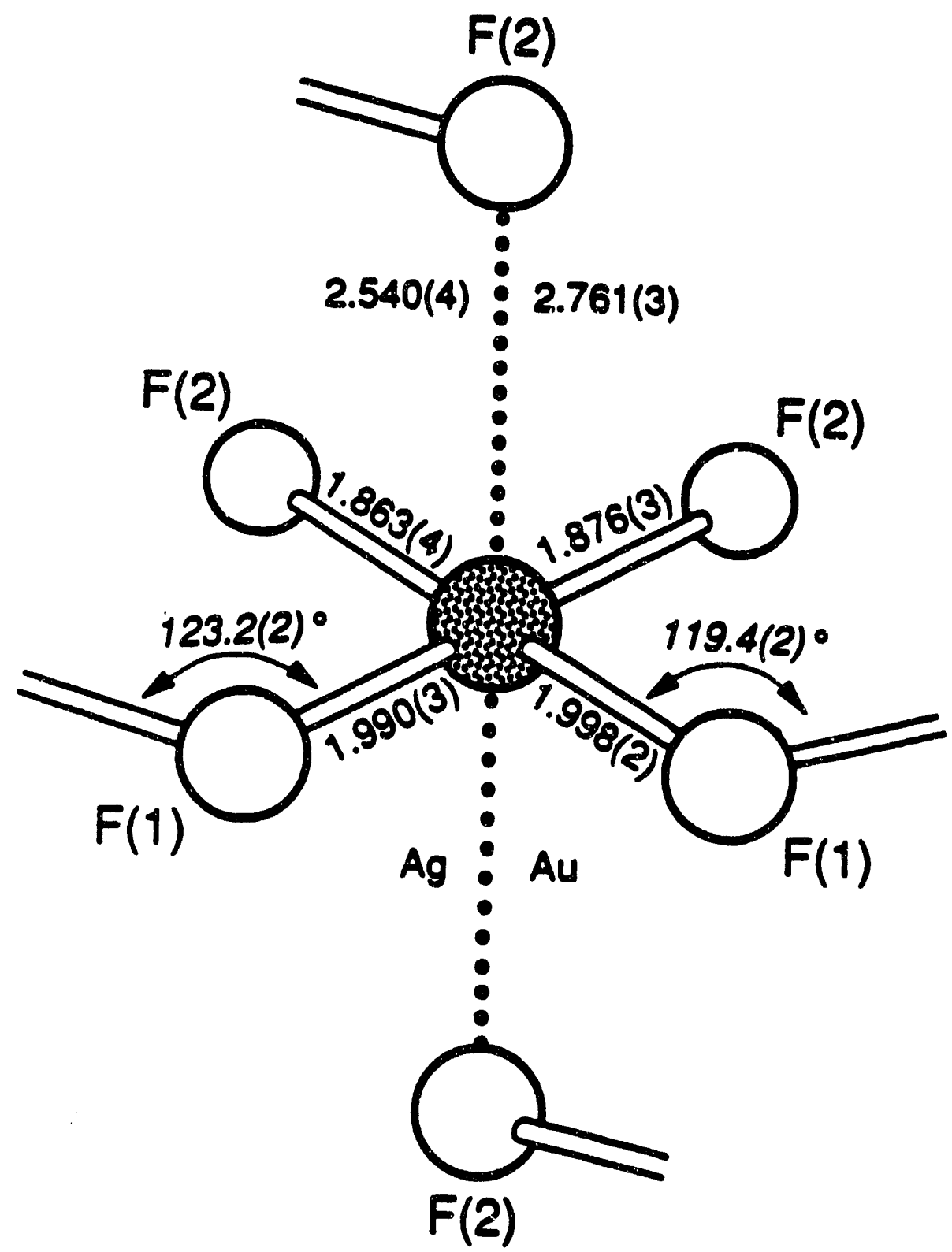

Figure 5.4. Interatomic distances $(\AA)$ for the elongated octahedral $F$ ligand arrangement about the metal atom in $\mathrm{AgF}_{3}$ and $\mathrm{AuF}_{3}$ (estimated standard deviations in parenthesis) 


\section{Chapter 6}

\section{The Synthesis, Structural Characterization, and Magnetic Properties of $\mathrm{AgF}^{+}$Salts}

\section{Introduction}

The fluorine chemistry of silver is remarkably diverse, involving the metal in oxidation states ranging, from $+1 / 2$ in $\mathrm{Ag}_{2} \mathrm{~F}$ to +3 in the thermally unstable trifluoride. Even $\mathrm{Ag}(\mathrm{V})$ has been claimed to exist under extraordinary conditions. ${ }^{1} \mathrm{Ag}(\mathrm{I})$ fluoride is readily prepared in high purity and is a sufficiently strong base to form a bifluoride, $\mathrm{AgHF}_{2}$, akin to those of the alkali - matels. In contrast $\mathrm{Cu}(\mathrm{I})$ fluoride and $\mathrm{Au}(\mathrm{I})$ fluoride are not known. The difluoride of silver, is a true $\mathrm{Ag}(\mathrm{II})$ material, the $\mathrm{d}^{9}$ species being antiferromagnetically coupled. A canting of the spins in the puckered sheet structure of $\mathrm{AgF}_{2}$ however, results in an observed ferromagnetism. This contrasts with the oxide "AgO" which is the mixed oxidation state material, $\mathrm{Ag}^{\mathrm{I}} \mathrm{AgIII}_{2}$ in the oxide. ${ }^{2}$ Indeed, there is yet no structural evidence for any mixed valence $\mathrm{Ag}(\mathrm{I}) / \mathrm{Ag}(\mathrm{III})$ fluoride.

In recent years, with the improved techniques for handling $\mathrm{AHF}, \mathrm{AgF}_{2}$ has been shown to behave as a fluorobase, exhibiting some similarity to the alkaline - earth fluorides in combination with strong Lewis acids. Two compounds, $\mathrm{Ag}\left(\mathrm{SbF}_{6}\right)_{2}{ }^{4}$ and $\mathrm{Ag}\left(\mathrm{TaF}_{6}\right)_{2}, 5$ have been synthesized and structurally characterized prior to this work which contain isolated $\mathrm{Ag}(\mathrm{II})$ cations. A third cationic $\mathrm{Ag}(\mathrm{II})$ compound, $\mathrm{AgF}^{+} \mathrm{AsF}_{6}{ }^{-}$, had also been prepared from $\mathrm{AsF}_{5}$ and $\mathrm{AgF}_{2}$ and the structure showed 6 that it contained $\mathrm{Ag}(\mathrm{II})$ as the endless chain cation $(\mathrm{AgF})_{\mathrm{n}}{ }^{\mathrm{n}+}$. The $\mathrm{Ag}\left(\mathrm{MF}_{6}\right)_{2}$ compounds were reported to be paramagnetic, but little else was known about the physical properties of the cationic Ag(II) materials.

The finding that $\mathrm{AsF}_{5}$ interacts with $\mathrm{AgF}_{3}$ to produce $\mathrm{AgFAsF}_{6}$ also led to its identification as a powerful oxidizer (see Chapter 7). This prompted a further investigation 
of this $\mathbf{A g}(\mathrm{II})$ salt, including its structure and magnetic properties, and a systematic effort to generate additional $\mathrm{AgF}^{+}$salts. In chapter $5, \mathrm{AgFAsF}_{6}$ was used as a reagent in the synthesis of the first mixed valence $\mathrm{Ag}(\mathrm{II}) / \mathrm{Ag}(\mathrm{III})$ compounds, $\mathrm{Ag}_{2} \mathrm{~F}_{5}$ and $\mathrm{Ag}_{3} \mathrm{~F}_{8}$. The fair solubility of $\mathrm{AgFAsF}_{6}$ suggested that it could be useful in the synthesis of other cationic $\mathrm{Ag}(\mathrm{II})$ salts. It has subsequently been used to synthesize a variety of $\mathrm{AgF}^{+}$salts. The relatively weak Lewis acids $\mathrm{BF}_{3}, \mathrm{AgF}_{3}$ and $\mathrm{AuF}_{3}$ have all proved to be capable of stabilizing the chain cation, $(\mathrm{Ag}-\mathrm{F})_{n}{ }^{\mathrm{n}+}$. Remarkably, $\mathrm{AgF}_{3}$ and $\mathrm{AuF}_{3}$ even stabilize 1:2 compounds $\mathrm{Ag}\left(\mathrm{MF}_{4}\right)_{2}$, the simple Curie paramagnetism of which indicate that they are $\mathrm{Ag}^{2+}$ salts.

\section{Experimental.}

Materials. Commercial AgF (Ozark - Mahoning - Pennwalt, Tulsa, OK) was purified by recrystallization from $\mathrm{AHF}$. AgSbF 6 (Aldrich, Milwaukee, WI) was recrystallized from AHF, a final purity check being made by $X$-Ray powder photography before use. ${ }^{7}$ AgBF $_{4}$ was prepared by addition of excess $\mathrm{BF}_{3}$ to a solution of $\mathrm{AgF}$ in $\mathrm{AHF} . \mathrm{KAuF}_{4}{ }^{8}, \mathrm{KAuF}_{6}{ }^{9}$, $\mathrm{O}_{2} \mathrm{AuF}_{6}{ }^{9}$, and $\mathrm{AgF}_{2}{ }^{10}$ were prepared by literature methods. $\mathrm{Ag}\left(\mathrm{SbF}_{6}\right)_{2}$ was prepared by the method of Ganter et al. ${ }^{4}, F_{2}$ being added to insure complete oxidation of $\mathrm{Ag}(\mathrm{I})$.

Preparation of $\mathrm{AgFBF}_{4}$. In the DRILAB a one armed Teflon/FEP reactor was loaded with $1.37 \mathrm{mmol} \mathrm{AgF}$. The reactor was evacuated and charged with $5 \mathrm{ml}$ AHF. The solution was treated with $\mathrm{BF}_{3}$ and immediately a copious white precipitate of $\mathrm{AgBF}_{4}$ formed. The pressure of $\mathrm{BF}_{3}$ was maintained above 1300 Torr until no further uptake was observed. On addition of $F_{2}$, to a total pressure of $2 \mathrm{~atm}$, an immediate blue coloration of the sediment occured. The $F_{2}$ pressure was maintained near 2 atm until after $3 \mathrm{hr}$ gas uptake was no longer observed. A deep blue precipitate remained in a pale blue supernatant 
solution. Removal of volatile materials under vacuum through a soda - lime scrubber left $0.270 \mathrm{~g}$ ( $1.30 \mathrm{mmol})$ of deep blue solid for a 93\% yield based on $\mathrm{AgFBF}_{4}$. X - Ray powder data for $\mathrm{AgFBF}_{4}$ were indexable on the basis of a tetragonal unit cell and are given in Table 6.1.

Preparation of $\mathrm{AgFBF}_{4}$ from $\mathrm{AgF}_{2}$ and $\mathrm{BF}_{3}$. In the DRILAB $2.03 \mathrm{mmol} \mathrm{AgF}_{2}$ was loaded into a one armed Teflon/FEP reactor. The reactor was charged with $5 \mathrm{ml}$ AHF and 2atm $\mathrm{BF}_{3}$ were admitted at room temperature. Over $30 \mathrm{~min}$ with intermittant agitation, there was no observable reaction, or $\mathrm{BF}_{3}$ uptake. The reactor was cooled to near the freezing point of $\mathrm{AHF}\left(\approx-80^{\circ} \mathrm{C}\right)$ and allowed to warm slowly to room temperature to facilitate the uptake of $\mathrm{BF}_{3}$. During warming, the $\mathrm{AgF}_{2}$ began to dissolve giving a royal blue solution and a blue green precipitate. Vigorous gas evolution was observed as the solution approached room temperature, but the final pressure indicated significant $\mathrm{BF}_{3}$ uptake. Thermal cycling of the reaction between $\approx-80^{\circ} \mathrm{C}$ and room temperature was repeated until $\mathrm{AgF}_{2}$ was no longer visible, a blue - green solid, in a pale blue supernatant remaining. Volatile materials were removed leaving a green - blue solid. X - Ray powder photographs of this solid indicated that it was largely $\mathrm{AgFBF}_{4}$, however, they also revealed the presence of $\mathrm{AgF}_{2}$.

Table 6.1. X - Ray Powder Data for $\mathrm{AgFBF}_{4}$ (CuK $\alpha$ Ni Filter) ${ }^{\mathrm{a}}$

$\begin{array}{cccc}\mathrm{I}_{\mathrm{o}} & 1 / \mathrm{d}^{2} \times 10^{4} \text { obsd } & 1 / \mathrm{d}^{2} \times 10^{4} \text { calcd } & h \mathrm{kl} \\ \mathrm{s} & 442 & 446 & 110 \\ \mathrm{~m} & 623 & 624 & 001 \\ \text { vs } & 845 & 847 & 101,011 \\ \text { vs } & 889 & 893 & 200,020 \\ --- & --- & 1070 & 111 \\ \text { w } & 1520 & 1517 & 201,021 \\ \text { s } & 1738 & 1740 & 211,121 \\ \text { m } & 1792 & 1786 & 220 \\ \text { vs } & 2239 & 2232 & 310,130 \\ \text { vvw } & 2427 & 2410 & 221 \\ \text { m } & 2506 & 2495 & 002\end{array}$


Table 6.1. cont.

\begin{tabular}{|c|c|c|c|}
\hline $\mathbf{I}_{\mathbf{n}}$ & $1 / d^{2} \times 10^{4}$ obsd & $1 / d^{2} \times 10^{4}$ calcd & $h k l$ \\
\hline s & 2637 & 2633 & 301,031 \\
\hline $\mathbf{m}$ & 2718 & 2718 & 102,012 \\
\hline $\mathbf{w}$ & 2871 & 2856 & 311,131 \\
\hline m & 2944 & 2941 & 112 \\
\hline m & 3393 & 3388 & 202,022 \\
\hline $\mathbf{s b}$ & 3532 & 3526 & 321,231 \\
\hline \multirow[t]{2}{*}{ wb } & 3604 & 3572 & 400,040 \\
\hline & & 3611 & 212,122 \\
\hline \multirow[t]{2}{*}{$\mathbf{w}$} & 4036 & 4018 & 330 \\
\hline & & 4195 & 401,041 \\
\hline $\mathbf{w}$ & 4304 & 4281 & 222 \\
\hline \multirow{2}{*}{$\mathrm{mb}$} & 4441 & 4419 & 141,411 \\
\hline & & 4465 & 420,240 \\
\hline $\mathbf{s}$ & 4730 & 4727 & 312,132 \\
\hline vvw & 5098 & 5088 & 421,241 \\
\hline $\mathbf{s}$ & 5399 & 5397 & 322,232 \\
\hline $\mathbf{v w}$ & 5613 & 5614 & 003 \\
\hline \multirow[t]{2}{*}{$\mathrm{mb}$} & 5822 & 5804 & 510,150 \\
\hline & & 5837 & 103,013 \\
\hline \multirow[t]{2}{*}{ m } & 6068 & 6060 & 113 \\
\hline & & 6067 & 402,042 \\
\hline \multirow[t]{2}{*}{$\mathbf{m}$} & 6221 & 6205 & 501,051 \\
\hline & & 6205 & 431,341 \\
\hline \multirow[t]{2}{*}{$\mathbf{w}$} & 6300 & 6290 & 412,142 \\
\hline & & 6427 & 511,151 \\
\hline \multirow[t]{2}{*}{$\mathrm{m}$} & 6522 & 6507 & 203,023 \\
\hline & & 6513 & 332 \\
\hline $\mathbf{w}$ & 6723 & 6730 & 213,123 \\
\hline \multirow[t]{2}{*}{$\mathrm{mb}$} & 6988 & 6960 & 422,242 \\
\hline & & 7079 & 521,251 \\
\hline $\mathrm{mb}$ & 7144 & 7143 & 440 \\
\hline$w b$ & 7411 & 7400 & 223 \\
\hline \multirow[t]{3}{*}{$\mathrm{mb}$} & 7615 & 7590 & 530,350 \\
\hline & & 7623 & 303,033 \\
\hline & & 7766 & 441 \\
\hline \multirow[t]{2}{*}{$\mathrm{mb}$} & 7847 & 7846 & 313,133 \\
\hline & & 8036 & 600,060 \\
\hline \multirow[t]{3}{*}{ wb } & 8077 & 8076 & 502,052 \\
\hline & & 8076 & 432,342 \\
\hline & & 8213 & 531,351 \\
\hline
\end{tabular}


Table 6.1. cont.

\begin{tabular}{|c|c|c|c|}
\hline$I_{0}$ & $1 / d^{2} \times 10^{4}$ obsd & $1 / d^{2} \times 10^{4}$ calcd & $h k l$ \\
\hline $\mathbf{w b}$ & 8317 & 8299 & 512,152 \\
\hline \multirow[t]{2}{*}{ vwb } & 8534 & 8516 & 323,233 \\
\hline & & 8659 & 601,061 \\
\hline m & 8891 & 8883 & 611,161 \\
\hline \multirow[t]{5}{*}{ m } & 8961 & 8929 & 620,260 \\
\hline & & 8969 & 522,252 \\
\hline & & 9184 & 403,043 \\
\hline & & 9408 & 413,143 \\
\hline & & 9552 & 621,261 \\
\hline \multirow[t]{2}{*}{$\mathbf{w}$} & 9654 & 9632 & 333 \\
\hline & & 9637 & 442 \\
\hline \multirow[t]{2}{*}{$\mathbf{w}$} & 9794 & 9776 & 541,451 \\
\hline & & 9979 & 004 \\
\hline \multirow[t]{2}{*}{$\mathbf{w}$} & 10110 & 10078 & 423,243 \\
\hline & & 10085 & 532,352 \\
\hline \multirow[t]{4}{*}{$\mathrm{m}$} & 10202 & 10203 & 104,014 \\
\hline & & 10425 & 114 \\
\hline & & 10530 & 602,062 \\
\hline & & 10668 & 631,361 \\
\hline \multirow[t]{2}{*}{$\mathbf{w}$} & 107471 & 10755 & 612,162 \\
\hline & & 10871 & 204,024 \\
\hline m & 11089 & 11096 & 214,124 \\
\hline \multirow[t]{7}{*}{$\mathrm{m}$} & 11144 & 11162 & 710,170 \\
\hline & & 11162 & 550 \\
\hline & & 11193 & 503,053 \\
\hline & & 11193 & 433,343 \\
\hline & & 11416 & 513,153 \\
\hline & & 11423 & 622,262 \\
\hline & & 11561 & 701,071 \\
\hline \multirow[t]{5}{*}{ mvb } & 11632 & 11608 & 640,460 \\
\hline & & 11648 & 542,452 \\
\hline & & 11764 & 224 \\
\hline & & 11784 & 711,171 \\
\hline & & 11784 & 551 \\
\hline \multirow[t]{5}{*}{ m } & $11995 \alpha_{1}$ & 11989 & 304,034 \\
\hline & $11984 \alpha_{2}$ & 11989 & \\
\hline & & 12086 & 523,253 \\
\hline & & 12211 & 314,134 \\
\hline & & 12231 & 641,461 \\
\hline $\mathbf{w}$ & $12508 \alpha_{1}$ & 12455 & 721,271 \\
\hline
\end{tabular}


Table 6.1 cont.

$\begin{array}{cccc}\mathrm{I} / \mathrm{I}_{\mathrm{O}} & 1 / \mathrm{d}^{2} \times 10^{4} \text { obsd } & 1 / \mathrm{d}^{2} \times 10^{4} \mathrm{calcd} & h k l \\ & 12503 \alpha_{2} & 12540 & 632,362 \\ \mathrm{~m} & 12902 \alpha_{1} & 12756 & 443 \\ & 12913 \alpha_{2} & 12882 & 324,234 \\ & & & \\ \mathrm{w} & 13207 \alpha_{1} & 12948 & 730,370 \\ & 13194 \alpha_{2} & 13204 & 533,353\end{array}$

$$
13194 \alpha_{2}
$$

a Tetragonal unit cell with $\left(20^{\circ} \mathrm{C}\right) \mathrm{a}_{0}=6.693(3) \AA ; c_{0}=4.004(3) \AA ; \mathrm{V}=179.4 \AA^{3}$; $\mathrm{Z}=2$; possible space group, $\mathrm{P} 4 / \mathrm{n}$.

\section{$\mathrm{AgFAsF}_{6}$ from fluorination of $\mathrm{AgAsF}_{6}$ in $\mathrm{AHF}$ with excess $\mathrm{AsF}_{5}$. (A) In the} DRILAB, (1301mg, 10.25mmol) AgF was loaded into a 1/2 in. O.D. FEP tube fitted with a teflon valve. AHF (6ml) was condensed under vacuum onto the $\mathrm{AgF}$ and this gave a colorless solution at room temperature. $\mathrm{AsF}_{5}$ was allowed to dissolve in the solution and immediately produced a colorless precipitate of $\mathrm{AgAsF}_{6}$. When no further $\mathrm{AsF}_{5}$ uptake was observed at 1.5 atm, the $\mathrm{AsF}_{5}$ supply was closed and the reactor was pressurized with $F_{2}$ to $2 \mathrm{~atm}$. The mixture was vigorously agitated and uptake of $F_{2}$ was observed, the $H F$ solution simultaneously becoming blue. After $24 \mathrm{hrs} \mathrm{F}_{2}$ uptake had ceased and a deep, royal-blue solution free of solid remained. The excess $\mathrm{F}_{2}, \mathrm{AsF}_{5}$, and $\mathrm{HF}$ were removed at room temperature in a dynamic vacuum to leave a dark, blue-green solid. The solid (3160mg, $10.01 \mathrm{mmol} \mathrm{AgFAsF}_{6}$ ) was heid under vacuum for another $2 \mathrm{hrs}$ with no color change. X-Ray powder photographs showed AgFAsF 6 lines only (based on an indexing from single crystal data given by Gantar ef al ) 6 . Variable temperature magnetic susceptibility measurements showed temperature independent paramagnetism above $63 \mathrm{~K}$ with a small paramagnetic impurity evident at temperatures below 63K. No field dependence was observed from 6 to $280 \mathrm{~K}$ on switching from a 5 to $40 \mathrm{kGauss}$ field. The data are shown as A in Fig.6.1. 
AgFAsF $_{6}$ crystallized from AHF with excess $\mathrm{AsF}_{5}$ at low temperature. In an identical experiment, a solution of $\mathrm{AgFAsF}_{6}$ was made up in $\mathrm{AHF}$ with a 5 fold excess of $\mathrm{AsF}_{5}$. The solution was cooled to $-60^{\circ} \mathrm{C}$ at which time removal of the $\mathrm{AsF}$ / $/ \mathrm{AHF}$ solution was begun. After 24 hrs a blue - green solid remained. X - Ray powder photographs were identical to those observed above for $\mathrm{AgFAsF}_{6}$. Variable temperature magnetic susceptibility data are not significantly different from those obtained above.

AgFAsF 6 from stoichiometric AsF5 addition. (B). Several preparations were carried out in the following way. In the DRILAB, AgF (usually $300 \mathrm{mg}, 2.4 \mathrm{mmol}$ ) was loaded into an FEP T-reactor fitted with a Teflon valve. When the AHF ( $3 \mathrm{ml})$ which had been transferred in a dynamic vacuum was warmed to room temperature, a small amount of dark, insoluble material (perhaps $\mathrm{AgF}_{2}$ from the fluorine used to passivate the reactor) precipitated out of the colorless solution. The solution was decanted into the free leg of the $\mathrm{T}_{\text {and }} \mathrm{AsF}_{5}$ was admitted as above. On complete conversion of $\mathrm{AgF}_{\mathrm{g}}$ to $\mathrm{AgAsF}_{6}$ as judged by no further uptake of $\mathrm{AsF}_{5}$, the $\mathrm{AHF}$ and any excess $\mathrm{AsF}_{5}$ were removed in a dynamic vacuum, which was maintained for 3 hrs. The colorless solid, AgAssF6, which remained, was washed twice with AHF (4ml) by decantation to remove any unreacted $\mathrm{AgF}$. This washed $\mathrm{AgAsF}_{6}$ in $\mathrm{AHF}(4 \mathrm{ml})$ was pressurized with $\mathrm{F}_{2}$ to 2 atm and the mixture was agitated. A deep blue solid formed as $F_{2}$ was taken up. $F_{2}$ uptake ceased after $8 \mathrm{hrs}$. Removal of $\mathrm{F}_{2}$ and AHF left a dark blue solid (usually $700 \mathrm{mg}, 2.2 \mathrm{mmol}$

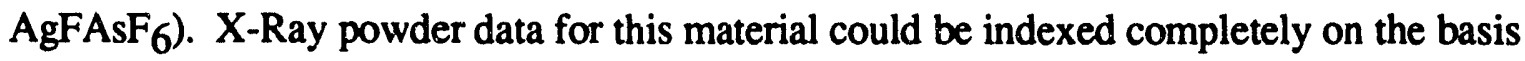
of the AgFAsF 6 phase. However, a few weak reflections which were not visible in the $\mathrm{AgFAsF}_{6}$ material prepared by route $(\mathrm{A})$, were observed. The results of variable temperature magnetic susceptibility measurements varied somewhat from sample to sample, however, a representative set is shown as B in Fig.6.1.

In sample B, the appearance of a small field dependence below $163 \mathrm{~K}$ signifies a 
small $\mathrm{AgF}_{2}$ impurity (see Fig. 6.5 for the susceptibility temperature profile for a dilute $\mathrm{AgF}_{2}$ sample). Even with the $\mathrm{AgF}_{2}$ impurity the paramgnetism appears to be temperature independent down to $63 \mathrm{~K}$ where a drop in susceptibility occurs. The susceptibility of the $\mathrm{AgF}_{2}$ impurity and perhaps a paramagnetic impurity eventually offset this decrease in chi as the temperature falls.

AgFAuF $_{4}$. In the DRILAB, AgFAsF 6 (453mg, $1.43 \mathrm{mmol}$ ) prepared by method (A) and $\mathrm{KAuF}_{4}(402 \mathrm{mg}, 1.29 \mathrm{mmol}$ ) were loaded into an FEP T-reactor fitted with two $3 / 8 \mathrm{in}$. O.D. FEP tubes and a Teflon valve. The reactor was exposed to vacuum (better than 0.05 torr) and anhydrous HF ( $4 \mathrm{ml})$ was condensed onto the solid mixture. On warming to room temperature an insoluble green precipitate formed, the supernatant solution being colorless. The reactor was then pressurized with $F_{2}$ to 2 atm. No $F_{2}$ uptake was observed over several hours. The insoluble green product was washed free of $\mathrm{KAsF}_{6}$ and excess $\mathrm{AgFAsF}_{6}$ by decantation and back distillation of the $\mathrm{AHF}$, this being repeated 10 times. X-Ray powder photographs of the green material were indexed on the basis of a $\mathrm{CuFAuF}_{4}$ type cell ${ }^{11}$ as given in Table 6.2. Magnetic susceptibility data are shown in Fig.

6.2 .

Table 6.2. X - Ray powder data for $\mathrm{AgFAuF}_{4}(\mathrm{CuK \alpha} \text {, Ni Filter })^{\mathrm{a}}$

\begin{tabular}{|c|c|c|c|c|}
\hline $1 / \mathrm{d}^{2} \times 10^{4}$ obsd & $1 / d^{2} \times 10^{4}$ calcd & $\mathrm{I} / \mathrm{I}_{\mathrm{O}}$ obsd & $\mathrm{I} / \mathrm{I}_{\mathrm{o}}$ calcd $^{\mathrm{b}}$ & $h k l$ \\
\hline 293 & 296 & w & 90 & 100 \\
\hline 479 & 483 & $\mathbf{w}$ & 75 & 010 \\
\hline \multirow[t]{2}{*}{725} & 730 & vs & 1000 & 010 \\
\hline & 730 & & 906 & $1 \overline{1} 0$ \\
\hline 826 & 828 & $\mathbf{s}$ & 753 & 110 \\
\hline --- & 858 & --- & 19 & $01 \overline{1}$ \\
\hline$-\cdots$ & 862 & --- & 52 & $10 \overline{1}$ \\
\hline 939 & -.- & vvw & --- & imp \\
\hline 1038 & 1039 & $\mathbf{s}$ & 493 & $11 \frac{1}{1}$ \\
\hline \multirow[t]{2}{*}{1183} & 1184 & $\mathbf{s}$ & 414 & 200 \\
\hline & 1189 & & 44 & 101 \\
\hline 1256 & 1268 & $\mathrm{~m}$ & 231 & \\
\hline
\end{tabular}


Table 6.2. cont.

\begin{tabular}{|c|c|c|c|c|}
\hline $\begin{array}{c}1 / d^{2} \times 10^{4} \text { obsd } \\
1487\end{array}$ & $\begin{array}{c}1 / \mathrm{d}^{2} \times 10^{4} \text { calcd } \\
-- \\
1567\end{array}$ & $\begin{array}{c}\mathrm{I} / \mathrm{I}_{\mathrm{o}} \text { obsd } \\
\text { vvw }\end{array}$ & \begin{tabular}{c}
$\mathrm{I}_{\mathbf{O}}$ calcd \\
\hdashline-- \\
98
\end{tabular} & $\begin{array}{l}h k l \\
\text { imp } \\
011\end{array}$ \\
\hline \multirow[t]{2}{*}{1578} & 1569 & $\mathrm{mbr}$ & 33 & $2 \overline{1} 0$ \\
\hline & 1586 & & 138 & $20 \overline{1}$ \\
\hline 1652 & 1650 & $\mathrm{~m}$ & 280 & $1 \overline{1} \overline{1}$ \\
\hline --- & 1765 & --- & 2 & 210 \\
\hline -- & 1813 & -.- & 11 & $21 \overline{1}$ \\
\hline \multirow[t]{2}{*}{1947} & 1931 & sbr & 193 & 020 \\
\hline & 1952 & & 155 & $02 \overline{1}$ \\
\hline 2080 & 2075 & $\mathbf{m}$ & 182 & 111 \\
\hline \multirow{2}{*}{--} & 2129 & -- & 1 & $1 \overline{2} 0$ \\
\hline & 2182 & & 51 & $12 \overline{1}$ \\
\hline \multirow[t]{3}{*}{2233} & 2240 & sbr & 201 & 201 \\
\hline & 2270 & & 37 & $2 \overline{1} 1$ \\
\hline & 2313 & & 5 & $1 \overline{2} 1$ \\
\hline \multirow[t]{2}{*}{2329} & 2325 & vvw & 11 & 120 \\
\hline & 2326 & & 13 & $2 \overline{1} \overline{1}$ \\
\hline 2477 & --- & vvw & --- & imp \\
\hline 2565 & --- & vvw & --- & imp \\
\hline --- & 2663 & --- & 5 & 300 \\
\hline --- & 2692 & -- & 1 & $01 \overline{2}$ \\
\hline \multirow[t]{2}{*}{2716} & 2710 & $\mathrm{~m}$ & 206 & $11 \overline{2}$ \\
\hline & 2887 & -- & 4 & $10 \overline{2}$ \\
\hline-- & 2903 & -.- & 10 & $30 \overline{1}$ \\
\hline \multirow[t]{2}{*}{2917} & 2918 & $\mathbf{S}$ & 119 & 002 \\
\hline & 2919 & & 163 & $2 \overline{2} 0$ \\
\hline 3000 & 2999 & $\mathbf{m}$ & 180 & $3 \overline{1} 0$ \\
\hline \multirow[t]{2}{*}{3020} & 3004 & $\mathrm{~m}$ & 134 & $22 \overline{1}$ \\
\hline & 3176 & & 2 & 211 \\
\hline 3191 & 3178 & $\mathrm{~m}$ & 104 & $31 \overline{1}$ \\
\hline \multirow[t]{3}{*}{3246} & 3265 & $\mathrm{~m}$ & 82 & $1 \overline{1} 2$ \\
\hline & 3266 & & 91 & $2 \overline{2} 1$ \\
\hline & 3293 & & 112 & 310 \\
\hline \multirow[t]{2}{*}{3302} & 3311 & $\mathrm{~m}$ & 108 & 220 \\
\hline & 3320 & & 9 & $21 \overline{2}$ \\
\hline 3376 & 3370 & w & 85 & 021 \\
\hline--- & 3405 & --- & 5 & $1 \overline{2} \overline{1}$ \\
\hline \multirow[t]{2}{*}{3442} & 3431 & $\mathrm{mbr}$ & 104 & $02 \overline{2}$ \\
\hline & 3448 & & 77 & $20 \overline{2}$ \\
\hline$\cdots$ & 3498 & -- & 11 & $12 \overline{2}$ \\
\hline
\end{tabular}


Table 6.2. cont.

$\begin{array}{ccccc}1 / \mathrm{d}^{2} \times 10^{4} \text { obsd } & 1 / \mathrm{d}^{2} \times 10^{4} \text { calcd } & \mathrm{I}_{\mathrm{O}} \text { obsd } & \mathrm{I} / \mathrm{I}_{\mathrm{O}} \text { calcd } & \mathrm{hkl} \\ --- & 3541 & -- & 1 & 102 \\ 3583 & 3593 & \mathrm{mbr} & 86 & 3 \overline{1} \overline{1} \\ 3858 & 3864 & \mathrm{mbr} & 92 & 3 \overline{1} 1 \\ -- & 3883 & -- & 15 & 301 \\ --- & 3928 & --- & 5 & 121 \\ -- & 3956 & --- & 6 & 1 \overline{2} 2\end{array}$

a Triclinic cell with $a_{0}=5.906(6) \AA ; b_{o}=4.769(6) \AA ; c_{o}=3.933(5) \AA ; \alpha=107.01(5)^{\circ}$; $\beta=99.46(4)^{\circ} ; \gamma=90.75(4)^{\circ} ; V=104.3 \AA^{3}$.

b The calculated intensities were based on parameters given by B.G. Müller ${ }^{11}$ for the structure of $\mathrm{CuFAuF}_{4}$. Calculations were performed using the program LAZY ${ }^{12}$.

AgFAuF6: In the DRILAB, $(683 \mathrm{mg}, 1.95 \mathrm{mmol}) \mathrm{KAuF}_{6}$ and $(810 \mathrm{mg}, 2.56 \mathrm{mmol})$ AgFAsF6, prepared by method (A), were loaded into one leg of an FEP T-reactor as described above. AHF ( $5 \mathrm{ml})$ was transferred into the reactor under static vacuum and warming to room temperature provided a dark, green-blue precipitate, the supernatent solution being pale blue. The solid proved to be insoluble and was washed free of $\mathrm{KAsF}_{6}$ and excess $\mathrm{AgFAsF}_{6}$ by decantation and back distillation of the AHF. After 6 washings the AHF over the solid was colorless. The AHF was removed in a dynamic vacuum, and the solid was dried under vacuum overnight. X-Ray powder photographs of the solid showed it to be isomorphous with AgFAsF6. The X-Ray data are given in Table 6.3. Variable temperature magnetic susceptibility measurements (Fig.6.1, C) showed behavior very similar to those for $\mathrm{AgFAsF}_{6}$. Again a small $\mathrm{AgF}_{2}$ impurity appears to be present, otherwise the susceptibility exhibits temperature-independent paramagnetism above $63 \mathrm{~K}$, with a sharp drop just below that temperature. The apparent field-dependence, even at temperatures above the Curie temperature for $\mathrm{AgF}_{2}(163 \mathrm{~K})$, is puzzling and could arise from a ferromagnetic contaminent, e.g. nickel metal. 
Table 6.3. X - Ray powder data for $\mathrm{AgFAuF}_{6}(\mathrm{CuK} \alpha, \mathrm{Ni}$ Filter)

\begin{tabular}{|c|c|c|c|c|}
\hline $1 / \mathrm{d}^{2} \times 10^{4}$ obsd & $1 / \mathrm{d}^{2} \times 10^{4}$ calcd & $I / I_{0}$ obsd & $\mathrm{I} / \mathrm{I}_{0}$ calcd & $h k l$ \\
\hline 268 & 270 & w & 119 & 101 \\
\hline 286 & 293 & $\mathbf{w}$ & 41 & 011 \\
\hline--- & 389 & -.. & 8 & 002 \\
\hline 425 & --. & vw & --- & imp \\
\hline 463 & 466 & vs & 1000 & 111 \\
\hline 562 & 562 & m & 263 & 102 \\
\hline 665 & --- & $\mathbf{w}$ & --- & imp \\
\hline 689 & 692 & wbr & 131 & 200 \\
\hline--- & 758 & ..- & 19 & 112 \\
\hline \multirow{2}{*}{782} & 781 & sbr & 381 & 020 \\
\hline & 790 & & 193 & 201 \\
\hline--- & 888 & --- & 0.2 & 210 \\
\hline 976 & 985 & vw & 20 & 211 \\
\hline -.. & 1049 & --- & 4 & 103 \\
\hline.-- & 1052 & --- & 29 & 121 \\
\hline \multirow[t]{2}{*}{1070} & 1071 & $\mathbf{s}$ & 391 & 013 \\
\hline & 1082 & & 64 & 202 \\
\hline -.- & 1170 & --.- & 1.5 & 022 \\
\hline 1250 & 1244 & vvw & 56 & 113 \\
\hline 1287 & 1277 & $\mathrm{~m}$ & 213 & 212 \\
\hline 1350 & 1344 & $\mathbf{m}$ & 173 & 122 \\
\hline \multirow{3}{*}{1473} & 1474 & vwbr & 41 & 220 \\
\hline & 1557 & & 17 & 004 \\
\hline & 1568 & & 1 & 203 \\
\hline 1571 & 1571 & wb & 59 & 221 \\
\hline 1653 & 1655 & $\mathbf{w}$ & 35 & 301 \\
\hline --- & 1730 & -.. & 18 & 104 \\
\hline \multirow{2}{*}{1774} & 1764 & w & 92 & 213 \\
\hline & 1830 & & 27 & 123 \\
\hline \multirow[t]{2}{*}{1854} & 1851 & $\mathbf{w}$ & 63 & 311 \\
\hline & 1855 & & 12 & 031 \\
\hline 1857 & 1863 & m & 23 & 222 \\
\hline$\cdots$ & 1925 & --- & 8 & 114 \\
\hline --- & 1947 & --- & 0.2 & 302 \\
\hline 2045 & 2028 & wbr & 54 & 131 \\
\hline 2142 & 2143 & wbr & 52 & 312 \\
\hline \multirow[t]{2}{*}{$\ldots$} & 2250 & --. & 0.1 & 204 \\
\hline & 2320 & & 0.1 & 132 \\
\hline \multirow[t]{2}{*}{2321} & 2338 & vvw & 24 & 024 \\
\hline & 2349 & & 1 & 223 \\
\hline
\end{tabular}


Table 6.3. cont.

\begin{tabular}{|c|c|c|c|c|}
\hline $1 / d^{2} \times 10^{4}$ obsd & $\begin{array}{l}1 / d^{2} \times 10^{4} \text { calcd } \\
\quad 2434\end{array}$ & $\mathrm{I} / \mathrm{I}_{0}$ obsd & $\begin{array}{l}\mathrm{I} / \mathrm{I}_{\mathbf{0}} \text { calcd } \\
0.1\end{array}$ & $\begin{array}{l}h k l \\
303\end{array}$ \\
\hline & 2437 & & 41 & 321 \\
\hline \multirow[t]{2}{*}{2451} & 2445 & $\mathbf{w}$ & 32 & 214 \\
\hline & 2450 & & 2 & 230 \\
\hline 2513 & 2511 & $\mathbf{w}$ & 99 & 124 \\
\hline --- & 2547 & --- & 11 & 231 \\
\hline -.. & 2606 & -.- & 1 & 105 \\
\hline \multirow[t]{2}{*}{$-\cdots$} & 2628 & -- & 0.5 & 015 \\
\hline & 2629 & & 9.5 & 313 \\
\hline 2636 & 2633 & $\mathrm{mbr}$ & 151 & 033 \\
\hline --- & 2728 & -- & 12 & 322 \\
\hline \multirow[t]{3}{*}{---} & 2770 & --. & 3 & 400 \\
\hline & 2801 & & 22 & 115 \\
\hline & 2806 & & 22 & 133 \\
\hline 2826 & 2839 & $\mathrm{~m}$ & 103 & 232 \\
\hline $28: 52$ & 2867 & w & 13 & 401 \\
\hline & 2965 & vw & 29 & 410 \\
\hline \multicolumn{5}{|c|}{$\begin{array}{l}\text { a Orthorhombic unit cell with } a_{0}=7.600(4) \AA ; b_{0}=7.156(4) \AA ; c_{o}=10.137(5) \AA ; \\
V=551.3 \AA^{3} \text {. Probable space group, } \text {;nma. }\end{array}$} \\
\hline
\end{tabular}

$\operatorname{Ag}\left(\mathrm{AuF}_{4}\right)_{2}$. In the $\mathrm{DRILAB}_{1} \mathrm{AgFAsF}_{6}$ from preparation (A) $(1.6 \mathrm{mmol})$ and $\mathrm{KAuF}_{4}(3.2 \mathrm{mmol})$ were loaded into separate legs of a Teflon T-reactor, described above. AHF (4ml) was condensed into each leg of the reactor under static vacuum, resulting in yellow and blue solutions of $\mathrm{KAuF}_{4}$ and $\mathrm{AgFAsF}_{6}$, respectively. Pouring the $\mathrm{KAuF}_{4}$ solution onto the $\mathrm{AgFAsF}_{6}$ solution produced an olive-green precipitate, the supernatent solution being yellow. The reactor was pressurized with $2 \mathrm{~atm}$ of $\mathrm{BF}_{3}$ until the supernatant solution became colorless. The light green precipitate was washed 10 times by decantation and back distillation of the $\mathrm{AHF}$ to remove $\mathrm{KAsF}_{6}$ and $\mathrm{KBF}_{4}$ side products. AHF was removed and the light green solid was dried in a dynamic vacuum overnight. X-Ray powder photographs showed a new phase similar to $\mathrm{Ag}\left(\mathrm{AgF}_{4}\right)_{2}$ (chapter 5) and are given in Table 6.4. No lines attributable to $\mathrm{AgFAuF}_{4}$, or $\mathrm{AuF}_{3}$ were 
observed. Variable temperature magnetic susceptibility measurements from 6 to $280 \mathrm{~K}$ at 5 and 40kGauss obeyed the Curie-Weiss law for a dilute one-electron paramagnet with $\mu_{\text {eff }}=1.82$ B.M. and $\theta=-2^{\circ}$ The Curie - Weiss plots of $\mathrm{AgAu}_{2} \mathrm{~F}_{8}$ and $\mathrm{Ag}\left(\mathrm{SbF}_{6}\right)_{2}$ are shown as (A) and (B) in Fig. 6.3.

Table 6.4 . $\mathbf{X}$ - Ray powder data for $\mathrm{AgAu}_{2} \mathrm{~F}_{8}$ (CuK $\alpha$, Ni Filter)

$\begin{array}{cc}\text { I//o } & 1 / d^{2} \times 10^{4} \text { obsd } \\ \text { vw } & 544 \\ \text { vww } & 664 \\ \text { s } & 708 \\ \text { s } & 727 \\ \text { w } & 756 \\ \text { s } & 850 \\ \text { s } & 1067 \\ \text { vw } & 1105 \\ \text { m } & 1330 \\ \text { vw } & 1459 \\ \text { w } & 1505 \\ \text { vw } & 1559 \\ \text { wb } & 1674 \\ \text { w } & 1769 \\ \text { s } & 1818 \\ \text { m } & 1905 \\ \text { w } & 2017 \\ \text { m } & 2136 \\ \text { m } & 2176 \\ \text { m } & 2388 \\ \text { m } & 2467 \\ \text { w } & 2567 \\ \text { w } & 2699 \\ \text { s } & 2904 \\ \text { m } & 2962 \\ \text { m } & 3120 \\ \text { w } & 3249 \\ \text { m } & 3361 \\ \text { w } & 3526 \\ \text { m } & 3583 \\ \text { m } & 3980 \\ \text { m } & 4277 \\ \text { m } & 4462 \\ & \end{array}$


Table 6.4. cont.

$\begin{array}{cc}\mathrm{I} / \mathrm{I}_{\mathrm{o}} & 1 / \mathrm{d}^{2} \times 10^{4} \text { obsd } \\ \mathrm{m} & 4681 \\ \mathrm{~m} & 4767 \\ \mathrm{~s} & 6594 \\ \mathrm{~s} & 6732\end{array}$

AgISbF 6 with Fluorine in AHF. In the DRILAB AgSbF 6 was loaded into a two armed Teflon/FEP reactor. After charging with $5 \mathrm{ml}$ AHF the system was pressurized with 2 atm $\mathrm{F}_{2}$. Immediately the poorly soluble $\mathrm{AgSbF}_{6}$ took on a tan color which quickly changed to blue. Fluorination over several hours left deep blue crystals in a pale blue supernatant solution. When no further $F_{2}$ uptake was observed, the AHF solution was slowly evacuated. Removal of the AHF resulted in a destruction of the crystals, however, and a finely divided dark blue powder remained. X - Ray powder photographs indicated a new phase of very poor crystallinity. Magnetic suceptibility measurements show TIP down to $163 \mathrm{~K}$ where onset of a large field dependence indicative of $\mathrm{AgF}_{2}(10 \%)$ was observed.

Reaction of $\mathrm{O}_{2}+\mathrm{AuF}_{6}-$ with $\mathrm{AgF}$. In the DRILAB, $0.23 \mathrm{~g}$ ( $\left.0.68 \mathrm{mmol}\right) \mathrm{O}_{2} \mathrm{AuF}_{6}$ and $0.096 \mathrm{~g}(0.76 \mathrm{mmol}) \mathrm{AgF}$ were loaded into a one armed Teflon/FEP tube reactor which had been passivated with $2 \mathrm{~atm} F_{2}$ for several hours. The reactor was attatched to the teflon manifold of a S.S. vacuum line, evacuated, and charged with $4 \mathrm{ml}$ of AHF. On warming to room temperature vigorous gas evolution was observed, while the solir?s became dark brown. When gas evolution had ceased, a black solid remained in a pale yellow solution. Volatile materials and AHF were removed under dynamic vacuum through a soda - lime scrubber leaving $0.30 \mathrm{~g}$ of black, solid product. $\mathrm{X}$ - Ray powder photographs of the black solid revealed a fairly simple, broad lined pattern.

$\mathrm{O}_{2}+\mathrm{AuF}_{6}-$ and $\mathrm{AgFBF}_{4}$. Under identical conditions to those above, $0.30 \mathrm{~g}$ 
(0.88 mmol) $\mathrm{O}_{2} \mathrm{AuF}_{6}$ and $0.19 \mathrm{~g}(0.88 \mathrm{mmol}) \mathrm{AgFBF}_{4}$ were allowed to react in $\mathrm{AHF}$. Vigorous gas evolution was again observed, which on ending left a dark blue solid in a yellow solution. Evacuation of volatile materials and AHF left $0.4200 \mathrm{~g}$ of dark blue, solid product. $\mathrm{X}$ - Ray powder photographs revealed $\mathrm{O}_{2} \mathrm{AuF}_{6}$ and lines attributable to the black phase observed in the $\mathrm{O}_{2} \mathrm{AuF}_{6} / \mathrm{AgF}$ reaction. The crystallinity of the material was greatly improved, however, and the data are shown in Table 6.5.

Table 6.5. X - Ray Powder Data for $\mathrm{O}_{2} \mathrm{AuF}_{6} \mathrm{AgFBF}_{4}$ Phase (CuKa, Ni Filter)

\begin{tabular}{|c|c|}
\hline $\begin{array}{l}1 / I_{n} \\
m\end{array}$ & $\begin{array}{c}1 / d^{2} \times 10^{4} \text { obsd } \\
675\end{array}$ \\
\hline vs & 686 \\
\hline $\mathbf{s}$ & 1233 \\
\hline w & 1268 \\
\hline s & 1463 \\
\hline vww & 1703 \\
\hline vww & 1884 \\
\hline $\mathbf{m}$ & 2126 \\
\hline vw & 2186 \\
\hline$w$ & 2684 \\
\hline $\mathbf{s}$ & 2720 \\
\hline $\mathbf{s}$ & 3123 \\
\hline $\mathbf{s}$ & 3159 \\
\hline $\mathbf{m}$ & 3224 \\
\hline w & 3471 \\
\hline $\mathbf{w}$ & 3533 \\
\hline $\mathbf{s b}$ & 3610 \\
\hline $\mathbf{m b}$ & 4138 \\
\hline wb & 4270 \\
\hline $\mathbf{s b}$ & 4398 \\
\hline mb & 4927 \\
\hline vwb & 5056 \\
\hline wb & 5190 \\
\hline wb & 5873 \\
\hline wb & 6126 \\
\hline wb & 6330 \\
\hline
\end{tabular}


Interaction of $\mathrm{AgFAsF}_{6}$ with AHF. In a reaction originally designed to produce $\mathrm{AgFAuF}_{4}, \mathrm{KAuF}_{4}$ was loaded into one arm of a two armed Teflon/FEP reactor and $\mathrm{AgFAsF}_{6}$ from preparation (A) was loaded into the other arm. Both arms of the reactor were charged with AHF on the vacuum line. Decantation of the blue "AgFAsF 6 " solution on to the yellow $\mathrm{KAuF}_{4}$ solution and solid, produced a lime - green solid. This AHF was distilled back into the tube containing the $\mathrm{AgFAsF}_{6}$ which had been cooled to $-196^{\circ} \mathrm{C}$. The decantation and back distillation procedure was repeated until colorless AHF was left in the tube originally containing the $\mathrm{AgFAsF}_{6}$. A small amount of insoluble black solid remained in this tube, while an insoluble lime green solid had been produced in the other tube. AHF was removed under dynamic vacuum through the soda - lime scrubber. X - Ray powder photographs of the black solid revealed a pattern which was isomorphous with the blue and black phase obtained from the $\mathrm{O}_{2} \mathrm{AuF}_{6}$ reactions. Subsequent washing of the green solid (to remove $\mathrm{KAsF}_{6}$ ) left $\mathrm{AgAu}_{2} \mathrm{~F}_{8}$ as evidenced by the $\mathrm{X}$ - Ray powder data. Magnetic susceptibility data for the black phase are given in Fig. 6.4.

\section{Results and Discussion}

Three different methods have been used in the synthesis of a variety of new $\mathrm{AgF}^{+}$ salts. The first simply involves the acid - base interaction of $\mathrm{AgF}_{2}$ with strong fluoroacids in AHF in a manner similar to that used by Gantar et al in the synthesis of $\mathrm{AgFAsF}_{6}$ and $\mathrm{Ag}\left(\mathrm{SbF}_{6}\right)_{2}$, eq 1

$$
\begin{aligned}
\mathrm{AgF}_{2}+\mathrm{A} \stackrel{\mathrm{AHF}}{\longrightarrow} & \mathrm{AgF}^{+} \mathrm{AsF}_{6}- \\
\mathrm{A} & =\mathrm{AsF}_{5}, \mathrm{BF}_{3}
\end{aligned}
$$

While this procedure allows the synthesis of members of this class of salts from commercially available starting materials, thus avoiding the use of elemental $F_{2}$, the 
resulting products are inevitably contaminated with the $\mathrm{Ag}(\mathrm{I})$ fluoroacid salt and, or $\mathrm{AgF}_{2}$. The quantities of these contaminents can be large if the quality of $\mathrm{AgF}_{2}$ is inferior. Recently Žemva has shown that reaction (1) is in equilibrium even for the strong acid $\mathrm{AsF}_{5}$ unless the acid concentration is high. ${ }^{13}$ Indeed, he has shown that, in the presence of a large amount of $\mathrm{AsF}_{5}$ free $\mathrm{AHF}, \mathrm{AgFAsF}_{6}$ is solvolyzed to $\mathrm{AgF}_{2}$ provided the $\mathrm{AsF}_{5}$ produced in the back reaction is effectively removed. This equilibrium was far more obvious when the weaker acid, $\mathrm{BF}_{3}$ was used, this being in part due to the low solubility of this acid in $\mathrm{AHF}$ at room temperature. Cooling of the $\mathrm{BF}_{3} / \mathrm{AHF} / \mathrm{AgF}_{2}$ reaction mixture to $-20^{\circ}$ was required to achieve a $\mathrm{BF}_{3}$ concentration in solution high enough to drive the forward reaction.On allowing the insoluble solid $\mathrm{AgFBF}_{4}$ to stand in $\mathrm{AHF}$ at room temperature, partial decomposition to $\mathrm{AgF}_{2}$ occurs, $\mathrm{BF}_{3}$ being effectively removed from solution by its low solubility.

A much more effective synthesis for high purity $\mathrm{AgF}^{+}$salts, is by the direct fluorination of the available $\mathrm{Ag}(\mathrm{I})$ fluorometallate salts, eq 2

$$
\begin{array}{r}
\mathrm{Ag}^{\mathrm{I}} \mathrm{MF}_{6}+1 / 2 \mathrm{~F}_{2} \stackrel{\mathrm{AHF}}{\longrightarrow} \mathrm{AgF}^{+} \mathrm{MF}_{\mathbf{X}}^{-} \\
\mathrm{MF}_{\mathbf{X}}^{-}=\mathrm{AsF}_{6}^{-}, \mathrm{BF}_{4}^{-}, \mathrm{SbF}_{6}^{-}
\end{array}
$$

This method has resulted in the first high purity synthesis of $\mathrm{AgFBF}_{4}$. On the other hand, the product of the interaction of $\mathrm{AgSbF}_{6}$ with $\mathrm{F}_{2}$ has remained difficult to characterize due to poor crystallinity of the final deep blue solid. The production of a seemingly crystalline product in AHF perhaps indicates that HF molecules contained in the crystal lattice are removed during the final evacuation of solvent AHF from it. $X$ - Ray powder photographs, however, show no traces of the $\mathrm{Ag}\left(\mathrm{SbF}_{6}\right)_{2}$ salt, which is light blue and sufficiently soluble to provide well developed crystals from AHF.

The purest samples of $\mathrm{AgFAsF}_{6}$ and $\mathrm{AgFBF}_{4}$, as judged by $\mathrm{X}$-Ray powder data 
and variable temperature magnetic susceptibility data, have been obtained by a combination of reactions (1) and (2), that is direct fluorination of the $\mathrm{Ag}(\mathrm{I})$ fluorometallate salt in the presence of the conjugate acid. X - Ray powder photographs for samples of $\mathrm{AgFBF}_{4}$ prepared in this way indicated that the material was free of both $\mathrm{AgBF}_{4}$ starting material and $\mathrm{AgF}_{2}$ and was of good crystallinity. These data were indexed readily on the basis of a tetragonal unit cell (Table 6.1). The tetragonal symmetry of the cell and the unit cell volume which required $2 \mathrm{AgF}^{+}$chain fragments per cell provided for a correct deduction of the structure prior to the availability of single crystals. 14 This was possible, because the chains had to be parallel to the shortest axis, the $c$ axis. Since $c_{0}=4.013 \AA$ and the chain $\mathrm{Ag}-\mathrm{F}$ interatomic distance is expected to be nearly $2.00 \AA$ based on the AgFAsF $_{6}$ structure, it was concluded that the $\mathrm{Ag}-\mathrm{F}^{+}$chain had to be linear. This result has been confirmed from a single crystal structure determination carried out in these laboratories by Dr. Horst Bormann from single crystals prepared by Mr. George Lucier. 15 That reaction (2) proceeded at all without the addition of small amounts of added acid was initially somewhat surprising given the inability of molecular $F_{2}$ to oxidize pure AgF in AHF at room temperature. 16

$$
\mathrm{AgF}+1 / 2 \mathrm{~F}_{2}-1 \rightarrow \mathrm{AgF}_{2}
$$

The $\mathrm{AgF}^{+}$salts are much more powerfully oxidizing (chapter 7) than the neutral difluoride and are therefore expected to be much more difficult to obtain by direct fluorination. Catalytic amounts of $\mathrm{BF}_{3}$ were found to bring reaction (3) to completion very quickly 16 , however, suggesting that the $\mathrm{Ag}(\mathrm{I})$ fluorometallates must undergo some solvolysis in $\mathrm{AHF}$ to produce this catalytic amount of acid. Once a small amount of the $\mathrm{AgF}^{+}$salt is formed solvolysis can provide enough acid to catalyze the further fluorination.

A final preparative method, which has significantly increased the number of these 
salts, involves the metathesis of $\mathrm{AgFAsF}_{6}$ with potassium fluorometallate salts.

$$
\begin{gathered}
\mathrm{AgF}^{+} \mathrm{AsF}_{6}^{-}+\mathrm{KMF}_{\mathbf{x}} \stackrel{\mathrm{AHF}}{\longrightarrow} \mathrm{AgF}^{+} \mathrm{MF}_{\mathbf{X}}^{-}+\mathrm{KAsF}_{6} \\
\mathrm{MF}_{\mathbf{x}}=\mathrm{AgF}_{4^{-}}, \mathrm{AuF}_{4}^{-}, \mathrm{AuF}_{6}^{-}
\end{gathered}
$$

In all cases the reaction is driven to completion by the formation of an insoluble $\mathrm{AgF}^{+}$salt. Thus far, the only structural information available for these materials comes from $\mathbf{X}$ - Ray powder data, which are, however, very informative. $\mathrm{X}$ - Ray powder data for $\mathrm{AgFAuF}_{4}$ (Table 6.2) can be indexed completely on the basis of the triclinic CuFAuF 4 type cell, known from single crystal data. ${ }^{11}$ Rough intensities from the $\mathrm{AgFAuF}_{4}$ powder data correlate well with the intensities anticipated on the basis of a $\mathrm{CuFAuF}_{4}$ structure, with $\mathrm{Ag}$ substituted for $\mathrm{Cu}$. This indicates that the two salts are isostructural. This structure contains a nearly linear $(M-F)_{n}^{n+}$ chain. The $P \overline{1}$ symmetry of the cell does not allow for non - linearity of the chain, however the large thermal parameter observed for the chain $F$ atoms in the structure of Müller et al. ${ }^{11}$ suggests slight deviations of the chain from linearity, so P1 may be the true symmetry of the cell. If in fact the chain is parallel to the c axis as described, the known chain $\mathrm{Ag}-\mathrm{F}$ interatomic distance from the $\mathrm{AgFAsF}_{6}$ and $\mathrm{AgFBF}_{4}$ structures which are barely significantly different from $2.000 \AA$ would need a bridging $\mathrm{M}-\mathrm{F}-\mathrm{M}$ angle of $159^{\circ}$ based on $\mathrm{c}_{\mathrm{o}}=3.933 \AA$ in the $\mathrm{AgFAuF}_{4}$ cell. $\mathrm{X}$ - Ray data for $\mathrm{Ag}_{2} \mathrm{~F}_{5}$ (Chapter 5) have not yet been indexed, owing to impurity lines which include those of $\mathrm{Ag}_{3} \mathrm{~F}_{8}$. However, when known impurity lines are subtracted from the data (Table 5.5) the remaining data are markedly similar to those of $\mathrm{AgFAuF}_{4}$, again suggesting the $\mathrm{AgFAgF}_{4}$ formulation and a structural relationship to $\mathrm{CuFAuF}_{4}$.

Under acidic conditions a 1:2 ratio of $\mathrm{AgFAsF}_{6}$ to $\mathrm{KAgF}_{4}$ was observed to give $\mathrm{Ag}_{3} \mathrm{~F}_{8}$ (see chapter 5). A similar set of conditions using $\mathrm{KAuF}_{4}$ produces a phase distinct from that of $\mathrm{AgFAuF}_{4}$ which is akin to $\mathrm{Ag}_{3} \mathrm{~F}_{8}$. Indeed the magnetic data are similar to 
those for $\mathrm{Ag}\left(\mathrm{AgF}_{4}\right)_{2}$ (q.v.) and indicate the formulation $\mathrm{Ag}^{2+}\left(\mathrm{AuF}_{4}^{-}\right)_{2}$. Under these synthetic conditions it was realized that the oxidation of $\mathrm{AuF}_{4}^{-}$to $\mathrm{AuF}_{6}^{-}$cationic $\mathrm{Ag}$ (II) was also a possibility. No soluble $\mathrm{AuF}_{6}-$ salt was observed, however, and basic solvolysis of the insoluble, olive - green product, $\mathrm{AgAu}_{2} \mathrm{~F}_{8}$, with $\mathrm{KF}$ in $\mathrm{AHF}$, produced only $\mathrm{KAuF}_{4}$ and $\mathrm{AgF}_{2}$, eq 5

$$
\mathrm{AgAu}_{2} \mathrm{~F}_{8}+2 \mathrm{KF} \stackrel{\mathrm{AHF}}{\longrightarrow} \mathrm{AgF}_{2}+2 \mathrm{KAuF}_{4}
$$

In order to synthesize the $\mathrm{Au}(\mathrm{V}) \mathrm{AgF}^{+}$analogue, $\mathrm{Au}(\mathrm{V})$ starting materials were required. X-Ray powder data for insoluble, aqua colored $\mathrm{AgFAuF}_{6}$ is nearly identical to that observed for $\mathrm{AgFAsF}_{6}{ }^{17}$ and can be indexed completely on the basis of the $\mathrm{AgFAsF}_{6}$ type cell (Table 6.3). Again rough intensity data indicate that these two $\mathrm{AgF}^{+}$salts are probably isostructural. The $\mathrm{Ag}-\mathrm{F}$ - Ag bridging angle determined by Gantar et al. ${ }^{6}$ to be $143^{\circ}$ in $\mathrm{AgFAsF}_{6}$ must be nearly the same in the $\mathrm{Au}(\mathrm{V})$ analog.

In the metathesis, reaction (4), generally either the solid reagents were mixed, followed by the addition of AHF, or the potassium fluorometallate salt dissolved in AHF was poured on to $\mathrm{AgFAsF}_{6}$ in $\mathrm{AHF}$. Reactions were carried out in this manner to avoid local excesses of the fluorometallate salts which would favor formation of $\operatorname{Ag}\left(\mathrm{MF}_{\mathrm{x}}\right)_{2}$ salts. It was subsequently found that when solutions of $\mathrm{AgFAsF}_{6}$ were repeatedly decanted, an insoluble black solid eventually remained. X - Ray powder photographs of this material revealed that it was identical to a black solid obtained by Žemva and his coworkers ${ }^{13}$ when less than one equivalent of $\mathrm{AsF}_{5}$ was added to pure $\mathrm{AgF}_{3}$ in $\mathrm{AHF}$. Interestingly, the material was clearly isomorphous with the dark blue product observed when a large excess of $\mathrm{O}_{2}{ }^{+} \mathrm{AuF}_{6}{ }^{-}$was reacted with $\mathrm{AgFBF}_{4}$, eq 6

$1-\mathrm{x} \mathrm{O}_{2}+\mathrm{AuF}_{6}^{-}+\mathrm{AgFBF}_{4} \stackrel{\mathrm{AHF}}{\longrightarrow}$ dark blue solid $+\mathrm{O}_{2}+\mathrm{BF}_{3}+\mathrm{xO}_{2}+\mathrm{AuF}_{6}^{-}$ 
Reaction (6) was originally proposed as a means to make $\mathrm{AgFAuF}_{6}$. In a subsequent experiment by Zemva, it was discovered that $\mathrm{AgFAsF}_{6}$ could be completely solvolyzed in AHF to the black solid and $\mathrm{AgAsF}_{6}$ by adding adding successive aliquots of $\mathrm{AsF}_{5}$ free AHF to it. ${ }^{13}$ Apparently the total solvolysis is normally prevented by the increasing concentration of free $\mathrm{AsF}_{5}$ in solution. Only by effectively removing this $\mathrm{AHF}$ could the solvolysis go to completion.

In our studies of the $\mathrm{AgF}^{+}$salts, it was discovered that the solubility of $\mathrm{AgFAsF}_{6}$ in AHF was greatly enhanced by the addition of $\mathrm{AsF}_{5}$. This probably means that the $\mathrm{Ag}(\mathrm{II})$ is then present as $\mathrm{AHF}$ solvated $\mathrm{Ag}^{+2}$ species. A puzzling feature was the seemingly significant solubility of $\mathrm{AgFAsF}_{6}$ which produces dark blue solutions in $\mathrm{AHF}$, in contrast to all other $\mathrm{AgF}^{+}$salts, which are nearly insoluble in $\mathrm{AHF}$. Since it is now apparent that addition of $\mathrm{AHF}$ to $\mathrm{AgFAsF}_{6}$ releases some "free" $\mathrm{AsF}_{5}$, the solubility of $\mathrm{AgFAsF}_{6}$ in AHF can now be interpreted as due to the solvolysis of this material producing black solid, $\mathrm{AgAsF}_{6}$ and $\mathrm{AsF}_{5}$, the last of which aids in the dissolution of the remaining $\mathrm{AgFAsF}_{6}$. It is expected that in the absence of $\mathrm{AsF}_{5}$ the solubility would be comparable with other $\mathrm{AgF}^{+}$salts.

A closer inspection of the $\mathrm{X}$ - ray powder data revealed that $\mathrm{AgFAsF}_{6}$ prepared by reaction (2) contained a small amount of the black solid, the strongest lines of that impurity being barely visible in the $\mathrm{AgFAsF}_{6}$ data. $\mathrm{AgFAsF}_{6}$ prepared using excess $\mathrm{AsF}_{5}$, however, showed no traces of this impurity. Still, all $\mathrm{AgFAsF}_{6}$ used in metatheses, reaction (4), was dissolved in $\mathrm{AsF}_{5}$ free $\mathrm{AHF}$ and therefore must have been tainted with the black solid, as a consequence of the solvolysis. It was expected that each product from these reactions might contain traces of this material. Indeed, $\mathrm{X}$ - ray powder photographs of $\mathrm{AgFAuF}_{6}$ and $\mathrm{Ag}_{2} \mathrm{~F}_{5}$ do contain the strongest lines of the pattern of the black solid. Interestingly, the $\mathrm{AgFAuF}_{4}$ data, which was indexable, shows no signs of the black solid phase. It is possible that the black solid which must contain some $\mathrm{Ag}(\mathrm{III})$, since $\mathrm{Ag}(\mathrm{I})$ is 
also formed in its production from the solvolysis of $\mathrm{AgFAsF}_{6}$, is reduced by $\mathrm{KAuF}_{4}$ in eq (3) to produce $\mathrm{KAuF}_{6}$ which is washed away in the $\mathrm{AgFAuF}_{4}$ synthesis. Subtracting the lines due to the black solid from the $\mathrm{Ag}_{2} \mathrm{~F}_{5}$ pattern subsequently revealed a much closer relationship to the $\mathrm{AgFAuF}_{4}$ pattern, suggesting a similar cell and structure. Unfortunately, removal of all the lines which could be attributable to the black solid, including those which are probably coincident with authentic $\mathrm{Ag}_{2} \mathrm{~F}_{5}$, leaves too few data to index the cell.

\section{Magnetic Measurements}

Variable temperature magnetic susceptibility measurements have proven to be extremely sensitive to the environment about the $\mathrm{d}^{9} \mathrm{Ag}(\mathrm{II})$ species and readily distinguish $\mathrm{AgF}_{2}, \mathrm{AgF}^{+}$, and $\mathrm{Ag}^{+2}$ species. $\mathrm{AgF}_{2}$ is paramagnetic with a ferromagnetic transition below $163 \mathrm{~K} .{ }^{18}$ The sudden onset of field dependence at $163 \mathrm{~K}$ serves as a very sensitive test for $\mathrm{AgF}_{2}$ impurities in $\mathrm{Ag}(\mathrm{II})$ salts, the effect being pronounced in a sample diluted to $15 \%$ with $\mathrm{CaF}_{2}$ (see Fig. 6.5). Salts containing isolated $\mathrm{Ag}(\mathrm{II})$ cations such as $\mathrm{Ag}\left(\mathrm{SbF}_{6}\right)_{2}$ , " $\mathrm{Ag}\left(\mathrm{AgF}_{4}\right)_{2}$ ", and " $\mathrm{Ag}\left(\mathrm{AuF}_{4}\right)_{2}$ " have room temperature moments similar to that of $\mathrm{AgF}_{2}$. However, like $\mathrm{Ag}_{3} \mathrm{~F}_{8}$, these materials show no field dependence and obey the Curie law as magnetically dilute systems to very low temperatures, Fig. 6.3. This behavior was anticipated, as in these salts, the paramagnetic $\mathrm{Ag}(\mathrm{II})$ ions must be well separated by the two diamagnetic anions. Interestingly, it is the hexafluoroantimonate salt, containing the largest diamagnetic anions among the the $\mathrm{Ag}^{+2}$ salts, which shows the most significant deviation from Curie behavior at low temperatures, but this is indicative of only weak antiferromagnetic coupling, evidently fostered by the anions.

In contrast to these materials, with their relatively large susceptibilities, the $\mathrm{AgF}^{+}$ salts containing $\mathrm{Ag}(\mathrm{II})$ in a 2 - D chain, are only weakly paramagnetic with room temperature $\chi_{\mathrm{g}}$ measurements nearly two orders of magnitude smaller than those of other 
$\mathrm{Ag}$ (II) materials. Remarkably, the observed paramagnetism in all of the $\mathrm{AgF}^{+}$salts studied thus far appears to be temperature independent at least down to temperatures below $60 \mathrm{~K}$ where the impact of small amounts of paramagnetic $\mathrm{Ag}^{+2}$ or ferromagnetic $\mathrm{AgF}_{2}$ becomes large.

Unfortunately there was great variability in the magnetic data, the presence of impurity phases having large effect on the small $\mathrm{AgF}^{+}$susceptibilities. Certainly there was much difficulty in obtaining $\mathrm{AgFAuF}_{4}$ and $\mathrm{AgFAgF}_{4}$ free from the 1:2 complexes $\mathrm{AgAu}_{2} \mathrm{~F}_{8}$ and $\mathrm{Ag}_{3} \mathrm{~F}_{8}$, which probably contribute to the increased magnetization observed at lower temperatures for these $\mathrm{AgF}^{+}$salts. Even so, these materials exhibit small, roughly temperature independent paramagnetism, further supporting their formulation as $\mathrm{AgF}^{+}$ salts. The scatter seen in Fig. 6.2 below 163K may also indicate the presence of some $\mathrm{AgF}_{2}$. The variances in susceptibility data for $\mathrm{AgFAsF}_{6}$ and $\mathrm{AgFAuF}_{6}$ are somewhat more difficult to rationalize. All samples, regardless of the method of preparation show increased magnetization at low temperatures, this in spite of the instability of the corresponding 1:2 complex $\mathrm{Ag}\left(\mathrm{AsF}_{6}\right)_{2}$ in the absence of $\mathrm{AsF}_{5}$ rich $\mathrm{AHF}$. As expected preparations using a large excess of $\mathrm{AsF}_{5}$ were free of $\mathrm{AgF}_{2}$, as indicated by the lack of any field dependence below $163 \mathrm{~K}$. In contrast samples prepared by reaction 2 involving a stoichiometric quantity of $\mathrm{AsF}_{5}$, show a field dependence below $163 \mathrm{~K}$, the presence of $1 \% \mathrm{AgF}_{2}$ being suggested by comparison with the $15 \%$ diluted $\mathrm{AgF}_{2} / \mathrm{CaF}_{2}$ measurement. $\mathrm{AgFAuF}_{6}$ data indicated a field dependence over the entire range of temperatures, this possibly arising from ferromagnetic $\mathrm{NiF}_{2}$ impurity in the original $\mathrm{KAuF}_{6}$ starting material which was made in a Monel bomb.

With the exception of $\mathrm{AgFAsF}_{6}$ prepared under $\mathrm{AsF}_{5}$ rich conditions, all $\mathrm{AgFAsF}_{6}$ and indeed all $\mathrm{AgF}^{+}$salts prepared from $\mathrm{AgFAsF}_{6}$ showed a significant drop in susceptibility below $63 \mathrm{~K}$ before rising again at $\approx 30 \mathrm{~K}$. The absence of such a drop in susceptibility in the purest samples of $\mathrm{AgFAsF}_{6}$, suggests that an impurity common to the 
remaining $\mathrm{AgF}+$ salts is responsible for this susceptibility drop. Since the new black phase was known to be present in all of these samples, it was anticipated that susceptibility data on the pure material would show a large drop at 63K. However, as the data shown in Fig. 6.4 indicate, no such drop is observed. In fact the data are very similar to those for pure $\mathrm{AgFAsF}_{6}$, i.e., a small temperature independent paramagnetism from 280 to $50 \mathrm{~K}$ with an increase in susceptibility below $50 \mathrm{~K}$. The identity of the impurity phase which is producing this ubiquitous drop in susceptibility at $63 \mathrm{~K}$ is unclear, however, the absence of any effect of the fluorometallate anion on the temperature of this transition in the different samples, suggest that the impurity may simply be a binary silver fluoride. It is possible that pure $\mathrm{Ag}_{2} \mathrm{~F}_{5}$, in the absence of any paramagnetic $\mathrm{Ag}_{3} \mathrm{~F}_{8}$ impurity would exhibit a more substantial drop in suceptibility at $63 \mathrm{~K}$, such that a small amount of it interposed on the already weakly paramagnetic $\mathrm{AgF}^{+}$salts would produce the observed impurity behavior.

Nevertheless, the low, temperature - independent susceptibilities observed to be general for the $\mathrm{AgF}^{+}$salts are intriguing, as they are indicative of a partially filled band, obeying Fermi - Dirac, rather than Boltzmann statistics. 19 Apparently there is a high degree of electron mobility in the $(\mathrm{Ag}-\mathrm{F})_{\mathrm{n}^{\mathrm{n}}}{ }^{\mathrm{n}}$ chains. The $\mathrm{Ag}-\mathrm{F}$ interatomic distances in these chains appear to be nearly $2.00 \AA$ in all cases and compared to the nearest $\mathrm{Ag}$ anionic F contacts which are closer to $2.35 \AA$, indicate considerable covalent bonding and overlap of the $\mathrm{Ag}(\mathrm{II})$ valence $4 \mathrm{~d}_{\mathrm{z}} 2$ orbitals and $\mathrm{F} 2 \mathrm{p}_{\mathrm{z}}$ orbitals in the chains. The chemistry of the cationic $\mathrm{Ag}(\mathrm{II})$ systems (Chapter 7) indicates that these materials are powerful electrophilic oxidizers comparable with $\mathrm{F}$ atoms. This suggests that the $\operatorname{Ag}(\mathrm{II}) 4 \mathrm{~d}_{\mathrm{z}} 2$ and the $\mathrm{F} 2 \mathrm{p}_{\mathrm{z}}$ orbitals must be very close in energy. This would provide the basis for the metallic magnetic properties observed here, since the conduction band would be half filled. Direct conductivity measurements on the $\mathrm{AgF}^{+}$salts are extremely difficult owing to oxidation of electrode materials by these compounds. It remains to be proved that crystals of these salts do indeed carry electricity. 


\section{Conclusions}

A number of fluorometallate anions, of varying acidity are capable of stabilizing cationic $\mathrm{Ag}(\mathrm{II})$ either as $\mathrm{Ag}^{+2}$, or as $\mathrm{AgF}^{+}$. The available structure data suggest that all $\mathrm{AgF}^{+}$salts contain the $\mathrm{Ag}(\mathrm{II})$ in chains, $(\mathrm{Ag}-\mathrm{F})_{\mathrm{n}}{ }^{\mathrm{n}+}$, which may be linear as in $\mathrm{AgFBF}_{4}$ and possibly $\mathrm{AgFMF}_{4}(\mathrm{M}=\mathrm{Ag}, \mathrm{Au})$, or bent as in $\mathrm{AgFMF}_{6}(\mathrm{M}=\mathrm{As}, \mathrm{Au}) . \mathrm{All} \mathrm{AgF}^{+}$salts exhibit very low, temperature independent paramagnetism to low temperatures. This contrasts the behavior of the $\mathrm{Ag}^{+2}\left(\mathrm{MF}_{\mathrm{x}}^{-}\right)_{2}\left(\mathrm{MF}_{\mathrm{x}}^{-}=\mathrm{AgF}_{4}^{-}, \mathrm{AuF}_{4}^{-}\right.$, and $\left.\mathrm{SbF}_{6}{ }^{-}\right)$which obey the Curie law as simple one electron paramagnets.

\section{References}

1. Sorbe, P.; Grannec, J.; Portier, J.; Hagenmuller, P. J. Fluor. Chem. 1978,11, 243.

2. Yvon, K.; Betzinge, A.; Tissot, P.; Fischer, J. J. Solid State Chem, 1986, 60, 225.

3. Jesih, A.; Lutar, K.; Žemva, B.; Bachmann, B.; Becher, St.; Müller, B.G.; Hoppe, R. Z. Anorg. allg. Chem. 1990, 588, 77.

4. Gantar, D.; Leban, I.; Frlec, B.; Holloway, J.H. J.Chem. Soc. Dalton Trans. 1989, 2379.

5. Müller, B. G. Angew. Chem., Int. Ed. Eng. 1987, 26, 689.

6. Gantar, D; Frlec, B.; Russell, D.R.; Holloway, J. Acta Crystallogr. Sect. C Cryst. Struct. Commun. 1987, 43, 618.

7. Kemmitt, R.D.W.; Russell, D.R.; Sharp, D.W.A. J. Chem. Soc. 1963, 4408.

8. Sharpe, A.G. J.Chem. Soc. 1949, 613, 2901.

9. Bartlett, N.; Leary, K. Rev, Chim. Minér. 1976, 13, 82.

10. Gruner, E.; Klemm, W. Naturwissenschaften 1937, $25,59$.

11. Müller, B.G. Angew. Chem. Int. Ed. Eng. 1987, 26, 688. 
12. Yvon, K.; Jeitschko, W.; Parthe, E. "LAZY PULVERIX, A Program to Calculate Theoretical X - ray and Neutron Diffraction Powder Patterns," 1977.

13. B. Žemva, unpublished results.

14. Žemva, B.; Hagiwara, R.; Casteel, Jr., W.J.; Lutar, K.; Jesih, A.; Bartlett, N. J. Am. Chem. Soc. 1990, 112, 4846.

15. Casteel, Jr., W.J.; Lucier, G.; Hagiwara, R.; Bormann, H.; Bartlett, N. J. Solid State Chem. 1992, 96, 84.

16. R. Hagiwara, unpublished result.

17. S. Mayorga, Ph.D. Thesis, U.C. Berkeley 1988.

18. Chapin, P.; Dianoux, A.J.; Marquet - Ellis, H.; Nguyen - Nghi C.R. Acad. Sci. Paris $1967,264,1108$.

19. Kittel, C. "Introduction to Solid State Physics," p.413, Wiley, New York, 1986. 

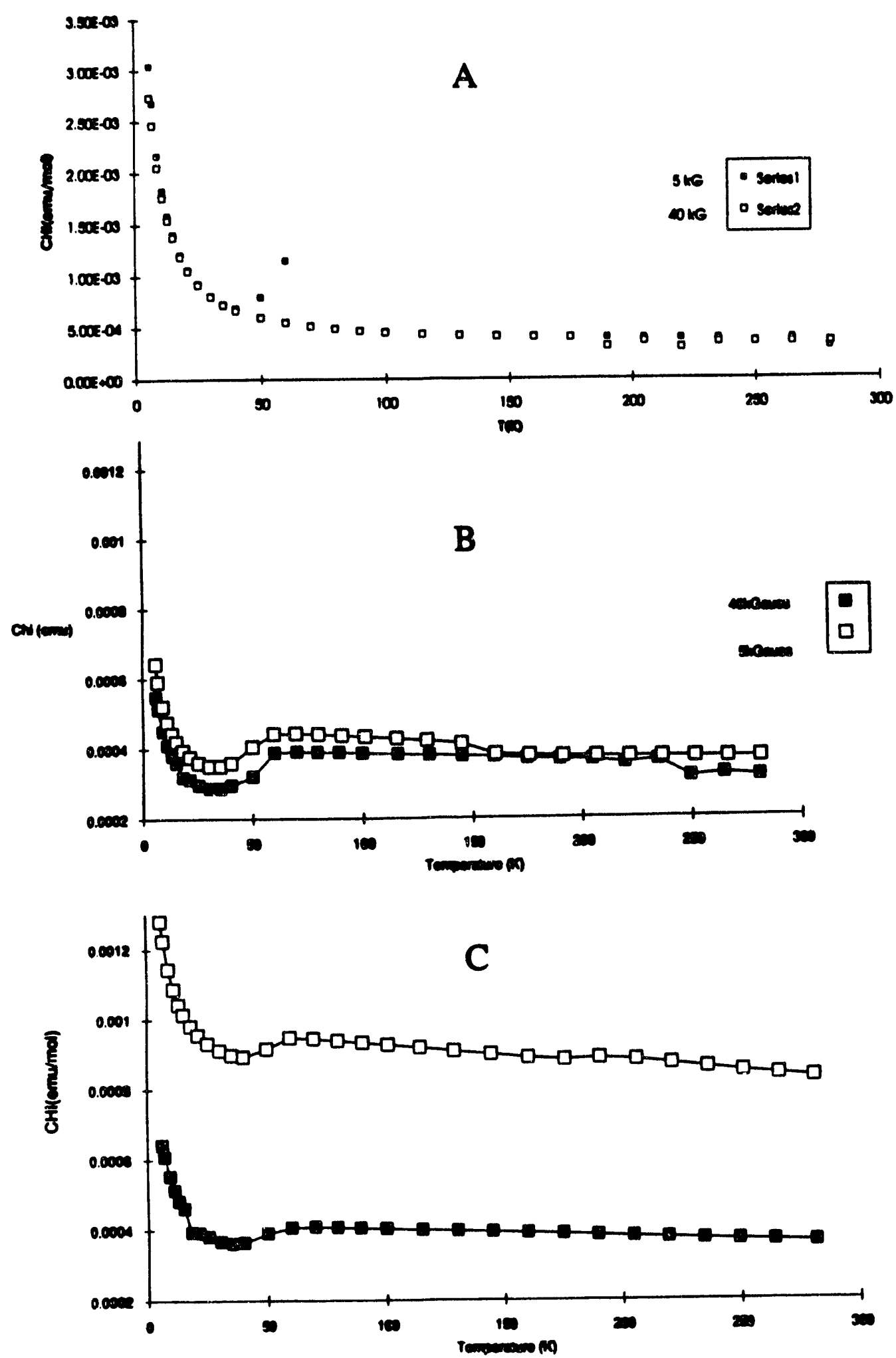

Figure 6.1. Magnetic susceptibility data for $\operatorname{AgFAsF}_{6}(\mathrm{~A}, \mathrm{~B})$ and $\operatorname{AgFAuF}_{6}(\mathrm{C})$. $5 \mathrm{kG}(\square), 40 \mathrm{kG}(\mathbf{\square})$. 

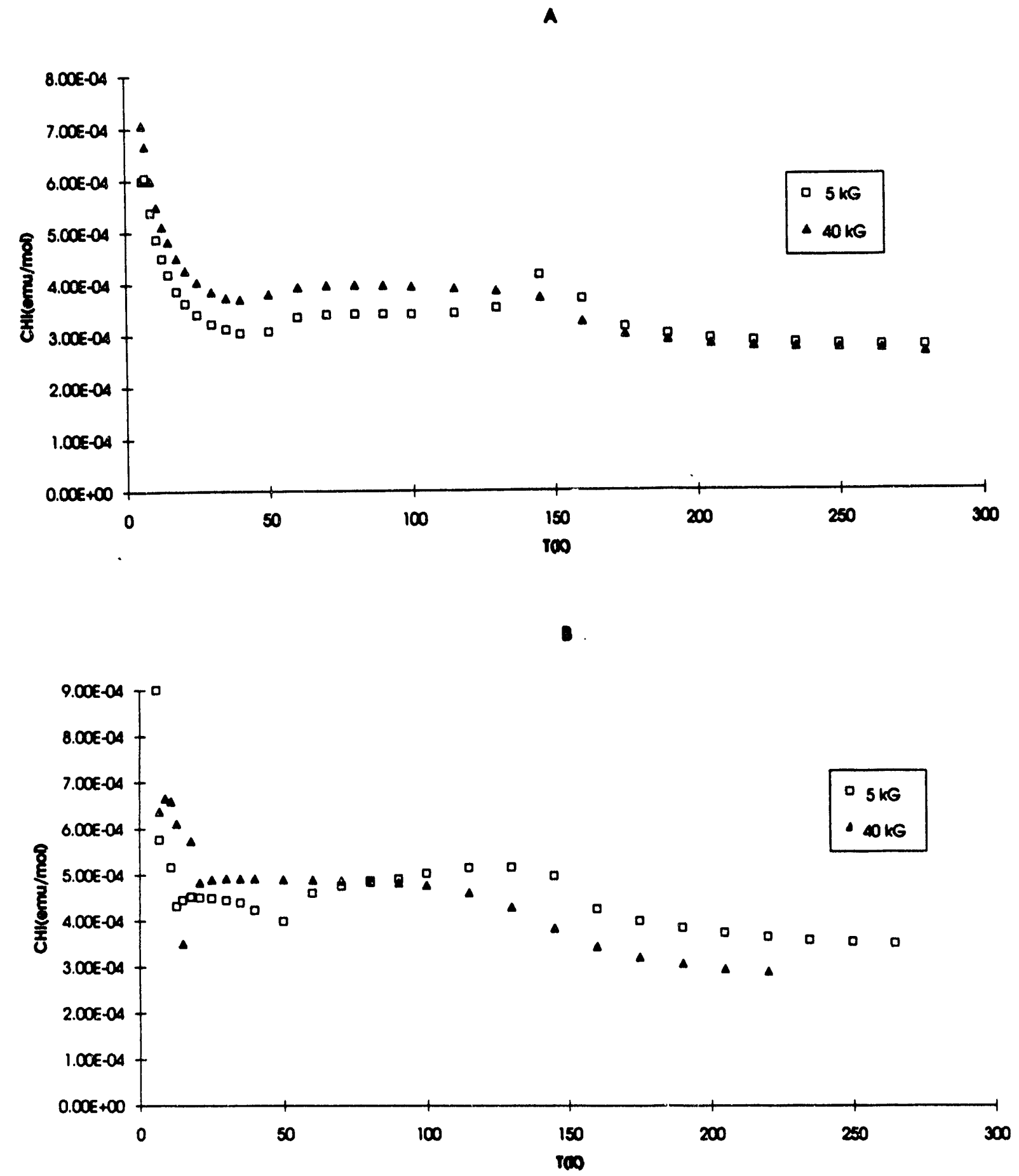

Figure 6.2. Magnetic susceptibility data for $\mathrm{Ag}_{2} \mathrm{~F}_{5}(\mathrm{~A})$ and $\mathrm{AgFAuF}_{4}(\mathrm{~B}) .5 \mathrm{kG}(\square)$ 40kG ( $\triangle$ ). 

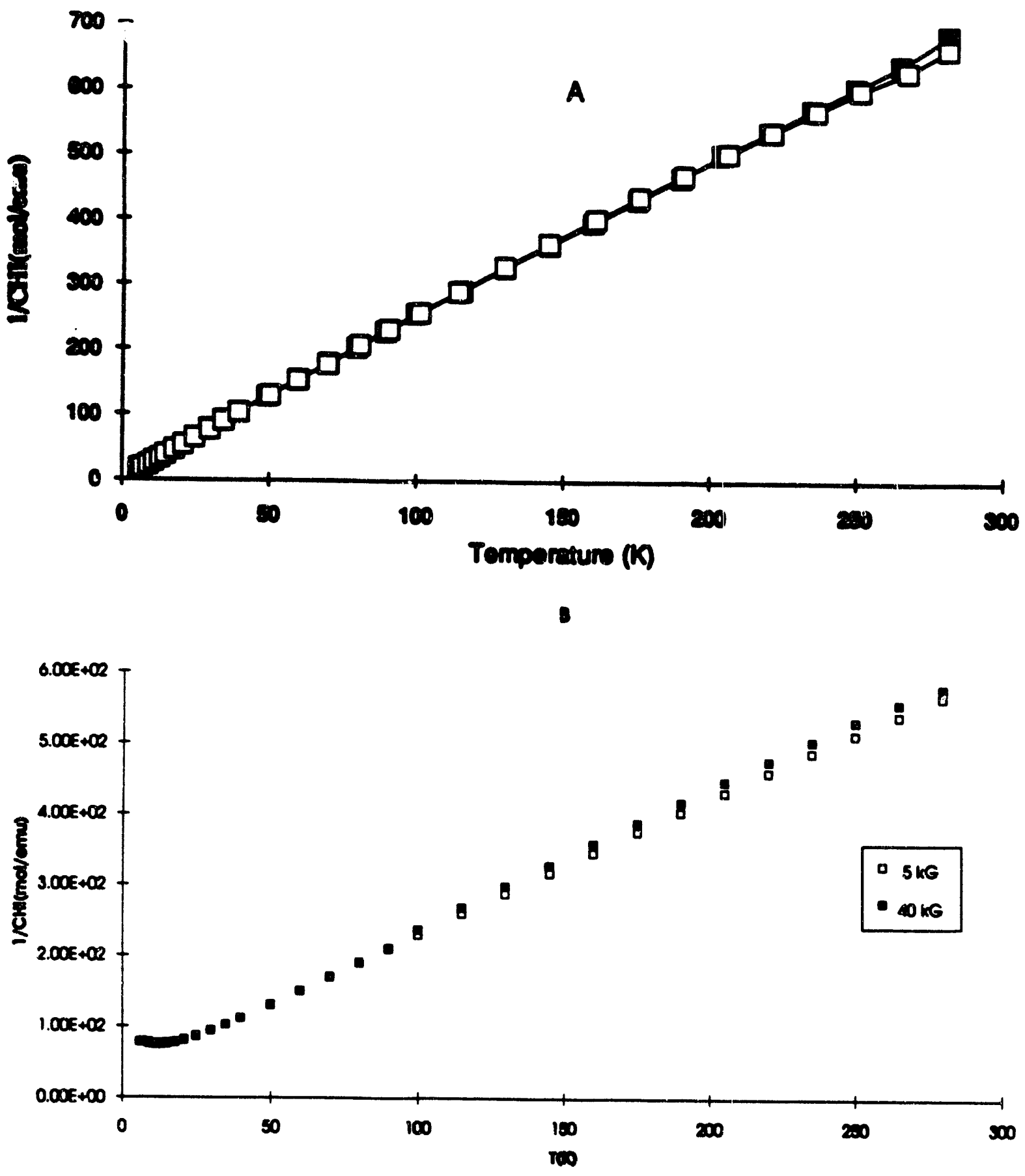

Figure 6.3. Curie - Weiss Plots for $\mathrm{AgAu}_{2} \mathrm{~F}_{8}(\mathrm{~A})$ and $\mathrm{Ag}\left(\mathrm{SbF}_{6}\right)_{2}$ (B). $5 \mathrm{kG}(\square)$ 40kG (D). 
Black Solvolyts Phase

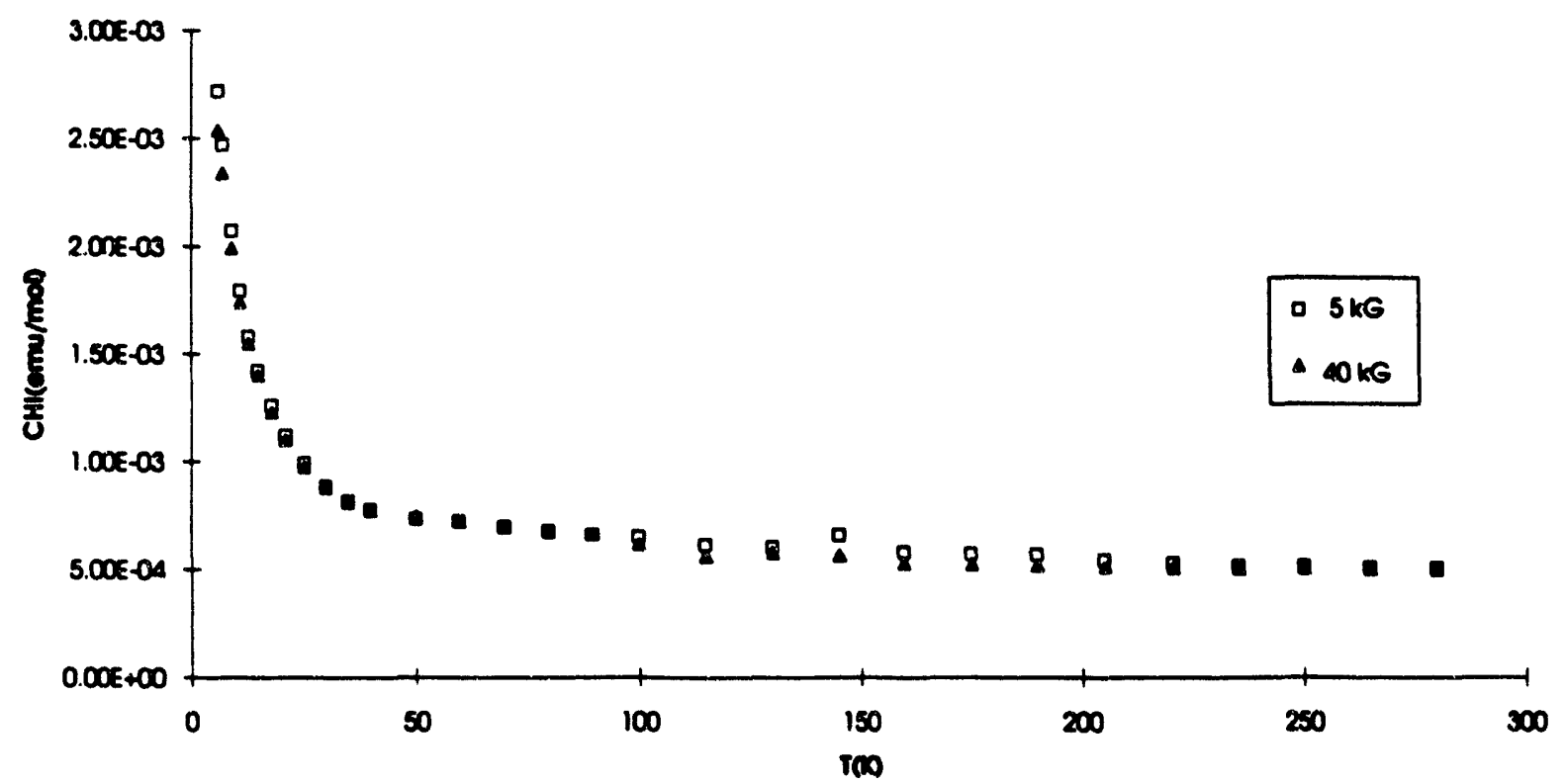

Figure 6.4. Magnetic susceptibility data for the black solvolysis product of AgFAsF6. 5kG(口) 40kG ( $\triangle$ ). 


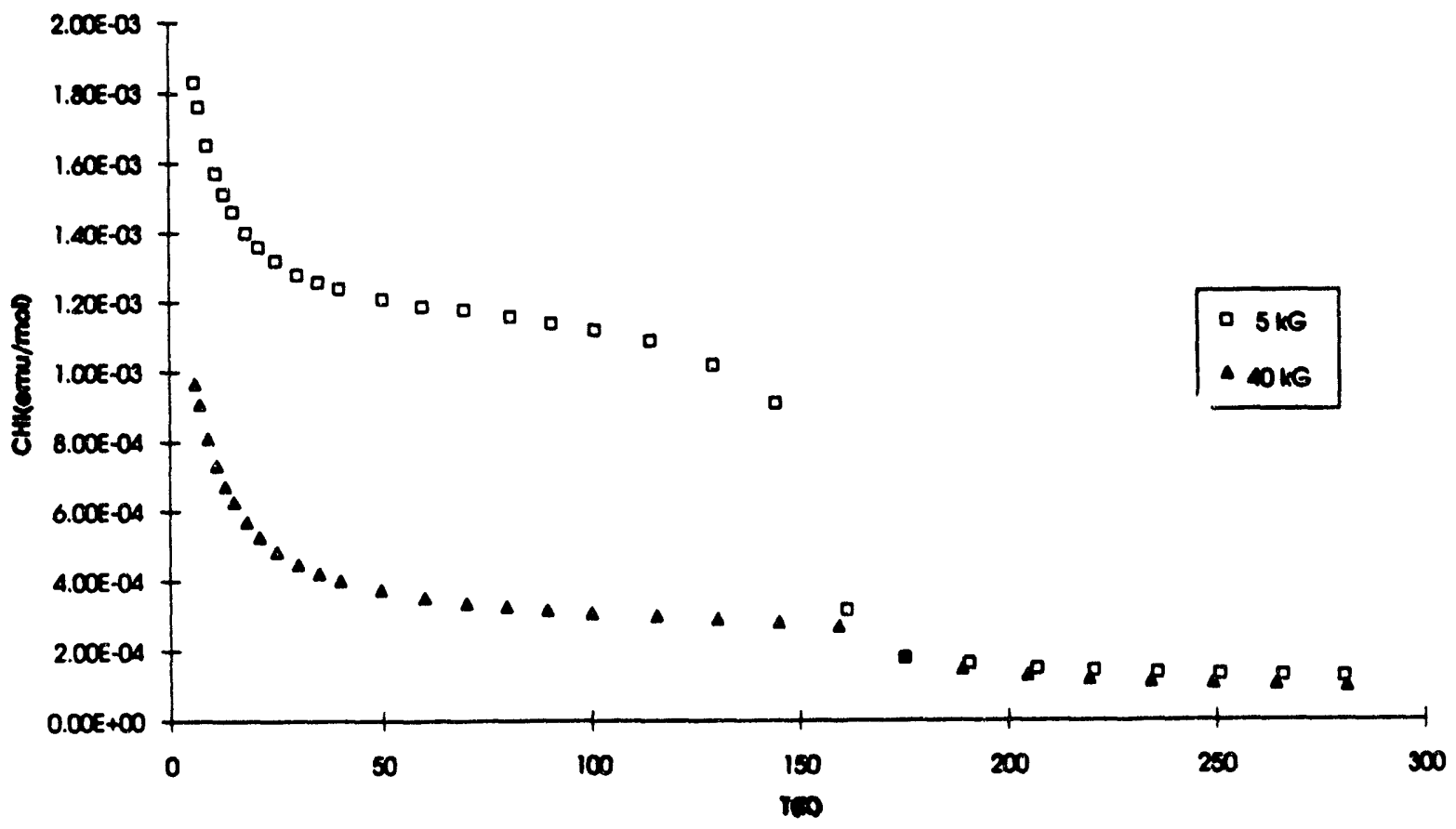

Figure 6.5. Magnetic susceptibility data for dilute $\mathrm{AgF}_{2}\left(15 \% \mathrm{AgF}_{2}, 85 \% \mathrm{CaF}_{2}\right) .5 \mathrm{kG}(\square)$ 40kG (A). 


\section{Chapter 7}

The Oxidizing Properties of Cationic $\mathbf{A g}(\mathrm{II})$ and a Comparison with $\mathbf{A g}(\mathrm{III})$

\section{Introduction}

Subsequent to its discovery, ${ }^{1} \mathrm{AgF}_{3}$ was observed to be, as anticipated, an extremely powerful oxidizer. Indeed Žemva and his coworkers have demonstrated that it is capable of oxidizing $\mathrm{Xe}_{\mathrm{e}}$ to $\mathrm{XeF}_{6}$ at room temperature. ${ }^{2}$ It was conjectured that the loss of $F_{2}$ from the thermally unstable trifluoride was under strongly acidic conditions:

$$
\mathrm{AgF}_{3}+\mathrm{AsF}_{5} \stackrel{\mathrm{AHF}}{\longrightarrow} \mathrm{AgF}^{+} \mathrm{AsF}_{6}^{-}+1 / 2 \mathrm{~F}_{2}
$$

occuring through a cationic $\mathrm{Ag}$ (III) species, $\mathrm{AgF}_{2}{ }^{+}$. If this were so, it was believed that such a cation, would be more powerfully oxidizing than neutral $\mathrm{AgF}_{3}$ alone. In fact dissolution of $\mathrm{AgF}_{3}$ in acidified $\mathrm{HF}$ was observed to oxidize Xe at ordinary temperatures and pressures but, remarkably, $\mathrm{Ag}(\mathrm{I})$ in the form of $\mathrm{AgAsF}_{6}$ was observed in the products 3

$$
2 \mathrm{AgF}_{3}+3 \mathrm{AsF}_{5}+2 \mathrm{Xe} \stackrel{\mathrm{AHF}}{\longrightarrow} \mathrm{Xe}_{2} \mathrm{~F}_{3}+\mathrm{AsF}_{6}+2 \mathrm{AgAsF}_{6}
$$

This indicated that even $\mathrm{Ag}(\mathrm{II})$, in cationic form, was capable of oxidizing xenon.

The remarkable oxidizing power of cationic $\mathrm{Ag}(\mathrm{II})$ has been further exemplified in these studies, by employing as reducing agents $\mathrm{C}_{6} \mathrm{~F}_{6}$ and $\mathrm{C}_{3} \mathrm{~F}_{6}$. The products of these reactions indicate that the first step is transfer of an electron from the substrate to cationic $\mathrm{Ag}(\mathrm{II})$. An attempt has been made to evaluate the upper limits of the oxidizing power of cationic $\mathrm{Ag}(\mathrm{II})$. In addition, reaction (1) as a potential source of $\mathrm{AgF}_{2}{ }^{+}$has been 
investigated to assess the upper limits of its oxidizing power.

\section{Experimental}

Materials. $\mathrm{AgF}_{3}$ was prepared as described in Chapter $5 . \mathrm{AgFAsF}_{6}$ and $\mathrm{AgFBF}_{4}$ were prepared as described in Chapter $6 . \mathrm{NF}_{3}$ was prepared by the room temperature direct fluorination of $\mathrm{N}_{2} \mathrm{~F}_{4}$ (Airco, Riverton, $\mathrm{NJ}$ ), and checked for impurities by infrared spectroscopy before use. ${ }^{4}$ House $\mathrm{O}_{2}$ was dried by passing through a coil cooled to $-196{ }^{\circ} \mathrm{C}$ before use. The purity of $\mathrm{C}_{3} \mathrm{~F}_{6}$, and $\mathrm{C}_{6} \mathrm{~F}_{6}$ (PCR,inc., Gainesville, FL) was checked by I.R. spectroscopy $5, \mathrm{C}_{3} \mathrm{~F}_{6}$ being used without further purification while $\mathrm{C}_{6} \mathrm{~F}_{6}$ was kept dry by storing it over $\mathrm{P}_{2} \mathrm{O}_{5}$. Xenon and krypton (Airco, Riverton, $\mathrm{NJ}$ ) were used as received.

Cationic $\mathrm{Ag}$ (II) from $\mathrm{AgFBF}_{4}$ and $\mathrm{BF}_{3}$ with $\mathrm{Xe}$ in $\mathrm{AHF}$. In the DRILAB $0.179 \mathrm{~g}$, $(0.839 \mathrm{mmol}) \mathrm{AgFBF}_{4}$ was loaded into a one armed Teflon/FEP reactor. On the vacuum line $5 \mathrm{ml}$ AHF was condensed into the reaction vessel by cooling it to $-196{ }^{\circ} \mathrm{C}$. Warming to room temperature resulted in no visible dissolution of $\mathrm{AgFBF}_{4}$, the blue solid remaining in colorless AHF. The reactor was pressurized to $2 \mathrm{~atm}$ with Xe and agitated for $2 \mathrm{hrs.} \mathrm{No}$ Xe uptake and no change in appearence of the reactants was observed. The Xe pressure was reduced 200 torr by opening to a ballast volume on the line and $\mathrm{BF}_{3}$ was now admitted to the reactor until a pressure of 1500 Torr had been restored. Still, no change in the reactants was observed. In order to saturate the $\mathrm{AHF}$ with $\mathrm{BF}_{3}$ and $\mathrm{Xe}$ the solution was frozen and warmed slowly back to room temperature. At lower temperatures $\left(\leq-30^{\circ} \mathrm{C}\right)$ a blue solution was observed. The solution became paler and vigorous gas evolution was observed on warming to room temperature, the final pressure, however being lower than 1500 Torr. The pressure was restored to 1500 Torr with Xe and the cooling - warming cycle was repeated. After 5 thermal cycles between the freezing point 
of AHF and room temperature, a colorless solid remained in a colorless solution. Volatile materials were removed at $-45^{\circ} \mathrm{C}$ in a dynamic vacuum for $5 \mathrm{hr}$. $\mathrm{XeF}_{2}$ was evacuated for $15 \mathrm{~min}$ at $40^{\circ} \mathrm{C}$ into a FEP U - trap cooled to $-78^{\circ} \mathrm{C}$. and was shown to be $\mathrm{XeF}_{2}$ by $\mathrm{X}$ ray powder photography and its intense Raman band 6 at $498 \mathrm{~cm}^{-1}$. The combined yield of $\mathrm{XeF}_{2}$ and $\mathrm{AgBF}_{4}$, characterized by $\mathrm{X}$ - Ray powder photography, ${ }^{7}$ was $235.3 \mathrm{mg}$ (theoretical $234.3 \mathrm{mg}$ ): yield of recovered $\mathrm{XeF}_{2}, 46.8 \mathrm{mg}, 66.0 \%$.

Interaction of Cationic $\mathrm{Ag}(\mathrm{II})$ with $\mathrm{C}_{3} \mathrm{~F}_{6}$ in $\mathrm{AsF}_{5}$ rich $\mathrm{AHF}$. In a one - armed Tefion tube reactor $\mathrm{AgFAsF}_{6}$ was synthesized in situ from $0.238 \mathrm{~g} \mathrm{AgAsF}_{6}(0.795 \mathrm{mmol})$ and in a greater than two fold molar excess of AsF5. The procedure (A) in Chapter 6 was followed. An overpressure of 2 atm of fluorine was maintained until a royal blue solution with no colorless precipitate was obtained. The solution was frozen at $-196^{\circ} \mathrm{C}$ and opened to a dynamic vacuum through the soda - lime scrubber to remove residual fluorine. With the reactor still at $-196{ }^{\circ} \mathrm{C}, \mathrm{C}_{3} \mathrm{~F}_{6}(0.36 \mathrm{mmol} ; 220$ Torr $\times 30 \mathrm{ml})$ was added to the frozen mixture in 3 separate aliquots of $0.2,0.1$, and $0.06 \mathrm{mmol}$. The reaction mixture was allowed to warm to $-70^{\circ} \mathrm{C}$ after the addition of each aliquot. A colorless precipitate was observed to form at the first signs of melting of the AHF. Each successive aliquot resulted in a paler blue supernatent solution over larger quantities of colorless solid. In the end (the entire reaction took $\approx 5 \mathrm{~min}$ ) a pale blue supernatent solution and a copious colorless solid remained. Volatile materials were condensed, under static vacuum, into a tube filled with $\mathrm{NaF}$, which had been cooled to $-196^{\circ} \mathrm{C}$. The volatile materials were allowed to remain in this tube for $15 \mathrm{~min}$ at room temperature in order trap $\mathrm{AHF}$ and $\mathrm{AsF}_{5}$ and then were condensed, at $-196^{\circ} \mathrm{C}$, into a $5 \mathrm{ml}$ stainless steel tube reactor which was sealed at one end and equipped with a SS-KS4 Whitey valve at the other. The weight of collected volatile compound was $70 \mathrm{mg}$ which corresponds to $0.35 \mathrm{mmol}$ of $\mathrm{C}_{3} \mathrm{~F}_{8}$, this being the only material observed in the I.R. ${ }^{8}$ of the coiliected volatiles. No traces of $\mathrm{CF}_{4}, \mathrm{C}_{2} \mathrm{~F}_{6}$, or residual $\mathrm{C}_{3} \mathrm{~F}_{6}$ were observed. 
Interaction of Cationic $\mathrm{Ag}(\mathrm{II})$ with $\mathrm{C}_{6} \mathrm{~F}_{6}$ in $\mathrm{AsF}_{5}$ rich $\mathrm{AHF}$. A solution of cationic $\mathrm{Ag}$ (II) was made up in the same way as above from $0.190 \mathrm{~g}$ (1.31 mmol) $\mathrm{AgF}_{2}$. After freezing the solution at $-196^{\circ} \mathrm{C}$ to remove residual fluorine under vacuum, $1 \mathrm{ml}(8.6$ mmol) $\mathrm{C}_{6} \mathrm{~F}_{6}$ was condensed on to the frozen solution. As soon as the AHF began to melt a bright yellow solid began to form, the reaction being completed in less than one minute, as judged by the disappearance of blue color characteristic of cationic $\mathrm{Ag}$ (II), at temperatures below $-50^{\circ} \mathrm{C}$. Even at $-60^{\circ} \mathrm{C}$ the yellow solid appeared to have significant solubility in AHF and was washed by several decantations into the free arm of the reactor. In the end a colorless solid in colorless AHF was left in the original reaction arm, bright yellow solid remaining in the second. AHF and excess $\mathrm{C}_{6} \mathrm{~F}_{6}$ were removed under vacuum through a soda - lime scrubber, while holding the arm containing the yellow solid at $0{ }^{\circ} \mathrm{C}$. The total weight of products in both arms of the reactor was $0.4311 \mathrm{~g}$. Assuming product formation follows reaction (5), the anticipated yield of $\mathrm{AgAsF}_{6}$ is $0.387 \mathrm{~g}$ and of $\mathrm{C}_{6} \mathrm{~F}_{6} \mathrm{AsF}_{6}$ is $0.491 \mathrm{~g}$. It is likely that much of the $\mathrm{C}_{6} \mathrm{~F}_{6} \mathrm{AsF}_{6}$ formed was evacuated as the thermal decomposition products ${ }^{9} \mathrm{C}_{6} \mathrm{~F}_{6}$ and $1,4 \mathrm{C}_{6} \mathrm{~F}_{8}$ (see reaction 6). The yield of $\mathrm{C}_{6} \mathrm{~F}_{6} \mathrm{AsF}_{6}$, assuming $0.387 \mathrm{~g}$ of the product is $\mathrm{AgAsF}_{6}$, is $44 \mathrm{mg}(0.09 \mathrm{mmol}), 7 \% . \mathrm{X}$ Ray powder photographs revealed that the yellow product contained $\mathrm{C}_{6} \mathrm{~F}_{6}{ }^{+} \mathrm{AsF}_{6}-$ and AgAsF $_{6} \cdot{ }^{10}$ The colorless solid in the other arm was $\mathrm{AgAsF}_{6}$.

\section{Interaction of Cationic $\mathrm{Ag}(\mathrm{II})$ and $\mathrm{O}_{\mathbf{2}}$ in $\mathrm{AsF}_{5}$ rich $\mathrm{AHF}$. In the DRILAB $0.68 \mathrm{~g}$} (2.2 mmol) AgFAsF $_{6}$ was loaded into one arm of a two armed Teflon/FEP reactor. On the vacuum line $5 \mathrm{ml} \mathrm{AHF}$ and $2.0 \mathrm{~g}(12 \mathrm{mmol}) \mathrm{AsF}_{5}$ were condensed on to the solid at $-196{ }^{\circ} \mathrm{C}$. Warming to room temperature resulted in a royal blue solution free of solids. The reactor was cooled again to $-196^{\circ} \mathrm{C}$ and evacuated under dynamic vacuum to ensure the absence of molecular $\mathrm{F}_{2}$. The royal blue solution was allowed to equilibrate at $-70^{\circ} \mathrm{C}$ for $15 \mathrm{~min}$. No sediment appeared during this time. Opening the reactor to the vacuum 
line, which had been pressurized with 1600 Torr of dry $\mathrm{O}_{2}$, produced an immediate drop due to expansion into the reactor volume. This was followed by a further steady, slow decrease in pressure accompanied by the formation of a colorless solid and a near disappearance of the blue solution color. Within $15 \mathrm{~min} \mathrm{O}_{2}$ uptake had ceased and the colorless precipitate was copious. Warming the reaction mixture slightly to $-60^{\circ} \mathrm{C}$ resulted in an increase in line pressure, an increase in intensity of the blue color in the solution, and a decrease in the quantity of colorless solid. At $-40^{\circ} \mathrm{C}$, no solid remained in the royal blue solution and the line pressure had returned to the level observed immediately after opening the line to the reactor. Warming to room temperature and removing the $\mathrm{AsF}_{5} / \mathrm{AHF}$ solution under vacuum left only $\mathrm{AgFAsF}_{6}$ which was identified by $\mathrm{X}$ - ray powder photography. Restoring the $A s F_{5} / \mathrm{AHF}$ solution and cooling to $-70^{\circ} \mathrm{C}$ again, resulted in $\mathrm{O}_{2}$ uptake and again produced the colorless solid. To facilitate removal of the $\mathrm{AsF}_{5} / \mathrm{AHF}$ solution under vacuum the mixture was warmed to $-60^{\circ} \mathrm{C}$ and in consequence of this, the colorless solid diminished in quantity. On drying under dynamic vacuum $0.80 \mathrm{~g}$ of light blue solid product remained for a yield of $\approx 0.16 \mathrm{~g}$ ( $0.79 \mathrm{mmol} ; 37 \%$ ) $\mathrm{O}_{2} \mathrm{AsF}_{6}$ based on the anticipated formation of $0.64 \mathrm{~g}$ of $\mathrm{AgAsF}_{6}$. $\mathrm{X}$ - Ray powder photographs of the solid indicated that it contained $\mathrm{O}_{2}{ }^{+} \mathrm{AsF}_{6}-$ and AgAsF $_{6}{ }^{11}$ The blue tint indicates that some $\mathrm{AgFAsF}_{6}$ was also present, but this was not revealed by the $\mathrm{X}$ - Ray powder photographs.

Interaction of $\mathrm{AgF}_{3}$ with $\mathrm{O}_{2}$ in $\mathrm{AsF}_{5}$ rich $\mathrm{AHF}$. In the DRILAB $0.147 \mathrm{~g}$ ( $0.893 \mathrm{mmol}) \mathrm{AgF}_{3}$ was loaded into one arm of a two armed Teflon/FEP reactor which had been passivated for several hours with $2 \mathrm{~atm} \mathrm{~F}_{2}$. The reactor was evacuated and charged with $3 \mathrm{ml}$ AHF and $1.5 \mathrm{~g}(8.8 \mathrm{mmol}) \mathrm{AsF}_{5}$ by cooling the tube containing the $\mathrm{AgF}_{3}$ to $-196^{\circ} \mathrm{C}$. While warming this tube to $-70^{\circ} \mathrm{C}$, the entire vacuum system and reactor $(125 \mathrm{ml})$ was pressurized to $1500 \mathrm{Torr}(10 \mathrm{mmol})$ with dry $\mathrm{O}_{2}$. The pressure of the system 
increased slightly until the $\mathrm{AsF}_{5} / \mathrm{AHF}$ mixture began to melt. Then the pressure in the line immediately began to drop, and a coloress solid and pale blue solution began to form. The reaction arm was allowed to warm to $-60^{\circ} \mathrm{C}$ and held at that temperature for $20 \mathrm{~min}$ with intermittent agitation until all traces of the red solid, $\mathrm{AgF}_{3}$, had disappeared. A voluminous colorless solid and a blue solution remained and the latter appeared to become more intensely colored as the solution was warmed. The pressure fell approximately 200 Torr during the reaction for an $\mathrm{O}_{2}$ uptake of $\approx 1.0 \mathrm{mmol}$. The pressure varied considerably, however, with fluctuations in temperature. With the coloriess solid held at $-60^{\circ} \mathrm{C}$, the blue solution was decanted into the free arm of the reactor. Volatile materials were removed from the reaction vessel as it was allowed to warm to room temperature. The colorless solid was identified as $\mathrm{O}_{2}+\mathrm{AsF}_{6}-$ based on its $\mathrm{X}$ - Ray powder pattern and its characteristic $\mathrm{O}_{2}{ }^{+}$Raman stretch $11_{\text {at }} 1857 \mathrm{~cm}^{-1}$. The weight of $0.13 \mathrm{~g}$ corresponds to ( $0.64 \mathrm{mmol}) ; 72 \%$ yield based on $\mathrm{AgF}_{3}$.

$\mathrm{AgF}_{3}$ with $\mathrm{NF}_{3}$ in $\mathrm{AsF}_{5}$ rich $\mathrm{AsF}_{5}$. In the DRILAB $0.14 \mathrm{~g}(0.84 \mathrm{mmol}) \mathrm{AgF}_{3}$ was loaded into one arm of a two armed teflon/FEP reactor. The reaction was set up identically to that for the interaction of $\mathrm{AgF}_{3}$ with $\mathrm{O}_{2}$ in acidified AHF. Following the transfer of the $\mathrm{AHF} / \mathrm{AsF}_{5}$ mixture on to the $\mathrm{AgF}_{3}$ by cooling this arm of the reactor to $-196{ }^{\circ} \mathrm{C}$ the reactor was pressurizerd to 1100 Torr with $\mathrm{NF}_{3}$ as it was allowed to warm to $-60{ }^{\circ} \mathrm{C}$. The reactor was left open to the Helicoid gauge to monitor the pressure.The solution was cycled between $-90^{\circ} \mathrm{C}$ and $-60^{\circ} \mathrm{C}$ several times in an effort to saturate it with $\mathrm{NF}_{3}$. No significant pressure change was observed as the $\mathrm{AgF}_{3}$ began to dissolve in the $\mathrm{AsF}_{5} / \mathrm{AHF}$ solution. Within $15 \mathrm{~min}$ all $\mathrm{AgF}_{3}$ had dissolved (the dissolution of $\mathrm{AgF}_{3}$ in acidified AHF being much more rapid at $-60^{\circ} \mathrm{C}$ than at temperatures only slightly cooler). The mixture was allowed to stand at $-60^{\circ} \mathrm{C}$ with occasional agitation for another hour. $\mathrm{NF}_{3}$ and the $\mathrm{AsF}_{5} / \mathrm{AHF}$ solution were removed under dynamic vacuum through a soda - 
lime scrubber as the reaction tube was warmed to room temperature. The solid blue products were dried under vacuum for $1 \mathrm{hr}$ at room temperature. $\mathrm{X}$-Ray powder photographs revealed $\mathrm{AgFAsF}_{6}$ and an additional uncharacterized phase. Raman spectroscopy revealed a weak band at $1125 \mathrm{~cm}^{-1}$, which is in a region where $\mathrm{N}-\mathrm{F}$ stretches are known to occur, however, it does not correspond to that of any $\mathrm{NF}_{4}{ }^{+}$ species. 12

$\mathrm{AgF}_{3}$ with $\mathrm{Kr}$ in $\mathrm{AsF}_{5}$ rich $\mathrm{AHF}$. In a similar reaction $0.15 \mathrm{~g}(0.91 \mathrm{mmol}) \mathrm{AgF}_{3}$ was allowed to interact with $1500 \mathrm{Torr}(10 \mathrm{mmol}) \mathrm{Kr}$ at $-70^{\circ} \mathrm{C}$ as it was dissolved in $\mathrm{AsF}_{5}$ (5:1 molar excess of $\mathrm{AgF}_{3}$ )/AHF solution. Thermal cycling between -90 and $-70^{\circ} \mathrm{C}$ resulted in $\mathrm{Kr}$ uptake. At $-70^{\circ} \mathrm{C}$, the $\mathrm{AgF}_{3}$ took several hours to dissolve (in contrast to the relatively rapid dissolution at $-60^{\circ} \mathrm{C}$ ), eventually leaving a deep blue solution and a small amount $(=5 \mathrm{mg})$ of white precipitate which readily dissolved at higher temperatures. Because of the thermal instability of $\mathrm{KrF}^{+} \mathrm{AsF}_{6}^{-}$and the volatility of $\mathrm{KrF}_{2}$, at temperatures which would permit the removal of the $\mathrm{AsF}_{5} / \mathrm{AHF}$ solution under vacuum, efforts were made to obtain Raman spectra on the colorless solid and the frozen solution at $-196{ }^{\circ} \mathrm{C}$, still in the $\mathrm{FEP}$ tube reactor. No frequencies characteristic ${ }^{13}$ of $\mathrm{KrF}^{+}, \mathrm{KrF}_{2}$, or $\mathrm{Kr}_{2} \mathrm{~F}_{3}{ }^{+}$were observed either from the colorless solid, or the frozen blue solution. However, bands attributable to $\mathrm{AsF}_{6}^{-}$as well as FEP were observed.

\section{Results and Discussion}

$\mathrm{AgF}_{2}$ has long been an important oxidative fluorinator in organo - fluorine chemistry and has been desribed as the most oxidizing of the divalent metal fluorides. 14 The $\mathrm{Ag}(\mathrm{II})$ in the positively charged $(\mathrm{Ag}-\mathrm{F})_{n}{ }^{\mathrm{n}+}$ cation is expected to be more electronegative, and hence more oxidizing than in the neutral species and $\mathrm{Ag}^{+2}$ solvated with neutral HF molecules might be expected to be un even more potent oxidizer than $(\mathrm{Ag}-\mathrm{F})_{\mathrm{n}}^{\mathrm{n}+}$. 
The oxidation of $\mathrm{Xe}$ by $\mathrm{AgF}^{+} \mathrm{AsF}_{6}-$ as described by $\check{Z}_{\text {emva et al }}{ }^{3}$ proceeds very slowly in neutral AHF solution, the reactivity being greatly enhanced by the addition of $\mathrm{AsF}_{5}$ to the solution

$$
4 \mathrm{AgFAsF}_{6}+2 \mathrm{Xe}+\mathrm{AsF}_{5} \stackrel{\mathrm{AHF}}{\longrightarrow} \mathrm{Xe}_{2} \mathrm{~F}_{3}+\mathrm{AsF}_{6}+4 \mathrm{AgAsF}_{6}
$$

The presence of additional $\mathrm{AsF}_{5}$ certainly facilitates oxidation of $\mathrm{Xe}$ and its presence may be necessary for any oxidation of Xe to occur at all. In Chapter 6, it was pointed out that dissolution of $\mathrm{AgFAsF}_{6}$ in AHF was always accompanied by a solvolysis reaction releasing $\mathrm{AsF}_{5}$ into the solution. Recently in these laboratories 15 it has been established that a large molar excess of $\mathrm{AHF}$ leads to precipitation of $\mathrm{AgF}_{2}$.

That additional acid is a necessary component of $\mathrm{Xe}$ oxidation by $\mathrm{Ag}(\mathrm{II})$ is more clearly demonstrated in the oxidation of $\mathrm{Xe}_{\text {by }} \mathrm{AgFBF}_{4}$. The poorly soluble $\mathrm{AgFBF}_{4}$ exhibited no signs of interaction with Xe in AHF over several hours. Even in the presence of an overpressure of $\mathrm{BF}_{3}$, at room temperature, no signs of reaction were observed. However, under these conditions there was no hint of blue color in the solution, either, probably indicating the absence of $\mathrm{Ag}$ (II) in solution. Cooling solutions of AHF had been observed to greatly enhance the solubility of $\mathrm{BF}_{3}$ in them, this being utilized in the synthesis of $\mathrm{AgFBF}_{4}$ from $\mathrm{AgF}_{2}$ and $\mathrm{BF}_{3}$ (Chapter 6). Indeed, cooling AHF containing $\mathrm{AgFBF}_{4}$ resulted in considerable uptake of $\mathrm{BF}_{3}$ as judged by tensimetry and the production of a royal blue supernatent solution over the dark blue solid. When Xe was added to this blue solution at $-40^{\circ} \mathrm{C}$ a slow reaction did proceed as judged by the gradual lightening of the solid materal in equilibrium with the solution. The speed of the reaction was significantly increased by thermal cycling of the solution between the freezing point of AHF and $0{ }^{\circ} \mathrm{C}$. It is probable that at lower temperatures the solution becomes more saturated with $\mathrm{Xe}$ and $\mathrm{BF}_{3}$ the latter facilitating the dissolution of $\mathrm{AgFBF}_{4}$. Warming the 
solution must provide greater activation energy for the oxidation and coupled with the short lived supersaturation of the $\mathrm{AHF}$ solution with $\mathrm{BF}_{3}$ and $\mathrm{Xe}$, makes for more favorable reaction kinetics.

Because $\mathrm{BF}_{3}$ is a weaker acid than $\mathrm{AsF}_{5}, 16$ and unlike the latter is incapable of stabilizing $\mathrm{Xe}$ (II) fluorocations out of solution, the isolated Xe product from its oxidation by $\mathrm{AgFBF}_{4}$ is $\mathrm{XeF}_{2}$

$$
2 \mathrm{AgFBF}_{4}+\mathrm{Xe}+\mathrm{BF}_{3} \stackrel{\mathrm{AHF}}{\longrightarrow} 2 \mathrm{AgBF}_{4}+\mathrm{XeF}_{2}+\mathrm{BF}_{3}
$$

The effect of additional fluoroacid in facilitating the reastion of cationic $\mathbf{A g}$ (II) species is not established, but it probably involves the formation of an $\mathrm{Ag}^{+2}\left(\mathrm{AF}^{-}\right)_{2}$ species (where $\mathrm{A}=\mathrm{BF}_{3}$ or $\mathrm{AsF}_{5}$ ), the cation and anion being solvated with neutral HF molecules. Such salts are known (Chapter 6), and although, in the case of the $\mathrm{BF}_{4}^{-}$and $\mathrm{AsF}_{6}^{-}$salts, are not derivable from AHF solution, they are suggested by the greatly increased solubilities of $\mathrm{AgFBF}_{4}$ and $\mathrm{AgFAsF}_{6}$ when additional acid is provided. The formation of a more charged $\mathrm{Ag}(\mathrm{II})$ cation by effectively removing the covalently bound bridging $\mathrm{F}$ ligands of the $(\mathrm{Ag}-\mathrm{F})_{\mathrm{n}}{ }^{\mathrm{n}+}$ chain, is expected to increase the electron affinity (EA) of the cationic $\mathrm{Ag}(\mathrm{II})$ making it a more powerful oxidizer than $(\mathrm{Ag}-\mathrm{F})_{n^{n+}}$.

The remarkable oxidizing power of $\mathrm{Ag}$ (II) correlates with the high second ionization potential of silver. That is compared with those of other coinage metals and that of xenon in Table 7.1 
Table 7.1. The $2^{\text {nd }}$ Ionization Potentials of the Coinage Metals and Xenon 17

$\begin{array}{cc}\mathrm{M} & 2^{\text {nd }} \mathrm{I.P}(\mathrm{eV}) \\ \mathrm{Cu} & 20.29 \\ \mathrm{Ag} & 21.49 \\ \mathrm{Au} & 20.5 \\ \mathrm{Xe} & 21.21\end{array}$

The $2^{\text {nd }}$ I.P. of $\mathrm{Ag}$ is higher than those of $\mathrm{Cu}$ or $\mathrm{Au}$, and, in fact is higher than that of any non - alkali metal. Because the $\mathrm{d}^{9}$ configuration is strongiy antibonding (both sigma and pi), the binding of the solvent molecules (such as HF) must be weak. The electron affinity of $\mathrm{Ag}(\mathrm{HFF})_{\mathrm{x}}+2$ must therefore be high. It is therefore plausible to postulate that the first step in the oxidation by cationic $\mathrm{Ag}(\mathrm{II})$ is the transfer of an electron from the species to be oxidized to that cation.

The behavior of the reducing agents $\mathrm{C}_{6} \mathrm{~F}_{6}$ and $\mathrm{C}_{3} \mathrm{~F}_{6}$ in the presence of $\mathrm{AgFAsF}_{6} / \mathrm{AsF}_{5}$ in $\mathrm{AHF}$ strongly suggest that such electron transfer is, in fact, occuring. In reactions with additional $\mathrm{AsF}_{5}, \mathrm{C}_{6} \mathrm{~F}_{6}$ in combination with $\mathrm{AgFAsF}_{6}$ gave the radical cation salt $\mathrm{C}_{6} \mathrm{~F}_{6}{ }^{+} \mathrm{AsF}_{6}-$, the acid reaction proceeding via

$$
\mathrm{Ag}^{2+}(\text { solv })+\mathrm{C}_{6} \mathrm{~F}_{6} \stackrel{\mathrm{AHF} / \mathrm{AsF}_{3}}{\longrightarrow} \mathrm{C}_{6} \mathrm{~F}_{6}{ }^{+} \text {(solv) }+\mathrm{Ag}_{(\text {solv })}^{+}
$$

This salt is unstable ${ }^{9}$ at room temperature and decomposes to $\mathrm{C}_{6} \mathrm{~F}_{6}$ and the fluorinated product, which is the specific diene, $1,4 \mathrm{C}_{6} \mathrm{~F}_{8}$

$$
2 \mathrm{C}_{6} \mathrm{~F}_{6}{ }^{+} \mathrm{AsF}_{6}-\mathrm{C}_{6} \mathrm{~F}_{6}+1,4 \mathrm{C}_{6} \mathrm{~F}_{8}
$$


The initial formation of the radical cation salt rather than the fluorinated cyclic olefin demonstrates the electron transfer. The relative ease of this reaction, which proceeds rapidly near the melting point of $\mathrm{AHF}\left(\approx-80^{\circ} \mathrm{C}\right)$ is in accord with the relatively low $1^{\text {st }}$ I.P. of $\mathrm{C}_{6} \mathrm{~F}_{6}(9.97 \mathrm{eV}) .{ }^{18}$

That $\mathrm{AgFAsF}_{6} / \mathrm{AsF}_{5}$ solutions are not behaving simply as $\mathrm{F}$ atom sources, is further borne out in their reaction with the fluorinated olefin, $\mathrm{C}_{3} \mathrm{~F}_{6}$. Again the reduction of $\mathrm{Ag}(\mathrm{II})$ is observed to proceed rapidly at low temperatures, $\mathrm{C}_{3} \mathrm{~F}_{6}(1 \mathrm{st}$ I.P. $=10.62 \mathrm{eV}), 19$ $\mathrm{C}_{3} \mathrm{~F}_{8}$ being the only observed fluorinated organic product. By analogy with reaction 5 , a radical cation, $\mathrm{C}_{3} \mathrm{~F}_{6}{ }^{+}$, is probable, but in this case not isolable as a salt.

$$
\mathrm{Ag}^{+2} \text { (solv) }+\mathrm{C}_{3} \mathrm{~F}_{6} \stackrel{\mathrm{AHF} / \mathrm{AsF}_{3}}{\longrightarrow}\left[\mathrm{C}_{3} \mathrm{~F}_{6}{ }^{+}\right]_{(\text {solv })}+\mathrm{Ag}^{+} \text {(solv) }
$$

This may be attacked by $\mathrm{F}^{-}$to yield the $\mathrm{C}_{3} \mathrm{~F}_{7}$ radical, which in turn is oxidized by a second equivalent of $\mathrm{Ag}^{+2}$ (solv) to the cation $\mathrm{C}_{3} \mathrm{~F}_{7}{ }^{+}$, this then yielding $\mathrm{C}_{3} \mathrm{~F}_{8}$. If the $\mathrm{Ag}$ (II) cation in AHF were simply acting as a $\mathrm{F}$ atom sous ces, fluorination with $\mathrm{C}-\mathrm{C}$ bond cleavage to create $\mathrm{CF}_{4}$ and $\mathrm{C}_{2} \mathrm{~F}_{6}$ would have been expected. ${ }^{20}$ No such fragmentation was detected in these cationic $\mathbf{A g}(\mathrm{II})$ oxidations. 
Fig 7.1. Electron Oxidation by Cationic Ag(II)

1. $\mathrm{Ag}^{+2}\left(\mathrm{AF}^{-}\right)_{2}+\mathrm{Xe} \longrightarrow \mathrm{Xe}^{+} \mathrm{AF}^{-}+\mathrm{Ag}^{+} \mathrm{AF}^{-}$

2. $\mathrm{Xe}^{+} \mathrm{A}-\mathrm{F}^{-} \longrightarrow \cdot \mathrm{Xe}-\mathrm{F}+\mathrm{A}$

3. $\mathrm{Ag}^{+2}\left(\mathrm{AF}^{-}\right)_{2}+\cdot \mathrm{Xe}-\mathrm{F} \longrightarrow \mathrm{XeF}^{+} \mathrm{AF}^{-}+\mathrm{Ag}^{+} \mathrm{AF}^{-}$

4.(opt) $\quad \mathrm{XeF}^{+} \mathrm{A}-\mathrm{F}^{-} \longrightarrow \mathrm{XeF}_{2}+\mathrm{A}$

net reaction: $2 \mathrm{Ag}^{+2}\left(\mathrm{AF}^{-}\right)_{2}+\mathrm{Xe} \longrightarrow \mathrm{XeF}_{2}+2 \mathrm{Ag}^{+} \mathrm{AF}^{-}$

where $\mathrm{A}=\mathrm{BF}_{3}$ and $\mathrm{AsF}_{5}$

As indicated in Fig 7.1, the oxidation of Xe probably begins with the removal of an electron from $\mathrm{Xe}$. The $\mathrm{Xe}^{+}$cation is a strong acid since the $\mathrm{XeF}$ radical is bound $\left(\Delta \mathrm{H}^{\circ} \mathrm{Xe}_{(\mathrm{g})}+\mathrm{F}_{(\mathrm{g})} \rightarrow \mathrm{XeF}_{(\mathrm{g})}=3.5 \mathrm{kcal} \mathrm{mol}^{-1}\right)^{21}$. As Bartlett and Sladky 22 point out in their outline of the thermochemical series for the formation of $\mathrm{XeF}_{2}$ and $\mathrm{XeF}^{+}$from $\mathrm{Xe}$ and $\mathrm{F}$ atoms, the I.P. of XeF radical is equal to the I.P of Xe less the difference in bond energies of $\mathrm{XeF}$ and $\mathrm{XeF}^{+}$. A number of independent studies place the bond dissociation energy of $\mathrm{XeF}^{+}$at $2.0 \mathrm{eV},{ }^{23}$ while Tellinghuisen ${ }^{21}$ finds that a reasonable estimate for $\mathrm{XeF}$ is $\approx 0.15 \mathrm{eV}$. This means that the I.P of the $\mathrm{XeF}$ radical is nearly $2 \mathrm{eV}$ lower than that of $\mathrm{Xe}$ atoms. Hence, oxidation by a second $\mathrm{Ag}(\mathrm{II})$ species readily occurs to form $\mathrm{XeF}^{+}$in step 3. This cation is also an extremely strong acid. This is indicated by the crystal structure of FXe - F - AsF5, where the bridging F ligand is making a strong interaction with the cationic $\mathrm{XeF}$ species. ${ }^{24} \mathrm{The} \mathrm{XeF}^{+}$cation readily abstracts a F- to form $\mathrm{XeF}_{2}$ 
from $\mathrm{BF}_{4}^{-}$since $\mathrm{BF}_{3}$ is a weaker fluoroacid (step 4). The situation with $\mathrm{AsF}_{5}$ is more complex. $\mathrm{XeF}^{+} \mathrm{AsF}_{6}{ }^{-}$is stable, but in $\mathrm{AHF}^{25}$, partial solvolysis occurs to yield $\mathrm{Xe}_{2} \mathrm{~F}_{3}+\mathrm{AsF}_{6}$. Formation of the last product results from a combination of steps 3 and 4 .

This reaction scheme is helpful for understanding the ineffectiveness of $\mathrm{AgF}^{+}$salts alone in oxidizing Xe. The $\mathrm{F}^{-}$ligand donates electrons more effectively than the HF molecule. The electron affinity of any monocation $\mathrm{AgF}(\mathrm{HF})_{\mathrm{y}}{ }^{+}$is therefore likely to be lower than that of the dication $\mathrm{Ag}(\mathrm{HF})_{\mathbf{x}}{ }^{+2}$.

Attempts to oxidize $\mathrm{O}_{2}$ with $\mathrm{AgFAsF}_{6} / \mathrm{AsF}_{5}$ initially failed at room temperature even though the $1^{\text {st }}$ I.P. of $\mathrm{O}_{2}$ is measured to be the same as that of $\mathrm{Xe} .{ }^{26}$ While step 1 in the electron oxidation scheme is expected to be energetically similar for both Xe and $\mathrm{O}_{2}$, fluorine ligation to generate $\mathrm{XeF}^{+}$, significantly differentiates the two cases. The observed $\mathrm{O}$ - $\mathrm{O}$ stretching frequencies for $\mathrm{O}_{2}, \mathrm{O}_{2}^{+}$, and $\mathrm{O}_{2} \mathrm{~F}$ shown in Table 7.2 indicate that $\mathrm{F}$ ligation weakens the $\mathrm{O}-\mathrm{O}$ bond of $\mathrm{O}_{2}$. This is expected since the electron density from the $\mathrm{F}$ atom must flow into an $\mathrm{O}-\mathrm{O}$ antibonding $\pi$ orbital on $\mathrm{O}-\mathrm{F}$ bond formation. 27 Thus formation of an $\mathrm{O}_{2} \cdots \mathrm{F}$ bond simultaneously with electron removal does not significantly lower the ionization energy.

Table 7.2. Observed O - O Stretching Frequencies

$\begin{array}{cc} & \text { v } 0-\mathrm{O}^{\left(\mathrm{cm}^{-1}\right)} \\ \mathrm{O}_{2} \mathrm{~F} & 1490^{28} \\ \mathrm{O}_{2} \mathrm{~F}_{2} & 1210^{29} \\ \mathrm{O}_{2} & 1555^{30} \\ \left(\mathrm{O}_{2}{ }^{+}\right) & 1857^{11}\end{array}$


If $\mathrm{Xe}$, which is readily oxidized, is reacting via a first step which is energetically similar to that expected for $\mathrm{O}_{2}$, then $\mathrm{Ag}$ (II) under acidic conditions must be very close to oxidizing $\mathrm{O}_{2}$. Indeed, in subsequent experiments it was found that lowering the temperature of $\mathrm{AgFAsF}_{6} / \mathrm{AsF}_{5}$ solutions in the presence of $\mathrm{O}_{2}$ below $-50^{\circ} \mathrm{C}$, induced $\mathrm{O}_{2}$ uptake with the formation of $\mathrm{O}_{2}+\mathrm{AsF}_{6}-$. Nearly complete conversion to $\mathrm{O}_{2} \mathrm{AsF}_{6}$ and AgAsF 6 was observed at $-78^{\circ} \mathrm{C}$ as evidenced by the formation of large quantities of colorless $\mathrm{O}_{2} \mathrm{AsF}_{6}$ and $\mathrm{AgAsF}_{6}$ in a nearly colorless solution. By itself, $\mathrm{AgFAsF}_{6}$ is extremely soluble in $\mathrm{AsF}_{5}$ rich AHF even at these low temperatures, giving an intensely blue solution.

The reaction

$$
\mathrm{O}_{2}+\mathrm{Ag}^{+2} \text { (solv) } \stackrel{\mathrm{AHF} / \mathrm{AsF}_{3}}{\longrightarrow} \mathrm{O}_{2}+\mathrm{AsF}_{6}^{-}+\mathrm{Ag}^{+} \text {(solv) }
$$

is certainly in equilibrium as warming above $-50^{\circ} \mathrm{C}$ brought about a complete reversal of reaction (8). Apparently the reaction is sufficiently close thermally that the negative entropy term encountered on going from gaseous $\mathrm{O}_{2}$ to $\mathrm{O}_{2}+$ in a lattice $\left(\Delta S \approx-75 \mathrm{cal} \mathrm{deg}^{-1} \mathrm{~mol}^{-1}\right)^{31}$ makes the forward reaction unfavorable at higher temperatures. The enthalpy change for the forward reaction must be exothermic and approximately independent of temperature.

Yields in reaction (8) were usually low, because the $\mathrm{AsF}_{5} / \mathrm{AHF}$ solution could not be completely evacuated below $-70^{\circ} \mathrm{C}$. The higher temperatures required for that favored the reverse reaction. As expected yields were greatly increased when $\mathrm{AgF}_{3}$ was used as the starting material in $\mathrm{AsF}_{5}$ rich AHF

$$
\mathrm{AgF}_{3}+\mathrm{O}_{2}+\mathrm{AsF}_{5} \text { (excess) } \stackrel{\mathrm{AHF}}{\longrightarrow} \mathrm{O}_{2} \mathrm{AsF}_{6}+\mathrm{AgFAsF}_{6}
$$


for now the $\mathrm{O}_{2} \mathrm{AsF}_{6}$ is formed in the presence of a comparable oxidizer, cationic $\mathrm{Ag}$ (II).

If a cationic $\mathrm{Ag}(\mathrm{III})$ species, such as $\mathrm{AgF}_{2}{ }^{+}$, is formed it is perhaps not sufficiently long - lived to act as an oxidizer, for there is no conclusive evidence that the acidic $\mathrm{AgF}_{3}$ system reacts with the more difficult to oxidize $\mathrm{NF}_{3}\left(1^{\text {st }} \text { I.P. }=13.20 \mathrm{eV}\right)^{32}$ and $\operatorname{Kr}\left(1^{\mathrm{st}}\right.$ I.P. $=13.99 \mathrm{eV})^{33}$. It is possible that solid $\mathrm{AgF}_{3}$ in $\mathrm{AHF}$ is simply providing $\mathrm{F}$ atoms to refluorinate the $\mathrm{Ag}(\mathrm{I})$ as it is formed by $\mathrm{Ag}(\mathrm{II})$ oxidation of $\mathrm{O}_{2}$. At $-70^{\circ} \mathrm{C}$ reaction (9) appears to go slightly faster than reaction (8), however $\mathrm{O}_{2} \mathrm{AsF}_{6}$ is being formed very rapidly in both. A rate increase for reaction (8) is to be expected, however, because a large concentration of cationic $\mathrm{Ag}(\mathrm{II})$ is always maintained in reaction (9), until the $\mathrm{AgF}_{3}$ is depleted, while it is diminishing from the start of reaction (8).

A comparison of the chemistry of cationic $\mathrm{Ag}$ (II) with anionic $\mathrm{Ag}$ (III) highlights the remarkable nature of this oxidizer. In a reaction with Xe it was observed that a solution of $\mathrm{KAgF}_{4}$ rapidly produced $\mathrm{XeF}_{2}$ and $\mathrm{AgF}_{2}$. A comparabic nxidation of $\mathrm{O}_{2}$, however, has not been demonstrated. In fact $\mathrm{Mr}$. Byron Shen has shown ${ }^{34}$ that $\mathrm{O}_{2} \mathrm{AsF}_{6}$ will actually oxidize a mixture of $\mathrm{KF}$ and $\mathrm{AgF}$ to $\mathrm{Ag}(\mathrm{III})$ as $\mathrm{KAgF}_{4}$. At low temperatures, therefore cationic $\mathrm{Ag}(\mathrm{II})$ appears to be a stronger oxidizer than even certain $\mathrm{Ag}(\mathrm{III})$ systems.

\section{References}

1. Žemva, B.; Lutar, K.; Jesih, A.; Casteel, Jr., W.J.; Bartlett, N. J. Chem. Soc., Chem. Commun. 1989, 346.

2. B. Žernva and coworkers, unpublished results.

3. Žemva, B.; Hagiwara, R.; Casteel, Jr., W.J.; Lutar, K.; Jesih, A.; Bartlett, N. J. Am. Chem. Soc. 1990, 112, 4846.

4. Nakamato, K. Infrared Spectra of Inorganic and Coordination Compounds, " p.86, Wiley, New York, 1963. 
5. Hall, K.R.; Wilholt, R.C.; Fergusson, A.M.; Boyd, B. "Thermodynamic Research Center Data Project," Ser. \# 1010, Austin, TX, 1983.

6. Agron, P.A.; Begun, G.M.; Levy, H.A.; Mason, A.A.; Jones, G.; Smith, D.F. Science, $1963,139,842$.

7. Sharp, D.W.A.; Sharpe, A.G. J. Chem. Soc. 1956,1855.

8. Hall, K.R., Ser. \# 981

9. Richardson, T.J.; Tanzella, F.L.; Bartlett, N. J. Am. Chem. Soc. 1986, 108, 4937.

10. Cox, J. Chem. Soc. $1956,876$.

11. Shamir, J.; Binenboym, J.; Stringham, R.S.; Hill, M.E. Inorg. Chim. Acta. 1968, 2, 37.

12. Christe, K.O.; Guertin, J.P.; Pavlath, A.E.; Sawodny, W. Inorg. Chem. 1967, 6, 533.

13. Gillespie, R.J.; Schrobilgen, G.J. Inorg. Chem. 1976, 15, 22.

14. Meshri, D.T. "The Modern, Inorganic Fluorochemical Industry," J. Fluor. Chem. 1986, 33, p.211.

15. B. Žemva, unpublished results.

16. For the evaluation of the fluoride ion affinities of $\mathrm{BF}_{3}, \mathrm{AsF}_{5}$, and other fluoroacids see Mallouk, T. E.; Rosenthal, G. L.; Muller,G; Brusasco, R; Bartlett, N. Inorg. Chein., 1984, $23,3167$.

17. Ionization Potentials and Ionization Limits for Atomic Spectra. Moore, C.E. Natl. Stand. Ref. Data Ser., Natl. Bur. Stand. 1970, 34.

18. Ionization Potentials, Appearance Potentials, and Heats of Formation of Positive Ions. Levin, R.D.; Lias, S.G Natl. Stand. Ref. Data Ser., Natl. Bur. Stand. 1982, 273.

19. Ibid., 272

20. Banks, R.E.; Tatlow, J.C. "Synthesis of C - F Bonds: The Pioneering Years, 1835 1940," J. Fluor. Chem. 1986, 33, 81 - 89.

21. Tellinghuisen, P.C.; Tellinghuisen, J.; Coxon, J.A.; Velazco, J.E.; Setser, D.W.; J. Chem. Phys. 1978, 68, 5187. 
22. Bartlett, N.; Sladky, F.O "The Chemistry of Krypton, Xenon, and Radon,"

Comprehensive Inorganic Chemistry p.250 - 254, Pergamon Press, Oxford, 1973.

23. Berkowitz, J.; Chupka, W.A Chemical Physics Letters 1970, 7, 447.

24. Zemva, B.; Jesih, A.; Templeton, D.H.; Zalkin, A.; Cheetham, A.K.; Bartlett, N. J. Am. Chem. Soc. 1987, 109, 7420.

25. Morrison, J.D.; Nicholson, A.J.C.; O'Donnell, T.A. J. Chem. Phys. 1968, 49, 959.

26. Levin, R.D.; Lias, S.D, 170

27. Walsh, A.D. J. Chem. Soc. 1953, 467, 2266.

28. Kim, K.C.; Campbell, G.M Chem. Phys. Letters 1985, 23, 236.

29. Kim, K.C.; Campbell, G.M. J. Molec. Struct. 1985, 129, 263.

30. Nakamoto, K., p. 72.

31. T.E. Mallouk, Ph.D. Thesis, University of California, Berkeley, 1984.

32. Levin, R.D.; Lias, S.D., 279.

33. Ibid., 481.

34. C. Shen, Ph.D. Thesis, University of California, Berkeley, 1992. 

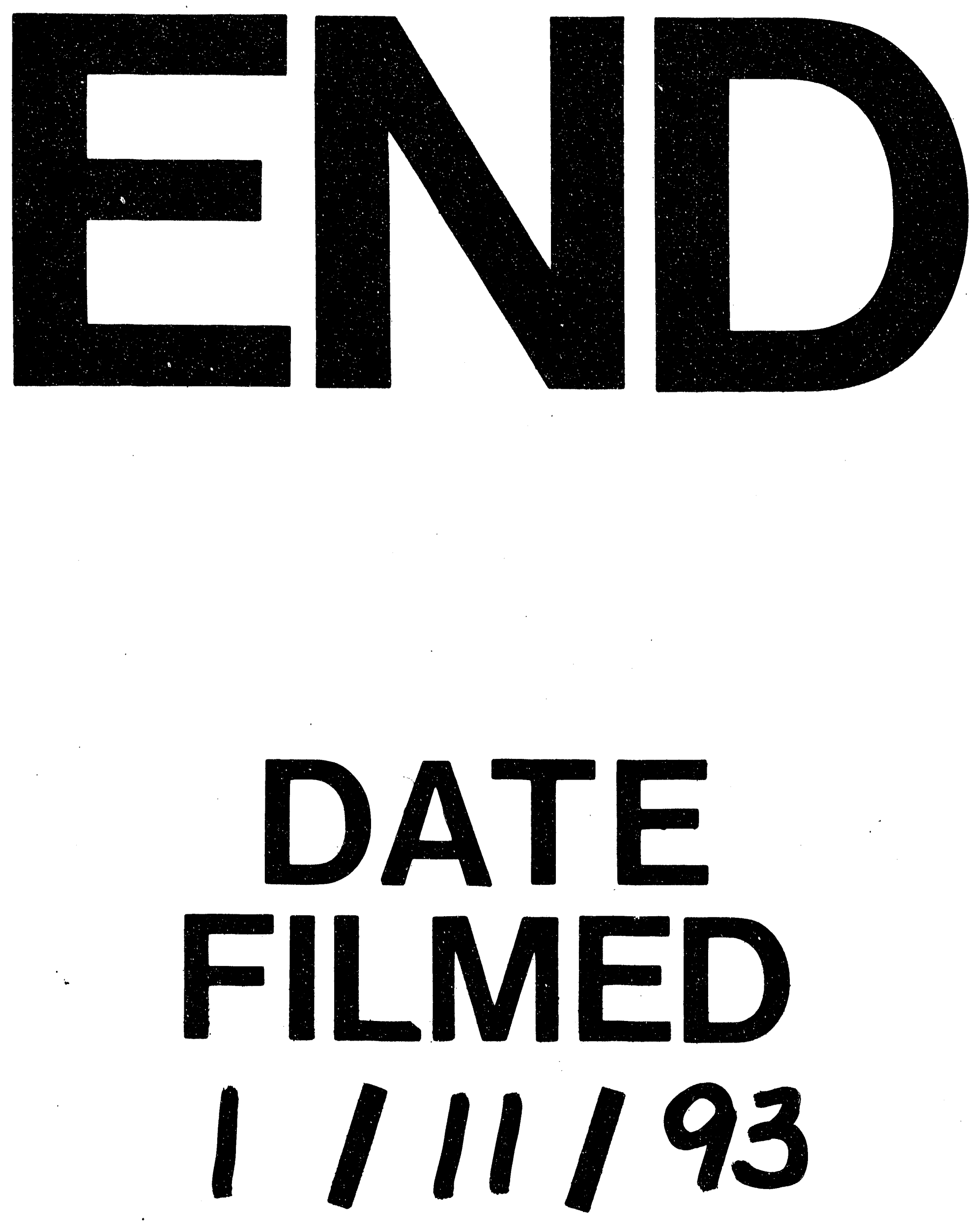

1 
